\title{
Dose-to-the-Population Exposure Estimates for Use of Plutonium-238-Powered Artificial Hearts
}

\author{
by \\ R. W. McKee \\ L. L. Clark \\ B. M. Cole
}

September 1976

Prepared for the Energy Research and Development Administration under Contract E(45-1)-1830 
NOTICE

This report was prepared as an account of work sponsored by the United States Government. Neither the United States nor the Energy Research and Development Administration, nor any of their employees, nor any of their contractors, subcontractors, or their employees, makes any warranty, express or implied, or assumes any legal liability or responsibility for the accuracy, completeness or usefulness of any imformation, apparatus, product or process disclosed, or represents that its use would not infringe privately owned rights.

PACIFIC NORTHWEST LABORATORY

operated by

BATTELLE

for the

ENERGY RESEARCH AND DEVELOPMENT ADMINISTRATION

Under Contract E(45-1)-1830

Printed in the United States of America Available from

National Technical Information Service

U.S. Department of Commerce

5285 Port Royal Road

Springfield, Virginia 22151

Price: Printed Copy \$9.00; Microfiche \$2.25 
BNWL-1915

UC-84

DOSE-TO-THE-POPULATION EXPOSURE ESTIMATES FOR USE OF PLUTONIUM-238-POWERED ARTIFICIAL HEARTS
by
R. W. McKee
L. L. Clark
B. M. Cole

September 1976

BATTELLE

Pacific Northwest Laboratories

Richland, Washington 99352 
CONTENTS

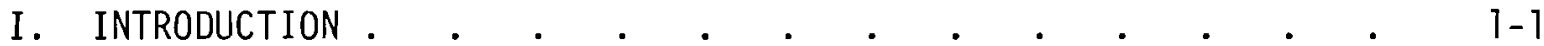

II. SUMMARY AND CONCLUSIONS . . . . . . . . . . . .

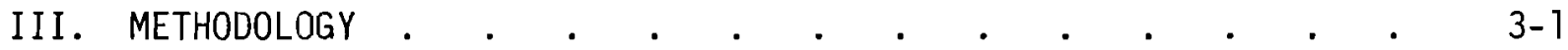

IV. ARTIFICIAL HEART USE PROJECTIONS . . . . . . . . . 4-1

A. Eligibility Considerations . . . . . . . . 4-2

B. Projected Future Incidence of Fatal Heart Disease . . 4-7

C. Population Growth Effects . . . . . . . . 4-15

D. Implant Rate Limitations . . . . . . . . 4-17

E. Natural-Cause Death Rates After Implant . . . . 4-20

F. Device Failure Death Rates . . . . . . . . 4-23

G. Cumulative Use Projections . . . . . . . . 4-26

V. CLASSIFICATIONS OF ARTIFICIAL HEART USERS . . . . . . 5-1

A. Age and Sex . . . . . . . . . . . 5-1

B. Occupation. . . . . . . . . . . . 5-1

C. Household Type . . . . . . . . . . . 5-4

D. Other Considerations . . . . . . . . . . . 5-6

VI. IDENTIFICATION OF RADIATION EXPOSURE SUBJECTS . . . . . 6-1

A. Spouses . . . . . . . . . • . . 6-1

B. Other Household Members . . . . . . . . 6-1

C. Associates . . . . . . . . . . . . 6-2

D. General Public . . . . . . . . . . . 6-2

VII. TIME-IN-ACTIVITY DATA $. \quad . \quad . \quad . \quad . \quad . \quad . \quad . \quad . \quad .7-1$

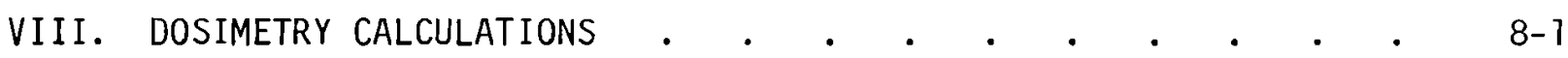

IX. SURVEYS OF INTERPERSONAL RELATIONSHIPS . . . . . . . . 9-1

A. Summary of Survey Model Development . . . . . 9-1

B. At-Home Activity Surveys . . . . . . . . 9-2

C. Public Activity Survey . . . . . . . . 9-5

D. Work Activity Survey . . . . . . . . . 9-5

$X$. THE REPRIEVE COMPUTER MODEL . . . . . . . . . . 10-1

A. Artificial Heart Use Calculations . . . . . . 10-1

B. Dose Calculations . . . . . . . . . . 10-11

C. Possible Uses of the Reprieve Mode1 . . . . . 10-21 


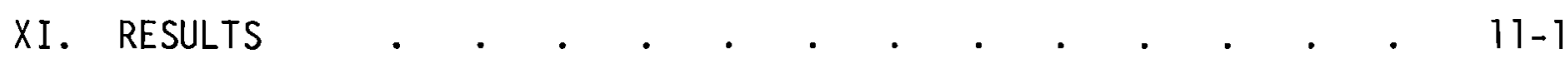

A. Base Case Estimate . . . . . . . . . 11-1

B. Sensitivity Analysis . . . . . . . . . . 11-8

REFERENCES . . . . . . . . . . . . . . . . 12-1

APPENDIX A: Artificial Heart Eligibility

(Modified Estimate) . . . . . . . . . A-1

APPENDIX B: Heart Disease Death Rate Projections . . . . . B-1

APPENDIX C: Occupation Classification for

Population Dose Study . . . . . . . . . C C

APPENDIX D: Time in A11 Nonwork Activities . . . . . . . $\quad$ D-1

APPENDIX E: Description of Surveys . . . . . . . . E-1

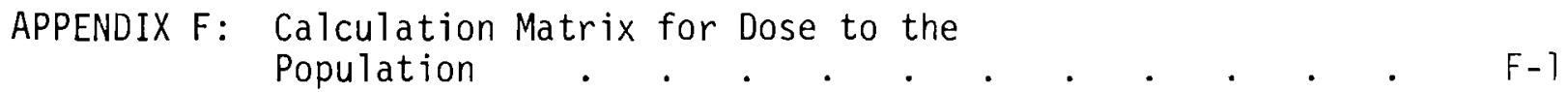

APPENDIX G: Incidental Random Dose Calculations . . . . . G-1

APPENDIX H: Dose-to-the-Population Summaries

of Various Reprieve Cases . . . . . . . . H- 


\section{$\underline{\text { LIST OF FIGURES }}$}

1 Comparison of Population Dose Distribution by Age for the Artificial Heart Population Dose with the Dose Distribution for a Uniform Population Exposure

2 Population Radiation Exposure Calculations for Use

of Nuclear-Powered Artificial Hearts

3 Expansion of Analytical Method to Identify Persons Exposed

4 Derivation of Candidates for Artificial Hearts from Coronary Heart Disease Using the Combined Framingham and Tecumseh Experience

5 Age-Adjusted Death Rates for Total Heart Disease and Component Diseases not Adjusted for International Classification of Diseases, Adapted (CDA) Revisions

6 Ischemic (Arteriosclerotic) Heart Disease Rates

7 Comparison of Actual Death Rates for Tuberculosis with Death Rates Projected by Death Rate Equation

8 Age-Adjusted Death Rate for Total Heart Disease Adjusted to 8 th International Classification of Diseases, Adapted Revision

9 Projected Age- and Sex-Adjusted Death Rates for Total Heart Disease

10 Projected Crude Death Rates for Total Heart Disease

11 Age-Specific Resident Male Population in Millions, 1940-2020

12 Annual Implant Projection

13 Comparisons of Life Expectancy Bases (Without Device Failure) for Artificial Heart Recipients

14 Comparisons of Device Reliability Bases 4-26

15 Estimates of Potential Artificial Heart Use 4-27

16 Effect of Fatal Heart Disease Incidence Estimates on Total Devices in Use

17 Effect of Eligible Candidate Estimates on Total Devices in Use 
18 Effect of Risk-of-Death Assumptions for Device Recipients on Total Devices in Use

19 The Effect of Failure Rate on Total Devices in Use

20 Subdivisions of Artificial Heart Recipient (AHR) Matrix

21 Age Profile of Artificial Heart Users in the Year 2000 Using Base Case Parameters

22 Subdivisions of RES Matrix

23 Standard Man Phantom

24 Dose Rates for a 24-W, ${ }^{238}$ Pu Power Source

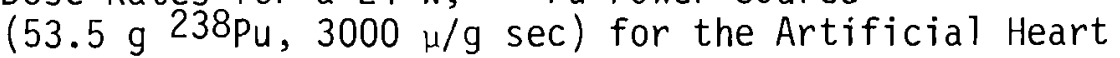

25 Relative Dose Rate Versus Time for a Single Device as a Function of PPM 236Pu Initially Present

26 Example Specific History of 10,000 Artificial Heart Recipients

27 REPRIEVE Matrix to Obtain Summations of Work and Nonwork Components of Dose-to-the-Population

28 Effect of Time on Population Dose Using Constant Base Case Parameters

29 Relative Dose Rate Versus Time Weighted for A11 Devices in Use at Varying Device Replacement Intervals

A. 1 Smoothed Data for Modified Estimate of Eligible Candidates

A.2 Comparison of Three Age Profiles of Artificial Heart Device Candidate Otherwise Dying from Coronary Heart Disease

A.3 Comparison of Tota 1 Devices in Use Using the NHI and Modified Age Distribution

A.4 Fraction of Fatal Heart Disease Victims Who Are Candidates

B. 1 Age-Adjusted Death Rates for Total Heart Disease and Major Component Heart Diseases Adjusted to the 8th ICDA Revision 
B.3 Age-Adjusted Death Rates for Total Heart Disease and Component Diseases not Adjusted for ICDA Revisions

B.4 Actual and Projected Ischemic (Arteriosclerotic) Heart Disease Death Rates

B.5a Age- and Sex-Specific Death Rates for Ischemic Heart Disease B-12

B.5b Age- and Sex-Specific Death Rates for Ischemic Heart Disease B-12

B.5c Age- and Sex-Specific Death Rates for Ischemic Heart Disease B-13

B.5d Age- and Sex-Specific Death Rates for Ischemic Heart Disease B-13

B.6a Age- and Sex-Specific Death Rates for Total Heart Disease B-14

B.6b Age- and Sex-Specific Death Rates for Total Heart Disease B-14

B.6c Age- and Sex-Specific Death Rates for Total Heart Disease B-15

B.7a Comparison of Actual Death Rates for Typhoid with Death Rates Projected by Death Rate Equation B-18

B.7b Comparison of Actual Death Rates for Hypertensive Heart Disease with Death Rates Projected by Death Rate Equation

B.7c Comparison of Actual Death Rates for Diptheria with Death Rates Projected by Death Rate Equation

B.7d Comparison of ActuaT Death Rates for Gastritis with Death Rates Projected by Death Rate Equation

E. 1 Illustration of BINGO Computer Code Calculations for a Classroom Situation

E.2 Questionnaire for the Salt Lake City Survey E-26 


\section{$\underline{\text { LIST OF TABLES }}$}

1 Year 2000 Population Dose Estimates from ${ }^{238}$ Pu-Powered Artificial Hearts

2 Modified Estimates of Artificial Heart Candidates

3 Comparison of Potential Artificial Heart Candidate Estimates

4 Age- and Sex-Specific Population Projections, 1990-2020

5 Equations Used to Determine Survivorship of Artificial Heart Recipients After Implant

6 Devices Remaining in Use Assuming a Device Failure Rate Equivalent to the Failure Rate of a Normal Human Heart

7 Artificial Heart Use Projections

8 Classification of Artificial Heart Recipients by 0ccupation

9 PHR Classifications for the Current Population Survey

10 Household Classifications

11 Distribution of Artificial Heart Recipients in Household Type

12 Nonwork Activity Classification

13 Work Activity Classification

14 Plutonium-238 Gamma Spectrum

15 Plutonium-236 Decay Scheme

16 Comparison Between QACIP5A Calculations and Experimenta1 Mea surement for $238 \mathrm{Pu}$ Gammas

17 External Dose Rates to a Standard Man Phantom from a 30 Watt $238 \mathrm{PuO}_{2}$ Power Source for a Circulatory Support System

18 Total External Dose Rates from an Implanted 24 Watt Artificial Heart

19 Effect of Fuel Age on Relative Dose Rate at 0.3 ppm Plutonium-236 8-9

20 Effect of Fuel Age on Plutonium-238 Dose Rate 8-9

21 Interpersonal Distance Surveys Completed and Sample Sizes 9-3 
22 A General Breakdown of the Salt Lake City Interpersonal Distance Survey of At-Home Activities

23 Life Table for Male Artificial Heart Recipients $10-4$

24 Survival Rate for Death Due to Device Failure 10-5

251990 Specific History for 6,339 Recipients -- Male 10-6

26 Example Calculation Showing the Derivation of Specific Histories 10-7

271990 Specific History for 9,999 Recipients -- Total 10-8

28 Artificial Heart Devices in Use Using Best Estimate Parameters 10-10

29 Equation for Calculation of Dose to the Population 10-12

$\begin{array}{ll}30 & \text { Size of Calculation Matrices }\end{array}$

31A Typical Values of Factors Used in Calculating Population Dose for Selected Activities and Household Types

$10-16$

31B Typical Values of Factors Used in Calculating Population Dose for Selected Activities and Household Types

31C Typical Values of Factors Used in Calculating Population Dose for Selected Activities and Household Types

32 Output Tables from REPRIEVE

33 Assumptions and Parameters Used in Defining the Base Case Estimate of Dose to the Population

34 Case 1A Dose to the Population in the Year 2000 from 201,549 Radioisotope-Fueled Devices

35 Dose to All Spouses According to Artificial Heart Recipient Activities and Household Types

36 Dose to General Public (Includes Dose to Family During Public Activities) According to Artificial Heart Recipient Activities and Age or Radiation Exposure Subjects

37 Dose to Associates of Artificial Heart Recipient According to Age of Associates and Age of Recipient

38 Summary of Population Dose Estimates for ${ }^{238}$ Pu-Powered Artificial Heart Devices

39 Case 6A Dose to the Population in the Year 2000 from 33,626

Radioisotope-Fueled Devices 
40 Case $2 A$ Dose to the Population in the Year 2000 from 258,757 Radioisotope-Fueled Devices

41 Amount of Dose Absorbed per Year per Device-in-Use, Using Base Case Parameters

42 Effect of Fuel Age on Relative Dose Rate at $0.3 \mathrm{ppm}$

Plutonium-236

43 Effect of Device Replacement Interval on Number of Implants

A. 1 Potential Candidates for Heart Replacement Among Persons Under Age 65 Dying of Heart Disease in the United States, 1967

A.2 Calculation of a Modified Estimate of Artificial Heart Device Candidates Using NHI Task Force and Hittman Data

A-4

A.3 Potential Candidates for an Artificial Heart Among Persons Dying of Heart Disease, United States, 1967

E.1 Statistical Correlation of Artificial Heart Dose Rate Data from the Battelle, Richland and Seattle Surveys

E.2 Statistical Correlation of Artificial Heart Dose Rate Data from the Richland and Seattle Surveys

E.3 Matrix of Interviewed Potential Heart Recipients (PHRs) in Salt Lake City

E.4 Target-Matrix of Potential Heart Recipients for the Salt Lake City Survey

E.5 Average Dose Per Household Member

F.l Components of Dose-to-Population Data Matrix

F.2 Dose to the Population Matrix Descriptions

G. 1 Effect of Population Density on Incidental Random (IR) Dose to the Population

G.2 Incidental Random Dose-to-the-Population Calculations

H. 1 Case 1B Dose to the Population in the Year 2000 from 220,330 Radioisotope-Fueled Devices

H.2 Case 1C Dose to the Population in the Year 2000 from 175,026 Radioisotope-Fueled Devices 
H. 3 Case 1D Dose to the Population in the Year 2000 from 247,446 Radioisotope-Fueled Devices

H. 4 Case 3A Dose to the Population in the Year 2000 from 105,306 Radioisotope-Fueled Devices

H. 5 Case 4A Dose to the Population in the Year 2000 from 64,030 Radioisotope-Fueled Devices

H. 6 Case 5A Dose to the Population in the Year 2000 from 81,491 Radioisotope-Fueled Devices

H. 7 Case 7 Dose to the Population in the Year 1990 from 4,160 Radioisotope-Fueled Devices

H. 8 Case 8 Dose to the Population in the Year 2010 from 287,544 Radioisotope-Fueled Devices

H. 9 Case 9 Dose to the Population in the Year 2020 from 317,746 Radioisotope-Fueled Devices

H. 10 Case 10 Dose to the Population in the Year 2030 from 322,835 Radioisotope-Fueled Devices 
DOSE-TO-THE-POPULATION EXPOSURE ESTIMATES

FOR USE OF PLUTONIUM-238-POWERED ARTIFICIAL HEARTS

\author{
R. W. McKee \\ L. L. Clark \\ B. M. Cole
}

\title{
I. INTRODUCTION
}

The objective of this study is to estimate the radiation dose to the population resulting from the development and widespread use of artificial heart devices powered by the radioisotope, plutonium-238. This work was carried out for the Division of Biomedical and Environmental Research of the Energy Research and Development Administration (ERDA) [formerly the U.S. Atomic Energy Commission] as a part of their Artificial Heart Program.

For many decades heart disease has been the leading cause of death in the United States. Because this disease often occurs in persons in their productive years, death from it not only causes suffering in their families, but has an adverse economic impact on the nation as wel1. Therefore, the development of a device to continue the heart function after normal heart failure could contribute to the welfare of our society. Powering such a device by means of a totally implantable, long-lived ${ }^{238} \mathrm{Pu}$ power source offers substantial advantages compared to other power sources. However, these advantages must be weighed against the gamma and neutron radiation risks to persons in the vicinity of the user. Although the dose rate from any one user would be very small (0.01-0.02 mrem/hr at $10 \mathrm{ft})$, currently accepted theory conservatively assumes that the effects of low-level radiation are cumulative. Since several hundreds of thousands of devices might eventually be in use, it is important to characterize the dose-to-thepopulation risk.

Development of dose-to-the-population estimates requires an analys is to determine the characteristics of those who would use the device, how many would be used, how long the recipients would live and what their 
personal interactions with other people would be. The scope of this study includes the following principal components.

1. Determination of the cumulative number of devices in use in each year based on estimates of:

a. Heart disease death rates

b. Fraction of those dying who would be eligible for a device implant

c. Rate of implantation

d. Life expectancy after implant

2. Estimates of radiation dose rates as a function of distance.

3. Classification of persons potentially exposed.

4. Estimates of interpersonal distance relationships between users of the devices and other persons.

5. Development of a computer model to use the above data to calculate total dose to the population.

Since considerable uncertainty exists in the projection of artificial heart use, the population dose results were developed parametrically with respect to factors (heart disease death rates, life expectancy, etc.) that would affect the number of artificial hearts in use. 


\section{SUMMARY AND CONCLUSIONS}

Estimates of dose to the population from ${ }^{238}$ Pu-powered artificial hearts were developed using a calculational model called REPRIEVE. This model develops the projected user population by incorporating assumptions regarding future heart disease death rates, the fraction dying who would be eligible candidates for artificial hearts, population projections, beginning implant rates, death rates after implant due to natural causes, and deaths caused by device failure.

The user population was characterized by age, sex, household description, employment status and occupation. Census data on household descriptions and special surveys in selected cities provided the information necessary to describe persons exposed during both household and public activities. These surveys further defined distance and time of contact factors for these persons.

Calculations using a dosimetry computer code defined the relationships between distance and dose. The validity of these calculations has been substantiated by experimental measurements.

Time-in-activity data were obtained from the Institute for Social Research at the University of Michigan. The data came from a nationwide sample of households as part of a multinational survey in 10 countries.

After developing the user population, the REPRIEVE program used the above data to perform population dose calculations. The final population dose is the result of approximately 220,000 summations of individual calculations. The program expresses the results in tables showing dose by the age and sex of the persons exposed as well as by heart recipient classifications.

A reference base case defined our best estimate of future conditions. Other cases examined the effect of user population parameters on final population dose. From this analys is we prepared credible maximum and minimum estimates of population dose. Table 1 on the following page summarizes the results of these calculations. 
TABLE 1. Year 2000 Population Dose Estimates From ${ }^{238}$ Pu-Powered Artificial Hearts

\begin{tabular}{|c|c|c|c|c|}
\hline $\begin{array}{c}\text { Population } \\
\text { Category }\end{array}$ & Estimate & $\begin{array}{l}\text { Population Dose } \\
\text { man-rem/year }\end{array}$ & $\begin{array}{l}\text { Percent } \\
\text { of Total }\end{array}$ & $\begin{array}{l}\text { verage Dose } \\
\text { Per Person } \\
\text { rem/year }\end{array}$ \\
\hline Spouses & $\begin{array}{l}\text { Minimum } \\
\text { Best } \\
\text { Maximum }\end{array}$ & $\begin{array}{r}21,000 \\
120,000 \\
152,000\end{array}$ & $\begin{array}{l}35.4 \\
35.3 \\
35.5\end{array}$ & $\begin{array}{l}0.860 \\
0.840 \\
0.830\end{array}$ \\
\hline $\begin{array}{l}\text { Other Household } \\
\text { Members }\end{array}$ & $\begin{array}{l}\text { Minimum } \\
\text { Best } \\
\text { Maximum }\end{array}$ & $\begin{array}{r}6,000 \\
36,000 \\
43,000\end{array}$ & $\begin{array}{l}10.2 \\
10.5 \\
10.1\end{array}$ & $\begin{array}{l}0.173 \\
0.170 \\
0.166\end{array}$ \\
\hline $\begin{array}{l}\text { Non-work } \\
\text { Associates }\end{array}$ & $\begin{array}{l}\text { Minimum } \\
\text { Best } \\
\text { Maximum }\end{array}$ & $\begin{array}{r}5,000 \\
31,000 \\
39,000\end{array}$ & $\begin{array}{l}9.1 \\
9.1 \\
9.1\end{array}$ & $\begin{array}{l}0.0073 \\
0.0071 \\
0.0070\end{array}$ \\
\hline Work Associates & $\begin{array}{l}\text { Minimum } \\
\text { Best } \\
\text { Maximum }\end{array}$ & $\begin{array}{r}6,000 \\
37,000 \\
46,000\end{array}$ & $\begin{array}{l}10.8 \\
10.9 \\
10.8\end{array}$ & $\begin{array}{l}0.0185 \\
0.0175 \\
0.0178\end{array}$ \\
\hline General Populace & $\begin{array}{l}\text { Minimum } \\
\text { Best } \\
\text { Maximum }\end{array}$ & $\begin{array}{r}20,000 \\
116,000 \\
148,000\end{array}$ & $\begin{array}{l}34.4 \\
34.2 \\
34.6\end{array}$ & $\begin{array}{l}0.00008 \\
0.00044 \\
0.00056\end{array}(a)$ \\
\hline TOTAL & $\begin{array}{l}\text { Minimum } \\
\text { Best } \\
\text { Maximum }\end{array}$ & $\begin{array}{r}58,000 \\
340,000 \\
428,000\end{array}$ & $\begin{array}{l}100.00 \\
\text { Average }\end{array}$ & $\begin{array}{l}0.00022 \\
\\
0.00128 \\
0.00161\end{array}$ \\
\hline
\end{tabular}
(a) The entire U.S. population in year 2000 is assumed to have received
some exposure.

The number of device users and hence the population dose appears to reach an equilibrium level at about year 2035 or 50 years after initial implants have begun. The best-estimate dose at this point is approximately $58 \%$ higher than in the year 2000 or 535,000 man-rem/year.

As seen from the table, spouses receive the largest individual doses. These amount to almost 1 rem/year, or seven to eight times normal background. It is important to recognize that most spouses are in older age groups where genetic effects are of little concern and where other competing risks of 
death may prevail before somatic radiation effects are evident. Furthermore, the risk would be a voluntary risk that could be reduced twofold or more by separate sleeping arrangements.

Average dose to other household members would be slightly higher than that of normal background. However, a significant portion of it would be absorbed by young persons under 18 years of age.

The dose to other associates and to the general populace, while comprising a significant portion of the total population dose; ranges from about $20 \mathrm{mrem} /$ year to a fraction of an mrem/year on an individual basis.

The total population exposure estimates range from 58,000 man-rem/year to 428,000 man-rem/year. Approximately 35\% of this is transmitted to individuals at rates that are only a fraction of $1 \%$ of normal background radiation. Approximately $30 \%$ is transmitted to individuals at rates that are in the range of $20 \%$ to $200 \%$ of normal background. The remaining approximately $35 \%$ is transmitted to individuals (spouses) at rates that are seven to eight times normal background.

Development of estimates of health effects that would result from these population exposure estimates was not included in this study. Substantial opinion now exists (1) that holds that the BEIR Report estimates (2) of health effects per man-rem at low dose rates are considerably overstated. Because of the large uncertainty regarding health effects at low dose rates an estimate of health effects was not included in this study. This study does, however, provide the age-specific dose data essential for analyzing potential health effects. This study also clearly shows that the health effects will be significantly less than the health effects for equal population exposures resulting from uniform exposure of the population (the usual basis for calculating population health effects) because of the disproportionate degree to which older age groups are exposed in the case of the artificial heart population dose.

The difference in the age distribution of the artificial heart population dose compared to a population dose based on a uniform exposure of the entire U.S. population is illustrated in Figure 1. For a uniform population exposure, approximately $75 \%$ of the dose would be received by persons under 50 years of age, while only $50 \%$ of the dose would be received by that age group in the case 
of the artificial heart population dose. This would reduce both the somatic and genetic effects for a given radiation exposure compared to effect estimates based on uniform population exposure.

Finally, considerations of the population exposure risk should be weighed against the potential benefit of saving on the order of 1 million man-years of life by the year 2000 and more in the years to follow.

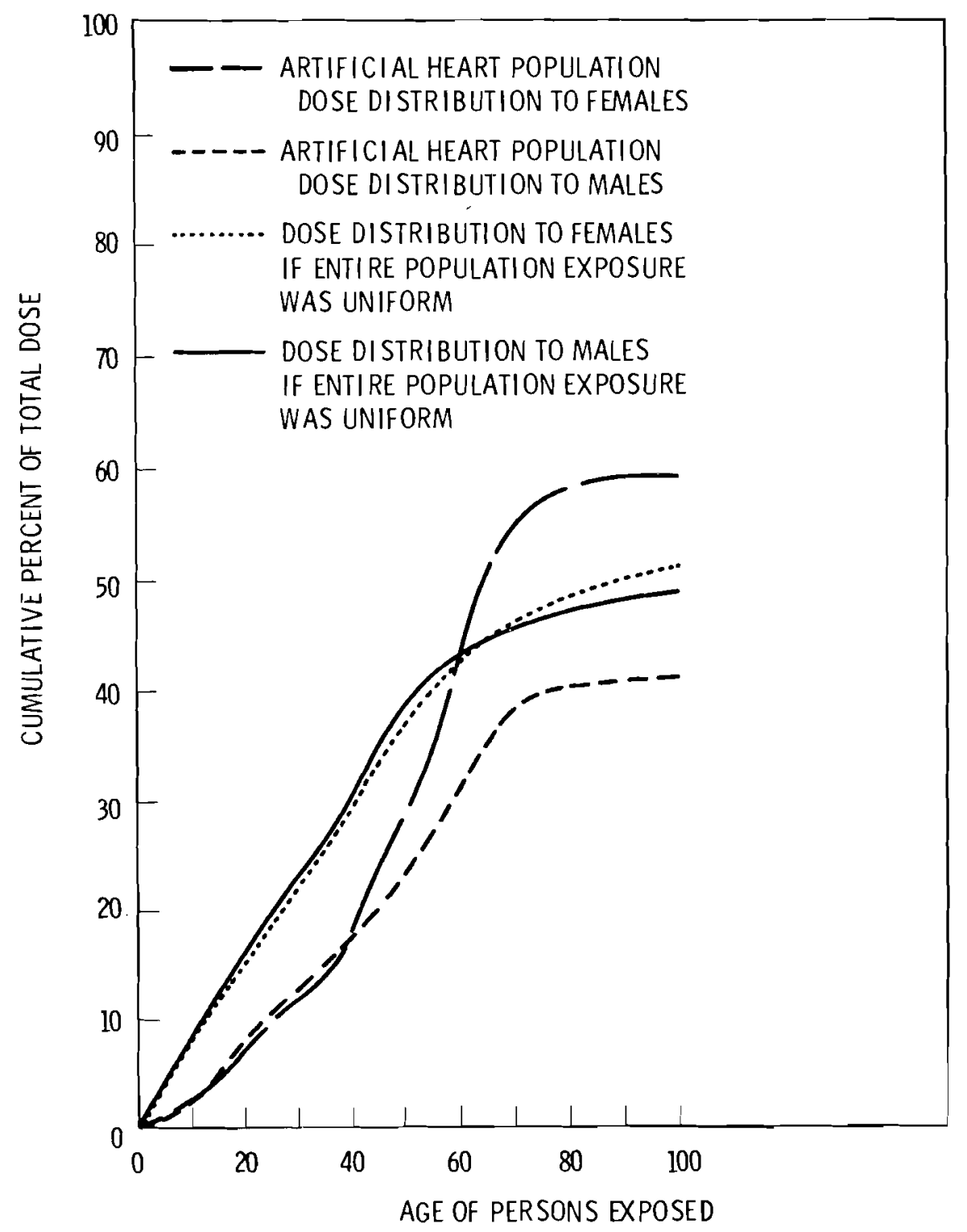

FIGURE 1. Comparison of Population Dose Distribution by Age for the Artificial Heart Population Dose with the Dose Distribution for a Uniform Population Exposure 


\section{METHODOLOGY}

This section briefly outlines the components of this study and their interrelationships. The study scope was originally developed to define the population dose in terms of the demographic characteristics of the device recipients without identification of persons exposed. However, because the age and sex of persons exposed are important factors for estimating potential somatic and genetic effects of low-level radiation, the scope was later broadened to identify the radiation dose by the age and sex of the person exposed.

Figure 2 shows the various components of the study as originally defined. Projections of fatal heart disease incidence were combined with estimates of artificial heart candidates to develop the projection of annual implants by age and sex. An assumed probability of death for each device recipient age and sex group and an assumed probability of device failure were combined with the annual implant projection to develop the number of surviving device recipients as a function of time for each implant year. Annual summations by age and sex of the number of surviving implants from each implant year provided the cumulative number of surviving device recipients in each year. (We assumed the implant program would begin in 1985.) The device recipient population was then further subdivided by occupation and household type, using U.S. Census and Current Population Survey (CPS) data.

In simplified form, the dose calculation for the initial study was:

Summations of $(P) \times(T) \times(C)=$ Population Dose

where

$$
\begin{aligned}
P= & \text { Number of device recipients in each subgroup, } \\
T= & \text { Amount of time spent in a defined activity, } \\
C= & \text { Dose rate to others from device recipient during a } \\
& \text { defined activity. }
\end{aligned}
$$

We obtained time-in-activity data from sample survey results conducted by the University of Michigan, Institute for Social Research (ISR). Data on 


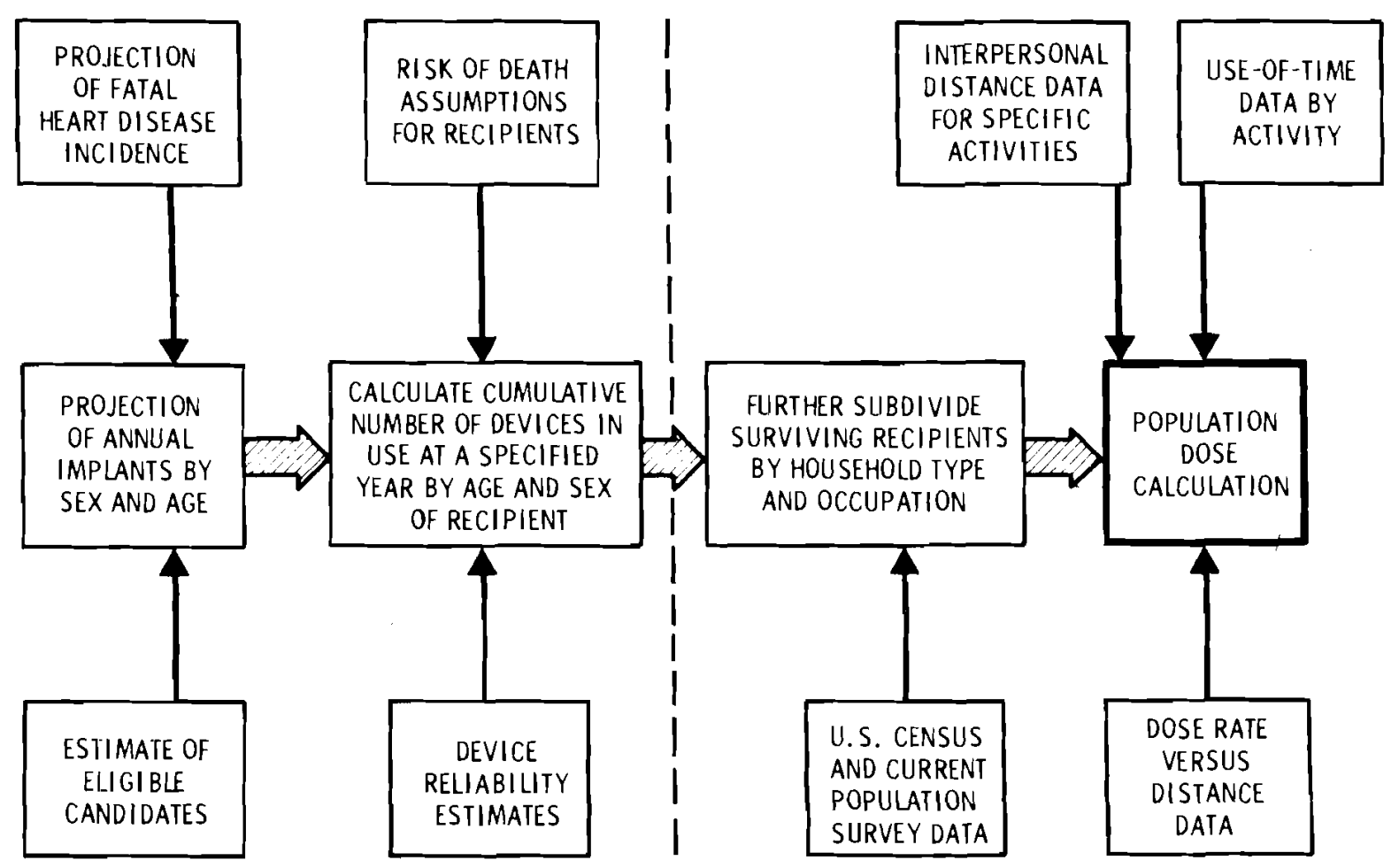

FIGURE 2. Population Radiation Exposure Calculations for Use of Nuclear-Powered Artificial Hearts

interpersonal distance relationships were collected from surveys among Battelle employees and random populations in Richland and Seattle, Washington. The interpersonal distance data were combined with dose rate yersus distance data (calculated with a dosimetry computer code) in a special computer program to calculate average dose rates for each specified activity. Another computer mode1, REPRIEVE, was developed to calculate the number of surviving implants and to combine this with the time-in-activity and dose rate data to calculate population dose. Using these calculations and the limited amount of pertinent household data available, initial estimates of dose to children, spouses and other population groups were developed.

The program was then expanded to obtain additional detail for estimates of dose to spouses, children, associates and the general public by age and sex. Figure 3 indicates schematicaliy the additional components needed for the expanded analysis. Data from the 1972 U.S. Census Current Population 


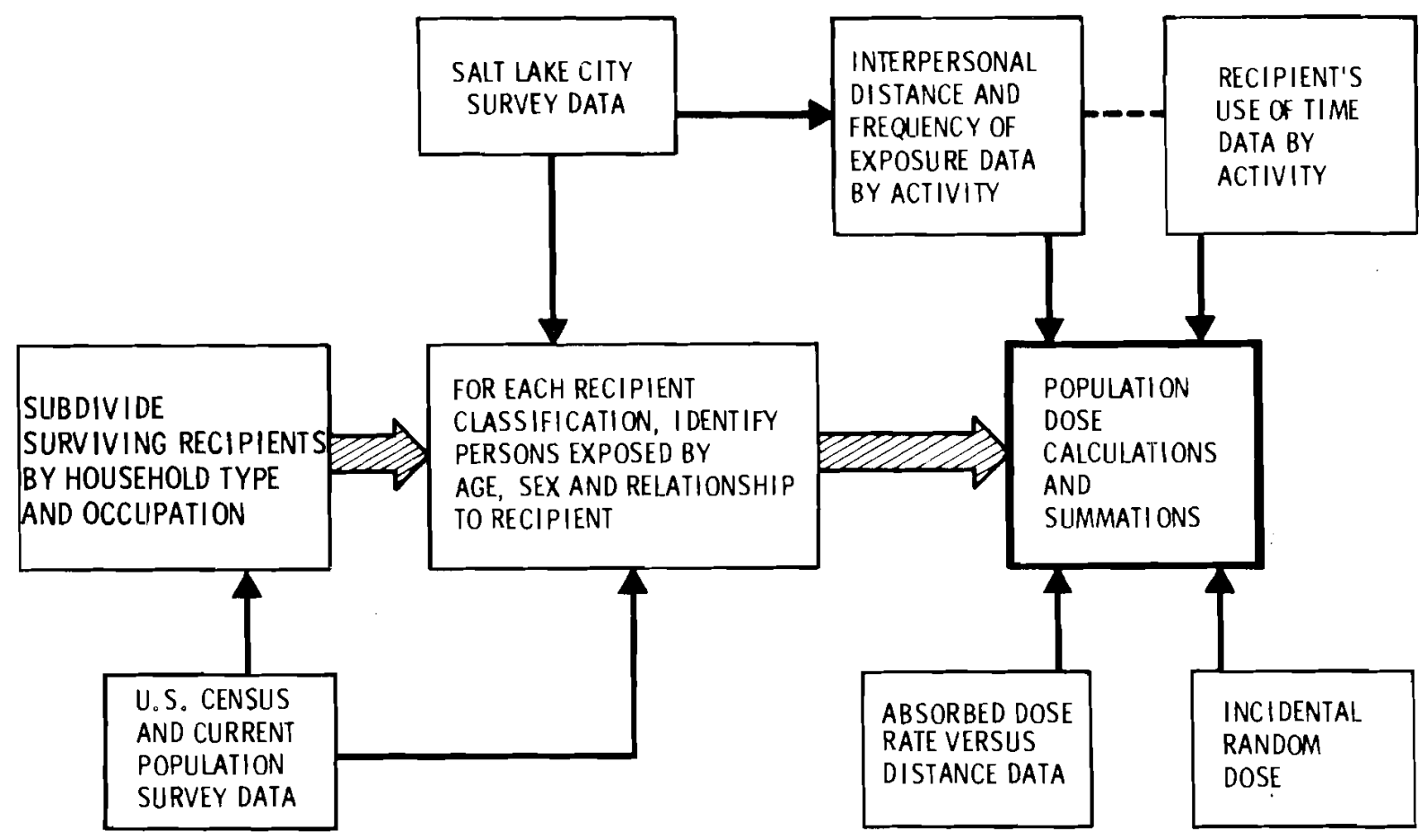

FIGURE 3. Expansion of Analytical Method to Identify Persons Exposed

Survey of over 40,000 households across the United States provided identification of potentially exposed household members by their age, sex, and relationship to the potential heart device recipient.

With assistance from Dr. Irwin Altman, Chairman, Department of Psychology, University of Utah, we devised and conducted a survey of approximately 400 homes in Salt Lake City, Utah, to obtain data to: 1) identify frequent visitors or associates in the home, 2) measure interpersonal distances between household members and associates, and 3) determine the frequency of exposure for these groups. These data, in addition to the previously developed device implant and use-of-time data, provided the necessary input to a modified and expanded REPRIEVE model. The expanded calculational basis in simplified form is:

Summations of $(P) \times(S) \times(T) \times(F) \times(C)=$ population dose components for work and nonwork activities 
where

$P=$ Number of persons in a device recipient group,

$S=$ Number of persons (in a defined group) exposed per recipient,

$T=$ Amount of time spent by device recipient group in a defined activity,

$F=$ Frequency of contact of persons exposed during a defined activity,

$C=$ Dose rate to persons exposed.

The total population dose consists of summations of the calculations above for work-related and nonwork-related activities plus a small incidental random component. This last component arises from radiation to not otherwise identifiable persons who are in the general vicinity of the device recipient. 


\section{ARTIFICIAL HEART USE PROJECTIONS}

The first step in estimating the dose-to-the-population is projecting the number of devices in use as a function of time. This requires estimates of the fraction of potential recipients in each age and sex group who would be eligible for implants, the number of devices implanted, and recipient life expectancy. The estimate includes the following principal components:

- Fraction of the persons presently dying who would be eligible for artificial heart devices (eligibility considerations)

- Projected future incidence of fatal heart disease

- Population growth effects

- Implant rate 1 imitations

- Natural-cause death rates after implant

- Device-failure death rates

Combination of the first four items produces the initial implant estimates. The last two items combine with the initial implant estimates to produce the final recipient populations as a function of time. Each of the above components requires estimates of a future condition. Some also require knowledge of conditions for which there is no current data base. For these reasons we developed the results parametrically encompassing a range of values for each component (except population growth). The above components and the assumptions used in their development are outlined in the succeeding sections.

Based on our analys is the total number of devices that could be in use in the year 2000 would range between 34,000 and 260,000 with a best estimate of 200,000 . Approximately $62 \%$ of these devices would be implanted in men-most of them between the ages of 45 to 74 . The remaining $38 \%$ of the devices would be implanted in women predominantly between the ages of 50 to 79 . 


\section{A. ELIGIBILITY CONSIDERATIONS}

The basis for determining the persons eligible to receive an artificial heart were derived largely from the following reports:

1. Cardiac Replacement, a report by Ad Hoc Task Force on Cardiac Replacement National Heart Institute. (3)

2. The Totally Implantable Artificial Heart, a report of the Artificial Heart Assessment Panel of the National Heart and Lung Association. (4)

3. Final Summary Report on Six Studies Basic to Consideration of the Artificial Heart Program, Hittman Associates, Inc. (5)

The risks attendant to entire cardiac replacement, even with the surgical procedures developed to transplant human hearts, are so formidable that surgeons will probably be extremely conservative in proposing such a course of action. Because of this risk, it is assumed that only in the event of imminent death would artificial heart implants be attempted. For this reason, the number of heart disease deaths would provide the upper 1 imit on number of implants. In addition, the circumstances surrounding heart disease deaths indicate that the actual number of candidates for cardiac replacement would be much less. Ischemic heart disease, including coronary heart disease which accounts for the overwhelming majority of heart disease deaths, frequently causes death within one hour of the onset of an attack. In many cases this would not allow time to get the victim to a hospital where life could be sustained long enough to attempt an artificial heart implant. In many of these deaths there is also no previous record of severe heart disease, indicating that prior preventative action could not have been taken. The conclusion is that only a small percentage of those dying from heart disease could be considered as eligible candidates.

One other condition for cardiac replacement eligibility is the absence of contraindicating diseases. The presence of these diseases would not only tend to substantially reduce the probability of surviving 
the implant procedure, but would limit the quality of life and life expectancy even if the implant operation were successful.

The best estimates of candidate eligibility available were made by the Ad Hoc Task Force in their report Cardiac Replacement. (3) This report was oriented mainly toward cardiac replacement using human heart transplants. However, most of the data and conclusions are also applicable to replacement using artificial hearts except that immuno-suppression is not a factor in considering contraindicative diseases.

The following quote from the Ad Hoc Task Force report defines succinctly the criteria used to define eligibility.

"If death occurs within one hour in a patient not previously known to have severe heart disease, there is little likelihood that it could have been prevented by total cardiac replacement, even if adequate temporary assist devices were readily available. On the other hand, if a longer period of time elapses between onset of symptoms and death and if an assist device were available, total cardiac replacement would be at least conceivable. Therefore, we have assumed that a patient dying one or more hours after admission, but not unexpectedly, could conceivably have such an assist device applied, and thus be a potential candidate for replacement. If death is sudden in a patient previously known to have severe heart disease, there is at least a chance that he might have received a total cardiac replacement at some time prior to his abrupt death." $(3, p .6)$

The Ad Hoc Task Force developed their eligibility estimates on a diseasespecific basis for coronary (ischemic), hypertensive, rheumatic and other heart diseases. The estimate of potential candidates having ischemic heart disease was derived from data collected in long-term followup studies in Framingham, MA and Tecumseh, MI. The distribution of this coronary death data in determining artificial heart eligibility by the above criteria is shown in Figure 4. This figure, with minor revisions, came directly from the Ad Hoc Task Force report. The low estimate of seven candidates out of 183 coronary deaths (3.8\%) includes only persons identified as having severe coronary heart disease prior to their fatal heart attack. The high estimate of 30 heart replacement candidates out of 183 coronary deaths $(16.4 \%)$ 


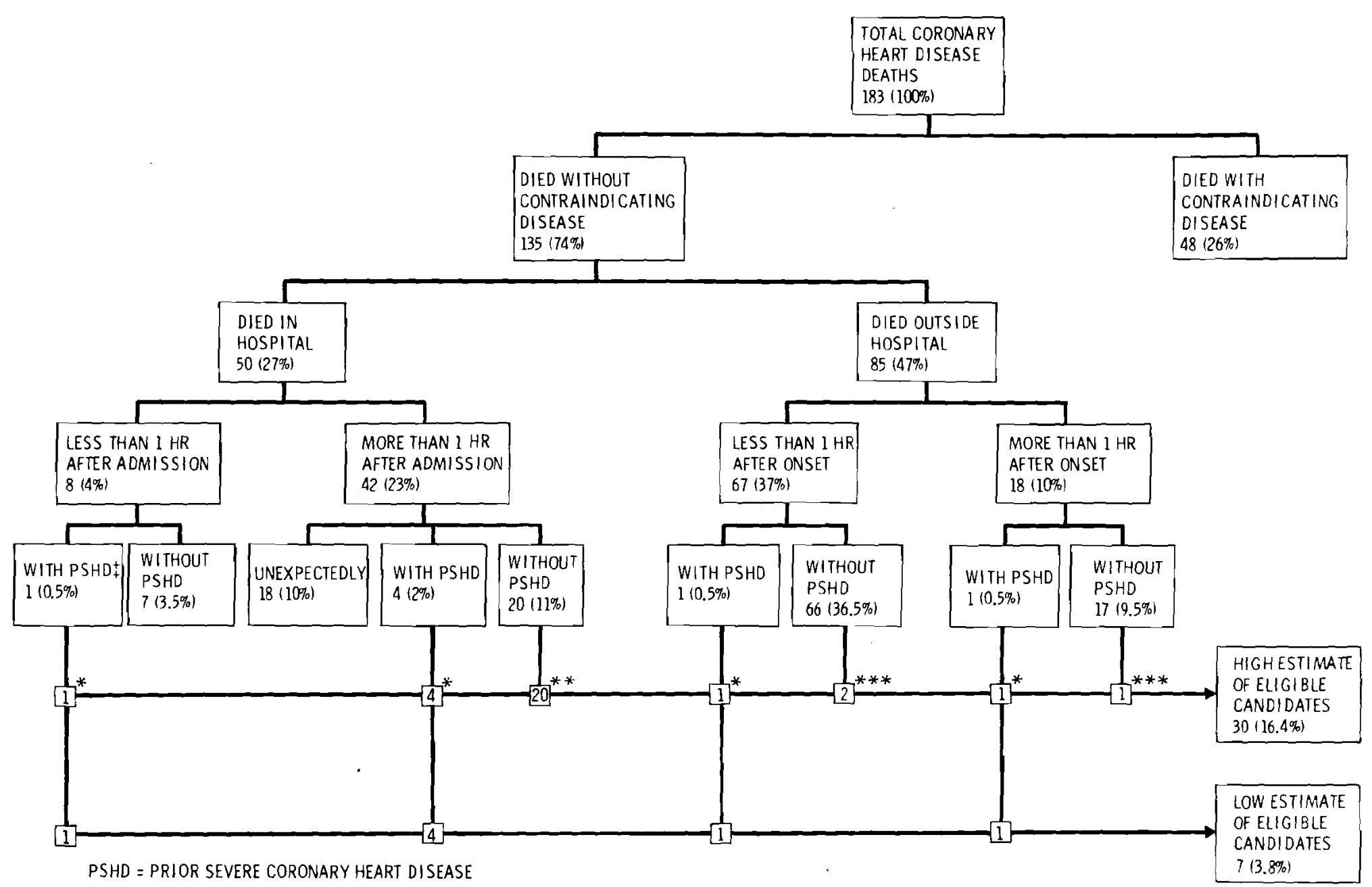

* patients who become candidates due to having Severe coronary heart disease prior to their fatal heart aitack

* PatIeNTS WHOSE CANDIDACY WOULD DEPEND ON DEVELOPMENT Of AN ARTIFICIAL HEART ASSIST DEVICE

PATIENTS NOT DEFINED AS HAVING SEVERE CORONARY HEART DISEASE, BUT WHO, ON REVIEW OF THEIR CLINICAL RECORDS, WERE CONSIDERED *** TO BE CANDIDATES ON CLINICAL GROUNDS (CANDIDACY WOULD ALSO DEPEND ON DEVELOPMENT OF ASSIST DEVICE)

\section{FIGURE 4. Derivation of Candidates for Artificial Hearts from Coronary Heart Disease} Using the Combined Framingham and Tecumseh Experience

Source: Cardiac Replacement, (Reference 3 , p. 9) 
includes 20 persons whose candidacy would depend on development of a heart assist device and three other persons who died outside of a hospital and who, on review of their records, were candidates on clinical grounds. The original estimate was developed with the primary concern being heart transplants. One of the main problems would be keeping a patient alive until a donor could be found. With an artificial heart this would not be a problem and the high estimate should be more nearly achievable.

While the Ad Hoc Task Force estimate of transplant candidates appears to represent a sound basis for estimates of artificial heart candidates, the data base is very small and does not provide adequate detail by age and sex. In addition, this estimate 1 imited candidates to persons under 65 years old-principally because no heart transplants were attempted in older age groups. As was pointed out in their study, however, "age per se rarely precludes even the most complex intracardiac operations, " $(3, \mathrm{p} .4)$ and artificial heart implants in persons over 65 could possibly account for a large proportion of the total.

Since eligibility estimates are a key factor in estimating potential artificial heart use, more detailed study is clearly needed to provide a broader data base on contraindicative circumstances surrounding cardiac death, with the ultimate objective of better defining candidate eligibility by age and sex.

Although we recognized the 1 imitations in the Ad Hoc Task Force data, these data were still the best and most recent available and, therefore, formed the foundation of our eligible candidate projections. Because of the previously mentioned lack of age-specific detail, the older Hittman Associates report ${ }^{(5)}$ based on analysis of clinical records of some 900 coronary patients was used to estimate age-group ratios for candidates and to extend the estimates to ages beyond age 65 (see Appendix A). Application of these ratios to the Ad Hoc Task Force data developed our agespecific eligible candidate estimates. These are listed in Table 2.

The Artificial Heart Assessment Panel (4) also developed candidate estimates based on the Ad Hoc Task Force data. They increased the estimates 
TABLE 2. Modified Estimates of Artificial Heart Candidates

\begin{tabular}{|c|c|c|c|c|c|}
\hline \multirow[b]{2}{*}{ Age } & \multicolumn{4}{|c|}{ Candidates by Age and Disease, Percent } & \multirow{2}{*}{$\begin{array}{c}\text { Total } \\
\text { Potential } \\
\text { Candidate } \\
\text { in } 1969 \\
\end{array}$} \\
\hline & $\begin{array}{l}\text { Ischemic } \\
\text { (Coronary) } \\
\end{array}$ & $\begin{array}{l}\text { Hyper- } \\
\text { tensive }\end{array}$ & Rheumatic & Other & \\
\hline \multicolumn{6}{|c|}{ HIGH ESTIMATE } \\
\hline $\begin{array}{l}30-34 \\
35-39 \\
40-44 \\
45-49 \\
50-54 \\
55-59 \\
60-64 \\
65-69 \\
70-74 \\
75-79 \\
80-84 \\
85+\end{array}$ & $\begin{array}{r}20.5 \\
20.0 \\
19.2 \\
17.5 \\
16.0 \\
14.8 \\
11.3 \\
8.5 \\
5.7 \\
2.5 \\
.5 \\
0\end{array}$ & $\begin{array}{l}6.0 \\
6.0 \\
5.5 \\
5.5 \\
5.0 \\
4.5 \\
4.0 \\
3.5 \\
3.0 \\
2.0 \\
1.0 \\
0\end{array}$ & $\begin{array}{r}12.0 \\
12.0 \\
11.5 \\
11.0 \\
10.0 \\
9.5 \\
8.5 \\
7.5 \\
6.0 \\
4.0 \\
1.0 \\
0\end{array}$ & $\begin{array}{r}18.0 \\
18.0 \\
17.0 \\
16.0 \\
14.5 \\
13.5 \\
11.0 \\
10.5 \\
8.5 \\
6.0 \\
2.0 \\
0\end{array}$ & $\begin{array}{r}342 \\
893 \\
2,057 \\
3,636 \\
5,327 \\
7,411 \\
7,730 \\
7,516 \\
6,161 \\
3,116 \\
636 \\
0\end{array}$ \\
\hline Total Potential & 40,432 & 368 & 1,148 & 2,877 & 44,825 \\
\hline \multicolumn{6}{|c|}{ LOW ESTIMATE } \\
\hline $\begin{array}{l}30-34 \\
35-39 \\
40-44 \\
45-49 \\
50-54 \\
55-59 \\
60-64 \\
65-69 \\
70-74 \\
75-79 \\
80-84 \\
85+\end{array}$ & $\begin{array}{l}5.0 \\
4.7 \\
4.6 \\
4.0 \\
3.8 \\
3.3 \\
2.6 \\
2.0 \\
1.2 \\
.25 \\
0 \\
0\end{array}$ & $\begin{array}{c}6.0 \\
6.0 \\
5.5 \\
5.5 \\
5.0 \\
4.5 \\
4.0 \\
3.5 \\
3.0 \\
2.0 \\
1.0 \\
0\end{array}$ & $\begin{array}{l}6.0 \\
6.0 \\
5.8 \\
5.5 \\
5.0 \\
4.8 \\
4.2 \\
3.8 \\
3.0 \\
2.0 \\
.5 \\
0\end{array}$ & $\begin{array}{r}18.0 \\
18.0 \\
17.0 \\
16.0 \\
14.5 \\
13.5 \\
11.0 \\
10.5 \\
8.5 \\
6.0 \\
2.0 \\
0\end{array}$ & $\begin{array}{r}149 \\
319 \\
663 \\
1,080 \\
1,562 \\
2,030 \\
2,158 \\
2,171 \\
1,687 \\
639 \\
129 \\
0\end{array}$ \\
\hline $\begin{array}{l}\text { Total Potential } \\
\text { Candidates In } \\
1969\end{array}$ & 8,767 & 368 & 575 & 2,877 & 12,587 \\
\hline
\end{tabular}


of candidates who would have died from coronary heart disease by including persons up to age 75. This increased the number of candidates in this disease category by $65 \%$ from 26,000 to 44,000 per year. They also increased the fraction of eligible candidates from hypertensive and rheumatic heart diseases, but these changes increased the estimates of total devices implanted only slightly.

Our estimates of total devices in use are a little lower than those of the Assessment Panel, but are essentially in agreement in spite of a somewhat different basis. These estimates are compared in Table 3 . The derivation of our analysis and the comparison with the Assessment Panel's estimates are explained in more detail in Appendix $A$.

\section{B. PROJECTED FUTURE INCIDENCE OF FATAL HEART DISEASE}

The next component in the artificial heart use projection is the projection of heart disease death rates. This parameter provides the upper limit in determining future device requirements and, therefore, becomes very important in the use projection.

At the present time there appears to be substantial evidence to conclude that heart disease has been brought under control.

- As shown in Figure 5 , the age-adjusted* death rate of ischemic (arteriosclerotic) heart disease appears to have peaked and

* NOTE: Three different measures of death rates are discussed in this report:

1. Crude death rate $=$ total deaths in a given year divided by total population.

2. Age-adjusted death rate $=$ total deaths weighted for the age distribution of the population in a base year (1940).

3. Age- and sex-adjusted death rate = total deaths weighted for the age and sex distribution of the population in a base year (1940).

Age-adjusted and age- and sex-adjusted death rates subtract the effects of any age- or age-and-sex-specific population shifts occurring over the years by using a constant population distribution. Although any base year may be used, the standard practice is to use the 1940 population. For a highly age- and sex-dependent disease such as heart disease, adjusted death rates give a much more accurate description of changes in the actual risk of death over the past 35 years than do crude death rates. 
begun a downward trend. Similar conclusions are reached by examining the data points plotted on Figure 6 for crude* (see footnote on page 4-7) and age-and-sex-adjusted* (see footnote on page 4-7) ischemic heart disease death rates. Since the incidences of other heart diseases have been steadily declining, total (cumulative) heart disease has been recently declining even more rapidly as indicated in Figure $5 .(6)$

- A similar conclusion was drawn in a report on male heart disease deaths by the Metropolitan Life Insurance Company. (7)

- The National Center for Health Statistics in a recent report stated, "The force of mortality for Ischemic heart disease reached a peak in 1963 and then finally started downward. "(8,p.10)

- Dr. Jeremiah Stamler, of Northwestern University, indicated that a study of heart attack death rates since 1940 suggests "that at long last a start has been made in turning the flank of this great modern plague." (10)

Since the downward trend in total heart disease death rates is only beginning, the basis for a projection is quite limited. Because of this, we studied the history of several other significant fatal diseases (11) which have clearly been brought under control to see if correlations could be developed that would aid in predicting future fatal heart disease levels. These other diseases included tuberculosis, diptheria, typhoid fever, gastritic diseases, influenza, pneumonia, and hypertensive heart disease.

Developing an equation which would fit the epidemiological data of both heart disease and the other diseases studied required a combination of logical and heuristic analysis. The objective was to define some kind of learning curve relationship that could be used to predict man's ability to control specific diseases. This equation and its development is explained in detail in Appendix B. The fundamental assumptions behind the equation are: 1) the rate of decline in death rate will be proportional to the difference between the peak rate and the rate at any later time (an indirect measure of 
TABLE 3. Comparison of Potential Artificial Heart Candidate Estimates

\begin{tabular}{|c|c|c|c|c|c|}
\hline \multirow[b]{2}{*}{ Candidate Classifications } & \multirow{3}{*}{$\begin{array}{l}\text { Total Heart } \\
\text { Disease } \\
\text { Deaths } \\
\text { In } 1969(\mathrm{a}) \\
\end{array}$} & \multicolumn{2}{|c|}{$\begin{array}{r}\text { Artificial Heart } \\
\text { Assessment Panel } \\
\text { Estimates(b) }\end{array}$} & \multicolumn{2}{|c|}{$\begin{array}{l}\text { Modified } \\
\text { Estimate Used In } \\
\text { This Study }\end{array}$} \\
\hline & & Percent & Number & Percent & Number \\
\hline & & \multicolumn{2}{|c|}{ High Estimate } & & \\
\hline $\begin{array}{l}\text { Under Age } 65 \\
\text { A11 Heart Diseases Except Congenital }\end{array}$ & 198,621 & 16.3 & 32,303 & 13.8 & 27,396 \\
\hline Congenital & 7,884 & 5.0 & 394 & -- & -- \\
\hline $\begin{array}{l}\text { Age } 65-74 \\
\text { All Heart Diseases Except Congenital }\end{array}$ & 195,383 & 9.0 & 17,639 & 7.0 & 13,677 \\
\hline Congenital & 111 & --- & --- & --- & $-\cdots$ \\
\hline $\begin{array}{l}\text { Age } 75+ \\
\text { All Heart Diseases Except Congenital }\end{array}$ & 345,066 & --- & --- & 1.1 & 3,752 \\
\hline Congenital & 76 & --- & --- & --- & --- \\
\hline TOTAL - All Heart Diseases & 747,141 & 6.7 & 50,336 & 6.0 & 44,825 \\
\hline & & Low & timate & & \\
\hline $\begin{array}{l}\text { Under } \text { Age } 65 \\
\text { All Heart Diseases Except Congenital }\end{array}$ & 198,621 & 6.4 & 12,674 & 4.0 & 7,961 \\
\hline Congenital & 7,884 & 5.0 & 394 & -- & --- \\
\hline $\begin{array}{l}\text { Age } 65-74 \\
\text { A11 Heart Diseases Except Congenital }\end{array}$ & $\begin{array}{l}195,383 \\
195,383\end{array}$ & 2.1 & 4,075 & 2.0 & 3,858 \\
\hline Congenital & 111 & --- & -- & --- & --- \\
\hline $\begin{array}{l}\text { Age } 75+ \\
\text { All Heart Diseases Except Congenital }\end{array}$ & 345,066 & --- & --- & 0.2 & 768 \\
\hline Congenital & 76 & $\ldots$ & --- & $-\cdots$ & --- \\
\hline TOTAL - Al1 Heart Diseases & 747,141 & 2.2 & 16,749 & 1.7 & 12,587 \\
\hline
\end{tabular}

(a) Source: Vital Statistics of the United States (Reference 8, p. 1-174 to 1-178).

(b) Source: The Totally Implantable Artificial Heart (Reference 4, p. 43). 


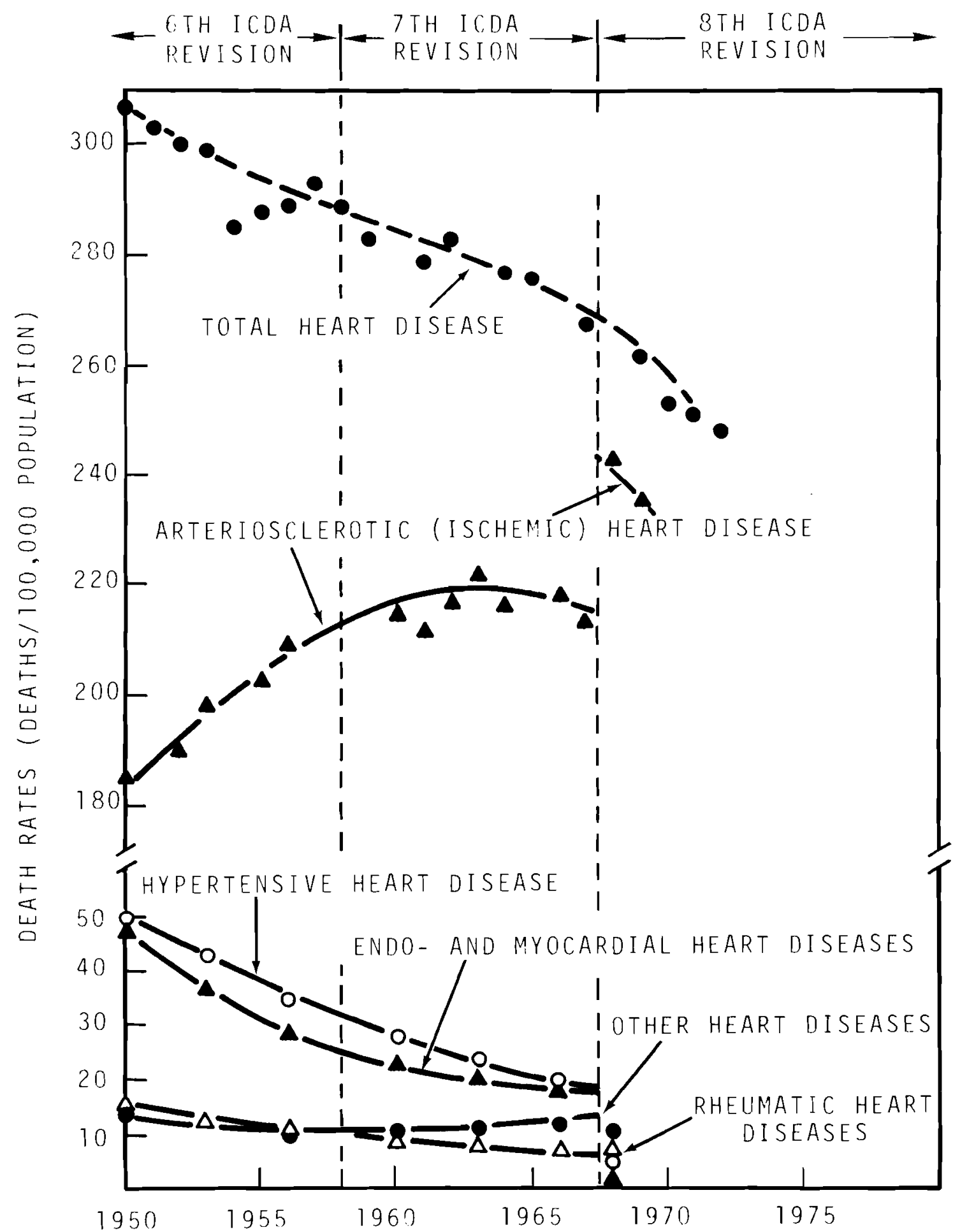

FIGURE 5. Age-Adjusted Death Rates for Total Heart Disease and Component Diseases not Adjusted for International Classification of Diseases, Adapted (ICDA) Revisions. Source: Mortality Trends for Leading Causes of Death (Reference 9, p. 8); Vital Statistics of the United States (Reference 6). 


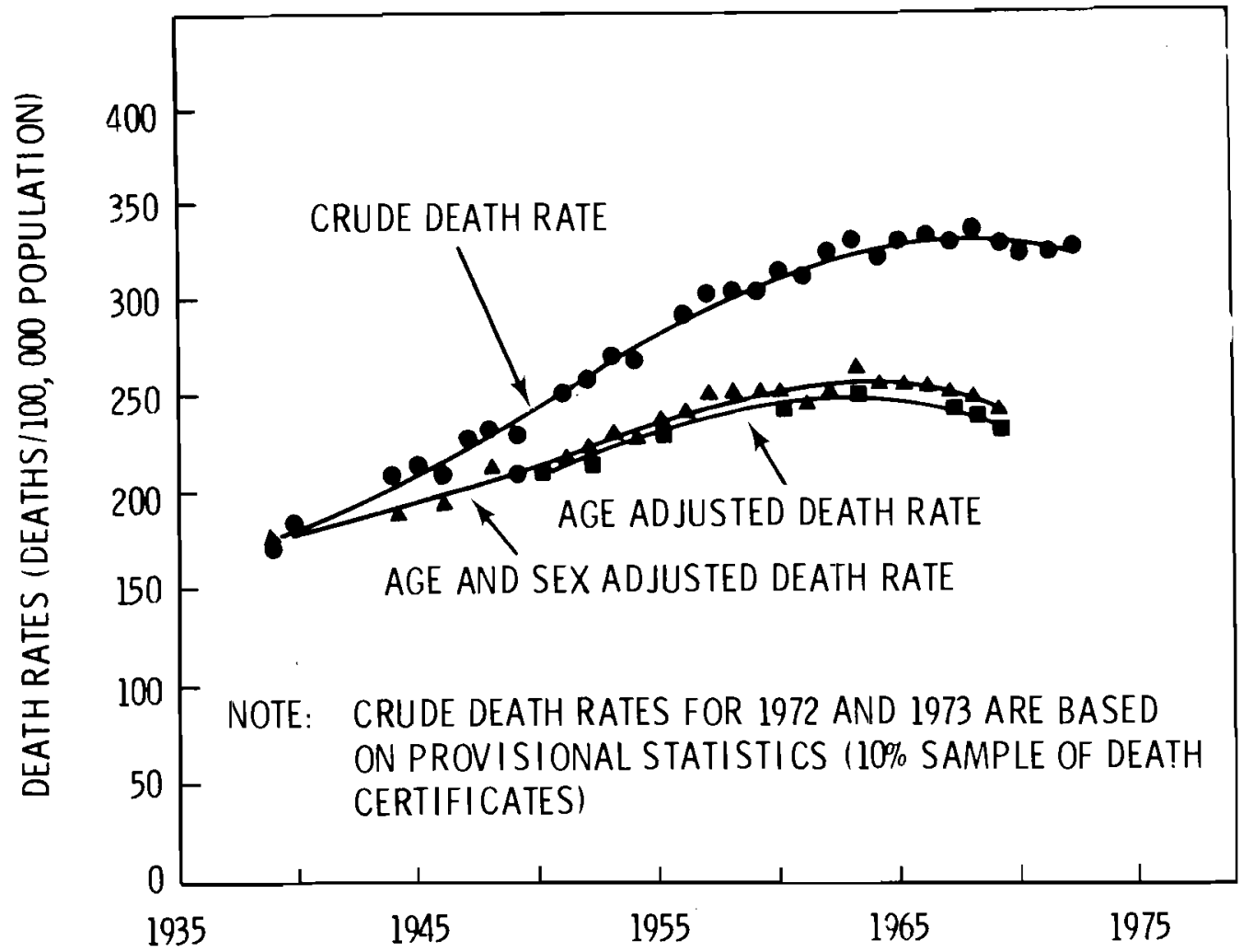

FIGURE 6. Ischemic (Arteriosclerotic) Heart Disease Rates. (8th International Classification of Diseases, Adapted Definition) Source: Vital Statistics of the United States (References 6 and 9).

knowledge of the disease), and 2) the rate of decline will be inversely proportional to some exponential function of the time elapsed since the peak rate was observed (an indirect measure of complacency once the incidence is substantially reduced).

In order to test the predictive ability of this equation, hereafter referred to as the Death Rate Equation (DRE), we applied it to data for the previously mentioned diseases. A least squares analysis showed a 94 to $98 \%$ correlation for all these diseases. A 95\% or better correlation is considered good. Figure 7 shows the projection for tuberculosis along with the data points for comparison. A computerized curve-fitting routine was used to calculate the constants in the DRE giving an optimum fit to the data. This corresponds to the best fit DRE curve shown in Figure 7 . These constants were 


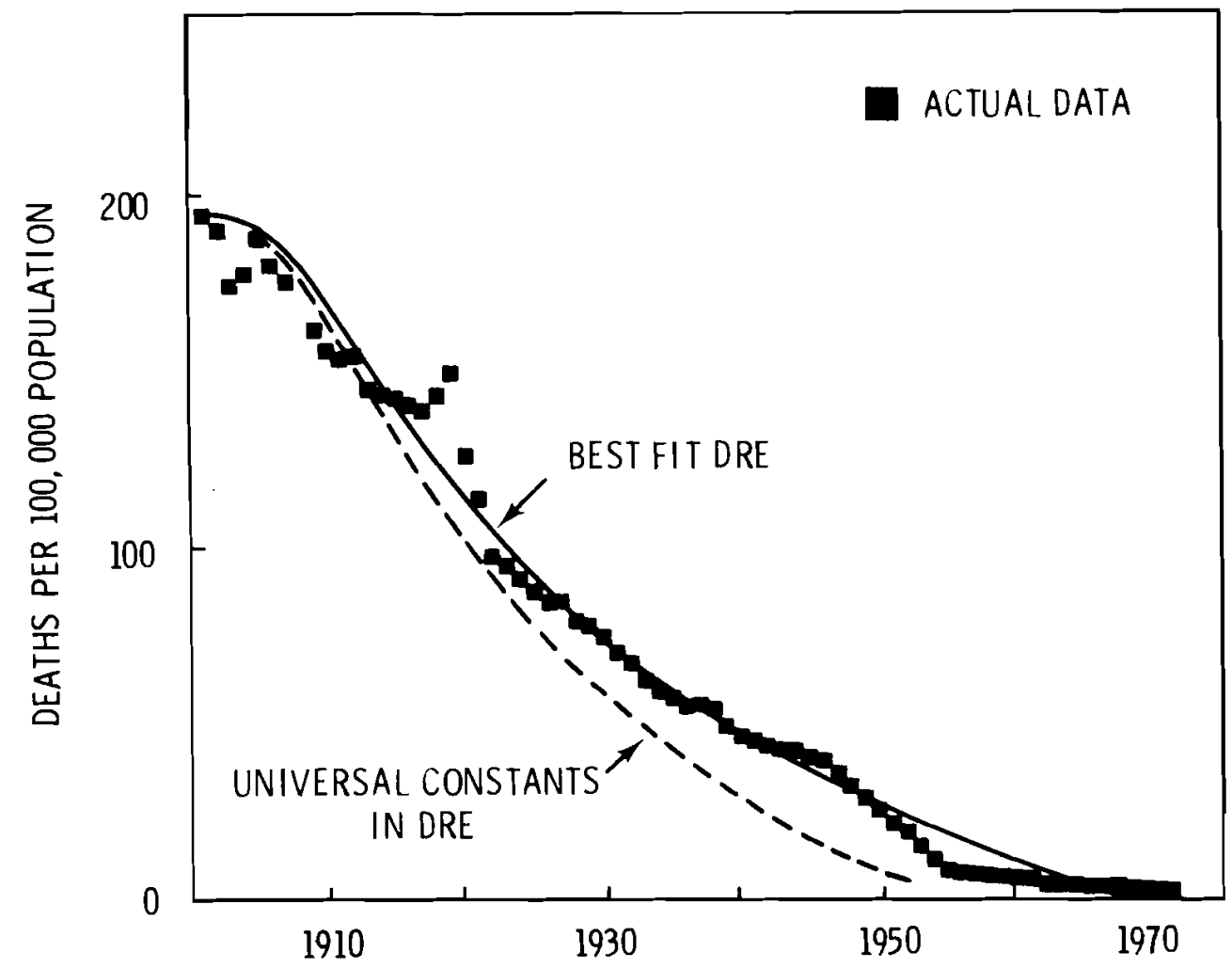

FIGURE 7. Comparison of Actual Death Rates for Tuberculosis with Death Rates Projected by Death Rate Equation. Source: Historical Statistics of the United States (Reference 11)

then averaged for all of the diseases to obtain a set of universal constants. A complete explanation of the Best Fit and Universal Constant Projections along with illustrations for the other diseases analyzed are included in the detailed explanations in Appendix B.

Recognizing that the correlation has been tested to only a limited extent, the inference is that it may be possible to project the future incidence of fatal diseases by knowing only the time and magnitude of the death rate when the rate first starts to decline.

Using the basic form of the equation, we developed a best estimate of future heart disease incidence. To provide an estimate of the maximum uncertainty associated with these projections, the best estimate was bracketed with maximum and minimum projections representing the highest and lowest conceivable death rates. To develop the best-estimate case, we 
determined values for parameters in the DRE using age- and sex-specific data on ischemic heart disease incidence. (Due to classification and diagnosis problems, total heart disease data could not be used as explained in Appendix B.) These values used in the equation generated our best estimates of future total heart disease incidence. We made maximum estimates of future heart disease incidence by assuming that the peaking of the crude total heart disease death rates merely represented a leveling off of these rates and that future crude death rates would remain constant at the average rate since 1965. (Indications are that the death rate is clearly downward, however.)

The declining trends in heart disease and other fatal diseases may be of a different nature. For example, once methods of combating and controlling the organism causing an infectious disease were developed, the disease could be almost totally eradicated over a period of time. Heart disease, on the other hand, is a degenerative disease. At the present time, it seems unlikely that the degeneration can be reversed or permanently halted and while the fatal effects of heart disease may be postponed to older age groups and even substantially diminished, near-total eradication of the disease seems a more remote prospect than eliminating an infectious disease. For these reasons, we concluded that using the universal projection parameters derived from the previously examined fatal diseases in the DRE would produce the limiting minimum estimate of future heart disease death rates.

The agreement of the best estimate projection of fatal heart disease incidence with the most recently published data has been remarkable. Figure 8 shows a smoothed plot of age-adjusted total heart disease death rates for 1950-1973. (9,12) We adjusted the data from 1950-1967 to a comparable classification basis with post-1967 data by applying comparability ratios.* (13) Provisional data from the National Center for Health Statistics (NCHS) based on a 10\% sample of death certificates in 1972 and 1973 reported age-adjusted death rates of 249 and 243 deaths/100,000, respectively. (12) Using death

* Appendix B explains changes in classification and the comparability of data in greater detail. 


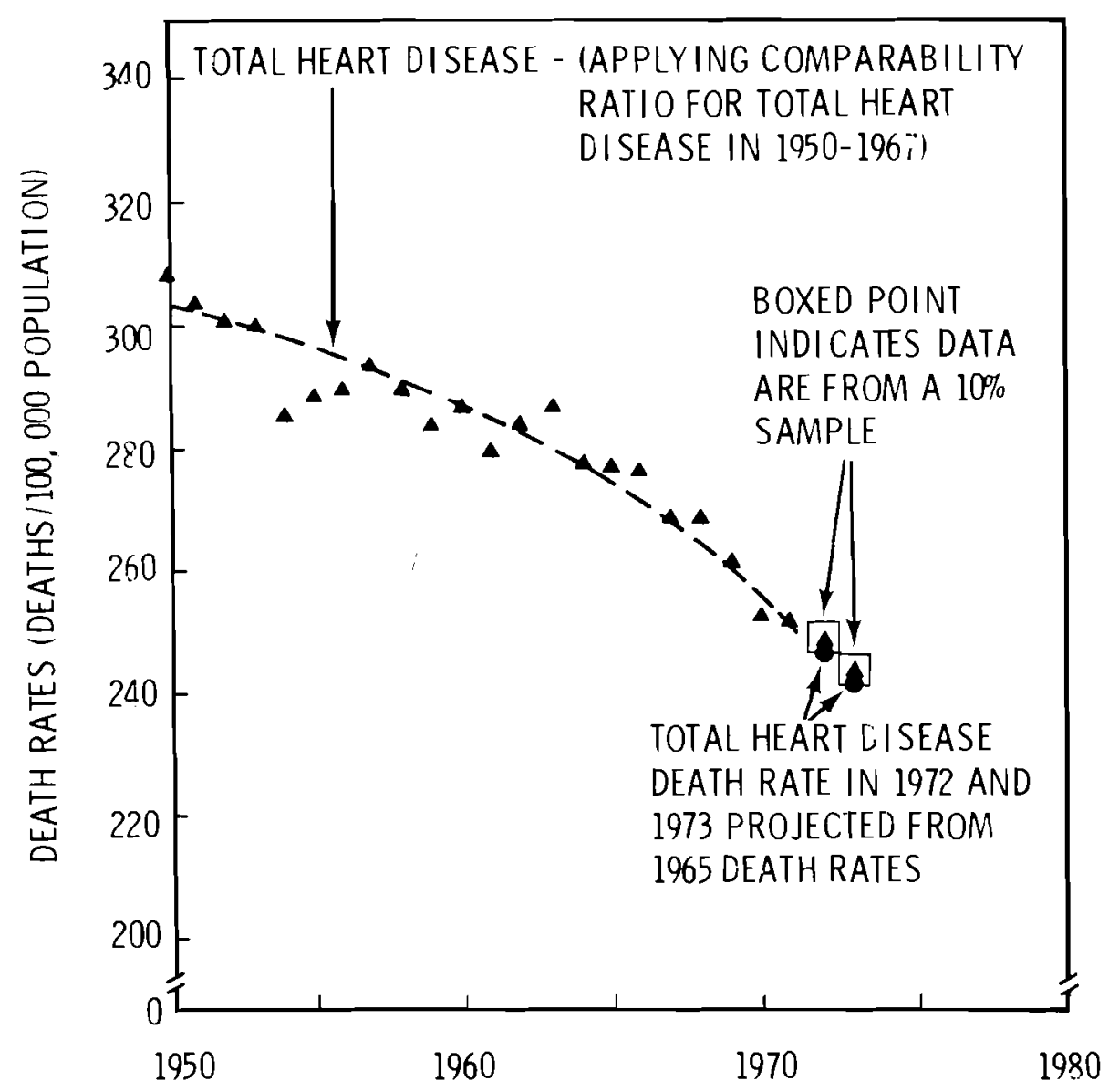

FIGURE 8. Age-Adjusted Death Rate for Total Heart Disease Adjusted to the 8th International Classification of Diseases, Adapted Revision

rates in 1965 as a base, our best estimate projection predicted age-adjusted death rates of 247 and 242 deaths $/ 100,000$ in 1972 and 1973 -- a remarkable match.

The projected age- and sex-adjusted death rates for the best maximum and minimum cases are illustrated in Figure 9. Final NCHS data on age- and sex-adjusted death rates were only available through 1969. ${ }^{(6)}$ These fit the best projection extremely well, however. Final age-only-adjusted death rates have been published to 1973 , and these are also shown on the illustration. $(9,12)$ Considering that the age-adjusted death rates are likely to be slightly lower than age- and sex-adjusted ones (see Figure 6 for example), these are also likely to fit the projection. 


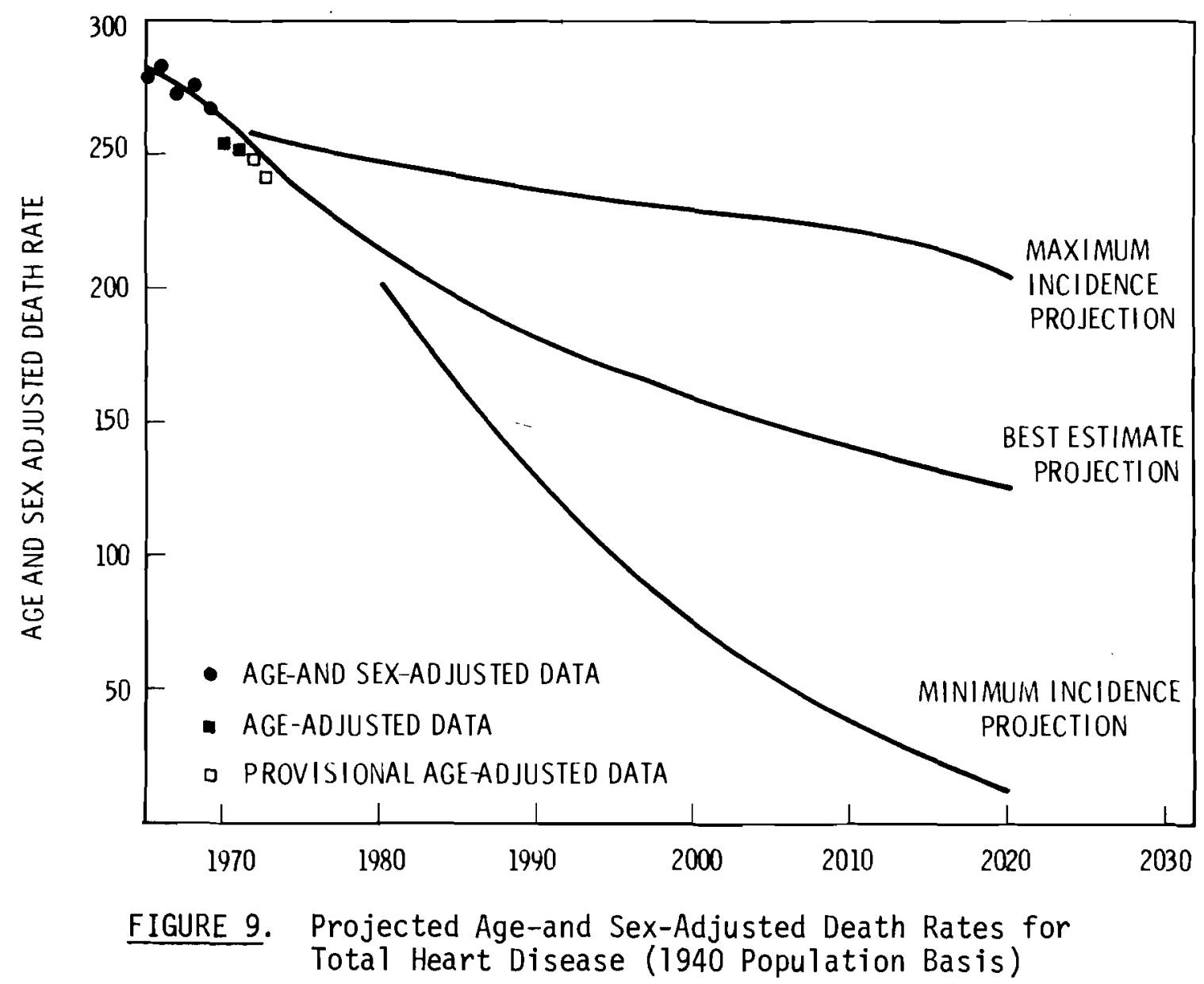

We used the best estimate projection of age- and sex-specific total heart disease death rates with population data from 1965-1973 $(14,15,16)$ and with projected population data from 1974 to $2020^{(17,18)}$ to develop projections of crude death rates through 2020 as illustrated in Figure 10. Plotted actual crude death rates from 1960 to 1973 agree quite well with the best estimate projections. (Author's note: Just prior to publication additional crude death rate data were obtained ${ }^{(19)}$ for 1974-1975 and plotted on Figure 10. The agreement of the data with the projection is remarkable.)

\section{POPULATION GROWTH EFFECTS}

Another component in the artificial heart use projection having a marked impact on projected implants is population. We assumed that increases or 


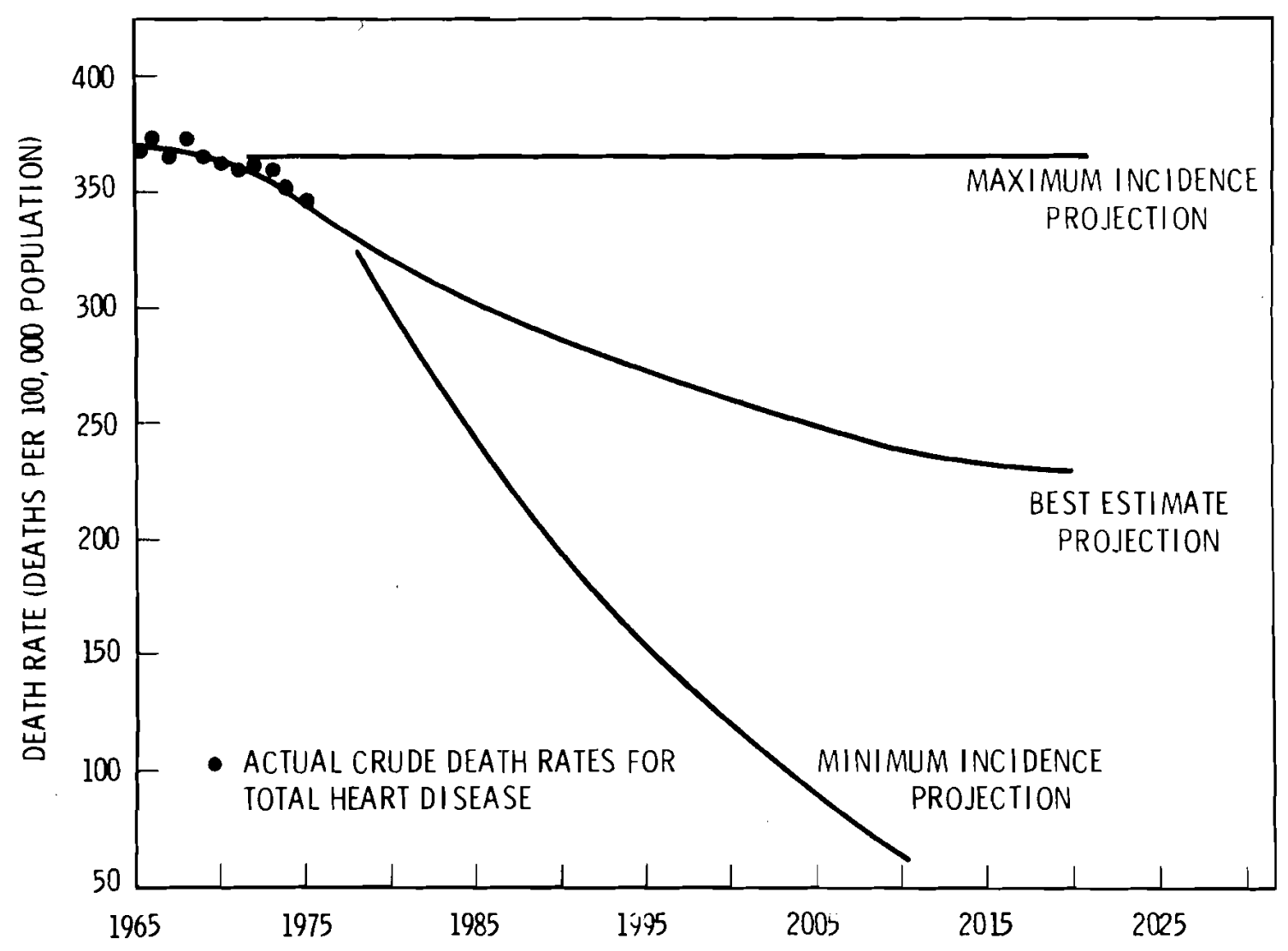

FIGURE 10. Projected Crude Death Rates for Total Heart Disease

decreases in the population of an age group would result in a proportionate increase or decrease in the total number of heart disease deaths in that age group.

To develop the population projection to the year 2000, we used the series E population projections published by the Bureau of the Census in their December 1972 Current Population Report. (18) (Series E uses a birth rate of 2.1 births per woman, close to the current rate.) These projections, however, only provided data on five-year age groups to age 75 . To estimate the data for age groups 75 to 79,80 to 84 and over 85 , we developed ratios from a previous cnesus report in November $1971^{(17)}$ which included these older age groups. The application of these ratios to the $75+$ age group total in the December 1972 report completed the age- and sex-specific population projections 
to the year 2000. Population projections in 2010 and 2020 were given in the November 1971 report, and although this report was somewhat outdated, we used these projections for lack of better data.

Population projections have three main components: birth rates, death rates and migration. An examination of the characteristics of these variables will give an indication of the reliability of our projections. Recently, the migration variable has accounted for a very small percentage of the population and, therefore, is postulated to have little effect on our projections. Death rates have remained quite constant over the past two decades. Birth rates, on the other hand, provide most of the variability in the projection. Since fatal heart disease incidence is not significant to people under age 30, our main concern is with the population older than this age. Up through 1995 all of the population age 30 and above has already been born. Therefore, assuming that the death rates continue to remain at recent levels, our population projection should be quite accurate through 1995. Past this time the projection becomes, of course, increasingly less certain.

One other population phenomenon having a profound effect on the projected artificial heart population is the population "wavefront." This phenomenon is due to the rapid rise in birth rates following World War II and will begin to have a marked effect on age groups eligible for artificial heart implants in approximately 1980. This effect is graphically illustrated in Figure 11 which shows a plot of the population of resident males by 10 -year age groups (over 35) as a function of time. As indicated, the effect of the population wave at its peak is to approximately double the age-specific population as it passes through each age group. As a result of this phenomenon, the future demand for artificial hearts should substantially exceed estimates based on current population figures (other things being equal). Values of the population projection used in this study are shown in Table 4.

D. IMPLANT RATE LIMITATIONS

After the artificial heart device has been sufficiently perfected for widespread clinical use, it will still take a few years to build up the capability of both professional surgical staff and industrial production. 


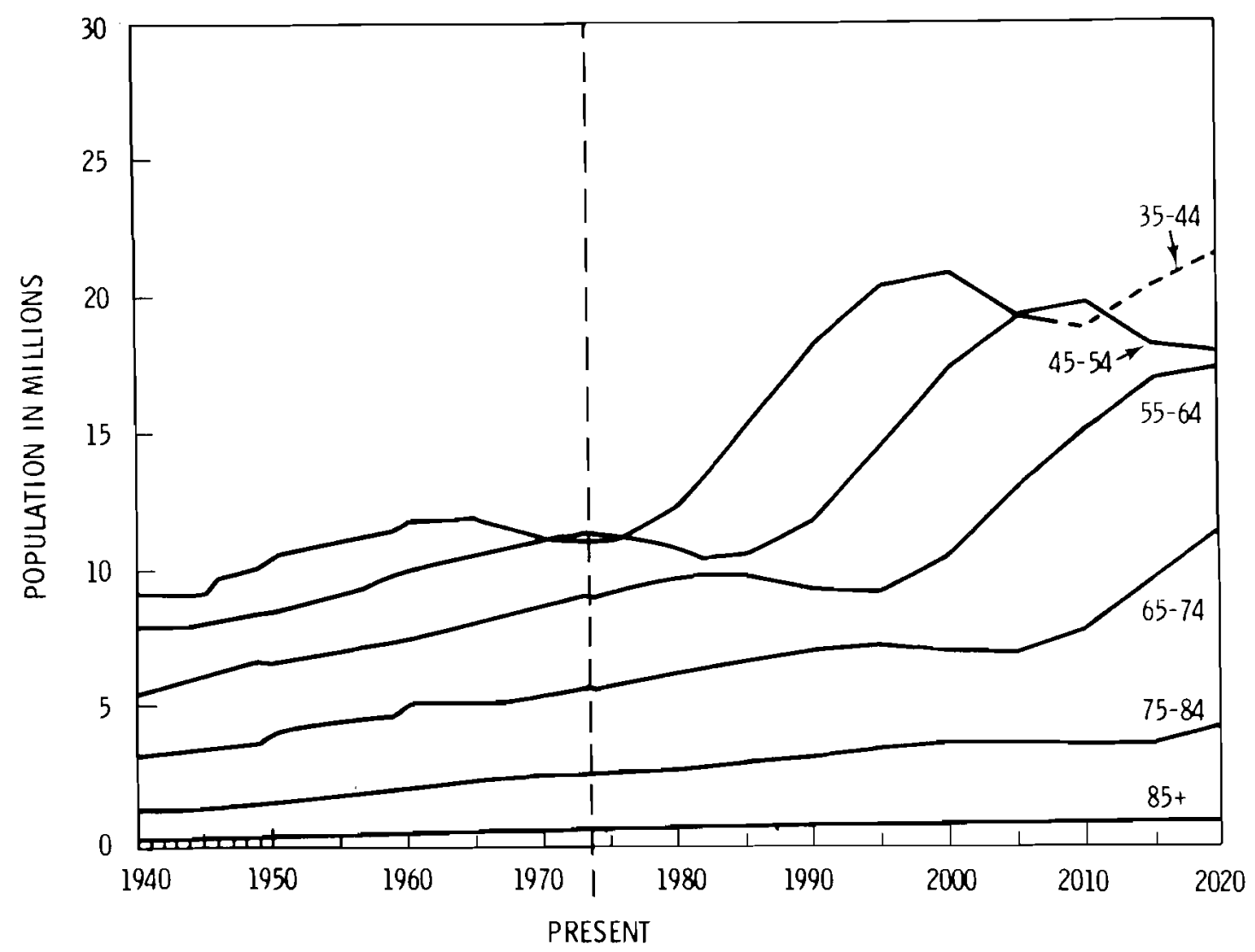

FIGURE 11. Age-Specific Resident Male Population in Millions, 1940-2020 Source: Population Projections (Reference 6, 17, 18)

In the absence of more definitive data we made the following estimates:

- Clinical implantation of artificial heart devices is assumed to begin in 1985 with 100 devices being implanted in that year.

- The number of implants in each succeeding year will be doubled until demand equilibrium is reached.

Figure 12 illustrates the number of devices implanted in each program year using our high estimate of eligible candidates, three levels of heart disease incidence projections, and the above implantation schedule. The increase in implants is quite rapid until demand equilibrium is reached. Thereafter, the estimate is mainly influenced by projected heart disease and population growth. In spite of the steep nature of the doubling function, 
TABLE 4. Age- and Sex-Specific Population Projections, 1990-2020 (in Thousands)

\begin{tabular}{|c|c|c|c|c|c|c|c|c|}
\hline \multirow{2}{*}{$\begin{array}{c}\text { Age } \\
\text { Group }\end{array}$} & \multicolumn{2}{|c|}{$1990^{(a)}$} & \multicolumn{2}{|c|}{$2000^{(a)}$} & \multicolumn{2}{|c|}{$2010^{(b)}$} & \multicolumn{2}{|c|}{$2020^{(b)}$} \\
\hline & Male & Fema le & Male & Female & Male & Female & Male & Female \\
\hline $30-34$ & 10,705 & 10,585 & 9,107 & 9,003 & 10,729 & 10,543 & 10,900 & 10,704 \\
\hline $35-39$ & 9,814 & 9,801 & 10,326 & 10,254 & 9,877 & 9,769 & 11,146 & 11,002 \\
\hline $40-44$ & 8,564 & 8,723 & 10,544 & 10,558 & 8,951 & 8,983 & 10,592 & 10,543 \\
\hline $45-49$ & 6,603 & 6,937 & 9,495 & 9,678 & 9,961 & 10,098 & 9,585 & 9,673 \\
\hline $50-54$ & 5,319 & 5,758 & 8,063 & 8,494 & 9,918 & 10,268 & 8,448 & 8,763 \\
\hline $55-59$ & 4,787 & 5,396 & 5,975 & 6,632 & 8,600 & 9,252 & 9,011 & 9,643 \\
\hline $60-64$ & 4,637 & 5,538 & 4,548 & 5,354 & 6,934 & 7,917 & 8,484 & 9,532 \\
\hline $65-69$ & 4,065 & 5,267 & 3,750 & 4,782 & 4,771 & 5,963 & 6,784 & 8,210 \\
\hline $70-74$ & 3,070 & 4,368 & 3,215 & 4,543 & 3,207 & 4,429 & 4,869 & 6,527 \\
\hline $75-79$ & 2,085 & 3,407 & 2,393 & 3,851 & 2,244 & 3,484 & 2,829 & 4,316 \\
\hline $80-84$ & 1,186 & 2,204 & 1,350 & 2,486 & 1,440 & 2,569 & 1,446 & 2,517 \\
\hline $85+$ & 674 & 1,441 & 795 & 1,676 & 920 & 1,912 & 905 & 1,857 \\
\hline
\end{tabular}

(a) Ages 30-75 obtained from December 1972 Population Projections, Series E (Reference 18) Ages 75-79, 80-84, and 85+ obtained by ratios of December 1972, 75+ totals derived from November 1971 Population Projections, Series E.

(b) Ages 30-85+ obtained from November 1971 Population Projections, Series E (Reference 17) 


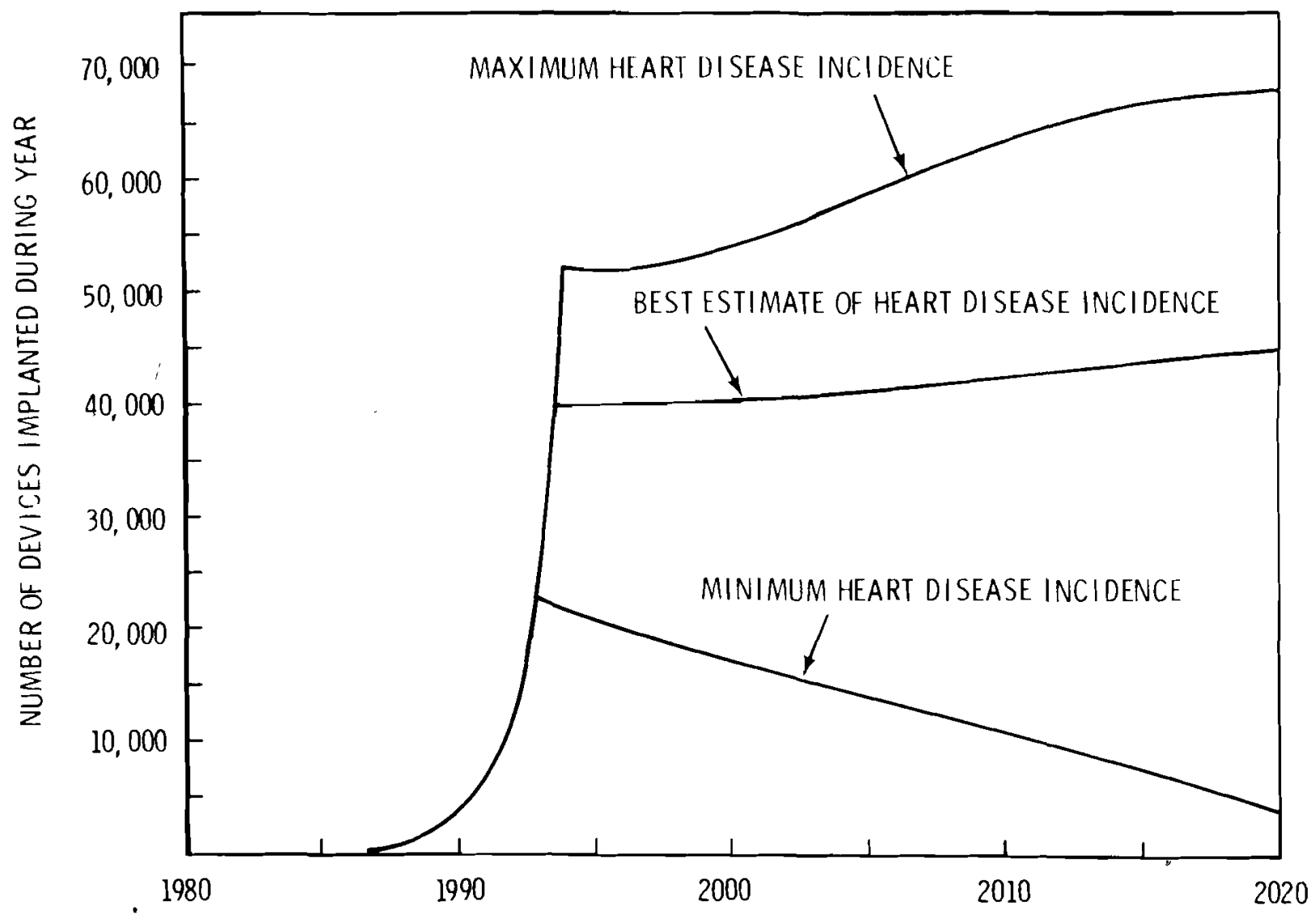

FIGURE 12. Annual Implant Projection (High Estimate of Eligible Candidates)

this increase is not believed to be unreasonable, given adequate economic incentives and strong public demand once the device is reasonably perfected.

\section{E. NATURAL-CAUSE DEATH RATES AFTER IMPLANT}

The number of artificial heart devices in use at any point in time will depend partly on the life expectancy of the recipients after implant. Consequentiy, it is important to estimate the death rates after implant as a function of the age and sex of the individuals receiving the device. Further, since no mechanical device is perfect, it is also important to quantify the possible number of deaths due to device failure, which is discussed in the next section.

To develop an estimate of survival from natural causes of death, the effect of eliminating heart disease as one of those causes must be considered. At present, heart disease mortality is such an overwhelming cause of death 
that deaths due to other competing risks are probably suppressed to some degree. If this is the case, then elimination of heart disease mortality in artificial heart recipients would increase risk of death from other causes. This may be especially true for major causes of death related to heart disease such as cerebral thrombosis and other arteriosclerotic diseases. Notwithstanding these increases in competing risks of death, elimination of heart disease would probably increase the survival rate if a recipient were considered in the same risk of death category as an individual with a natural heart. However, we do not believe this assumption to be reasonable in light of problems attendant to use of the device such as incompatibility of the device with the blood. We therefore used a survival probability of one-half that of a normal person as a best estimate of 1 ife expectancy after device implant.

The statistical theory regarding the probability of dying and survivorship has been well developed. The analysis described by Chiang ${ }^{(20)}$ uses the following steps. The normal probability of dying during an age interval $i$ (say 30-34) for a person at exact age $x_{j}$ (30) is given by Equation [1] in Table 5. However, since the risk of death from various causes has been altered for an artificial heart recipient (the person obviously cannot now die from heart disease), this probability must be adjusted to reflect these changes in risk. This is performed by Equation [2] in the same table. Using this equation, the risk of heart disease death can be removed and the risk of competing causes of death increased. After the probability of dying at exact age $X$ (30 in our example) has been satisfactorily adjusted, it is used in life table calculations shown in Equation [3] (21) to determine the probability of a person aged $X$ dying in an age interval (30-34 in our above example). The probability of any person surviving to the next age interval, shown in Equation [4], is identical to the fraction of the population living in one age interval who survive to the next one. Applying these age-specific fractions to the number of devices implanted in a given year develops the number of recipients surviving to any subsequent year.

After initial unsatisfactory attempts to estimate the increase and decrease in competing risks of death in Equation [2], we decided to parameterize the result by choosing simple fractions for $c 1$ to adjust the values 


\section{TABLE 5. Equations Used to Determine Survivorship of Artificial Heart Recipients After Implant}

$\begin{aligned} & \text { Normal probability of dying } \\ & \text { during age interval } i \text { for } \\ & \text { a person at exact age } x_{i}\end{aligned}=Q_{i}=1-P_{i}=\frac{n M_{i}}{1+\left(T-F_{j}\right) n M_{i}}$

where $M_{i}=$ age-specific death rate for all causes $=\frac{\text { total deaths }}{\text { total population }}$

$\mathrm{n}=$ length of age interval $=5$ years

$F_{i}=$ fraction of the age interval 1 ived by those who die during the interval

$P_{i}=\begin{aligned} & \text { Probability of person at exact age } x_{i} \text { surviving over the } \\ & \text { entire interval }\end{aligned}$

Probability of dying during

age interval $i$ for a person $=Q A_{i}=1-\left(P_{j}\right)\left(C 1 M_{i}-C 2 M_{a, i}+C 3 M_{b, j}\right) / M_{i}$ removal and addition of

competing risks.

where $\mathrm{Cl}=$ factor to adjust death rate for all causes

$\mathrm{C} 2$ = factor to reduce death rate for specific cause a

$\mathrm{C} 3$ = factor to increase death rate for specific cause $b$

$M_{a, i}=$ age-specific death rate for cause a which is being reduced

$M_{b, i}=$ age-specific death rate for cause $b$ which is being increased

$P_{i}=$ calculated from Equation [1]

Probability of dying during age interval $i$ for any person in age interval i, (life table calculation)

$=Q F_{i}=\frac{S_{i+1}}{S_{i}}$

where $S_{i}=\underset{\text { stationary population }}{\text { in age interval } i}=n\left[L_{i}\left(1-Q A_{i}\right)\right]+n F_{i} L_{i}\left(Q A_{i}\right)$

where $L_{i}=$ number living at exact age $X_{i}$

$Q A_{i}=$ calculated from Equation [2]

Probability of surviving to next

age interval for any person in age interval $i=P F_{i}=1-Q F_{i}$

Sources: Equations 1 and 2: C. L. Chiang, Introduction to Stochastic Processes in Biostatistics (Reference 20, pp. 256-258)

Equations 3 and 4: Vital Statistics of the United States (Reference 21, p. 5.6) 
of the death rate for all causes. For the reasons previously mentioned in this section, we assumed a survival probability of one-half that of a person with a normal heart as a best estimate (i.e., $\mathrm{C} 1=0.5, \mathrm{C} 2$ and $\mathrm{C} 3=0.0$ ). We estimated the upper limit of survival probability to be equal to survival probability with a normal heart. As a lower limit, we chose a one-fourth survival probability $(\mathrm{C} 1=0.25)$. A comparison of the fractions surviving over time for the above three estimates is illustrated in Figure 13. After 10 years of device 1 ife, approximately $69 \%$ of device recipients would be living under the normal probability of death estimate, $52 \%$ living under the one-half normal probability of death estimate, and $34 \% 1$ iving under the onefourth normal estimate. This range of estimates appears to give reasonable values for the life expectancy of device recipients. Separate calculation of a set of age-specific surviving fractions for both males and females makes the fractions both age- and sex-specific.

\section{F. DEVICE FAILURE DEATH RATES}

Because of its impact on lifetime after implant, especially in younger age groups, device failure is a variable that needs careful attention. Unfortunately, few, if any, mechanized systems have the operating lifetimes needed to develop a data base for such device failure estimates. The problem is easily understood by considering the almost unbelievable amount of work accomplished by the continuous, unattended operation of the normal human heart.

In the absence of such a data base, we felt that the best procedure was to express device failure rates in terms of a fraction of human heart failure rates (heart disease death rates). After calculation of many alternate bases, we decided that a device reliability of one-half that of a normal human heart best estimated possible future failure rates. This basis results in 50\% accumulated failures at 12 years and is believed to represent an achievable design goal for an artificial heart device. The method used in our analysis and the effect of our assumptions on total devices in use is discussed in the remainder of this section.

To develop device failure rates, we calculated the age-specific probability of death as if heart disease were the only risk present. We 


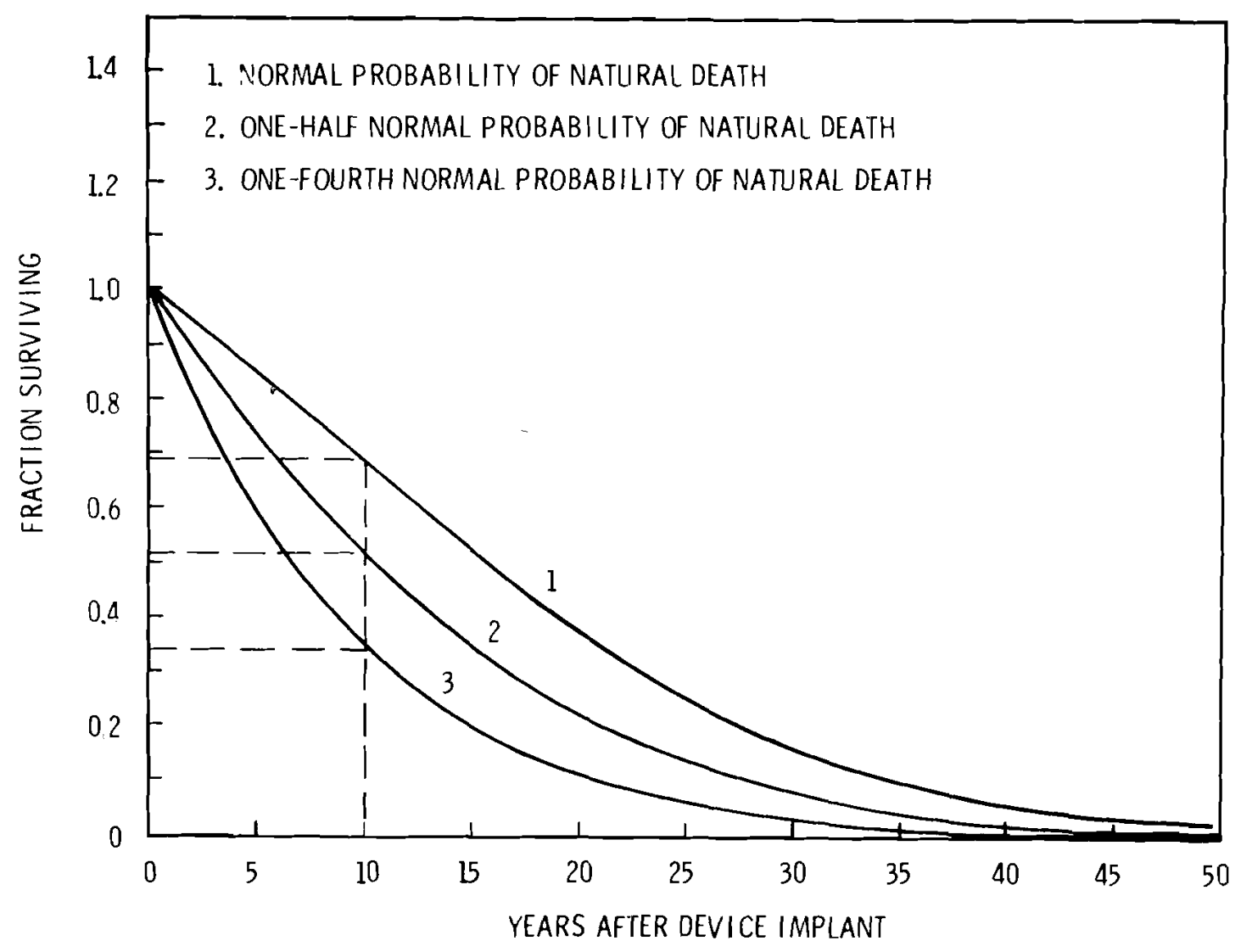

FIGURE 13. Comparisons of Life Expectancy Bases (Without Device Failure) for Artificial Heart Recipients

used the method outlined by Chiang ${ }^{(20)}$ for handling competing risks. Using this theory the probability of device failure is given by the following equation.

Probability of Failure in Interval $=1-\left(P_{j}\right)(C 1 \times M 1) / M$ where

$$
\begin{aligned}
P_{i}= & \text { Normal probability of surviving from age } \\
& \text { interval } i \text { to age interval } i+1 . \\
M= & \text { Death rate for a11 cause } \\
M 1= & \text { Death rate for heart disease. } \\
C 1= & \text { Factor to adjust death rate for heart disease. }
\end{aligned}
$$


In our first estimate of device failure rates, we assumed that the device would have a reliability equivalent to the average reliability of a normal human heart in the recipient age group (or $\mathrm{Cl}=1.0$ ). We used these probability data with our modified age profile in the REPRIEVE code to calculate the survivorship of 10,000 recipients. The totals, representing the composite mixture by age and sex, represented device reliability. Results of this calculation are shown in Table 6 . For example, the probability of the device operating 5 years would be $89.6 \%$; for 10 years, $77.8 \%$; for 15 years, $64.2 \%$; and so on. The distribution of device reliabilities based on this criteria is shown as Curve 1 in Figure 14.

Considering the length of continuous, unattended operation without failure of the normal human heart, we reasoned that device reliability approaching this is not a credible prospect in the foreseeable future. Assuming that the probability of failure in a 5 -year interval would be double the probability of nomal heart failure (from heart disease), the fraction surviving as a function of device age is shown as Curve 2 in Figure 14. This results in $42 \%$ failures in 10 years and 50\% failures in 12 years. This bas is is believed to represent an achievable design goal.

TABLE 6. Devices Remaining in Use Assuming a Device Failure Rate Equivalent to the Failure Rate of a Normal Human Heart

\begin{tabular}{|c|c|c|c|}
\hline $\begin{array}{l}\text { Year After } \\
\text { Implant }\end{array}$ & $\begin{array}{l}\text { Devices } \\
\text { in Use }\end{array}$ & $\begin{array}{l}\text { Year After } \\
\text { Implant } \\
\end{array}$ & $\begin{array}{l}\text { Devices } \\
\text { in Use } \\
\end{array}$ \\
\hline 0 & 10,000 & 40 & 973 \\
\hline 5 & 8,961 & 45 & 535 \\
\hline 10 & 7,777 & 50 & 270 \\
\hline 15 & 6,423 & 55 & 123 \\
\hline 20 & 5,011 & 60 & 46 \\
\hline 25 & 3,683 & 65 & 14 \\
\hline 30 & 2,535 & 70 & 2 \\
\hline 35 & 1,627 & & \\
\hline
\end{tabular}




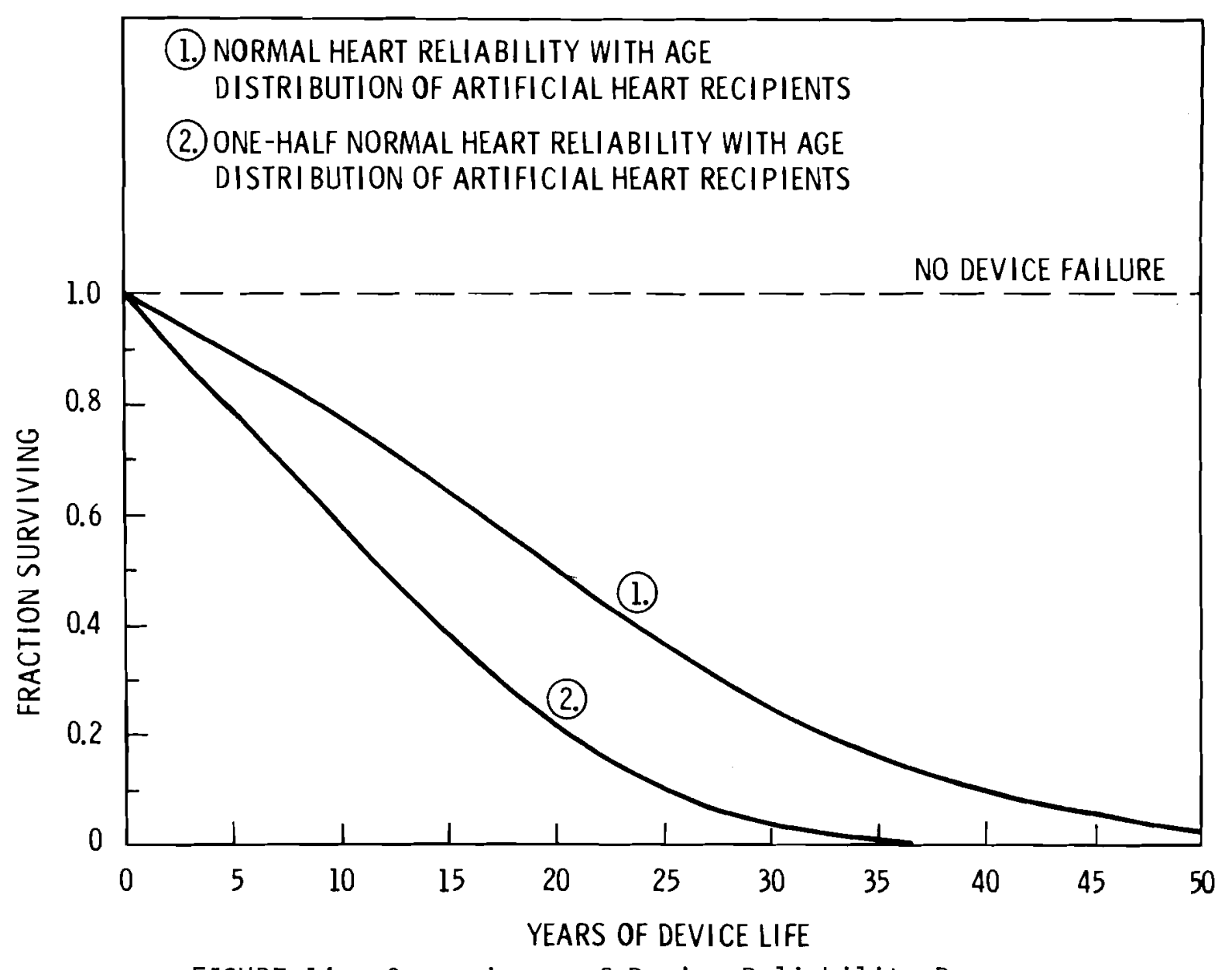

FIGURE 14. Comparisons of Device Reliability Bases

\section{G. CUMULATIVE USE PROJECTIONS}

We combined the parameters developed in the previous sections to develop the overall projection of artificial heart use. The high eligible candidate projection, the best estimate heart disease projection, the twice-normal probability of death calculation, and the one-half-normal heart reliability device failure assumption represent the best estimates of probable future occurrence. The number of devices in use as a function of time using these best estimates is shown in Figure 15 as the best estimate curve. In addition, the approximate maximum and minimum use projections are indicated. Table 7 shows the assumptions for these cases as we11 as the approximate number of devices in use at 5-year intervals. In the year 2000 we project about 200,000 


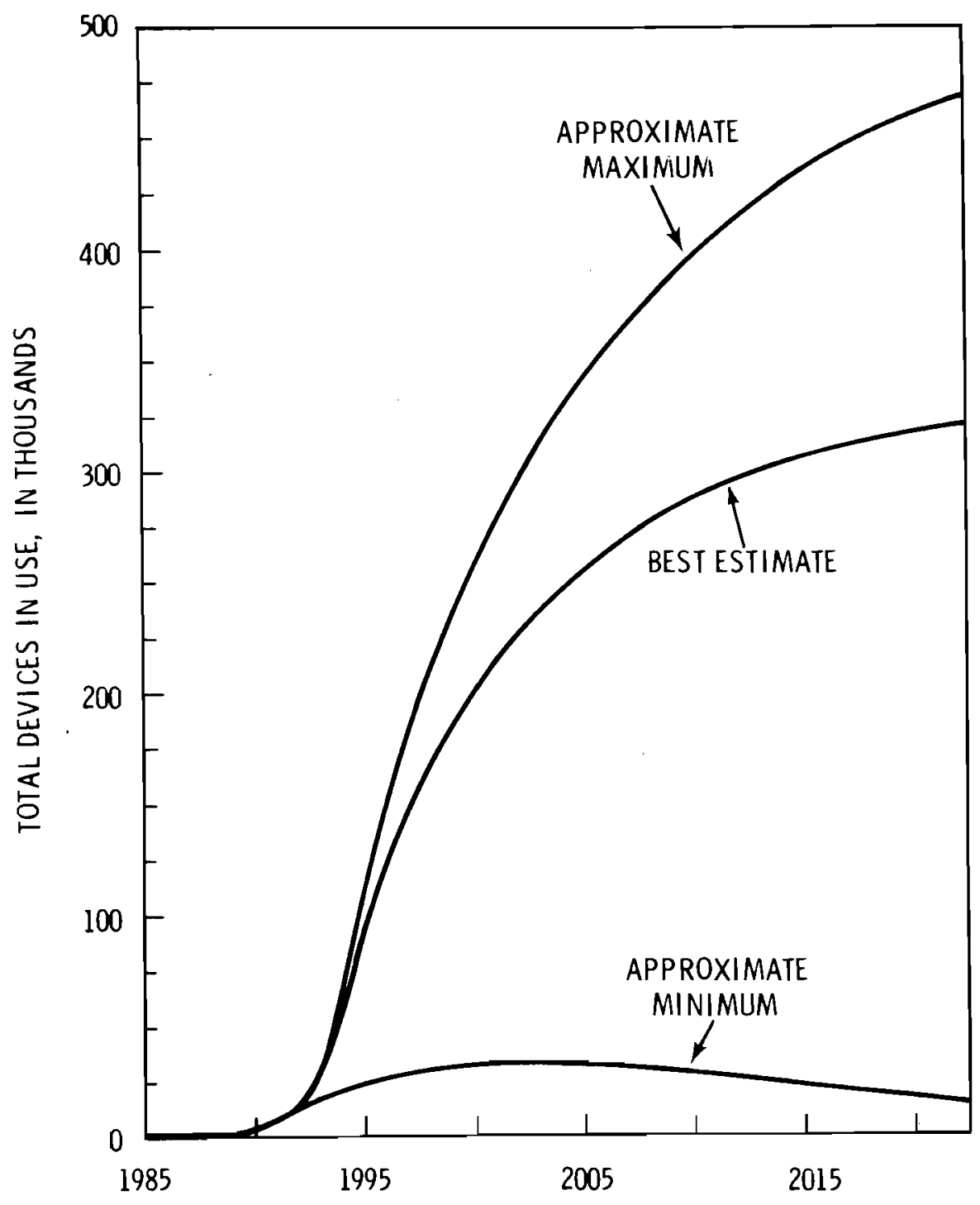

FIGURE 15. Estimates of Potential Artificial Heart Use

devices in use with a maximum of about 260,000 and a minimum of 34,000 . This represents a total variation of +30 to $-87 \%$ from the best estimate (reference base case).

Figures 16 through 19 show the effect of the range of assumptions for the individual parameters. Figure 16 shows the range of devices in use encompassing the uncertainty in our estimates of fatal heart disease incidence. 


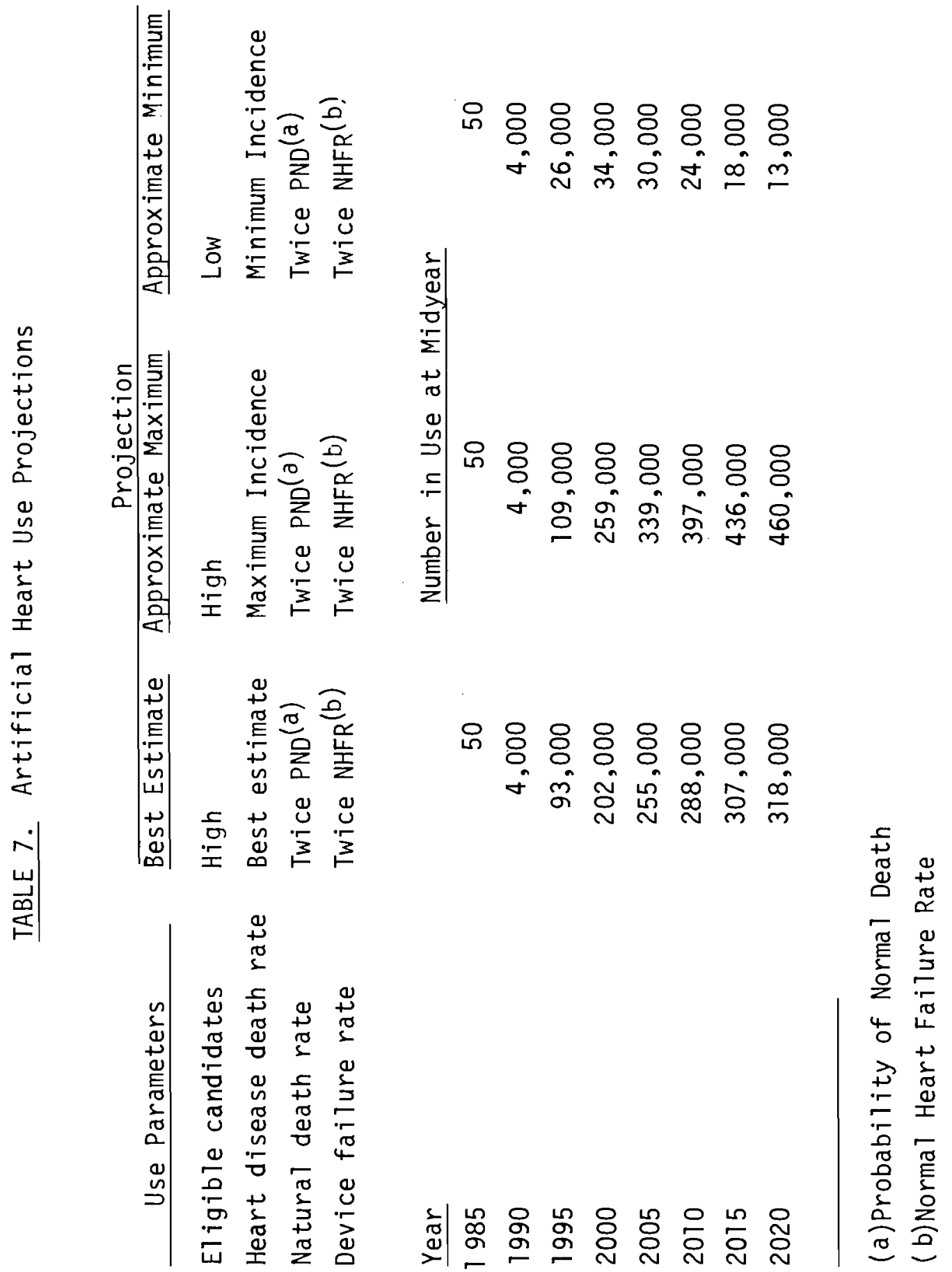



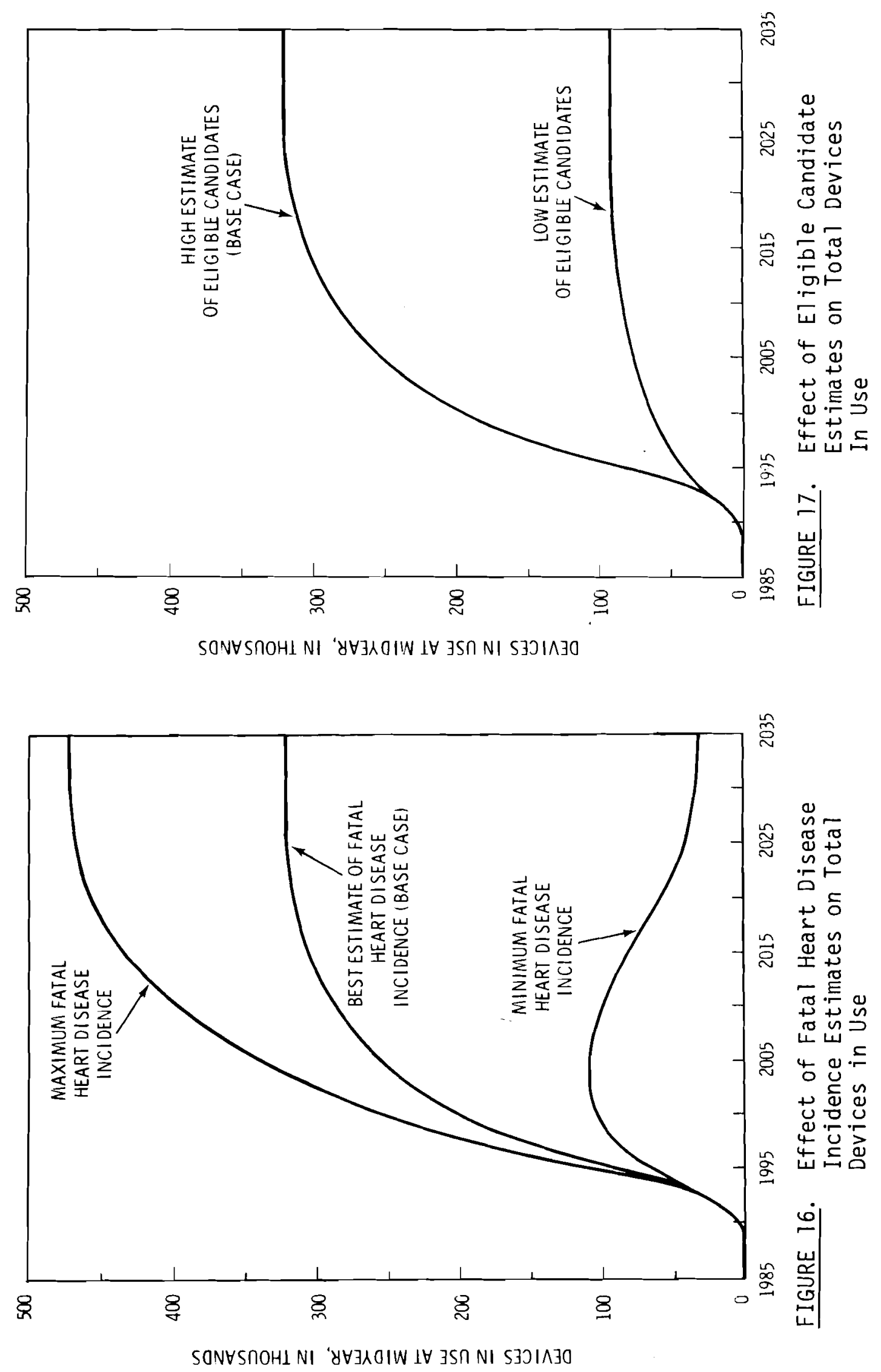

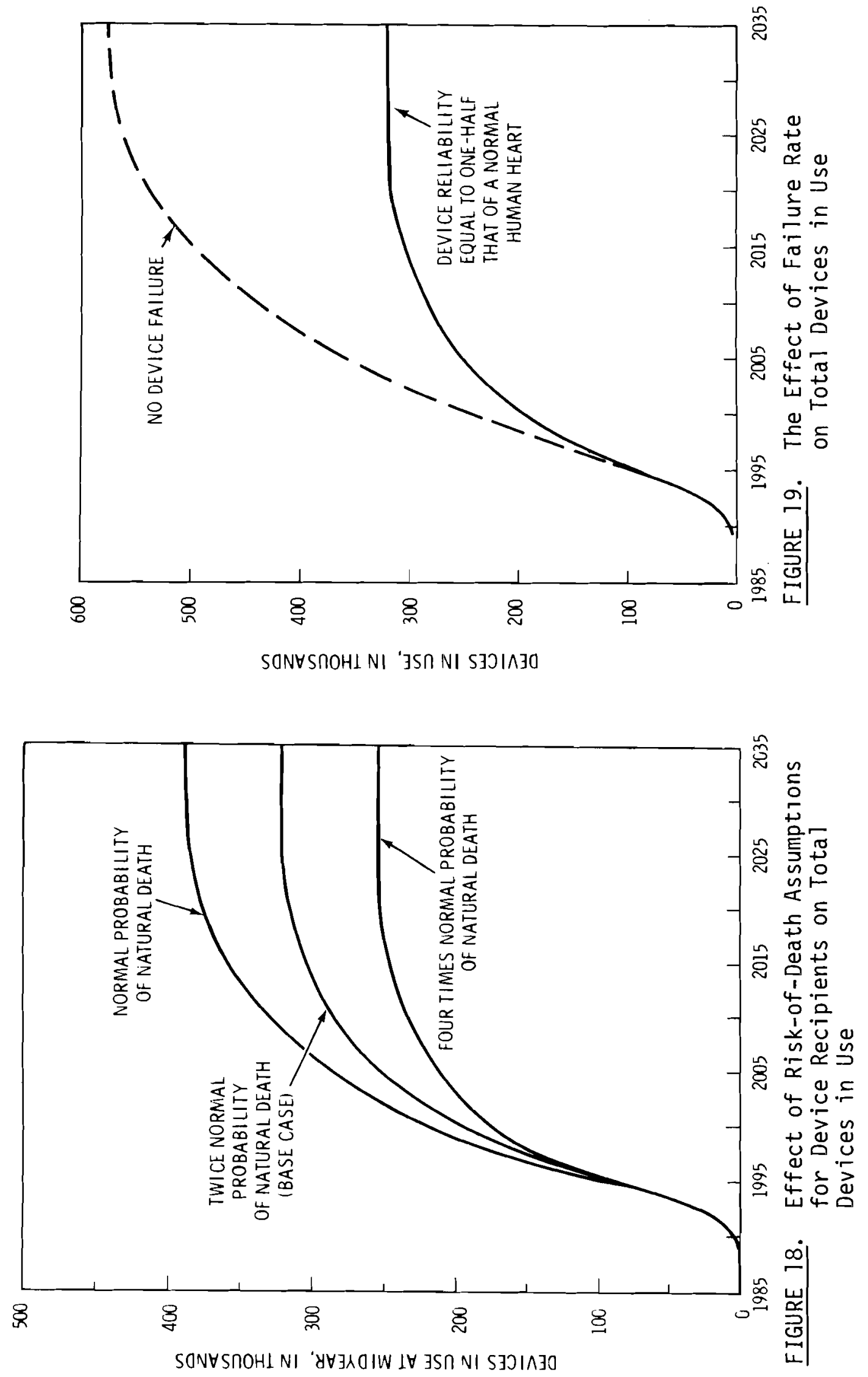
While the maximum and minimum estimates of disease incidence reflect a large range in the number of devices in use (from 100,000 to 260,000 in the year 2000), the close fit of the actual data to the best estimate projection of fatal heart disease incidence indicates a higher probability for the best estimate. Assuming that the base case values of the other parameters also reflect the highest probabilities, the most probable number of devices in use in the year 2000 would be approximately 200,000 (reference base case estimate). The percentage variations corresponding to the above mentioned maximum and minimum estimates are +30 to $-50 \%$.

Figure 17 indicates that the high and low estimates of eligible candidates for devices also span a wide range of total devices in use. Use of the low estimate lowers the number of devices in use to about 60,000 in the year 2000 - a drop of $70 \%$ from the reference base case estimate.

After device implant, one factor affecting the number of devices in use is the length of time the device recipient is expected to live after implant or the natural risk of death. The effect of this factor is shown in Figure 18. The assumption of a normal risk of death following implant is not credible although it may be considered an upper limit of the probability of survival. There is also a less well-defined point on the low side at which survival probability is so low that the trauma associated with the device implant is felt to outweigh the value of additional life gained (this is verified by current experience with heart transplants). There is currently no data to determine where the most probable natural risk of death lies between these extremes. As mentioned, we chose a value of twice the normal risk of natural death for our base case and a risk of four times normal for the lower limit. The use projection variation of this parameter is only $\pm 10 \%$ of the reference base case indicating that device use is much less sensitive to this parameter than to previous parameters.

The other factor tending to decrease the number of devices in use is device failure. Figure 19 illustrates the effect of the assumptions of no device failure and of a failure equal to twice the current heart disease death rate. The assumption of no device failure is not a credible case but illustrates the theoretical upper limit. Since no current basis exists for 
analytically estimating failure rates, we assumed a failure rate of twice natural heart failure rates as a realistic and achievable goal. Without a device failure assumption, tota 1 devices in use in the year 2000 would be increased by $25 \%$. 


\section{v. CLASSIFICATIONS OF ARTIFICIAL HEART USERS}

To obtain an estimate of population dose, the artificial heart population was subdivided into small groups such that daily activities were identifiable. The principal subdivisions were by age, sex, employment status, household type and occupation. Figure 20 shows the matrix resulting from the combination of these recipient classifications. This matrix has 1,476 subdivisions which gives an idea of the detailed nature of the recipient descriptions. The explanation of these classifications, including the derivations of the data base, follows.

\section{A. AGE AND SEX}

Since the artificial heart use projections developed in the preceding section were done on an age- and sex-specific basis, the recipient is already described by age and sex. To review briefly, we determined eligible artificial heart candidates on the basis of age groups, but insufficient data existed to make a valid sex differentiation. However, the heart disease death rate projections determined both age- and sex-specific estimates of the number dying from heart disease. We also developed estimates of 1 ife expectancy based on the age and sex of the recipient at the time of implant. Device failure rates are not a function of the age or sex of the recipients. Combinations of these four parameters developed the artificial heart use projection by sex and fiveyear age groups. Using our best estimates of the above parameters, the age and sex profile of artificial heart users in the year 2000 is shown in Figure 21.

\section{B. OCCUPATION}

Because of substantially different lifestyles, employed and nonemployed recipients should have discernably different patterns of radiation exposure. In addition, defining the employment status and occupation permits identification of the number of recipients in the work force and ultimately allows an identification of the dose to work associates. To classify the recipient population by employment status, we assumed that the employment distribution would be proportional to the employed-unemployed ratio in the total population. 


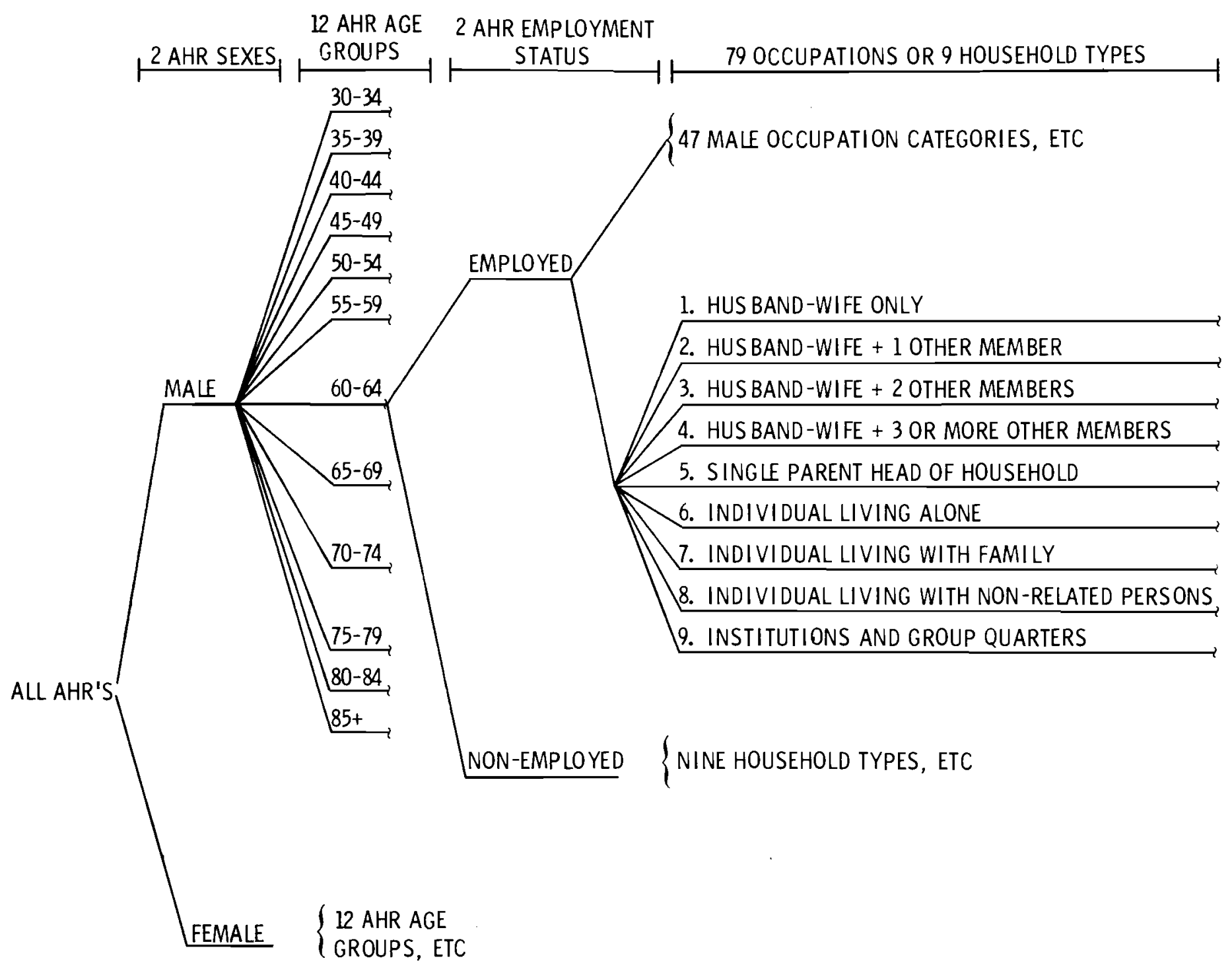

FIGURE 20. Subdivisions of Artificial Heart Recipient (AHR) Matrix 


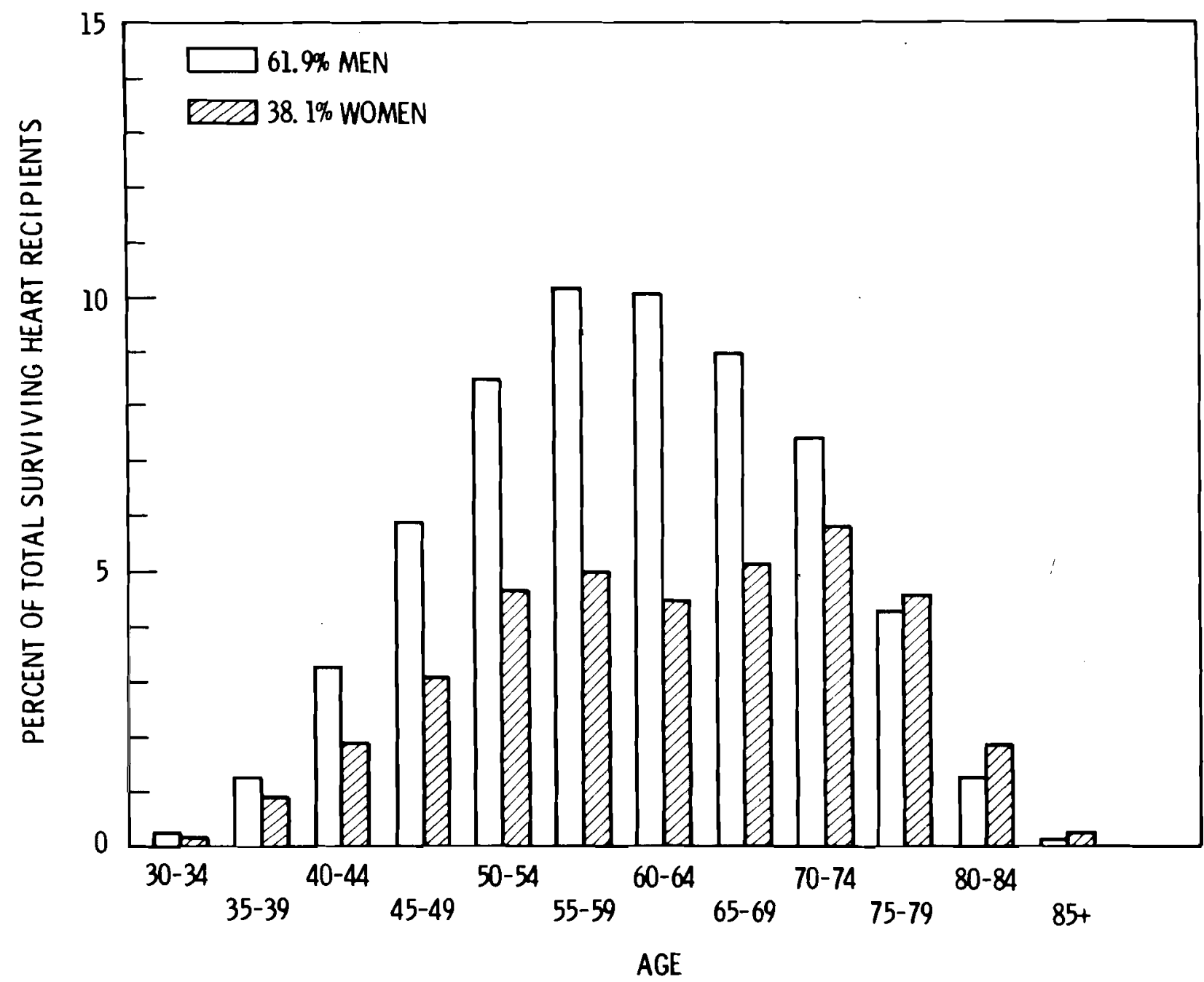

FIGURE 21. Age Profile of Artificial Heart Users in the Year 2000 Using Base Case Parameters

We further classified the employed fraction of recipients by occupation by assuming that their occupation distribution by age and sex would likewise be proportional to that of the total population. The 1970 population census provided the data for the occupation ratios by age and sex. ${ }^{(22)}$ Since the number of census occupations is much too large to handle in detail, we grouped occupations in 12 major groups with subdivisions into 79 occupation types--47 predominantly male and 32 predominantly female. The 12 major groups and the number of occupation classifications in each are listed in Table 8. This table also indicates the percentage of all employed males and females included in each major group. As shown, craftsmen and managers are the two largest 
TABLE 8. Classification of Artificial Heart Recipients by Occupation

\begin{tabular}{|c|c|c|c|c|}
\hline & $\begin{array}{c}\text { Male } \\
\text { Subdivisions } \\
\end{array}$ & $\begin{array}{c}\% \text { of } \\
\text { Employed } \\
\text { Males } \\
\end{array}$ & $\begin{array}{c}\text { Female } \\
\text { Subdivisions } \\
\end{array}$ & $\begin{array}{c}\% \text { of } \\
\text { Empl oyed } \\
\text { Females } \\
\end{array}$ \\
\hline $\begin{array}{l}1 \text { - Professional, Technical } \\
\text { and Kindred }\end{array}$ & 8 & 6 & 4 & 9 \\
\hline $\begin{array}{l}2 \text { - Farmers and Farm } \\
\text { Managers }\end{array}$ & 2 & 6 & 1 & 1 \\
\hline $\begin{array}{l}\text { 3- Managers, Officials, } \\
\text { Proprietors }\end{array}$ & 2 & 12 & 2 & 4 \\
\hline $\begin{array}{l}4 \text { - Clerical and } \\
\text { Kindred Workers }\end{array}$ & 4 & 3 & 6 & 17 \\
\hline 5 - Sales Workers & 3 & 6 & 2 & 8 \\
\hline $\begin{array}{l}6 \text { - Craftsmen, Foremen } \\
\text { and Kindred }\end{array}$ & 11 & 17 & - & - \\
\hline 7 - Operatives and Kindred & 6 & 7 & 7 & 9 \\
\hline 8 - Service Workers & 7 & 5 & 7 & 14 \\
\hline $\begin{array}{l}9 \text { - Farm Laborers } \\
\text { and Farmers }\end{array}$ & 2 & 2 & 1 & 1 \\
\hline 10 - Laborers & 1 & 6 & - & - \\
\hline 11 - Private Household Workers & - & - & 1 & 8 \\
\hline \multirow[t]{2}{*}{12 - Not Classified } & 1 & 30 & 1 & 29 \\
\hline & 47 & 100 & 32 & 100 \\
\hline
\end{tabular}

Source: 1970 Census of Population (Reference 22)

occupation groups for men. For women, clerical workers and operatives are the main occupation types. The occupation classifications chosen include $70 \%$ of al1 male occupations and $71 \%$ of all female occupations. A detailed table showing each occupation classification and related percentage data is included in Appendix C.

C. HOUSEHOLD TYPE

Classification of recipients by household type allows eventual identification of the dose to household members and associates in the home. We assumed 
that the distribution of household types in the recipient population was identical to the distribution in the entire population.

The standard census tabulations from which we derived the occupation data did not provide adequate detail on households. Each month the Census Bureau surveys some 45,000 households for a limited amount of information. In March of each year this current population survey is expanded to include great detail on household classifications. We obtained the data tapes for the March 1972 current population survey to provide the data base for our household type classifications. Computer programs sorted the data in terms of characteristics of Potential Heart Recipients (PHRs) and Radiation Exposure Subjects (RESs). Table 9 summarizes the parameters used to define each PHR and RES and shows the number of subdivisions for each parameter.

TABLE 9. PHR Classifications for the Current Population Survey Classification

\begin{tabular}{lc}
\multicolumn{1}{c}{ Classification } & \multicolumn{1}{c}{ Subdivision } \\
\cline { 1 - 2 } Age of PHR & 2 \\
Sex of PHR & 9 (+ two subclassifications) \\
Household-type of PHR & 2 \\
Household location (urban or rural) & 2 \\
Employment status of PHR & 6 \\
Age of spouse of PHR & 11 age groups \\
Number, age and sex of other household & 2 sexes \\
members related to PHR & 11 age groups \\
Number, age and sex of other household & 2 sexes \\
members not related to PHR
\end{tabular}

Using the above data base, we assigned the same set of household characteristics for a particular age and sex group of the PHR to the same age and sex group in the artificial heart recipient population. * This allowed us to identify by age and sex the number of household members exposed.

\footnotetext{
* Note: Some confusion may exist in the readers mind concerning the definition of artificial heart recipient and PHR. Artificial heart recipient refers to the actual recipient population and their characteristics as developed in the use projection. PHR refers to potential users of the device and is usually used in conjunction with persons sampled in the current population.
} 
The definitions of the nine household classifications used in this analysis are shown in Table 10. The approximate distribution of these householdtypes in the year 2000 is indicated in Table 11. (This is approximate due to the slightly different number of artificial heart recipients in each age and sex group, depending on the assumptions used in the artificial heart use projection.) The largest recipient group is husband-wife only* households, since the artificial heart population comprises a much older group than the population as a whole. There are, however, a significant number of devices in persons living in larger households (Types 2-4) and this causes some exposure to younger persons. Young persons may also be exposed due to an older person (grandfather, etc.) living in a younger family (household Type 7). Individuals living with nonrelated persons and persons living in group quarters are a very sma 11 percentage of the total number of recipients. Therefore, these groups do not contribute appreciably to the overall population dose.

\section{OTHER CONSIDERATIONS}

We considered additional variables in defining the PHR. These were living location (urban-rural) and income (high, medium and low). A statistical examination of data and dose rates in urban and rural families indicated very few significant differences, and this variable was then deleted to make the data matrix for REPRIEVE more manageable. Although interpersonal distance data were collected in interpersonal distance surveys (discussed in Section IX) by income level, we did not use it as part of the PHR description.

* Note: Since most households have more than one potential heart recipient in each household, it is important to note that:

1. Only one recipient was assumed in each household (since less than one person in a thousand would have a heart device).

2. The person having the device in the household is named in the household type (e.g., the husband or wife in household Types 1-4, the household head in Type 5, the relative, servant, etc., in Type 7 and so on). 
TABLE 10. Household Classifications

TYPE 1 - HUSBAND/WIFE HOUSEHOLD

Husband and Wife only (Age 30+)

and no other members

TYPE 2 - HUSBAND/WIFE HOUSEHOLD + ONE OTHER MEMBER

Husband and Wife (Age 30+)

and one other person (related or not)

TYPE 3 - HUSBAND/WIFE HOUSEHOLD + TWO OTHER MEMBERS

Husband and Wife (Age 30+)

and two other persons (related or not)

TYPE 4 - HUSBAND/WIFE HOUSEHOLD + THREE OR MORE OTHER MEMBERS

Husband and Wife (Age 30+)

and three or more other persons (related or not)

TYPE 5 - HEAD OF A SINGLE PARENT HOUSEHOLD OR NON-MARRIED FAMILY HEAD

Head of Household (Age 30+)

Includes: a) married, spouse absent

b) widowed

c) divorced

d) single

and one or more related members of any age or a non-related secondary family (Type 5 must include at least the above, but can also include one or more non-related members of any age.)

TYPE 6 - INDIVIDUAL AGE 30+ LIVING ALONE

Primary Individual Living Alone (Age $30+$ ) 
TABLE 10. (Contd)

TYPE 7 - PERSON LIVING WITH A FAMILY

7A - MARRIED PERSON AGE 30+ LIVING WITH A FAMILY

A11 Persons (Except Household Head or Wife), Age 30+

living with a household head (related or not)

Includes: Head of Secondary Family or

Head of Sub-Family

and married, spouse present

7B - PERSON AGE 30+ LIVING WITH A FAMILY (a)

A11 Persons (Except Household Head or Wife), Age 30+,

living with a family (related or not)

Includes: Individual or Head of Secondary Family or Head of Sub-Family
a) married, spouse absent
b) widowed
c) divorced
d) single

TYPE 8 - INDIVIDUAL AGE $30+$ LIVING WITH OTHER NON-RELATED PERSONS

A11 Persons, Age $30+$, 1iving with other persons in

a household where no family exists

TYPE 9 - PERSONS LIVING IN GROUP QUARTERS

9A - ALL PERSONS, AgE 30+, as INMATES OF INSTITUTIONS

9B - ALL PERSONS, AGE $30+$, IN GROUP QUARTERS AND NOT INMATES OF INSTITUTIONS

(a) The difference between household Type 7B and household Type 5 is that the artificial heart recipient in Type 5 is classified by the census as the head of the household whereas AHRs in 7B are not household heads. 
TABLE 11. Distribution of Artificial Heart Recipients in Household Type

Household Type

1. Husband/wife only

2. Husband/wife and one other member

3. Husband/wife and two other members

4. Husband/wife and three or more other members

5. Head of single parent household or nonmarried family head

6. Individual living alone

7. Person living with a family (married and single)

8. Individual 1 iving with nonrelated persons

9. Persons living in group quarters (institutions and other)
Approximate Distribution

in Year 2000

$37-39 \%$

$13-14 \%$

$8-10 \%$

$10-11 \%$

$5 \%$

$14-15 \%$

6- $8 \%$

$1 \%$

$2-3 \%$ 


\section{IDENTIFICATION OF RADIATION EXPOSURE SUBJECTS}

Expansion of the study scope to characterize the population dose by the age and sex of the Radiation Exposure Subject (RES) required collecting additional data. The Current Population Survey data described in the previous section enabled us to make this identification for household members. In addition, we also identified each RES by the characteristics of the recipient exposing him including the relationship of the RES to the recipient. This allows the tracing of most of the exposure back to the source classification. We made this identification to make it possible to study the effect of controls on the activities of the recipient in terms of the dose effect on RES's in frequent close contact.

To obtain data identifying household associates, we made provision in a survey performed in Salt Lake City (discussed in Section IX) to record this information.

\section{A. SPOUSES}

Using the household type definitions previously discussed, a computer sort of the Current Population Survey data determined spouses of PHRs by six age groups and two sexes. Subsequent dose calculations verified our expectations that this group of RES's received a much higher average dose than any other group.

\section{B. OTHER HOUSEHOLD MEMBERS}

This group consists not only of family members, but all other non-heartrecipient persons living in the household (e.g., grandparents, servants, boarders, another family, etc.). In classifying these data the CPS data sort made separations on the basis of 11 age groups and sex. Later examination of doses by age revealed no need for such an expanded age determination and we subsequently condensed the 11 groups into eight.

The dose calculations revealed a significant average dose to this RES group including even very young persons. (See section on Results for more detail.) 


\section{ASSOCIATES}

Household associates were defined as persons frequently (at least several times a year) in the vicinity of the recipient during household activities. We used our survey in Salt Lake city to develop information on the number of associates present during each PHR activity and their frequency of contact. We defined these associate data by three age groups for each of 15 household activities of the PHR. The small size of the data base prevented us from making any differentiation by sex.

Work associates are defined as persons in the vicinity of the recipient during work activities. We assumed that these persons would be continuously present during the entire working period. Our survey of occupations developed the number of work associates and their interpersonal distances to the PHR. Since our previous estimates had determined that occupation dose absorption was much less significant than that during other activities, we did not characterize work associates by age or sex. Subsequent calculations indicated that the dose transmitted during household activities was approximately five times that transmitted during work-related activities.

D. GENERAL PUBLIC

Dose to the general public is composed of:

1. Dose to persons exposed during public activities such as shopping, entertainment, etc. This component is classified by two age groups (i.e., approximately over or under 18) and by sex. Included in this component is dose to household members during these activities. Special random surveys of public activities developed these data.

2. Dose to not otherwise identifiable persons randomly located in the vicinity of the recipient. We developed these data using population density figures and a special computer code named BINGO. A description of this calculation and of BINGO itself is included in Appendix G. 
Since the eventual number of devices in use may be substantial, and because of the high degree of mobility in the U.S. population, we assumed that all of the population would receive some degree of exposure. The average received by a member of the general populace would, however, be very low (on the order of one millirem/year or less).

The RES matrix shown in Figure 22 illustrates the interrelationship of the factors defining the RES's for each recipient. This figure is a follow-on to Figure 20 which described recipient classifications. As indicated in the left column each work or nonwork activity branch occurs for each recipient classification. Visualization of the expansion of the matrix gives some comprehension of the enormous amount of data needed to provide RES identification. 


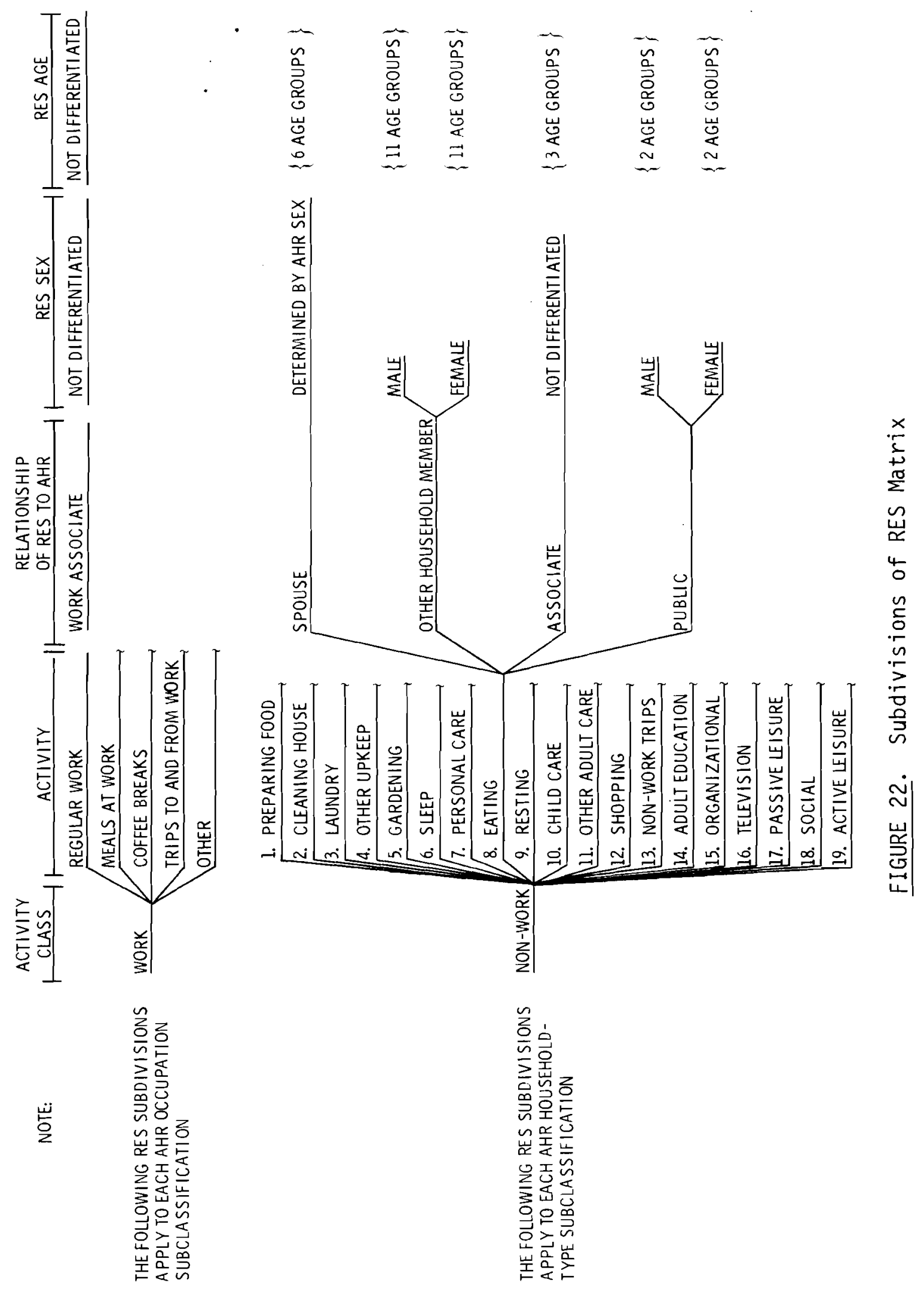




\section{TIME-IN-ACTIVITY DATA}

Use-of-time data classified by the characteristics of the artificial heart recipient and his activities are essential to the development of the population dose estimates. A number of use-of-time studies have been made, but the most comprehensive data on use of time for our purpose were from the University of Michigan's Institute for Social Research (ISR). These data represented a nationwide sample of 1,244 households covering all activities during a 24-hour period and included data on Saturday and Sunday activities as well as weekday activities. These data had been collected in 1966 as part of a multinational study carried out in 10 countries involving 13 surveys. ${ }^{(23)}$ The data contained information on the age and sex of the persons surveyed, their occupation, identification of age and sex of other members of the household, etc. The use-of-time data had 99 activity classifications.

The data were stored on computer cards, and we made arrangements with the ISR to obtain a special data sort to meet the requirements of the artificial heart dose-to-the-population study. For our purposes, activities were grouped into 19 nonwork activities and five work activity classifications. Although very few persons over 65 were included in the survey, examination of the data indicated that, above age 30 , age was not the most significant factor in a person's use of time. The employment status and household type were far more significant. The use-of-time classifications utilized were sex, employment status, household type, and the 19 nonwork activities shown in Table 12 and five work activities shown in Table 13.

Some data were not available in certain household types and we used data from household types as similar as possible to fill the gaps.

A more detailed breakdown for men and women 25 and older, without regard to household type, is shown in Table D. 1 in Appendix D. There the 19 nonwork activities are further subdivided into 85 activities.

Because of the small data base on ages over 65, a smal1 sample of use-oftime data from 57 households was collected during the survey of interpersonal distances in Salt Lake City. Due to the time required to edit and code these data, it was not processed beyond this point. A description of this survey is found on page E-15 in Appendix E. 
TABLE 12. Nonwork Activity Classifications

\begin{tabular}{|c|c|c|}
\hline Household & & Public \\
\hline 1 - Preparing Food & 8 - Eating $(a)$ & 1 - Shopping and Purchasing \\
\hline 2 - Cleaning House & 9 - Resting & 2 - Nonwork Trips \\
\hline 3 - Laundry, Mending & 10 - Child Care & 3 - Adult Education \\
\hline 4 - Other House Upkeep & 11 - Adult Care & 4 - Organizational Activity \\
\hline $\begin{array}{l}5 \text { - Gardening, Pets } \\
6 \text { - Sleep (a) }\end{array}$ & $\begin{array}{c}12-\text { Television } \\
\text { Viewing }(a)\end{array}$ & $\begin{array}{l}5 \text { - Social and Entertainment } \\
\text { Activities }\end{array}$ \\
\hline Personal C & Letsures & 6 - Sports and Active Leisure \\
\hline
\end{tabular}

(a) Five activities account for about $94 \%$ of nonwork activity dose.

TABLE 13. Work Activity Classification
1 - Regular Work
2 - Meals at Work
3 - Coffee Breaks
4 - Trips to and from Work
5 - Other 


\section{DOSIMETRY CALCULATIONS}

Using the QADP5A ${ }^{(24)}$ computer program, we calculated whole body dose rates to a $70 \mathrm{~kg}$ standard man phantom from an artificial heart containing a $30 \mathrm{~W},{ }^{238} \mathrm{Pu}$ power source. It was subsequently determined that sufficient power and longevity could be provided by a $24 \mathrm{~W}$ source, which reduced our dose rate calculations to $80 \%$ of the original values.

The power source for the $24 \mathrm{~W}$ heart device is projected to consist of 53.5 grams of sintered medical grade* ${ }^{238} \mathrm{Pu}$ oxide encapsulated inside a hypothetical device having a volume of approximately one liter. The device prototype used in our dosimetry calculations consisted of a stainless steel cylinder having a volume of $570 \mathrm{~cm}^{3}$. Encapsulated within the cylinder in layers of stainless steel and insulation (density $5.0 \mathrm{~g} / \mathrm{cm}^{3}$ ) was a tantalum cylinder of volume $21 \mathrm{~cm}^{3}$ containing the ${ }^{238} \mathrm{PuO}_{2}$. More recent developments in prototypic device systems indicate that quite a different device configuration may eventually be used. However, for the purposes of our study, we assumed that such changes would not have a great impact on dose measurements since distance is a much greater factor in determining external dose effects.

We assumed the source was centered at $(0,0,18)$ of the coordinate system shown in Figure 23 . The ${ }^{238} \mathrm{Pu}$ spectrum used in the QADP5A calculations is shown in Table 14. $(25,26)$ we determined the source strength by calculating the number of decays/sec based on the initial ${ }^{238} \mathrm{Pu}$ mass and the half-life. We also determined the ${ }^{236} \mathrm{Pu}$ source strength by calculating ${ }^{(27)}$ the amount of ${ }^{236} \mathrm{Pu}$ and ${ }^{236} \mathrm{Pu}$ daughters as a function of age assuming $0.3 \mathrm{ppm}{ }^{236} \mathrm{Pu}$ initially. The decay scheme is shown in Table $15^{(28)}$ and the flux-to-dose conversion factors used for the gamma cases are from Rockwe11. (29) The neutron spectrum used is the ${ }^{235} \mathrm{U}$ fission spectrum built into QAD. The error in dose contribution using this spectrum instead of the ${ }^{238} \mathrm{Pu}$ fission spectrum is believed to be less than $\pm 10 \%$. The neutron source strength was estimated at 3000 neutrons/ g-sec. (30) (A neutron source strength of 3300 neutrons/g-sec increases the dose by about $3 \%$.) The flux-to-dose conversion factors used for the neutrons are from 10 CFR 20. (31)

* Note: medical grade is $90 \%{ }^{238} \mathrm{Pu}_{2}$. 


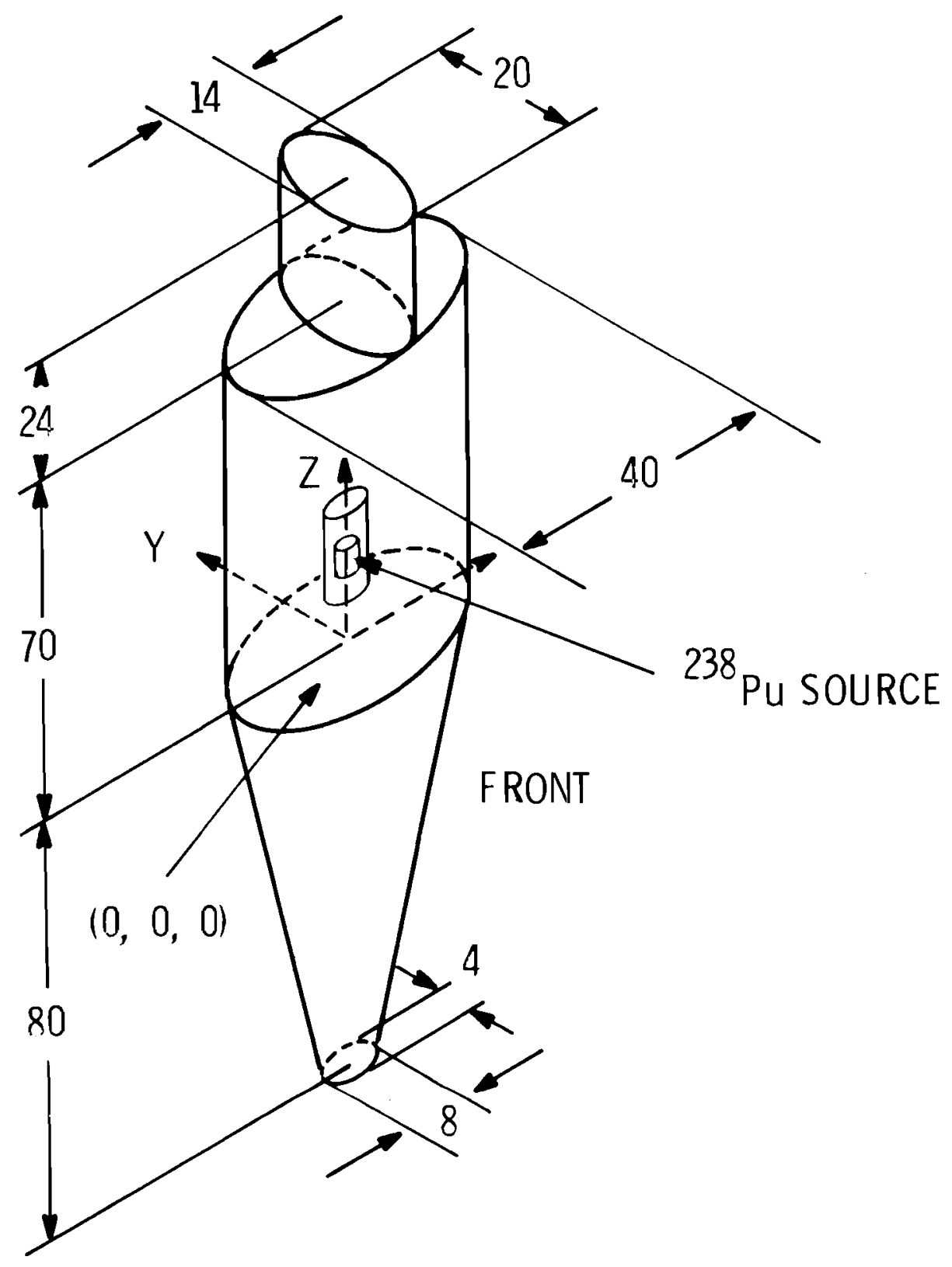

DIMENSIONS IN CENTIMETERS

FIGURE 23. Standard Man Phantom 
TABLE 14. Plutonium-238 Gamma Spectrum

\begin{tabular}{rr}
\multicolumn{2}{c}{ Energy $(\mathrm{keV})$} \\
\hline 1 & 43.49 \\
2 & 99.79 \\
3 & 125.15 \\
4 & 152.58 \\
5 & 158.80 \\
6 & 197.30 \\
7 & 199.35 \\
8 & 201.03 \\
9 & 251.00 \\
10 & 338.60 \\
11 & 350.69 \\
12 & 416.87 \\
13 & 439.86 \\
14 & 742.77 \\
15 & 766.35 \\
16 & 786.03 \\
17 & 808.70 \\
18 & 810.50 \\
19 & 852.20 \\
20 & 883.20 \\
21 & 904.34 \\
22 & 926.73 \\
23 & 942.02 \\
24 & 940.12 \\
25 & 1001.10 \\
26 & 1041.90 \\
27 & 1085.40 \\
& \\
\hline &
\end{tabular}

Gamma Rays/100 Decays

$3.80 \times 10^{-2}$

$8.00 \times 10^{-3}$

$3.80 \times 10^{-6}$

$1.27 \times 10^{-3}$

$1.90 \times 10^{-6}$

$1.40 \times 10^{-6}$

$1.90 \times 10^{-6}$

$4.40 \times 10^{-6}$

$1.10 \times 10^{-6}$

$7.40 \times 10^{-7}$

$2.40 \times 10^{-6}$

$2.80 \times 10^{-6}$

$3.60 \times 10^{-6}$

$6.50 \times 10^{-6}$

$2.80 \times 10^{-5}$

$7.20 \times 10^{-6}$

$1.20 \times 10^{-6}$

$1.30 \times 10^{-6}$

$2.10 \times 10^{-6}$

$1.30 \times 10^{-6}$

$6.21 \times 10^{-8}$

$6.15 \times 10^{-7}$

$5.26 \times 1.0^{-7}$

$1.03 \times 10^{-7}$

$1.30 \times 10^{-6}$

$2.29 \times 10^{-7}$

$2.29 \times 10^{-7}$

Source: 1-20: J. E. Cline, et al., Gamma Rays Emitted by the Fissionable Nuclides and Associated Isotopes (Reference 25) 20-27: R. Gunnik and R. J. Marrow, "Gamma-Ray Energies and Absolute Branching Intensities for 238,239,240,241pu and 241Am," (Reference 26). 
TABLE 15. Plutonium-236 Decay Scheme

\begin{tabular}{ccc} 
Isotope & & Half-Life \\
\cline { 1 - 1 } Pu-236 & & $2.85 \mathrm{yr}$ \\
U-232 & $72 \mathrm{yr}$ \\
Th-228 & $1.91 \mathrm{yr}$ \\
*Ra-224 & 3.64 days \\
Pb-212 & $10.64 \mathrm{hr}$ \\
* *Bi-212 & $60 \mathrm{~min}$ \\
Pb-208 & stable \\
*Included as part & \\
of Ra-224 & \\
Rn-220 & $55.3 \mathrm{sec}$ \\
Po-216 & $0.145 \mathrm{sec}$ \\
**Included as part \\
of Bi-212 \\
Tl-208 \\
Po-212
\end{tabular}
Source: H. H. Van Tuyl, Calculations of Gamma Dose Rates at the Surface of Plutonium 0xide Source (Reference 28).

Dose measurements between phantom recipients representing a device recipient and a bystander have been made by Dr. Fred Cross of Battelle-Northwest Laboratories. (32) Further data provided by Dr. Cross are shown in the far right column in Table 16. When lead buildup is used for the region of the artificial heart and water buildup is used for the recipient phantom in the QADP5A calculations, the agreement with Dr. Cross's results is within 10 to $25 \%$, with the QADP5A values being higher as shown on the following page. This agreement is within the range of error estimated for the phantom measurements. 
TABLE 16. Comparison Between QADP5A Calculations

and Experimental Measurement for

238pu Gammas

\begin{tabular}{|c|c|c|c|}
\hline $\begin{array}{l}\text { Distance } \\
\text { Center of } \\
(\mathrm{ft})\end{array}$ & $\begin{array}{l}\text { from } \\
\text { Source } \\
\text { (cm) } \\
\end{array}$ & $\begin{array}{l}\text { QADP5A } \\
\text { Dose Rate (a) } \\
\text { mrem/hr } \\
\end{array}$ & $\begin{array}{c}\text { Values Deduced from } \\
\text { Dose Measurements (b) } \\
\text { mrem/hr }\end{array}$ \\
\hline 2 & 61 & 0.19 & 0.14 \\
\hline 4 & 122 & 0.064 & 0.051 \\
\hline 6 & 183 & 0.030 & 0.025 \\
\hline 8 & 244 & 0.017 & 0.015 \\
\hline 10 & 305 & 0.011 & 0.010 \\
\hline
\end{tabular}

(a) Using lead buildup for the device, water buildup for the phantom.

(b) Source: F. T. Cross (Reference 32)

The dose rate results for a $30 \mathrm{~W}$ artificial heart are shown in Table 17. The results are calculated as a function of distance from the center of the phantom (Z-axis). An array of dose points are calculated vertically at the horizontal distance specified and the results averaged over a cross-sectional area of a standard man phantom to get an average whole body dose. Since the device is centered on the Z-axis of the phantom, only side and front measurements are needed.

For use in the dose-to-the-population estimates, we averaged these results over the front and side directions and summed the rates from each radiation component to represent a single average dose rate to a person in the vicinity of the artificial heart user. We reduced these rates by a factor of 0.8 to correspond to dose rates from a $24 \mathrm{~W}$ heart device. The resulting dose rates are shown in Table 18 and are plotted in Figure 24. If dose rates were expressed in terms of frontal dose only, they would be approximately $50 \%$ higher than the average in the front and side directions.

As will be noted from Table 17, the dose rate from a single device increases substantially with time for the first 10 to 18 years due to the decay of the ${ }^{236} \mathrm{Pu}$ impurity. In order to incorporate this effect into REPRIEVE, we built in a calculation which utilizes the Bateman equations 


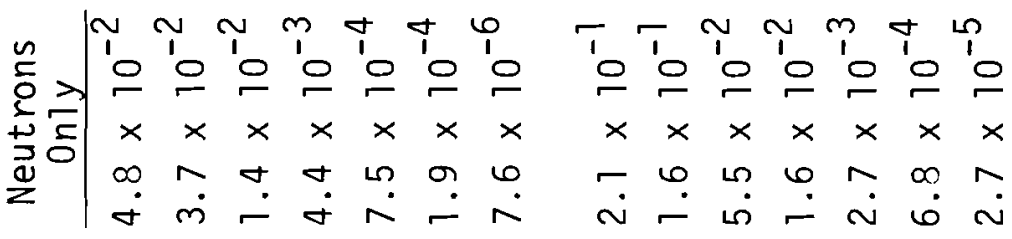

言

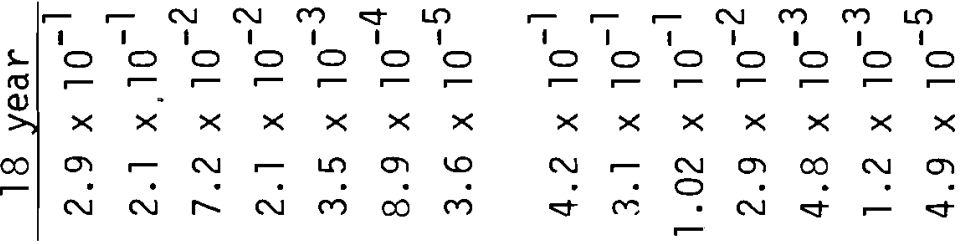

$=4$

元

밓ㅊ

तु

原

芯文

क⿺⿻一⿰冫⿰亅⿱丿丶丶⿱⿰㇒一乂

+ㅇํ

ज立

प्र

শัฒ

$\alpha+\frac{2}{3}$

a

象 $\frac{0}{3}$

- 9 엉

ह $\frac{\pi}{2}$

Ф E

这结兄

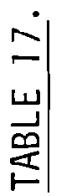

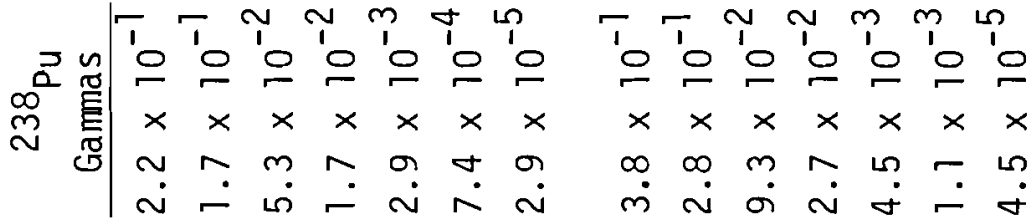

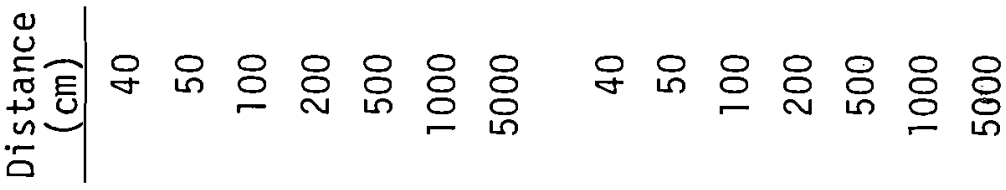

i⿱宀⿻上丨

岂 
TABLE 18. Total External Dose Rates from an Implanted

24 Watt Artificial Heart (mrem/hr)

\begin{tabular}{|c|c|c|c|c|c|}
\hline \multicolumn{2}{|c|}{ Distance } & \multicolumn{4}{|c|}{ Years After Separation } \\
\hline $\mathrm{ft}$ & in. & 0 & 5 & 10 & 18 \\
\hline 1.31 & 40 & $3.4 \times 10^{-1}$ & $4.9 \times 10^{-1}$ & $5.9 \times 10^{-1}$ & $6.3 \times 10^{-1}$ \\
\hline 1.64 & 50 & $2.6 \times 10^{-1}$ & $3.7 \times 10^{-1}$ & $4.5 \times 10^{-1}$ & $4.7 \times 10^{-1}$ \\
\hline 3.28 & 100 & $8.8 \times 10^{-2}$ & $1.3 \times 10^{-1}$ & $1.5 \times 10^{-1}$ & $1.6 \times 10^{-1}$ \\
\hline 6.56 & 200 & $2.6 \times 10^{-2}$ & $3.6 \times 10^{-2}$ & $4.3 \times 10^{-2}$ & $4.6 \times 10^{-2}$ \\
\hline 16.4 & 500 & $4.3 \times 10^{-3}$ & $6.0 \times 10^{-3}$ & $7.3 \times 10^{-3}$ & $7.7 \times 10^{-3}$ \\
\hline 32.8 & 1000 & $1.1 \times 10^{-3}$ & $1.5 \times 10^{-3}$ & $1.8 \times 10^{-3}$ & $1.9 \times 10^{-3}$ \\
\hline 164 & 5000 & $4.3 \times 10^{-5}$ & $6.0 \times 10^{-5}$ & $7.3 \times 10^{-5}$ & $7.8 \times 10^{-5}$ \\
\hline
\end{tabular}

to approximate the increase in dose rate. The calculation is based on the assumption that the increasing radiation dose from ${ }^{236} \mathrm{Pu}$ decay is proportional to the quantity of ${ }^{228}$ Th daughter present. This assumption is valid because of the very short half-lives of the radioactive decay-chain members subsequent to ${ }^{228} \mathrm{Th}$. Calibration of the dose rate predicted by the Bateman equations for the specific device and its location in the recipient is achieved using dose rate values derived from the QADP5A shielding code. Detailed calculations using the more sophisticated QADP5A code agree within $\pm 5 \%$ of those predicted with the calibrated Bateman equations. Using this model, we weighted the calculated percentage increase (relative to ${ }^{238} \mathrm{Pu}$ dose) in dose rate for each device age by the number of devices of corresponding age and calculated a weighted average dose rate for all devices in use. (Included in this calculation is an assumed six-month period between the time of ${ }^{238} \mathrm{Pu}$ purification and device implant.) This average increase in dose rate due to ${ }^{236} \mathrm{Pu}$ decay is printed out for five-year intervals. Table 19 shows a representative output for the year 2000 for our best estimate case. The dose-to-the-population calculation for a specified year incorporates the ${ }^{236} \mathrm{Pu}$ dose rate factor for that year.

In calculating the change in dose rate as a function of time, we included a correction for decreased radiation due to ${ }^{238} \mathrm{Pu}$ decay as we 11 as the ${ }^{236} \mathrm{Pu}$ correction. (About $8 \%$ of the ${ }^{238} \mathrm{Pu}$ decays away in 10 years.) Table 20 is representative of program output showing the effect of fuel age on ${ }^{238} \mathrm{Pu}$ dose rate weighted for all of the devices in use in the year 2000 (best estimate 


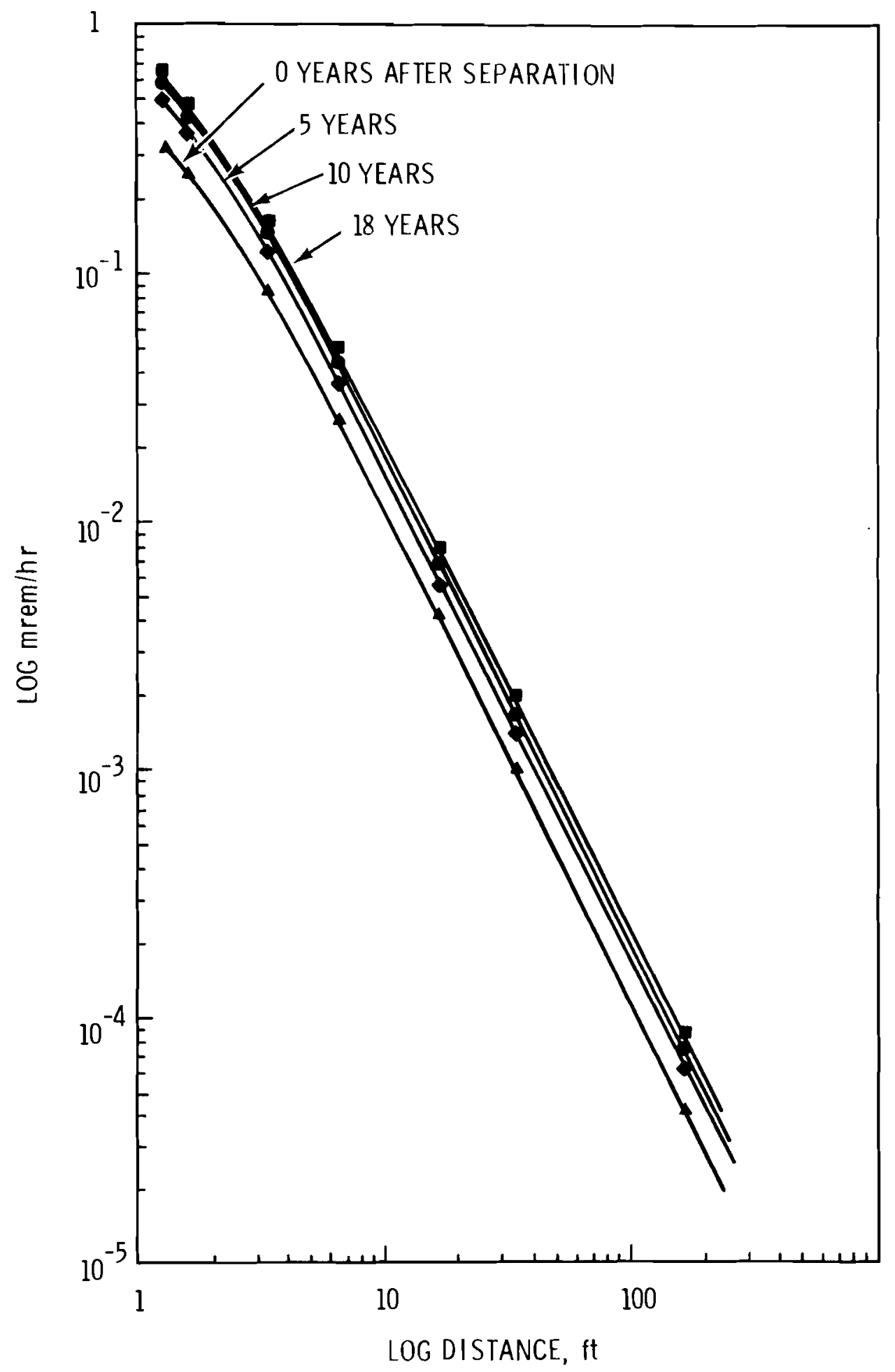

FIGURE 24. Dose Rates for a $24-W,{ }^{238}$ Pu Power Source (53.5 g 238Pu, $3000 \mu / \mathrm{g} \mathrm{sec}$ ) for the Artificial Heart 


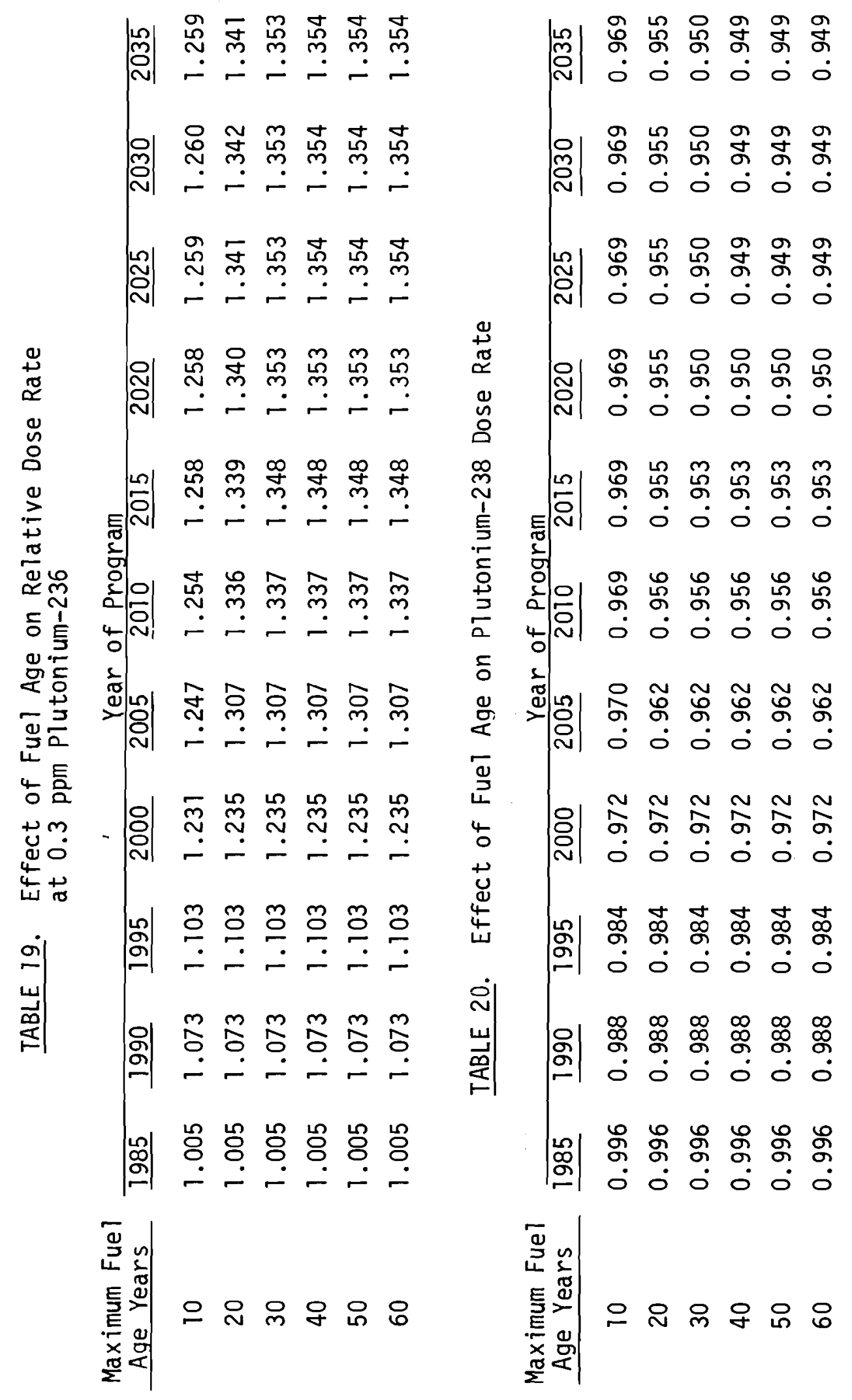


case). If just the effect of the increase in dose rate due to ${ }^{236} \mathrm{Pu}$ decay is desired, this can be obtained by simply subtracting the appropriate value in Table 20 from the corresponding value in Table 19.

Dose rates for ${ }^{236} \mathrm{Pu}$ concentrations other than $0.3 \mathrm{ppm}$ can be developed from the data in Table 17 by adding in fractions or multiples of the ${ }^{236} \mathrm{Pu}$ dose rates for $0.3 \mathrm{ppm}$ in proportion to the concentration desired. The effect of the ${ }^{236} \mathrm{Pu}$ content on the relative dose rate from an implanted artificial heart is shown in Figure 25.

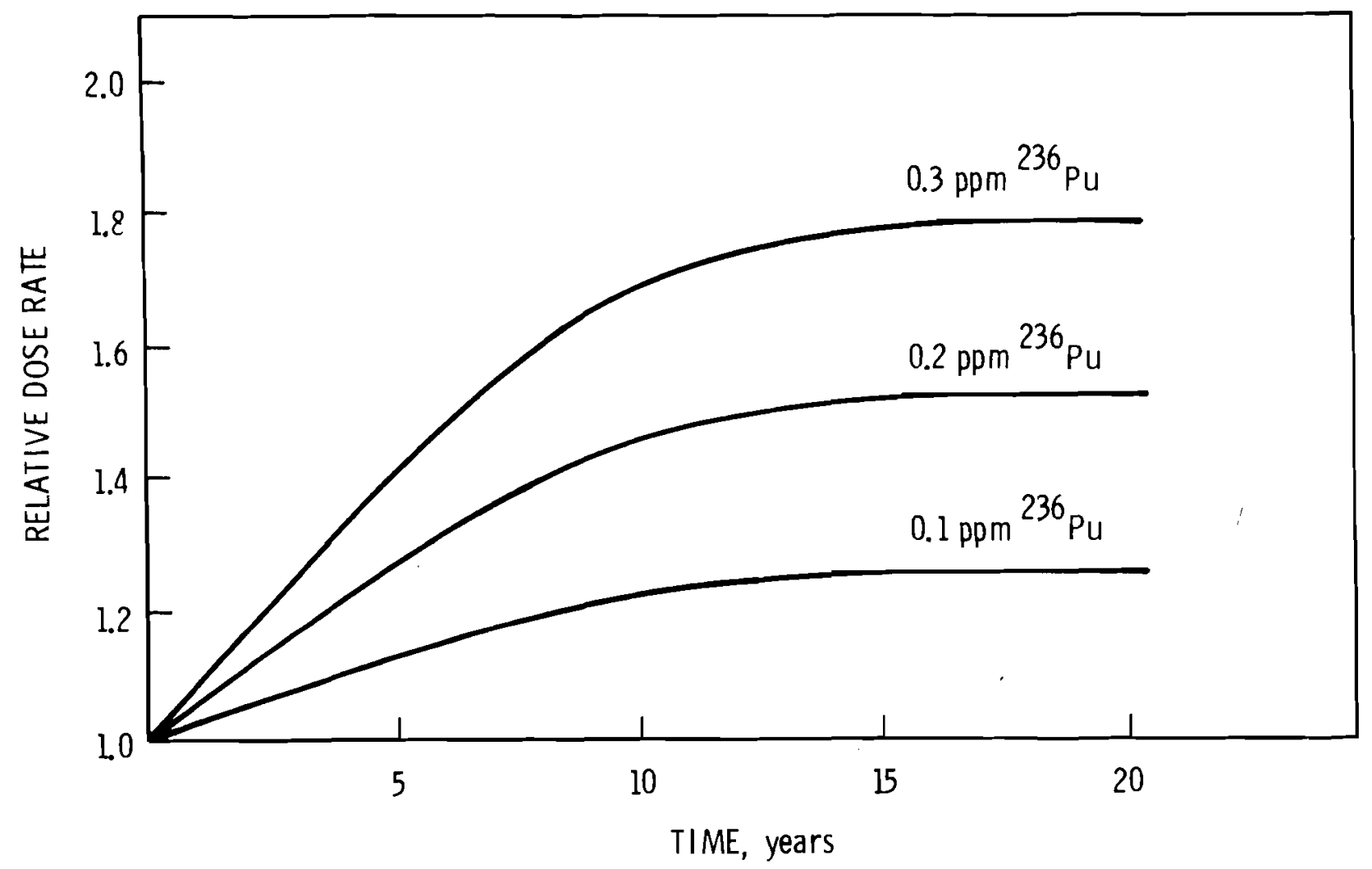

FIGURE 25. Relative Dose Rate Versus Time for a Single Device as a Function of PPM 236Pu Initially Present 


\section{SURVEYS OF INTERPERSONAL RELATIONSHIPS}

\section{A. SUMMARY OF SUIRVEY MODEL DEVELOPMENT}

Once the number and demographic distribution of artificial heart recipients were established, their interpersonal contacts needed to be defined in order to estimate population dose. A search of existing literature revealed no source of such information in enough detail for our needs. Therefore, we made plans to conduct our own field surveys to develop the data base required. We considered two possible methodologies.

1. Direct dose measurements

2. Estimation of dose by measurement of its three basic parameters:

(a) The distance of each person exposed from the source (or recipient)

(b) The time at each distance

(c) The number of persons exposed at each distance.

Direct measurement of population doses would require distributing lowlevel radiation-emitting devices to selected individuals and outfitting possibly contacted persons with highly sensitive counters. Aside from the question of whether or not such irradiation would be permitted, the cost and logistics of such a technique would make it impractical for this study. These factors persuaded us not to use direct measurement.

The method chosen, therefore, was individual measurement of the three basic dose parameters and use of a standard set of activities to correlate these measurements. These activities are shown in Table 12 in the time-inactivity section. We used the data collected in our surveys to estimate factors (a) and (c) above. The University of Michigan data on use of time (developed in the preceding section) formed the basis of our estimates of factor (b), time.

During the development of our survey methodology for collecting interpersonal distance data, Dr. Irwin Altman, Chairman of the Psychology Department at the University of Utah, served as a consultant. Dr. Altman's area of specialty is the interpersonal distance aspect of psychology. A fundamental precept, suggested by Dr. Altman and utilized in our development of 
survey methodology, was that the distances separating people during their activities are primarily determined by their environment; that is, room size, location of chairs, etc.

Surveys obtained data for both nonwork and work activities. Surveys for nonwork activities were of two types--surveys for at-home activities and surveys for public activities. The following paragraphs briefly discuss each of these surveys.

\section{B. AT-HOME ACTIVITY SURVEYS}

We made several different surveys for at-home activities to test survey techniques and to develop a broad data base. These surveys were conducted among Battelle-Northwest employees and among random populations in Richland and Seattle, Washington, and Salt Lake City, Utah. Table 21 indicates the sample sizes in these surveys.

The Battelle, Richland and Seattle surveys collected data in accordance with the original study scope for use in the initial population-dose estimates. After the expansion of the study scope (outlined in the section on methodology), we designed the survey in Salt Lake City to obtain additional data on household members, frequent associates, and their frequency-of-contact during at-home activities. Since the final population dose calculation now depends primarily on data from the Salt Lake City survey, a basic description of its methodology and the data obtained follows.

Although the data in the earlier surveys could not be used in the expanded study, the innovations and techniques successfully tested in these surveys formed the basis for much of the Salt Lake City model. The previous surveys had indicated that most of the dose for the 15 at-home activity types was absorbed during just five of them - sleeping, eating, television viewing, other passive leisure, and home entertainment. Therefore, we designed the Salt Lake City model to collect data on all of the five major activities and on one of the 10 remaining ones on a rotating basis. The Salt Lake City survey also employed a previously developed multistage sampling technique to randomly select households. 
TABLE 21. Interpersonal Distance Surveys Completed and Sample Sizes

- Telephone Survey

- Battelle Survey

- Richland Survey

- Seattle Survey

- Salt Lake City Survey

After household selections, personal interviews with an adult household member collected the following basic information:

1. Identification of Potential Heart Recipients (PHRs) in the household

2. The number of persons potentialiy exposed by their age, sex and relation to PHR for each activity

3. The distance to every person potentially exposed by their age, sex and relation to PHR for each activity

4. An estimate of frequency-of-presence of associates by their age, sex and relation to PHR for each activity.

Table 22 indicates distribution of PHRs sampled in the survey by several general classifications. The distribution of urban and rural respondents was approximately proportional to actual population conditions. The survey included a greater proportion of males since the risk of heart disease death is much greater for this sex. We weighted distribution of sampled income groups such that middle income groups were most frequently sampled. Since risk of death for heart disease dramatically increases with age, a much higher proportion of retired, nonemployed persons would be present in the artificial heart population. Therefore, we collected considerable data in this classification. Weighting the sampling in this manner allowed us to collect data in proportion to its relevance to the artificial heart population and thereby achieve a better estimate of population dose.

After completion of the Salt Lake City survey the data were processed to develop the necessary factors for input into the REPRIEVE computer model. 
TABLE 22. A General Breakdown of the Salt Lake City Interpersonal Distance Survey of At-Home Activities

- Number of PHR's Sampled by Location

$\begin{array}{lrl}\text { Urban } & 324 & (82 \%) \\ \text { Rural } & 69 & (18 \%) \\ \text { Total } & 393 & \end{array}$

- Number of PHR's Sampled by Sex

$$
\begin{array}{lll}
\text { Male } & 249 & (63 \%) \\
\text { Female } & 144 & (37 \%) \\
\text { Total } & 393 &
\end{array}
$$

- Number of PHR's Sampled by Income Group (Urban Only)

$$
\begin{array}{lrl}
\text { High } & 78 & (20 \%) \\
\text { Middle } & 184 & (47 \%) \\
\text { Low } & 62 & (16 \%) \\
\text { Total } & 324 &
\end{array}
$$

- Number of PHR's Sampled by Employment Status

Employed: Fu11 180 (46\%), Part 12 (3\%)

Nonemployed: 201 (51\%)

Total: 393 
Since dose rate is not proportional to distance, but varies more nearly as the reciprocal of distance squared, the distance data for duplicate situations could not be combined by simple averaging. Instead, computer codes transformed the distance data into dose rate data and then averaged the dose rates by activities and other PHR demographic characteristics to obtain average dose rate factors. The data on the number of associates per PHR and their frequency of contact were averaged directly to develop these factors for use in REPRIEVE.

\section{PUBLIC ACTIVITY SURVEY}

We developed other survey procedures to collect the data necessary to estimate potential public exposure. Data were collected during church, theater and sporting event attendance and during shopping, nonwork driving, and adult education activities. We developed the computer program, BINGO, to calculate the absorbed dose using the survey data. This program incorporates Monte Carlo methods to select a device recipient and calculate absorbed dose rate. The program reiterates this calculation for a large number of PHRs to obtain accurate mean absorbed dose rates for the sampled situation.

Since household relationships could not be distinguished by observation, we included the dose to household members during public activities in the category of dose to the general public.

\section{WORK ACTIVITY SURVEY}

For work activities, we surveyed representative occupations by personal observation. The distance and number-of-associates data obtained provided the data base needed to estimate dose rates to work associates.

A detailed description of the survey models for each of the surveys completed appears in Appendix E. 


\section{$X$. THE REPRIEVE COMPUTER MODEL}

The REPRIEVE computer program utilizes all of the information previously developed in this report to calculate dose to the population. At this point it may be helpful in understanding the overall operation of this model to review Figures 2 and 3 in the Methodology Section at the beginning of this report. These figures describe the construction of the model in general terms and the process outlined as follows. The program:

- Generates an age- and sex-specific artificial heart use projection by projecting heart disease incidence, applying eligible candidate fractions, and developing life expectancy estimates.

- Subdivides further the above-derived recipient population by employment status, occupation and household types.

- Estimates the number of persons exposed (RESs) by their age and sex and the characteristics of the artificial heart recipient exposing them.

- Calculates the population dose to the RESS so defined and expresses the result in tables by RES and artificial heart recipient classifications.

In addition, the model performs some incidental calculations relating to the above objectives. The immediately following subsections explain: (1) the artificial heart use projection, (2) the basic algorithm to calculate population dose, (3) the data matrix required for the calculation, and (4) some sample dose calculations. We also describe the output tables used to exhibit the results. At the end of this section we have included a discussion of possible uses of the model.

\section{A. ARTIFICIAL HEART USE CALCULATIONS}

Since most of the calculational detail has been explained earlier, only the calculations and methods used by REPRIEVE will be reviewed here.

Eligible candidate fractions by age and disease type are entered as input data. The code then accepts, as input data, the 1969 death rates for 
the four types of heart diseases. The code applies this latter data to the eligible candidate fractions to develop a weighted average set of candidate fractions by age.

Parameters for the death rate equation (DRE) are also inputs for the program. With these parameters, the code uses the DRE to develop fractions estimating the future decline in heart disease death rates with time. Application of these fractions to a set of age-specific, maximum death rates (also input) develops the age- and sex-specific heart-disease deathrate projections.

Age- and sex-specific populations at 10-year intervals (e.g., 1990, 2000 , etc.) are required as input data for the model. We also included the ability to specify, at the same intervals, the percentage of artificial hearts which would be nuclear powered as a user option. Using the candidate fractions, the heart disease death-rate projections and the population data, the code calculates age- and sex-specific implant projections at 10year intervals. Summing the implants by age and sex develops the total implants at each interval. Each age- and sex-specific component is then divided by the total implants and multiplied by 10,000 to develop a cohort* of 10,000 implants by age and sex for each 10-year interval.

The model then uses the inputted number of beginning implants in the first program year and a doubling function to calculate the implants in the initial years until the projected device demand level is reached. After this time the program uses the decennial projection (i.e., 1990, 2000, 2010 , etc.) developed above and an interpolating routine to estimate total implants during intervening years. These implants are then divided by 10,000 to develop the number of cohorts (histories) implanted in each program year. At this point the program uses the algorithms (discussed in the section on Natural Death Rates After Implants) to develop fractions surviving as a functon of the recipient's age and sex. Input data for this section consists of values for the variables described in Table 5 .

* Cohorts or histories refer to a standard-sized group of implants (i.e., 10,000) distributed by age and sex. 
A standard life table calculation is included in these algorithms. An explanation of life tables and their derivation may be found in the Public Health Services report in Reference 21 . Table 23 shows a representative calculation for males. The far right column indicates the fraction surviving at five-year intervals. To calculate the fraction of implants surviving device failure, the program requires a set of device failure rates by age of device. Using these failure rates the code calculates the survival rates for device ages up to 10 years. We assumed that devices still in use would be replaced after 10 years of service. Table 24 indicates the values of these rates as calculated by the code.

The specific history (or survival experience) of each cohort of 10,000 device implants is developed by multiplying each age and sex cell in the cohort by the age- and sex-specific natural-death survival fraction from the life table and by the survival fraction from device failures. Table 25 illustrates an example specific history for males showing survivors after implant at five-year intervals. Table 26 shows example calculations for the derivation of this history using the life table and survival rate calculations in Tables 23 and 24 . Histories for both males and females are developed and then summed. The summation history using our example is shown in Table 27. A pictorial representation of the same history (only using 10-year age groups) is shown in Figure 26. This representation shows quite vividly the long life expectation of the relatively few implants in the younger age groups and the large number of implants in older age groups having a substantially shorter average life.

Actual surviving implants from each implant year are calculated by multiplying the number of surviving recipients in each age and sex group in the specific history by the number of histories implanted. Table 28 shows the results of this calculation for each program year. The survival experience of implants in each program year is shown horizontally from left to right. (This may be verified for 1990 using our previous example by dividing history survival experiences by 10,000 and multiplying these fractions by the 3200 devices implanted in 1990.) Cumulative surviving implants in a desired year are then easily calculated by summing each column in 
TABLE 23. Life Table for Male Artificial Heart Recipients

\begin{tabular}{|c|c|c|c|c|c|c|c|c|}
\hline $\begin{array}{c}\text { Age } \\
\text { Interva } 1 \\
\text { I } \\
\end{array}$ & $\begin{array}{l}\text { Proportion } \\
\text { Dying } \\
Q(I) \\
\end{array}$ & $\begin{array}{l}\text { Number } \\
\text { Living at } \\
\text { Start of } \\
\text { Interval } \\
L(I) \\
\end{array}$ & $\begin{array}{c}\text { Number } \\
\text { Dying In } \\
\text { Interval } \\
D(I) \\
\end{array}$ & $\begin{array}{c}\text { Fraction } \\
\text { of Age } \\
\text { Interval } \\
\text { Lived } \\
A(I) \\
\end{array}$ & $\begin{array}{l}\text { Stationar } \\
\text { In } \\
\text { Interval } \\
\text { LS(I) } \\
\end{array}$ & $\begin{array}{l}\text { Population } \\
\text { In This } \\
\text { and Later } \\
\text { Intervals } \\
T(I) \\
\end{array}$ & $\begin{array}{c}\text { Life } \\
\text { Expectancy } \\
\text { At Start } \\
\text { of Interva } 1 \\
\text { E(I) } \\
\end{array}$ & $\begin{array}{c}\text { 5-Year } \\
\text { Survival } \\
\text { Rate } \\
\text { P5(I) } \\
\end{array}$ \\
\hline $30-34$ & .0225 & .100000 & 2,255 & .52 & 494,589 & $3,297,708$ & 33.0 & .9741 \\
\hline $35-39$ & .0308 & 97,745 & 3,014 & .54 & 481,794 & $2,803,120$ & 28.7 & .9620 \\
\hline $40-44$ & .0466 & 94,731 & 4,417 & .54 & 463,498 & $2,321,325$ & 24.5 & .9422 \\
\hline $45-49$ & .0716 & 90,314 & 6,469 & .54 & 436,694 & $1,857,828$ & 20.6 & .9101 \\
\hline $50-54$ & .1106 & 83,846 & 9,276 & .53 & 397,431 & $1,421,134$ & 16.9 & .8627 \\
\hline $55-59$ & .1676 & 74,570 & 12,499 & .52 & 342,852 & $1,023,703$ & 13.7 & .7990 \\
\hline $60-64$ & .2444 & 62,071 & 15,170 & .52 & 273,946 & 680,852 & 11.0 & .7181 \\
\hline $65-69$ & .3357 & 46,901 & 15,746 & .52 & 196,713 & 406,906 & 8.7 & .6159 \\
\hline $70-74$ & .4536 & 31,155 & 14,131 & .51 & 121,152 & 210,192 & 6.7 & .4998 \\
\hline $75-79$ & .5890 & 17,024 & 10,027 & .51 & 60,553 & 89,040 & 5.2 & .3658 \\
\hline $80-89$ & .7055 & 6,997 & 4,936 & .48 & 22,150 & 28,487 & 4.1 & .2512 \\
\hline $85-89$ & .8364 & 2,061 & 1,723 & .45 & 5,563 & 6,338 & 3.1 & .1329 \\
\hline $90-94$ & .9517 & 337 & 321 & .41 & 739 & 774 & 2.3 & .0468 \\
\hline $95-99$ & .9583 & 16 & 16 & .40 & 35 & 35 & 2.2 & .0196 \\
\hline $100+$ & 1.0000 & 1 & 1 & .20 & 1 & 1 & 1.0 & 0.0000 \\
\hline
\end{tabular}


TABLE 24. Survival Rate for Death Due to Device Failure

\begin{tabular}{cc}
$\begin{array}{c}\text { Age } \\
\text { of } \\
\text { Device, } \\
\text { Years }\end{array}$ & $\begin{array}{c}\text { Fraction } \\
\text { Surviving } \\
\text { to }\end{array}$ \\
\hline 0 & $\begin{array}{c}\text { Next Year } \\
\text { Next }\end{array}$ \\
1 & 1.000 \\
2 & .959 \\
3 & .917 \\
4 & .875 \\
5 & .833 \\
6 & .7905 \\
7 & .7479 \\
8 & .7055 \\
9 & .6635 \\
10 & .6210 \\
\hline 5 & .5785
\end{tabular}

Replace devices for survivors (repeat calculation) 
TABLE 25. 1990 Specific History for 6,339 Recipients - Male

$(J=$ Years After Implant $)(I=$ Age of Recipient at time of Implant $)$

\begin{tabular}{|c|c|c|c|c|c|c|c|c|c|c|c|c|c|c|}
\hline$I / J$ & 0 & 5 & 10 & 15 & 20 & 25 & 30 & 35 & 40 & 45 & 50 & 55 & 60 & 65 \\
\hline $30-34$ & 85 & 65 & 36 & 27 & 14 & 10 & 5 & 3 & 1 & 0 & 0 & 0 & 0 & 0 \\
\hline $35-39$ & 205 & 156 & 85 & 61 & 30 & 19 & 8 & 4 & 1 & 0 & 0 & 0 & 0 & 0 \\
\hline $40-44$ & 394 & 293 & 154 & 105 & 49 & 28 & 10 & 4 & 1 & 0 & 0 & 0 & 0 & 0 \\
\hline $45-49$ & 539 & 388 & 194 & 123 & 51 & 25 & 7 & 2 & 0 & 0 & 0 & 0 & 0 & 0 \\
\hline $50-54$ & 711 & 485 & 224 & 127 & 45 & 18 & 4 & 1 & 0 & 0 & 0 & 0 & 0 & 0 \\
\hline $55-59$ & 966 & 610 & 253 & 123 & 36 & 10 & 1 & 0 & 0 & 0 & 0 & 0 & 0 & 0 \\
\hline $60-64$ & 1,092 & 620 & 221 & 87 & 18 & 4 & 0 & 0 & 0 & 0 & 0 & 0 & 0 & 0 \\
\hline $65-69$ & 1,112 & 541 & 156 & 45 & 7 & 1 & 0 & 0 & 0 & 0 & 0 & 0 & 0 & 0 \\
\hline $70-74$ & 814 & 322 & 68 & 14 & 1 & 0 & 0 & 0 & 0 & 0 & 0 & 0 & 0 & 0 \\
\hline $75-79$ & 355 & 103 & 15 & 2 & 0 & 0 & 0 & 0 & 0 & 0 & 0 & 0 & 0 & 0 \\
\hline $80-84$ & 66 & 13 & 1 & 0 & 0 & 0 & 0 & 0 & 0 & 0 & 0 & 0 & 0 & 0 \\
\hline $85-89$ & 0 & 0 & 0 & 0 & 0 & 0 & 0 & 0 & 0 & 0 & 0 & 0 & 0 & 0 \\
\hline $90-94$ & 0 & 0 & 0 & 0 & 0 & 0 & 0 & 0 & 0 & 0 & 0 & 0 & 0 & 0 \\
\hline $95-99$ & 0 & 0 & 0 & 0 & 0 & 0 & 0 & 0 & 0 & 0 & 0 & 0 & 0 & 0 \\
\hline TOTAL & 6,339 & 3,596 & 1,407 & 714 & 251 & 115 & 35 & 14 & 3 & 0 & 0 & 0 & 0 & 0 \\
\hline
\end{tabular}


TABLE 26. Example Calculation Showing the Derivation of Specific Histories

\begin{tabular}{|c|c|c|c|c|c|}
\hline $\begin{array}{l}\text { Sex and } \\
\text { Age Group } \\
\text { at Time } \\
\text { of Implant }\end{array}$ & $\begin{array}{l}\text { N Years } \\
\text { After } \\
\text { Implant }\end{array}$ & $\begin{array}{l}\text { 5-Year } \\
\text { Survival } \\
\text { Rate From } \\
\text { Life Table }\end{array}$ & $\begin{array}{l}\text { Fraction } \\
\text { Surviving } \\
\text { Device } \\
\text { Failure } \\
\text { After } \\
\text { N Years }\end{array}$ & $\begin{array}{l}\text { Initial } \\
\text { Implants } \\
\text { (0 Years } \\
\text { After } \\
\text { Implant) }\end{array}$ & $\begin{array}{l}\text { Number of } \\
\text { Surviving } \\
\text { Recipients } \\
\text { N Years } \\
\text { After } \\
\text { Implant }\end{array}$ \\
\hline
\end{tabular}

MALE:

$\overrightarrow{0}$

30-34

5

.9741

$\times \quad .7905$

$x$

85

65

MALE:

45-49

$10 \stackrel{.9101}{5} \times \frac{x}{.8627} \times \frac{.7905}{x}$

$=$

194

MALE :

55-59

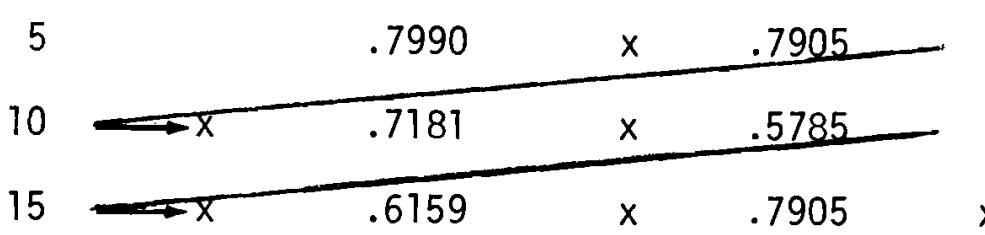


TABLE 27. 1990 Specific History for 9,999 Recipients - Total

$(J=$ Years After Implant $)(I=$ Age of Recipient at Time of Implant $)$

\begin{tabular}{|c|c|c|c|c|c|c|c|c|c|c|c|c|c|c|}
\hline $\mathrm{I} / \mathrm{J}$ & 0 & 5 & 10 & 15 & 20 & 25 & 30 & 35 & 40 & 45 & 50 & 55 & 60 & 65 \\
\hline $30-34$ & 148 & 114 & 64 & 48 & 26 & 19 & 10 & 6 & 2 & 0 & 0 & 0 & 0 & 0 \\
\hline $35-39$ & 379 & 244 & 134 & 98 & 50 & 33 & 15 & 8 & 3 & 1 & 0 & 0 & 0 & 0 \\
\hline $40-44$ & 581 & 436 & 233 & 163 & 79 & 48 & 19 & 9 & 2 & 0 & 0 & 0 & 0 & 0 \\
\hline $45-49$ & 789 & 576 & 295 & 195 & 86 & 46 & 15 & 5 & 1 & 0 & 0 & 0 & 0 & 0 \\
\hline $50-54$ & 1,067 & 746 & 359 & 217 & 85 & 39 & 10 & 3 & 0 & 0 & 0 & 0 & 0 & 0 \\
\hline $55-59$ & 1,324 & 864 & 378 & 199 & 65 & 22 & 3 & 0 & 0 & 0 & 0 & 0 & 0 & 0 \\
\hline $60-64$ & 1,610 & 967 & 376 & 169 & 42 & 10 & 1 & 0 & 0 & 0 & 0 & 0 & 0 & 0 \\
\hline $65-69$ & 1,793 & 956 & 316 & 110 & 20 & 3 & 0 & 0 & 0 & 0 & 0 & 0 & 0 & 0 \\
\hline $70-74$ & 1,462 & 663 & 170 & 41 & 4 & 0 & 0 & 0 & 0 & 0 & 0 & 0 & 0 & 0 \\
\hline $75-79$ & 744 & 261 & 46 & 6 & 0 & 0 & 0 & 0 & 0 & 0 & 0 & 0 & 0 & 0 \\
\hline $80-84$ & 162 & 39 & 3 & 0 & 0 & 0 & 0 & 0 & 0 & 0 & 0 & 0 & 0 & 0 \\
\hline $85-89$ & 0 & 0 & 0 & 0 & 0 & 0 & 0 & 0 & 0 & 0 & 0 & 0 & 0 & 0 \\
\hline $90-94$ & 0 & 0 & 0 & 0 & 0 & 0 & 0 & 0 & 0 & 0 & 0 & 0 & 0 & 0 \\
\hline $95-99$ & 0 & 0 & 0 & 0 & 0 & 0 & 0 & 0 & 0 & 0 & 0 & 0 & 0 & 0 \\
\hline TOTAL & 9,999 & 5,866 & 2,374 & 1,246 & 457 & 220 & 73 & 31 & 8 & 1 & 0 & 0 & 0 & 0 \\
\hline
\end{tabular}




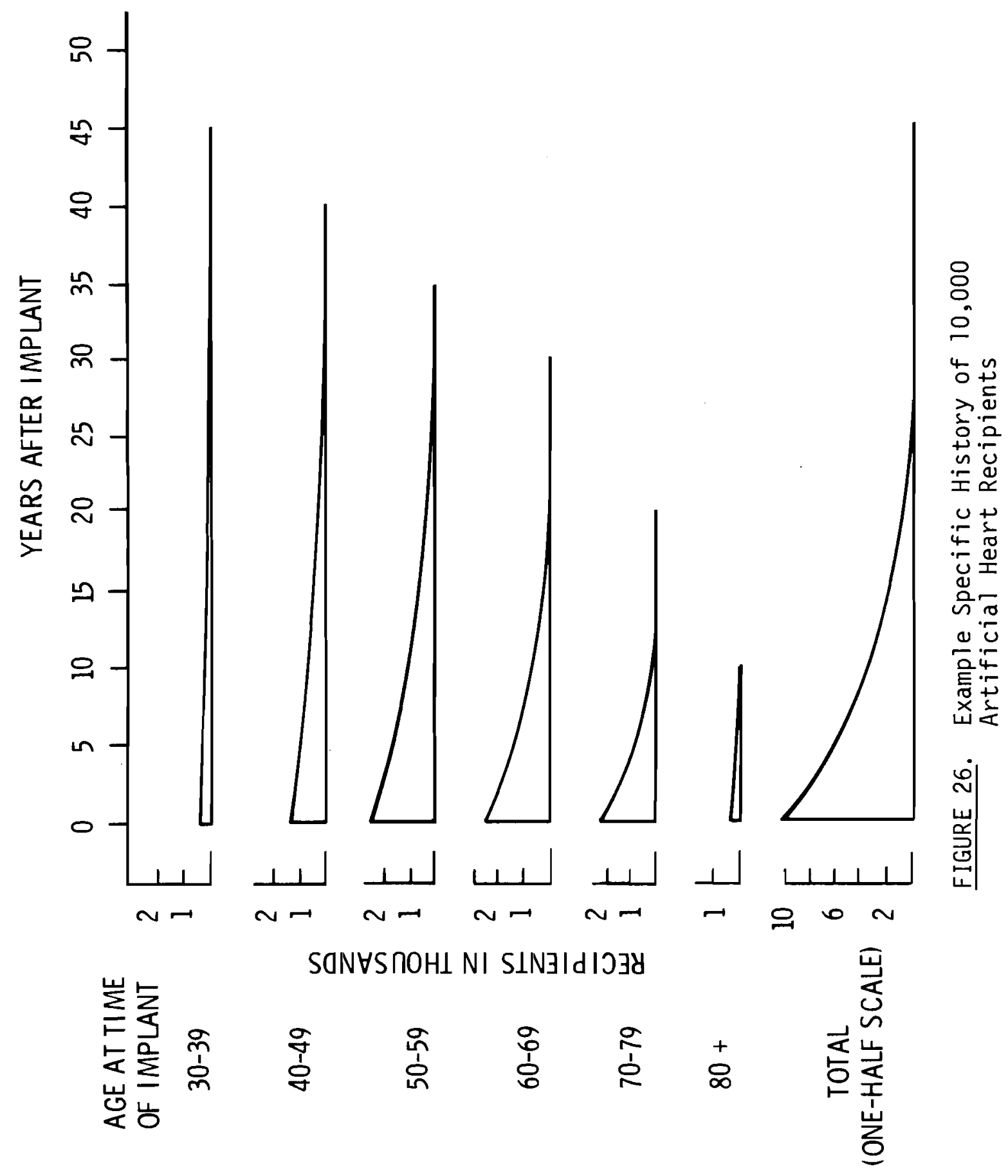




\section{TABLE 28. Artificial Heart Devices in Use Using Best Estimate Parameters}

\begin{tabular}{|c|c|c|c|c|c|c|c|c|c|c|c|}
\hline $\begin{array}{l}\text { Year of } \\
\text { Implant }\end{array}$ & 1985 & 1990 & 1995 & 2000 & $? 005$ & 2019 & $? 0 ! 5$ & 2020 & 2025 & 2030 & -2035 \\
\hline 1985 & $10 n$ & 59 & 24 & $1 \%$ & 5 & $?$ & 1 & 0 & D & 0 & 0 \\
\hline 1986 & & 131 & 5.4 & $2 R$ & 11 & 5 & , & 1 & 0 & 0 & 0 \\
\hline 1987 & & 291 & 124 & 64 & 35 & 12 & 4 & $?$ & 0 & 0 & 0 \\
\hline 1988 & & 647 & 2184 & 198 & 58 & 27 & 10 & 4 & 1 & 0 & 0 \\
\hline 1989 & & 1,438 & 648 & 332 & 134 & 63 & 23 & 10 & 3 & 1 & 0 \\
\hline 1990 & & 3,200 & 1.477 & 760 & 399 & 146 & 70 & 73 & 10 & 3 & 0 \\
\hline 1991 & & & 4.180 & 1.740 & 904 & 342 & 161 & 55 & 24 & 6 & 1 \\
\hline 1992 & & & 9,303 & 3.982 & 2.058 & 792 & 370 & $13 !$ & 56 & 15 & 4 \\
\hline 1993 & & & 20.692 & 9.043 & $4.66 ?$ & 1.443 & $\mathrm{R} 63$ & 305 & 131 & 41 & 13 \\
\hline 1994 & & & 35,999 & 16,238 & 9.318 & 3.364 & 1.570 & 571 & 244 & 76 & 32 \\
\hline 1995 & & & 10.159 & $24,(11)$ & $10.7 n .3$ & 5.429 & 2.055 & 1,006 & 337 & 132 & 36 \\
\hline 1996 & & & & 26.623 & 19.421 & 6.119 & 2.380 & 1,146 & 393 & 164 & 94 \\
\hline 1997 & & & & $29,5] 3$ & 12.980 & 6,915 & 2.754 & 1.323 & 477 & 196 & 52 \\
\hline 1998 & & & & 32,702 & 14,729 & ?, sing & 3.192 & $1,53 ?$ & 553 & 233 & 64 \\
\hline 1999 & & & & 36.231 & 16.715 & 9,837 & 3.699 & $1,7 \mathrm{TH}$ & 662 & 281 & 80 \\
\hline 2000 & & & & 40.175 & 24,056 & 10,020 & 5,437 & 2,059 & 1,007 & 337 & 132 \\
\hline 2001 & & & & & 26,847 & 11,515 & 6,169 & 2,400 & 1,156 & 396 & 166 \\
\hline 2002 & & & & & 23.967 & 13.171 & 7,017 & 2,795 & 1,342 & 484 & 199 \\
\hline 2003 & & & & & 33,397 & 15.1142 & 7,973 & 3,260 & 1,564 & 565 & 238 \\
\hline 2004 & & & & & 37,237 & 17,179 & 9,082 & 3,801 & 1,826 & 680 & 289 \\
\hline 2005 & & & & & 41.553 & 25,105 & 10,492 & 5,653 & 2,096 & $98 \varepsilon$ & 307 \\
\hline 2006 & & & & & & $27,98,3$ & 12,019 & 6.421 & 2.448 & 1.153 & 389 \\
\hline 2007 & & & & & & 31,174 & 13,768 & 7,296 & 2,860 & 1,346 & 463 \\
\hline 2008 & & & & & & 34,675 & 15,725 & 8,313 & 3,348 & 1.570 & 542 \\
\hline 2009 & & & & & & 38.56 月 & 17.953 & 9,496 & 3,928 & 1,840 & 660 \\
\hline 2010 & & & & & & 42,870 & 25,937 & 10,840 & 5.840 & 2,165 & 1.020 \\
\hline 2011 & & & & & & & $2 \mathrm{R}, 858$ & 12,396 & 6,622 & 2,525 & 1.189 \\
\hline 2012 & & & & & & & 32,092 & 14,174 & 7,511 & 2,944 & 1,385 \\
\hline 2013 & & & & & & & 35.634 & 16.160 & 8,543 & 3,441 & 1.614 \\
\hline 2014 & & & & & & & 39,567 & 18,417 & 9,702 & 4,030 & 1,888 \\
\hline 2015 & & & & & & & 43,912 & 25,996 & 10,574 & 5,542 & 2.016 \\
\hline 2016 & & & & & & & & 29.039 & 12.168 & 6,322 & 2.356 \\
\hline 2017 & & & & & & & & 32,420 & 13,976 & 7,207 & 2,770 \\
\hline 2018 & & & & & & & & 36.156 & 15.996 & 8,234 & 3.242 \\
\hline 2019 & & & & & & & & 40,320 & 78.348 & 9,440 & 3.785 \\
\hline 2020 & & & & & & & & 44,947 & 26,608 & 10,823 & 5,672 \\
\hline 2021 & & & & & & & & & 29,584 & 12,396 & 6,441 \\
\hline 2022 & & & & & & & & & 32,874 & 14,172 & 7,308 \\
\hline 2023 & & & & & & & & & 36.492 & 16,145 & 8.311 \\
\hline 2024 & & & & & & & & & 40,506 & 18.433 & 9,484 \\
\hline 2025 & & & & & & & & & 44,947 & 26.608 & 10.823 \\
\hline $2 n ? 6$ & & & & & & & & & & 27,584 & $7^{n}, 376$ \\
\hline 2027 & & & & & & & & & & 32.874 & 14.172 \\
\hline 2028 & & & & & & & & & & 36,492 & 16,145 \\
\hline 2029 & & & & & & & & & & 40,506 & 18,433 \\
\hline 2030 & & & & & & & & & & 44,947 & 26,608 \\
\hline 2031 & & & & & & & & & & & 29,584 \\
\hline 2032 & & & & $\cdot$ & & & & & & & 32.874 \\
\hline 2033 & & & & & & & & & & & 36,492 \\
\hline 2034 & & & & & & & & & & & 40,506 \\
\hline 2035 & $\ldots$ & & & & & & & & & & 44,947 \\
\hline $\begin{array}{l}\text { TOTAL AT } \\
\text { YEAR END }\end{array}$ & 100 & 5,766 & 113,254 & 221.626 & 275,428 & 309.013 & 328,789 & 340.251 & 344,797 & 345,337 & 345,172 \\
\hline $\begin{array}{l}\text { TOTAL AT } \\
\text { MID-YEAR }\end{array}$ & 50) & 0,166 & 93,219 & 201,558 & 254,676 & 287,574 & 306,833 & 317,777 & 322,323 & 322,863 & 322,698 \\
\hline
\end{tabular}


Table 28 vertically to obtain the totals shown at the bottom of the table. These totals are devices in use at the end of each five-year period. To estimate the average number of devices in use over the last year of the period, we summed only half of the last year's implants in the total. Figure 15 shows the range of cumlative number of implants estimated. This average cumulative number of devices in use in each year becomes the artificial heart recipient population by age and sex in that year. We then subdivided this poputation by employment status, occupation and household type, as explained previously, so that dose rates and persons exposed could be identified. The next section discusses the dose calculations in REPRIEVE and the data matrix necessary for the calculations.

\section{B. DOSE CALCULATIONS}

The next function of the REPRIEVE model is to perform the actual population dose calculations. To better understand the detailed calculation equation explained below, we suggest that a review of the simplified equation given in Section II might be helpful.

The detailed equation to calculate population dose is given in Table 29. The dose calculation consists of three parts--dose during work activities, dose during nonwork activities and incidental random dose. We summed the dose calculations in this manner because of the different subscripts on the submatrices defining work and nonwork activities. As seen by examination of Table 29, the calculation becomes complex because of the many classifications or subscripts for each of the submatrice components. A total of five submatrices exist in the equation.

1. $P$, the identity of the artificial heart recipient (AHR) as defined by sex, employment status, occupation, age, and household type.

2. S, the identity of the radiation exposure subject (RES) as defined by subject's relationship to the heart recipient, subject's age and sex, and heart recipient's age, sex, household type, employment status, and, in some cases, activity. 


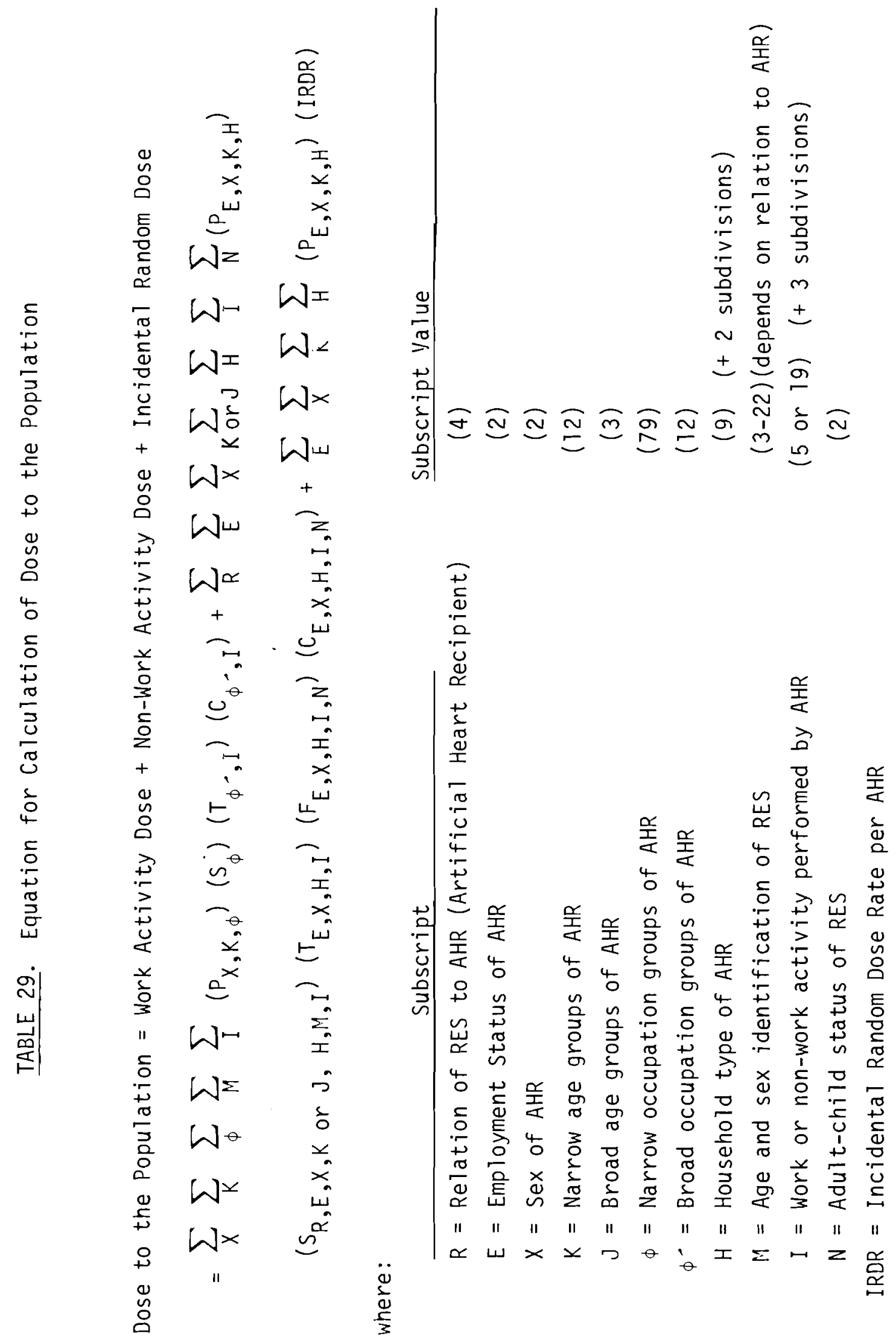


3. $T$, the time spent by the artificial heart recipient in performing daity activities as defined by activity, household type or occupation, sex and employment status of the recipient.

4. $F$, the fraction of an RES group contacted during specific activities as defined by the activity, the artificial heart recipient's household type and sex and whether or not the RES is a child or adult.

5. $C$, the dose factor associated with a radiation exposure subject (RES) as defined by activity, by the artificial heart recipient's household type, sex, and employment status and by whether or not the RES is a child or adult.

To adjust the population calculation to account for nonwork activities when household members are not present, we developed the $F$ factor matrix from the Salt Lake City survey data. This factor is the fraction of spouses and other household members present when the artificial heart recipient is performing each activity. The derivation of the factors for the other submatrices had been explained in previous sections. The number of intersections requiring data for each of these components in the basic dose equation is shown in Table 30.

TABLE 30. Size of Calculation Matrices

$\begin{array}{lrrrr} & \frac{\text { Nonwork }}{528} & \frac{\text { Work }}{948} & \frac{\text { Total }}{7,476} \\ \text { Artificial Heart Recipient Groups, P } & 11,690 & 79 & 11,769 \\ \text { Radiation Exposure Subject Groups, S } & 792 & 120 & 912 \\ \text { Time in Activity Factors, T } & 3,096 & -- & 3,096 \\ \text { Frequency of Contact, F } & 3,106 & 120 & \frac{3,226}{20,479} \\ \text { Dose Factors, C } & & & \frac{221,796}{}\end{array}$

The final dose to the population matrix is comprised of 221,796 unique summations of dose calculations using these components. 
The large size of the submatrices gives an indication of the large amount of data needed to use the equation.

Age of artificial heart recipient and urban-rural living location classifications were originally among the parameters describing the dose and $F$ factor submatrices. However, examination of the size of the data matrices needed to obtain this detail indicated data requirements far beyond the limits of this study. Subsequent statistical examination of dose factors by age, living location and employment status indicated that employment status was the only significant variable in determining dose rates. Therefore, we dropped dose factor classification by age and living location enabling us to reduce our data requirements to a manageable size. Additional detail on the testing of these factors is included on Page E-15 in Appendix E.

A factor that reduces the need for accurate data at all intersections is the very small effect that many of the intersections have on the final result--either because of a very low frequency for an activity or a very small number of artificial heart recipients in a particular sex-age-household type. Because of the ways the surveys have been structured, we believe that the most important intersections have good data.

In spite of our cautious reduction in data requirements, some intersections exist for which we do not have specific data. These "holes" appear mainly at intersections which are not critical from a radiation dose standpoint. We filled the missing intersections by matching missing intersection characteristics as closely as possible with intersection characteristics where data were available.

We have good data on many of the matrix intersections which are important from the standpoint of final impact on the total dose to the population. Our smallest data bases relate to: 1) the number of associates and friends present during family activities and the interpersonal distances between them, 2) the time spent by older people in family activities (if age is relevant to the time factor), 3) data on public activities, and 4) data on less critical family activities. However, these small data bases should not be critical to our estimates of population dose. A figure showing the 
detailed structure of the calculation matrices along with an accompanying explanation is found in Appendix F. Appendix $G$ explains the derivation of the Incidental Random dose component.

To illustrate the dose calculation, typical values of the factors entering the dose equation appear in simplified example calculations in Tables 31A to 31C. Each table shows the calculation of dose per person exposed (RES) and dose per artificial heart recipient for a different household type of recipient. Each table shows calculations for four of the 19 nonwork activities. These tables illustrate the following characteristics of the dose calculations.

- For several household types the number of household members per artificial heart recipient is contained in the definition of the household type (e.g., one spouse in husband-wife only households, one spouse and two other household members in husband-wife and two other members households and no other members in individual living alone households).

- Frequency of contact factors were postulated to be 1.0 for associates during certain activities such as home entertainment.

- The total dose per artificial heart recipient is the result of the interplay of four factors--the number exposed, the frequency of contact, the time in activity and the dose rate. The large dose during sleeping activity, for example, is the result of high dose rates, a large amount of time spent in the activity and a high frequency of contact factor. Although another activity such as home entertainment exposes more persons, the small amount of time spent in the activity and the low dose rate make the dose absorbed during this activity of much less consequence.

The actual calculations are considerably more complicated than shown in the tables because of the many subscripts on each of the above components.

The summation process is made clearer by examining the summation "tree" shown in Figure 27. This particular tree shows the calculation of population dose by summing first over RES characteristics and then over recipient 
TABLE 31A. Typical Values of Factors Used in Calculating Population Dose for Selected Activities and Household Types.

Household Type: Husband/Wife Only (38\% of all AHRs) ${ }^{(a)}$

\begin{tabular}{|c|c|c|c|c|c|c|c|}
\hline $\begin{array}{l}\text { Activity } \\
\text { Description }\end{array}$ & $\begin{array}{r}\text { Relationship } \\
\text { of RES to AHR } \\
\end{array}$ & $\begin{array}{l}\text { RES } \\
\text { per } \\
\text { AHR }(a)\end{array}$ & $\begin{array}{c}\text { Frequency of } \\
\text { Contact Factor } \\
(1.0=100 \% \text { of } \\
\text { Time in Activity) } \\
\end{array}$ & $\begin{array}{c}\text { Time Spent By } \\
\text { AHR in Activity } \\
\text { (hrs/day) } \\
\end{array}$ & $\begin{array}{l}\text { Dose Rate Factor } \\
\mathrm{rem} / \mathrm{hr} / \mathrm{RES} \times \frac{\text { day }}{\mathrm{yr}}\end{array}$ & $\begin{array}{l}\text { Dose Per } \\
\text { RES } \\
\text { (rem/yr) }\end{array}$ & $\begin{array}{c}\text { Dose per } \\
\text { AHR } \\
\text { (rem/yr) }\end{array}$ \\
\hline $\begin{array}{l}\text { Preparing } \\
\text { Meals }\end{array}$ & $\begin{array}{l}\text { Spouse } \\
\text { OHHN(b) } \\
\text { Associate }\end{array}$ & $\begin{array}{l}1.0 \\
0 \\
0.15\end{array}$ & $\begin{array}{c}0.8 \\
0 \\
0.24\end{array}$ & 1.3 & $\begin{array}{l}0.015 \\
0 \\
0.014\end{array}$ & $\begin{array}{c}0.0156 \\
0 \\
0.0 n 042\end{array}$ & $\begin{array}{c}0.0156 \\
0 \\
0.00006\end{array}$ \\
\hline Sleeping & $\begin{array}{l}\text { Spouse } \\
\text { OHM } \\
\text { As sociate }\end{array}$ & $\begin{array}{l}1.0 \\
0 \\
0.08\end{array}$ & $\begin{array}{l}1.0 \\
0 \\
0.20\end{array}$ & 8.0 & $\begin{array}{l}0.08 \\
0 \\
0.002\end{array}$ & $\begin{array}{c}0.64 \\
0 \\
0.003\end{array}$ & $\begin{array}{c}0.64 \\
0 \\
0.0003\end{array}$ \\
\hline Eating & $\begin{array}{l}\text { Spouse } \\
\text { OHM } \\
\text { Associate }\end{array}$ & $\begin{array}{l}1.0 \\
0 \\
0.08\end{array}$ & $\begin{array}{l}0.95 \\
0 \\
0.20\end{array}$ & 1.4 & $\begin{array}{l}0.045 \\
0 \\
0.048\end{array}$ & $\begin{array}{l}0.06 \\
0 \\
0.013\end{array}$ & $\begin{array}{c}0.06 \\
0 \\
0.0 n 1\end{array}$ \\
\hline $\begin{array}{l}\text { Home } \\
\text { Enterta inment }\end{array}$ & $\begin{array}{l}\text { Spouse } \\
\text { OHM } \\
\text { Associate }\end{array}$ & $\begin{array}{c}1.0 \\
0 \\
3.0\end{array}$ & $\begin{array}{l}0.81 \\
0 \\
1.0\end{array}$ & 0.26 & $\begin{array}{c}0.028 \\
0 \\
0.018\end{array}$ & $\begin{array}{l}0.0059 \\
0 \\
0.0047\end{array}$ & $\begin{array}{l}0.0053 \\
0 \\
0.014\end{array}$ \\
\hline
\end{tabular}

\footnotetext{
(a) Artificial Heart Reciplent

(b) Other Household Member
} 
TABLE 3]B. Typical Values of Factors Used in Calculating Population Dose for Selected Activities and Household Types.

Household Type: Husband/Wife + Two Other Members ( $9 \%$ of all AHRs) (a)

\begin{tabular}{|c|c|c|c|c|c|c|c|}
\hline $\begin{array}{c}\text { Activity } \\
\text { Description }\end{array}$ & $\begin{array}{l}\text { Relationship } \\
\text { of RES to AHR } \\
\end{array}$ & $\begin{array}{l}\text { RES } \\
\text { per } \\
\text { AHR (a) }\end{array}$ & $\begin{array}{l}\text { Frequency of } \\
\text { Contact Factor } \\
(1.0=100 \% \text { of } \\
\text { Time in Activity) } \\
\end{array}$ & $\begin{array}{c}\text { Time Spent By } \\
\text { AHR in Activity } \\
\text { (hrs/day) } \\
\end{array}$ & $\begin{array}{l}\text { Dose Rate Factor } \\
\text { rem/hr/persons } \times \frac{\text { day }}{\mathrm{yr}}\end{array}$ & $\begin{array}{c}\text { Dose Per } \\
\text { RES } \\
\text { (rem/yr) }\end{array}$ & $\begin{array}{c}\text { Dose per } \\
\text { AltR } \\
\text { (rem/yr) }\end{array}$ \\
\hline $\begin{array}{l}\text { Preparing } \\
\text { Meals }\end{array}$ & $\begin{array}{l}\text { Spouse } \\
\text { OHN (b) } \\
\text { Associate }\end{array}$ & $\begin{array}{l}1.0 \\
2.0 \\
0.16\end{array}$ & $\begin{array}{l}0.69 \\
0.61 \\
0.2\end{array}$ & 1.8 & $\begin{array}{l}0.0125 \\
0.1 \\
0.001\end{array}$ & $\begin{array}{l}0.016 \\
0.11 \\
0.00036\end{array}$ & $\begin{array}{l}0.016 \\
0.22 \\
0.00006\end{array}$ \\
\hline Sleeping & $\begin{array}{l}\text { Spouse } \\
\text { OHM } \\
\text { Associate }\end{array}$ & $\begin{array}{l}1.0 \\
2.0 \\
0.05\end{array}$ & $\begin{array}{l}1.0 \\
1.0 \\
0.16\end{array}$ & 7.8 & $\begin{array}{l}0.117 \\
0.006 \\
0.004\end{array}$ & $\begin{array}{l}0.913 \\
0.047 \\
0.031\end{array}$ & $\begin{array}{l}0.913 \\
0.094 \\
0.0016\end{array}$ \\
\hline Eating & $\begin{array}{l}\text { Spouse } \\
\text { OHM } \\
\text { Associate }\end{array}$ & $\begin{array}{l}1.0 \\
2.0 \\
0.03\end{array}$ & $\begin{array}{l}0.90 \\
0.87 \\
0.24\end{array}$ & 1.43 & $\begin{array}{l}0.04 \\
0.046 \\
0.04\end{array}$ & $\begin{array}{l}0.051 \\
0.057 \\
0.014\end{array}$ & $\begin{array}{l}0.051 \\
0.114 \\
0.0004\end{array}$ \\
\hline $\begin{array}{l}\text { Home } \\
\text { Enterta inment }\end{array}$ & $\begin{array}{l}\text { Spouse } \\
\text { OHM } \\
\text { Assoctate }\end{array}$ & $\begin{array}{l}1.0 \\
2.0 \\
3.2\end{array}$ & $\begin{array}{l}1.0 \\
0.90 \\
1.0\end{array}$ & 0.22 & $\begin{array}{l}0.024 \\
0.024 \\
0.027\end{array}$ & $\begin{array}{l}0.005 \\
0.005 \\
0.006\end{array}$ & $\begin{array}{l}0.005 \\
0.010 \\
0.019\end{array}$ \\
\hline
\end{tabular}

(a) Artificial Heart Recipient

(b) Other Household Member 
5

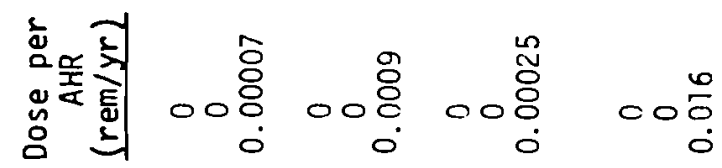

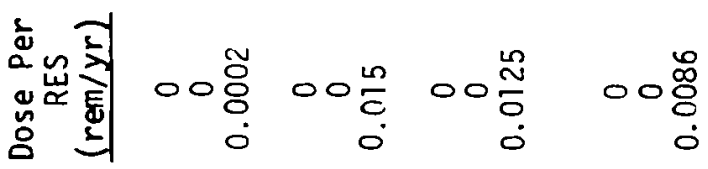

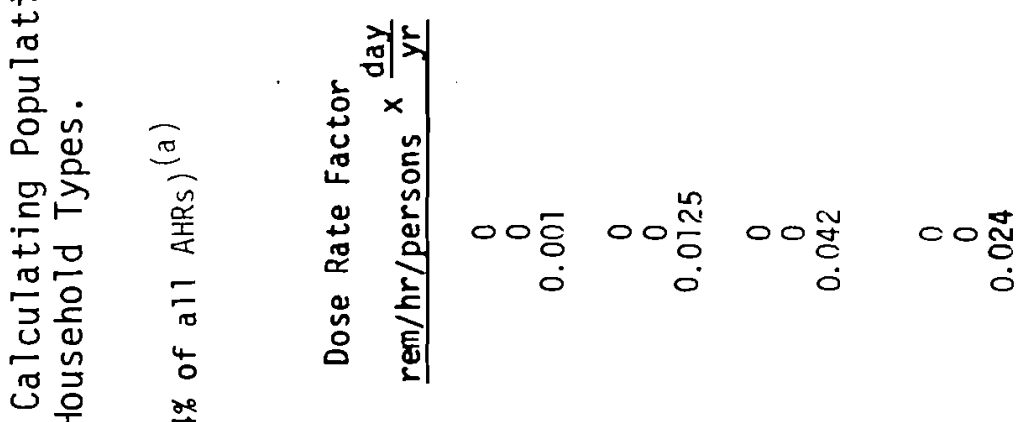

$=$ 도랄

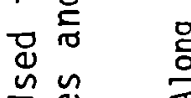

$\checkmark \frac{1}{2}$ क

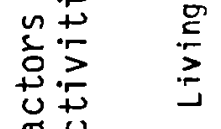

芒这

4 엉 च

ฯ

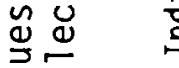

ฮั

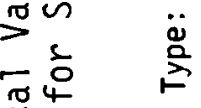

윽용

\begin{tabular}{l|}
$\dot{j}$ \\
$m$ \\
$m$ \\
$m$
\end{tabular}

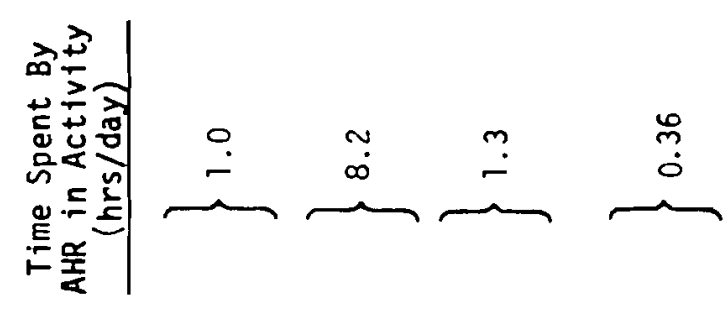

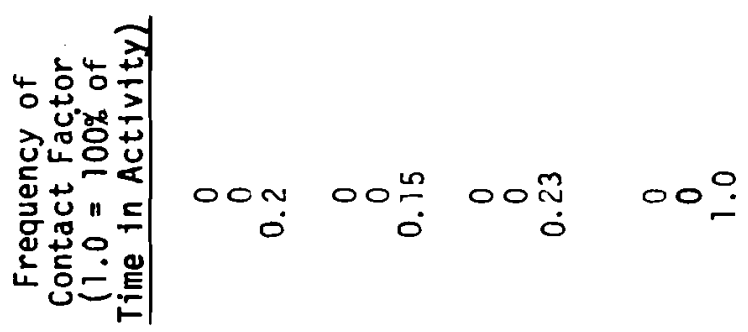

崫高童

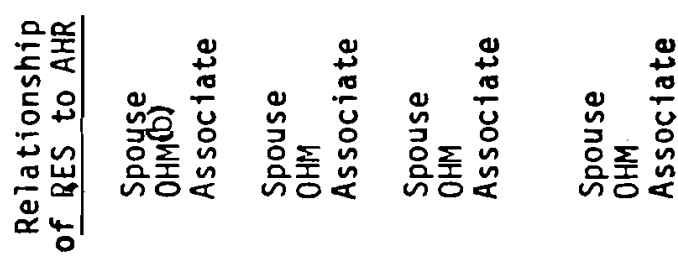

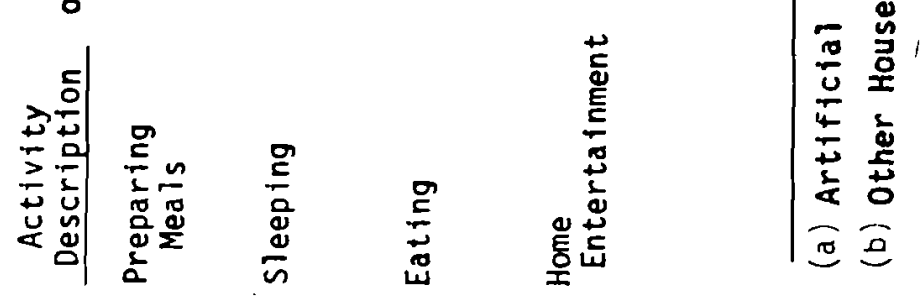




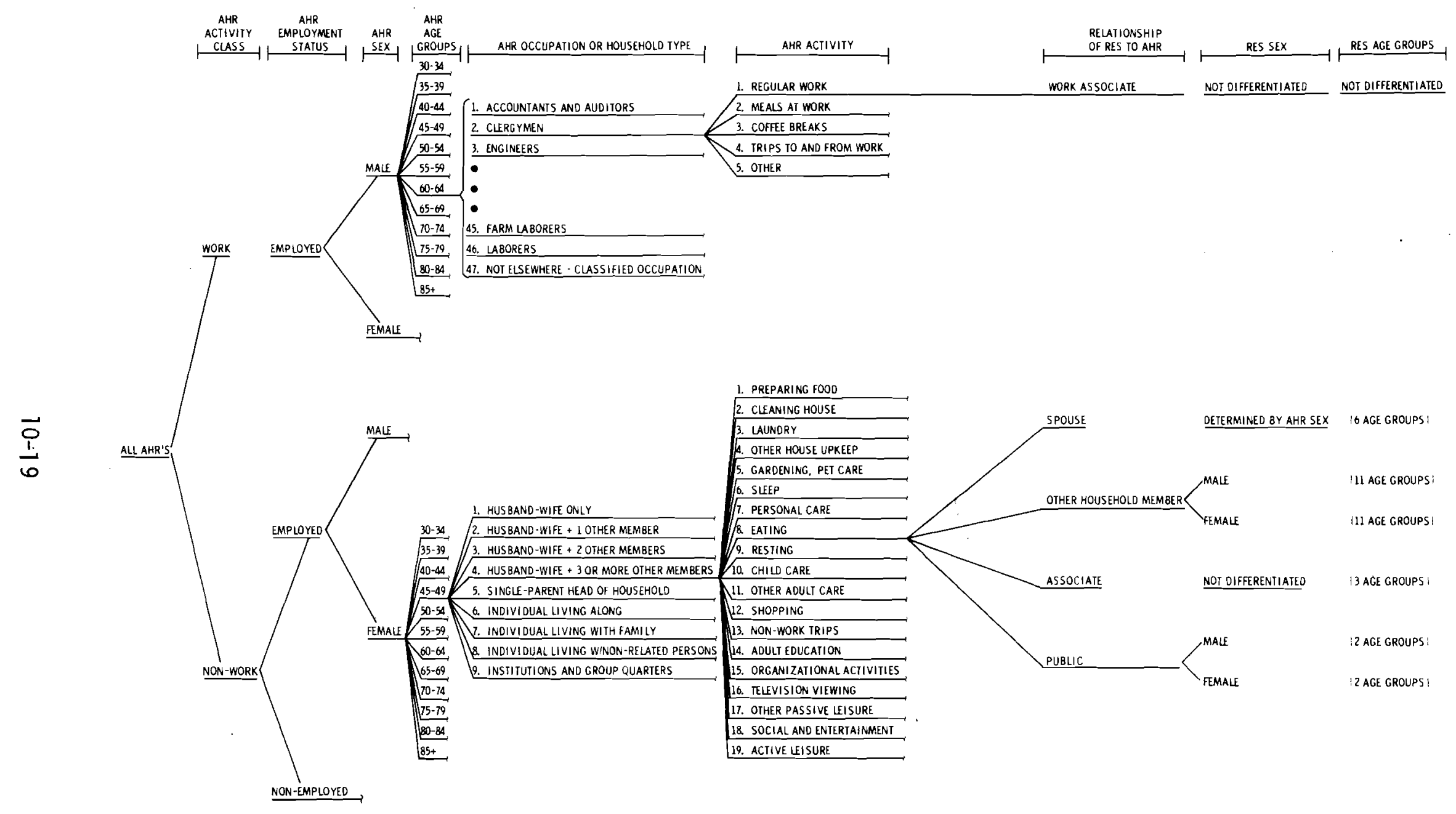

FIGURE 27. REPRIEVE Matrix to Obtain Summations of Work and Nonwork Components of Dose-to-the-Population 
activity, household type, occupation, age, sex, employment status, and finally work and nonwork activity class. Illustration of the results of this summation could be shown by employment status and sex in a $2 \times 3$ twodimensional result matrix. By altering the order of the summations, the population dose can be examined as a function of any desired pair of RES and/or recipient characteristics in a two-dimensional array. Table 32 illustrates the various kinds of dose tables that the REPRIEVE program provides. The first seven types of tables all provide information on dose to specific groups of RESs. The last two types provide information on dose from various classifications of artificial heart recipients.

Several other tables are given as output by REPRIEVE. These are:

1. Tables identifying the values of the input assumptions.

2. A table showing the increase in relative dose rate due to ${ }^{236} \mathrm{Pu}$ daughters with time and the effect of the device replacement period on this dose rate.

3. A table showing the decrease in relative dose rate due to ${ }^{238} \mathrm{Pu}$ decay and the effect of the device replacement period on this dose rate.

4. Tables showing the effect of device replacement period on the annual and cumulative demands for devices.

5. A table indicating the number of devices in use by device age.

6. An age and sex profile of device users in mid-year for a given program year.

7. A calculation of years of life provided by the artificial heart for a given program year.

8. Estimates of device cost using present value techniques.

9. Tables showing the occupation and household type distribution of artificial heart recipients.

10. Tables showing the number of RESs exposed corresponding to similar tables showing population dose. 


\section{TABLE 32. Output Tables from REPRIEVE}

- Dose to Spouses by Age of Each Partner and Number of Spouses by Age of Each Partner.

- Dose to Other Household Members by Age and Sex of Both Device User and Household Members.

- Dose to Associates of Device User According to Age of Associates and Age of Device User.

- Dose to the Above Three Population Exposure Groups by Age and Household Type of Device User.

- Dose to the Above Three Population Groups by Household Type and Activity of Device User.

- Dose to Work Associates by Age of Device User and Work Activity.

- Dose to General Public by Age Group and Age and Activity of Device User.

- Dose From Device User by Household Type, Activity and Sex of Device User.

- Dose From Device User by Age and Sex or Household Type of Device User for all Work and Non-Work Activities.

The last-mentioned tables are useful in identifying the effect of number-of-persons exposed on the population dose. A complete set of REPRIEVE Tables for the base case is shown in Appendix I for further reference. These many tables provide valuable detail, useful in determining the effects of alternate courses of action. The following section briefly explores some of these possible uses.

c. POSSIBLE USES OF THE REPRIEVE MODEL

Both somatic and genetic risks may be of possible concern in the widespread usage of artificial hearts. REPRIEVE allows these risks to be estimated by identifying potential exposure by age and sex groups.

REPRIEVE can also be used to model the effect of imposing restrictions on types of persons receiving implants or the activities of certain recipient types. 


\section{RESULTS}

We developed our best estimate of population dose using what we believe to be the most probable values of the variable parameters in the REPRIEVE program. This case is used as a baseline for comparison and is referred to as the reference base case in this report. Following this we calculated a number of REPRIEVE cases to develop a sensitivity analysis. This analysis identifies the effects on population dose of heart disease incidence, eligible candidate estimates, device failure rates, natural death rates after implant, and time.

\section{A. BASE CASE ESTIMATE}

The parameters and inherent assumptions defining the base case estimate of population dose are listed in Table 33. Subsequent cases use these same assumptions with the exception of the changes stated.

The population dose in the year 2000 for the base case is approximately $339,000 \mathrm{rem} /$ year, as noted in Table 34 which summarizes the results for this case. This is the average dose resulting from the use of an average of 201,549 devices during the year 2000. The largest segment of this dose is received by spouses and the general public who receive about 35 and $34 \%$, respectively. Nearly half of the dose to all spouses is absorbed by women 50 and over or essentially past their child-bearing years. Less than $30 \%$ of the dose to spouses is to persons under 50 . The average dose to spouse is approximately 0.8-0.9 rem/year/person--approximately six times higher than that of the next largest group, household members, and 1800 times that of the average dose to the general populace. However, this average dose to spouse is only about seven to eight times normal background.

Most of the dose to spouse is absorbed during sleep as shown in Table 35. This one activity accounts for about $75 \%$ of the total average dose. Other activities contributing significantiy to absorbed dose to spouse are eating and television viewing. Together these three activities account for about $92 \%$ of total absorbed dose. 
TABLE 33. Assumptions and Parameters Used in Defining the Base Case Estimate of Dose to the Population

\section{ASSUMPTIONS :}

1. Devices would only be implanted in persons in danger of imminent cardiac death.

2. Implantation of an artificial heart device would allow the user to return to his accustomed habits and lifestyle. Lifestyles will remain essentially the same as at present over the next 50 years.

3. All of the devices implanted would be powered by the ${ }^{238} \mathrm{Pu}$ power source described in this report.

4. Devices in recipients surviving after ten years would be replaced.

5. The devices (i.e., specifically the ${ }^{238} \mathrm{Pu}$ power sources) would be fabricated six months prior to implant.

6. Implants would start in 1985 with 100 being implanted in that year. The number of implants is successively doubled in following years until demand is satisfied.

7. The assumptions for the following variable parameters were used to develop the base case:

\section{Parameter}

1. Heart disease death rate projection

2. Eligible candidates

3. Death rates from natural causes after implant

4. Device failure rates

5. ${ }^{236} \mathrm{Pu}$ content in ${ }^{238} \mathrm{Pu}$

6. Power output (grams of ${ }^{238} \mathrm{pu}$ )

7. Program year of dose calculation
Value

Best estimate

High estimate using our modified age profile

Twice normal probability of death

Twice normal heart failure rate $0.3 \mathrm{ppm}$

24 watts (53.5 g of $\left.{ }^{238} \mathrm{Pu}\right)$

2000 A.D. 
TABLE 34. Case 1A Dose to the Population in the Year 2000 from 201,549 Radioisotope-Fueled Devices

Basis: 1. High Candidate Estimate

2. Best Heart Disease Incidence Estimate

3. Natural Death Rate = Twice PND(a)

4. Device Failure Rate = Twice NHFR(b)

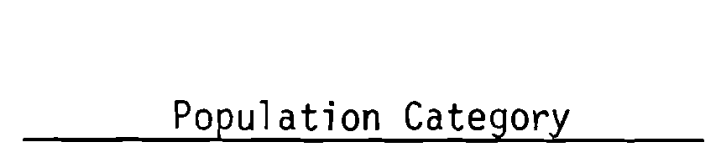

1. Spouses

Females - Age 49 and Under

- Age 50 and Over

Males - Age 49 and Under

- Age 50 and Over

2. Other Household Members

$$
\text { Age } \begin{gathered}
0-17 \\
18-49 \\
50+
\end{gathered}
$$

3. Non-work Associates

4. Work Associates

\begin{tabular}{|c|c|c|c|}
\hline $\begin{array}{l}\text { Number of } \\
\text { People } \\
\text { Exposed }\end{array}$ & $\begin{array}{l}\text { Dosage } \\
\text { rem/yr }\end{array}$ & $\begin{array}{l}\text { Percent of } \\
\text { Total Dose to } \\
\text { the Population }\end{array}$ & $\begin{array}{c}\text { Average Dose } \\
\text { Per Person } \\
\text { rem/yr } \\
\end{array}$ \\
\hline $\begin{array}{r}30,499 \\
70,037 \\
7,701 \\
34,740\end{array}$ & $\begin{array}{r}27,464 \\
56,649 \\
7,409 \\
28,227\end{array}$ & $\begin{array}{r}8.1 \\
16.7 \\
2.2 \\
8.3\end{array}$ & $\begin{array}{l}0.900 \\
0.809 \\
0.962 \\
0.813\end{array}$ \\
\hline $\begin{array}{r}109,814 \\
71,998 \\
27,954\end{array}$ & $\begin{array}{r}20,297 \\
11,325 \\
4,104\end{array}$ & $\begin{array}{l}6.0 \\
3.3 \\
1.2\end{array}$ & $\begin{array}{l}0.185 \\
0.157 \\
0.147\end{array}$ \\
\hline $4,305,397$ & 30,744 & 9.1 & 0.0071 \\
\hline $2,097,850$ & 36,816 & 10.9 & 0.0175 \\
\hline $265,000,000^{(c)}$ & 115,989 & 34.2 & 0.00044 \\
\hline$\overline{265,000,000}$ (c & 339,024 & $\overline{100.0}$ & ge 0.00128 \\
\hline
\end{tabular}

General Populace

Total

(a) Probability of normal death

(b) Normal heart failure rate

(c) The entire U.S. population is assumed to have received some exposure 
TABLE 35. Dose to A11 Spouses According to Artificial Heart Recipient Activities and Household Types (rem/year)

Household Type of Artificial Heart Recipient

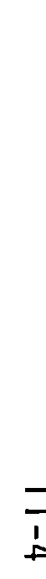

\begin{tabular}{|c|c|c|c|c|c|c|c|c|c|c|}
\hline \multirow{2}{*}{\multicolumn{2}{|c|}{ Activity }} & \multicolumn{9}{|c|}{ Household Type of Artificial Heart Recipient } \\
\hline & & \multirow{2}{*}{$\frac{1}{1088}$} & \multirow{2}{*}{$\frac{2}{221}$} & \multirow{2}{*}{$\frac{3}{121}$} & \multirow{2}{*}{$\begin{array}{l}4 \\
15\end{array}$} & \multirow[t]{2}{*}{5} & \multirow[t]{2}{*}{6} & \multirow{2}{*}{$\frac{7}{19}$} & 8 & 9 \\
\hline 1. & Prep. Food & & & & & & & & & \\
\hline 2. & Clean House & 70 & 23 & 19 & 31 & & & 1 & & \\
\hline 3. & Laundry & 128 & 11 & 13 & 13 & & & 3 & & \\
\hline 4. & House Upkeep & 143 & 125 & 1 & 40 & & & 1 & & \\
\hline 5. & Gardening & 4 & 2 & 0 & 0 & & & 0 & & \\
\hline & Sleep & 43202 & 15473 & 15732 & 15444 & & & 823 & & \\
\hline 7. & Personal Care & 208 & 107 & 255 & 112 & & & 5 & & \\
\hline 8. & Eating & 5092 & 1849 & 1043 & 1048 & & & 4 & & \\
\hline 9. & Resting & 307 & 90 & 25 & 7 & & & 3 & & \\
\hline 10. & Child Care & 34 & 6 & 512 & 1 & & & 3 & & \\
\hline 11. & Adult Care & 434 & 0 & 0 & 0 & & & 3 & & \\
\hline 14- 1. & Home Study & 4 & 1 & 2 & 0 & & & 0 & & \\
\hline 16. & Television & 3972 & 2337 & 1171 & 2763 & & & 2 & & \\
\hline $17-1$ & Reading & 886 & 396 & 286 & 233 & & & 0 & & \\
\hline $17-2$ & Telephoning & 163 & 44 & 30 & 21 & & & 0 & & \\
\hline 18-1. & Drop-In Visits & 1176 & 200 & 205 & 324 & & & 1 & & \\
\hline $18-2$ & Home Parties & 417 & 131 & 84 & 127 & & & 0 & & \\
\hline \multirow[t]{2}{*}{19.} & Active Leisure & 610 & 9 & 105 & 125 & - & - & 6 & 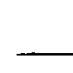 & - \\
\hline & TOTAL & 57937 & 21027 & 19605 & 20305 & & & 875 & & \\
\hline
\end{tabular}

Total Dose For All Households

$\begin{array}{r}1463 \\ 144 \\ 170 \\ 311 \\ 7 \\ 90675 \\ 686 \\ 9036 \\ 432 \\ 556 \\ 437 \\ 8 \\ 10245 \\ 1801 \\ 257 \\ 1906 \\ 759 \\ 855 \\ \hline 119749\end{array}$

Average Dose Per Spouse
0.010
0.001
0.001
0.002
0.000
0.634
0.005
0.063
0.003
0.004
0.003
0.000
0.072
0.013
0.002
0.013
0.005
$\underline{0.006}$
0.838 
The dose to the general populace component is the result of the dose absorbed during public activities and the incidental random dose occurring mostly in urban centers. The scope of this study allowed only a general identification of the persons receiving this dose segment and it is assumed that the distribution of this dose is reasonably uniform across the entire population. Using this assumption the average dose to the population would be about $0.0013 \mathrm{rem} /$ year, or only $1 \%$ of natural background radiation. Table 36 shows that most of the public exposure dose is absorbed by adults during organizational activities. Substantial amounts of dose are also received during nonwork trips (mostly to family members) and social activities. These three activities account for approximately $85 \%$ of dose to the general public. Only about $14 \%$ of the dose to the public is absorbed by persons under 18 .

Referring again to summary Table 34 it will be noted that dose to household members is about 36,000 rem/year or approximately $10 \%$ of the total. Although the total and average dose are small compared to the dose to spouses, this dose is significant since about two-thirds of it is absorbed by persons under 18. Still, the average dose is only on the order of current natural background. About $76 \%$ of the dose to other household members is absorbed during sleeping, eating and television viewing and is about equally divided among these activities.

Although dose to associates and work associates also each account for about $10 \%$ of the population dose, the average dose to these persons is much less than to household members. In addition, much less is absorbed in the younger age group of associates as seen by comparing the totals in the far right column in Table 37. All of the dose to work associates is assumed to be absorbed by adults.

A complete set of tables for the base case is included in Appendix I. These tables give further inofrmation on the number of spouses, household members and associates exposed by age and sex as well as additional detail on dose absorbed. 
TABLE 36. Dose to General Public (Includes Dose to Family During Public Activities) According to Artificial Heart Recipient Activities and Age or Radiation Exposure Subjects (RES) (rem/year)

\begin{tabular}{|c|c|c|c|c|c|}
\hline & Activity & $\begin{array}{r}\text { Age } 0 \\
\text { Less Than } 18 \\
\end{array}$ & $\begin{array}{l}\text { RES } \\
18 \text { and Over }\end{array}$ & $\begin{array}{l}\text { Total for } \\
\text { A11 Ages }\end{array}$ & $\begin{array}{c}\text { Average Per } \\
\text { Member of } \\
\text { General Public }\end{array}$ \\
\hline 12. & Shopping & 1823 & 4256 & 6078 & 0.00002 \\
\hline 13. & Nonwork Trips & 5206 & 20542 & 25748 & 0.00010 \\
\hline $14-2$. & Classroom Education & 0 & 990 & 990 & 0.00000 \\
\hline 15. & Organizational & 0 & 46959 & 46959 & 0.00018 \\
\hline $18-3$. & Other Social & 9681 & 16057 & 25738 & 0.00010 \\
\hline & $\begin{array}{l}\text { Incidental Random } \\
\text { Exposure }\end{array}$ & 2886 & 7590 & 10476 & $\underline{0.00004}$ \\
\hline & TOTAL & 16710 & 88804 & 115989 & 0.00044 \\
\hline
\end{tabular}


TABLE 37. Dose to Associates of Artificial Heart Recipient According to Age of Associates and Age of Recipient (rem/year)

\begin{tabular}{|c|c|c|c|c|c|c|c|c|c|c|c|c|c|}
\hline & \multicolumn{12}{|c|}{ Age of Artificial Heart Recipient } & \multirow{2}{*}{$\begin{array}{c}\text { Total Over } \\
\text { All Ages } \\
\text { of AHR } \\
\end{array}$} \\
\hline & $30-34$ & $35-39$ & $40-44$ & $45-49$ & $50-54$ & 55-59 & $60-64$ & $65-69$ & $70-74$ & $75-79$ & $80-84$ & $85+$ & \\
\hline $0-17$ & 38 & 163 & 336 & 531 & 1071 & 1103 & 1043 & 1113 & 1256 & 886 & 349 & 53 & 7953 \\
\hline $18-49$ & 77 & 322 & 686 & 1125 & 1678 & 1843 & 1826 & 1978 & 1810 & 1403 & 640 & 141 & 13529 \\
\hline $50+$ & 21 & 89 & 193 & 318 & 840 & 1048 & 1141 & 1371 & $\underline{1687}$ & 1519 & 820 & $\underline{215}$ & 9262 \\
\hline TOTAL & 135 & 574 & 1215 & 1973 & 3589 & 3995 & וז400 & 4462 & 4754 & 3808 & 1809 & 419 & 30744 \\
\hline
\end{tabular}




\section{B. SENSITIVITY ANALYSIS}

We developed an analys is of the variable parameters in the REPRIEVE code to determine their effect on dose to the population. This analysis is summarized in Table 38 . The results of the analys is indicate that the population dose estimates are relatively insensitive to changes in estimates of death rates due to natural causes. These changes only cause variations on the order of $\pm 10-12 \%$. Device failure rates are also not a very sensitive factor since the postulated extreme case of no device failure (not a creditable case) only increases the dose estimates approximately $25 \%$. The effect of projected heart disease death rates is more marked; the dose being nearly 50\% lower for the minimum incidence case and $25 \%$ higher for the maximum incidence case. The estimate of eligible candidate fractions is the most sensitive parameter in the projection decreasing the dose to $33 \%$ of that reported for the base case.

The approximate minimum dose given by case $6 \mathrm{~A}$, shown on Table 39 , combines the low candidate estimate with the minimum heart disease incidence projection. The dose of $58,100 \mathrm{rem} / \mathrm{year}$ is about $17 \%$ of the base case dose. The approximate maximum dose (case 2A) in the year 2000 is 428,000 rem/year or $26 \%$ higher than our base estimates. The results of this case are summarized in Table 40. Al though somewhat higher doses can be obtained by assuming that the device would function equally as well as a normal human heart, we do not believe this to be a credible assumption.

The effect of time on population dose (holding the other parameters constant at base case values) is given by cases 7 through 10 . Figure 28 shows this increase in population dose graphically. The dose rate under these assumptions would increase to approximately 535,000 rem/year by 2035 where it approaches equilibrium. However, improvements in energy conversion efficiencies during this time would tend to have a counterbalancing effect. Summary tables of the population dose for the remainder of the cases shown in Table 38 are found in Appendix $H$. 

TABLE 38. Summary of Population Dose Estimates for ${ }^{238}$ Pu-Powered
Artificial Heart Devices

\begin{tabular}{|c|c|c|c|c|c|c|c|c|}
\hline Case No. & $\begin{array}{l}\text { Eligible } \\
\text { Candidate } \\
\text { Estimate } \\
\end{array}$ & $\begin{array}{c}\text { Heart Disease } \\
\text { Death Rate } \\
\text { Estimate } \\
\end{array}$ & $\begin{array}{c}\text { Device } \\
\text { Failure Rate } \\
\text { Estimate } \\
\end{array}$ & $\begin{array}{c}\text { Natural } \\
\text { Death Rate } \\
\text { Estimate } \\
\end{array}$ & $\begin{array}{l}\text { Year of } \\
\text { Estimate }\end{array}$ & $\begin{array}{c}\text { Number of } \\
\text { Artificial } \\
\text { Heart Devices } \\
\text { In Use } \\
\end{array}$ & $\begin{array}{l}\text { Total Dose } \\
\text { to the } \\
\text { Population } \\
\text { (rem/year) }\end{array}$ & $\begin{array}{l}\text { Ratio to } \\
\text { Population } \\
\text { Dose For } \\
\text { Base Case } \\
\end{array}$ \\
\hline $\begin{array}{c}\text { IA (Base } \\
\text { Case) }\end{array}$ & High & Best Estimate & Twice NHR F* & Twice PND** & 2000 & 201,549 & 339,024 & 1.00 \\
\hline $\begin{array}{l}1 \mathrm{~B} \\
1 \mathrm{C} \\
1 \mathrm{D}\end{array}$ & " & " & 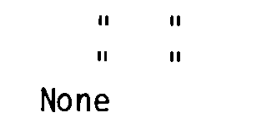 & $\begin{array}{l}\text { Equals PND } \\
4 \times \text { PND } \\
\text { Twice PND }\end{array}$ & $\begin{array}{l}" \\
" 1\end{array}$ & $\begin{array}{l}220,330 \\
175,026 \\
247,446\end{array}$ & $\begin{array}{l}370,216 \\
294,879 \\
424,063\end{array}$ & $\begin{array}{l}1.09 \\
.87 \\
1.25\end{array}$ \\
\hline $\begin{array}{l}4 A \\
5 A \\
6 A\end{array}$ & $\begin{array}{c}\text { Low } \\
\text { " } \\
" 1\end{array}$ & $\begin{array}{l}\text { Best Estimate } \\
\text { Maximum } \\
\text { Minimum }\end{array}$ & $\begin{array}{c}\text { Twice } \\
\text { NHFR } \\
" 1 \\
" 1\end{array}$ & $\begin{array}{cc}\text { Twice } & \text { PND } \\
" & " \\
" & "\end{array}$ & $\begin{array}{c}2000 \\
" \\
"\end{array}$ & $\begin{array}{l}64,030 \\
81,491 \\
33,626\end{array}$ & $\begin{array}{r}110,820 \\
138,812 \\
58,100\end{array}$ & $\begin{array}{l}.33 \\
.41 \\
.17\end{array}$ \\
\hline $\begin{array}{r}7 \\
8 \\
9 \\
10\end{array}$ & $\begin{array}{c}\text { High } \\
" 1 \\
"\end{array}$ & $\begin{array}{cc}\text { Best } & \text { Estimate } \\
" 1 & 11 \\
" 1 & " 1\end{array}$ & $\begin{array}{cc}\text { Twice } & \text { NHFR } \\
" 1 & 1 \\
" 1 & " 1 \\
" & " 1\end{array}$ & $\begin{array}{cc}\text { Twice } & \text { PND } \\
" 1 & \\
" 1 & " 1 \\
" & " 1\end{array}$ & $\begin{array}{l}1990 \\
2010 \\
2020 \\
2030\end{array}$ & $\begin{array}{r}4,160 \\
287,544 \\
317,746 \\
322,835\end{array}$ & $\begin{array}{r}6,106 \\
485,251 \\
529,402 \\
535,854\end{array}$ & $\begin{array}{l}.02 \\
1.43 \\
1.56 \\
1.58\end{array}$ \\
\hline
\end{tabular}

* Norma 1 Heart Failure Rate

** Probability of Natural Death 
TABLE 39. Case 6A Dose to the Population in the Year 2000 from 33,626 Radioisotope-Fueled Devices

Basis: 1. Low Candidate Estimate

2. Minimum Heart Disease Incidence Esstimate

3. Natural Death Rate = Twice PND $(a)$

4. Device Failure Rate $=$ Twice $\operatorname{NHFR}(b)$

\begin{tabular}{|c|c|c|c|c|}
\hline Population Category & $\begin{array}{l}\text { Number of } \\
\text { People } \\
\text { Exposed }\end{array}$ & $\begin{array}{l}\text { Dosage } \\
\mathrm{rem} / \mathrm{yr}\end{array}$ & $\begin{array}{l}\text { Percent of } \\
\text { Total Dose to } \\
\text { the Population }\end{array}$ & $\begin{array}{c}\text { Average Dose } \\
\text { Per Person } \\
\text { rem/yr }\end{array}$ \\
\hline $\begin{array}{l}\text { 1. Spouses } \\
\text { Females - Age } 49 \text { and Under } \\
\text { - Age } 50 \text { and Over } \\
\text { Males - Age } 49 \text { and Under } \\
\text { - Age } 50 \text { and Over }\end{array}$ & $\begin{array}{r}5,592 \\
12,309 \\
888 \\
5,027\end{array}$ & $\begin{array}{r}5,218 \\
10,310 \\
885 \\
4,156\end{array}$ & $\begin{array}{r}9.0 \\
17.7 \\
1.5 \\
7.2\end{array}$ & $\begin{array}{l}0.933 \\
0.838 \\
0.997 \\
0.827\end{array}$ \\
\hline $\begin{array}{l}\text { 2. Other Household Members } \\
\text { Age } 0-17 \\
18-49 \\
50+\end{array}$ & $\begin{array}{r}18,158 \\
11,734 \\
4,696\end{array}$ & $\begin{array}{r}3,397 \\
1,876 \\
710\end{array}$ & $\begin{array}{l}5.8 \\
3.2 \\
1.2\end{array}$ & $\begin{array}{l}0.187 \\
0.160 \\
0.151\end{array}$ \\
\hline 3. Non-work Associates & 721,066 & 5,269 & 9.1 & 0.0073 \\
\hline 4. Work Associates & 338,976 & 6,266 & 10.8 & 0.0185 \\
\hline General Populace & $265,000,000$ (c) & $20,01 ?$ & 34.4 & 0.00008 \\
\hline Total & $265,000,000$ & 58,100 & 100.0 & rage 0.00022 \\
\hline
\end{tabular}

\footnotetext{
(a) Probability of normal death

(b) Normal heart failure rate

(c) The entire U.S. population is assumed to have received some exposure
} 
TABLE 40. Case 2A Dose to the Population in the Year 2000 from 258,757 Radioisotope-Fueled Devices

Basis: 1. High Candidate Estimate

2. Maximum Heart Disease Incidence Estimate

3. Natural Death Rate = Twice PND(a)

4. Device Failure Rate $=$ Twice NHFR(b)
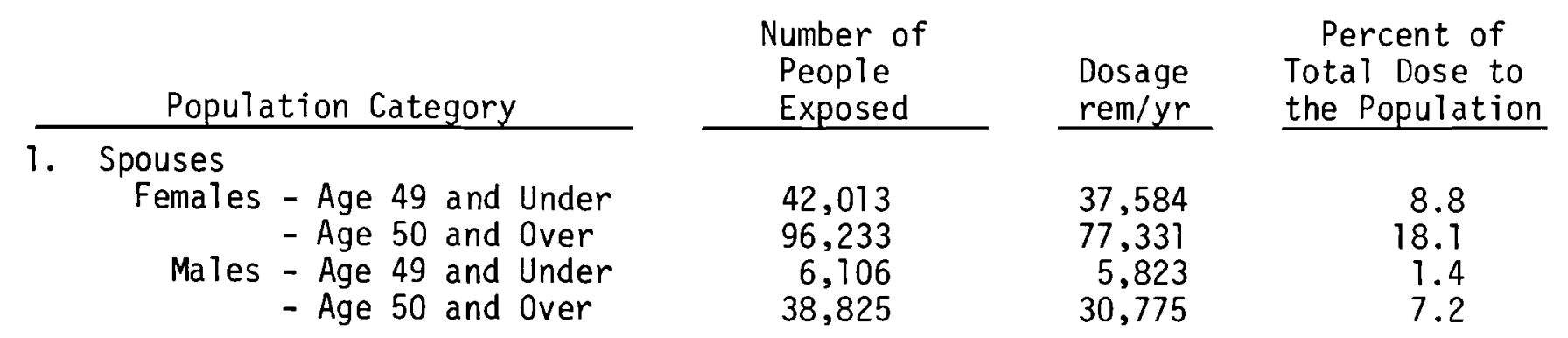

Average Dose
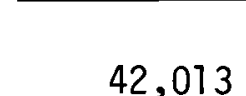

96,233

6,106

38,825

$$
\begin{array}{r}
37,584 \\
77,331 \\
5,823 \\
30,775
\end{array}
$$

8.8
18.1
1.4
7.2

Per Person

2. Other Household Members

$$
\text { Age } \begin{gathered}
0-17 \\
18-49 \\
50+
\end{gathered}
$$

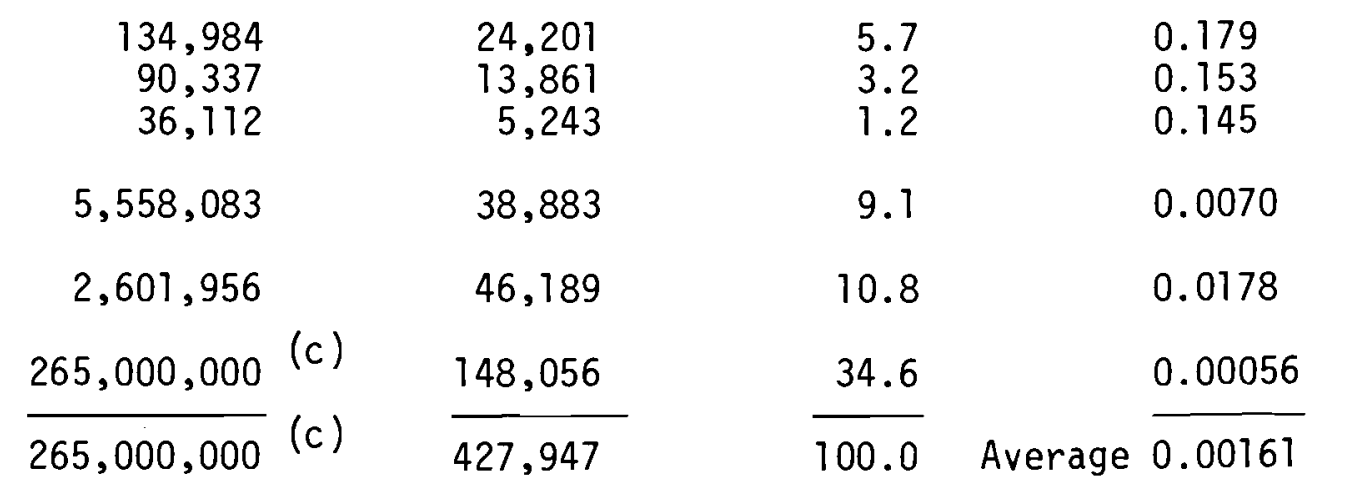

(a) Probability of normal death

(b) Normal heart failure rate

(c) The entire U.S. population is assumed to have received some exposure 


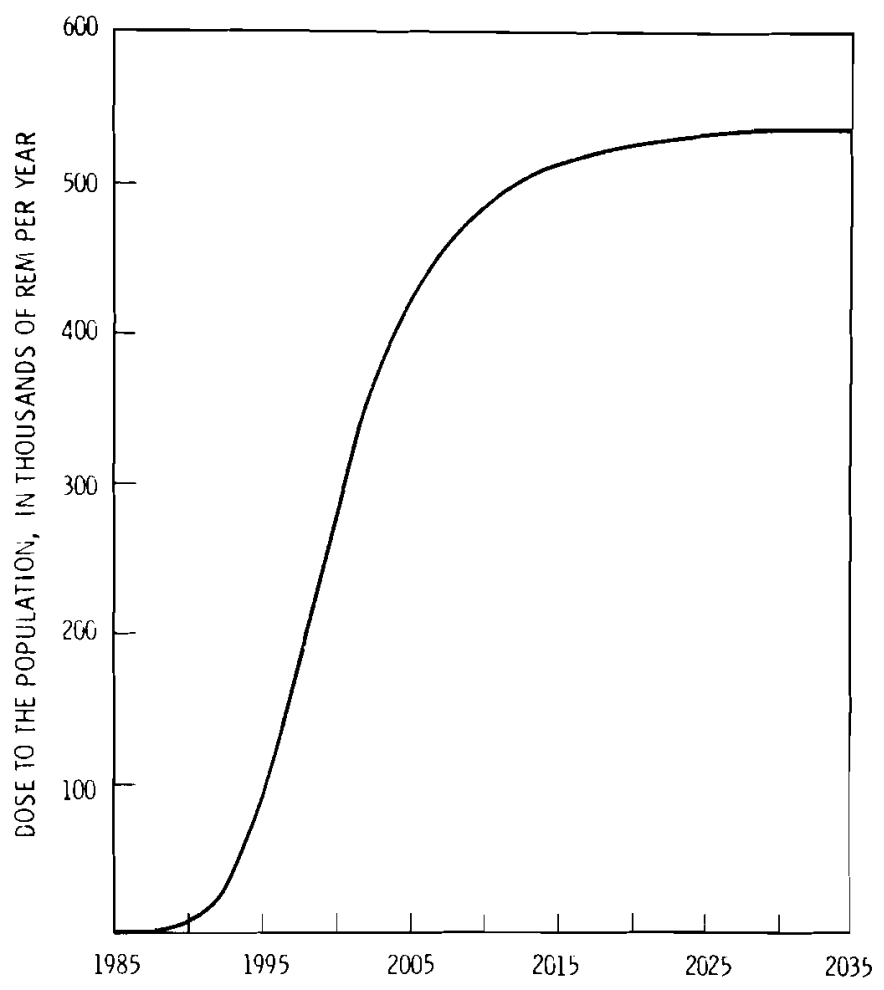

FIGURE 28. Effect of Time on Population Dose Us ing Constant Base Case Parameters

Since the dose to the various RES groups is almost a linear function of total population dose, an approximate idea of the dose to subgroups for cases other than the base case can be simply obtained. This is done by multiplying the population dose ratios (column 8 in Table 38 ) by the dose to the desired subgroup in the base case.

Table 41 indicates that the total dose per device-in-use varies within a fairly narrow range over time (it does for the other parameters as well). Therefore, the total population dose can be roughly estimated from independent calculations of devices-in-use, using this ratio.

The calculations just discussed assume a replacement interval of 10 years for the heart devices. This renews the power source for each user and reduces the dose because the ${ }^{236} \mathrm{Pu}$ contribution is reset to zero for each surviving recipient at 10-year intervals. If the replacement interval is increased, the population dose will increase because of the higher contribution of ${ }^{236} \mathrm{Pu}$. 
TABLE 41. Amount of Dose Absorbed per Year per Device-in-Use, Using Base Case Parameters

\begin{tabular}{|c|c|c|c|}
\hline Year & Devices in Use & $\begin{array}{l}\text { Population Dosage } \\
\text { (rem/year) }\end{array}$ & $\begin{array}{l}\text { Dose/Device } \\
\text { Ratio } \\
\end{array}$ \\
\hline 1990 & 4,160 & 6,106 & 1.466 \\
\hline 2000 & 201,549 & 339,024 & 1.682 \\
\hline 2010 & 287,544 & 485,251 & 1.687 \\
\hline 2020 & 317,746 & 529,402 & 1.666 \\
\hline 2030 & 322,835 & 535,854 & 1.660 \\
\hline
\end{tabular}

This effect is illustrated in Table 42. The first row of data represents a replacement interval of 10 years as was used in the population dose tabulations. The effect on population dose of a longer replacement interval can be considered relative to these 10-year replacement values by comparing the relative dose rates. For example, if a 20-year replacement interval were to be assumed rather than a 10-year replacement interval, the increase in the population dose in the year 2020 would be in the ratio of 1.34 to 1.258 or $6.5 \%$. Figure 29 shows a plot of the increase in the relative dose rate at various device replacement intervals. Almost no increase can be observed beyond a 30-year replacement interval.

Another effect of the device replacement interval that can be identified with the REPRIEVE program is its effect on the total annual number of implants required. The more frequent the replacement intervals, the more devices are required each year to provide not only the first implants, but also the replacement implants for devices previously in use. This effect is detailed in Table 43. When the replacement interval is short, on the order of two or three years, the effect on implant requirements is significant. Replacement requirements reach two to three times those of a 10-year replacement interval in the year 2000 . Replacement intervals beyond 20 years have a relatively small effect on the annual implant requirements. 


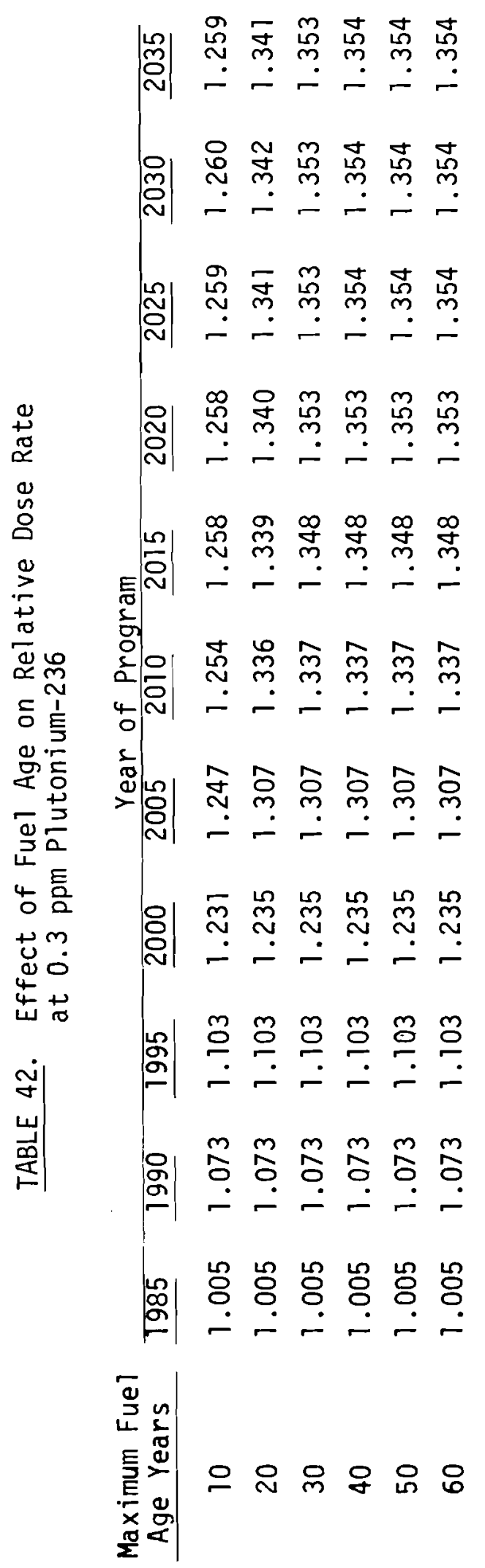




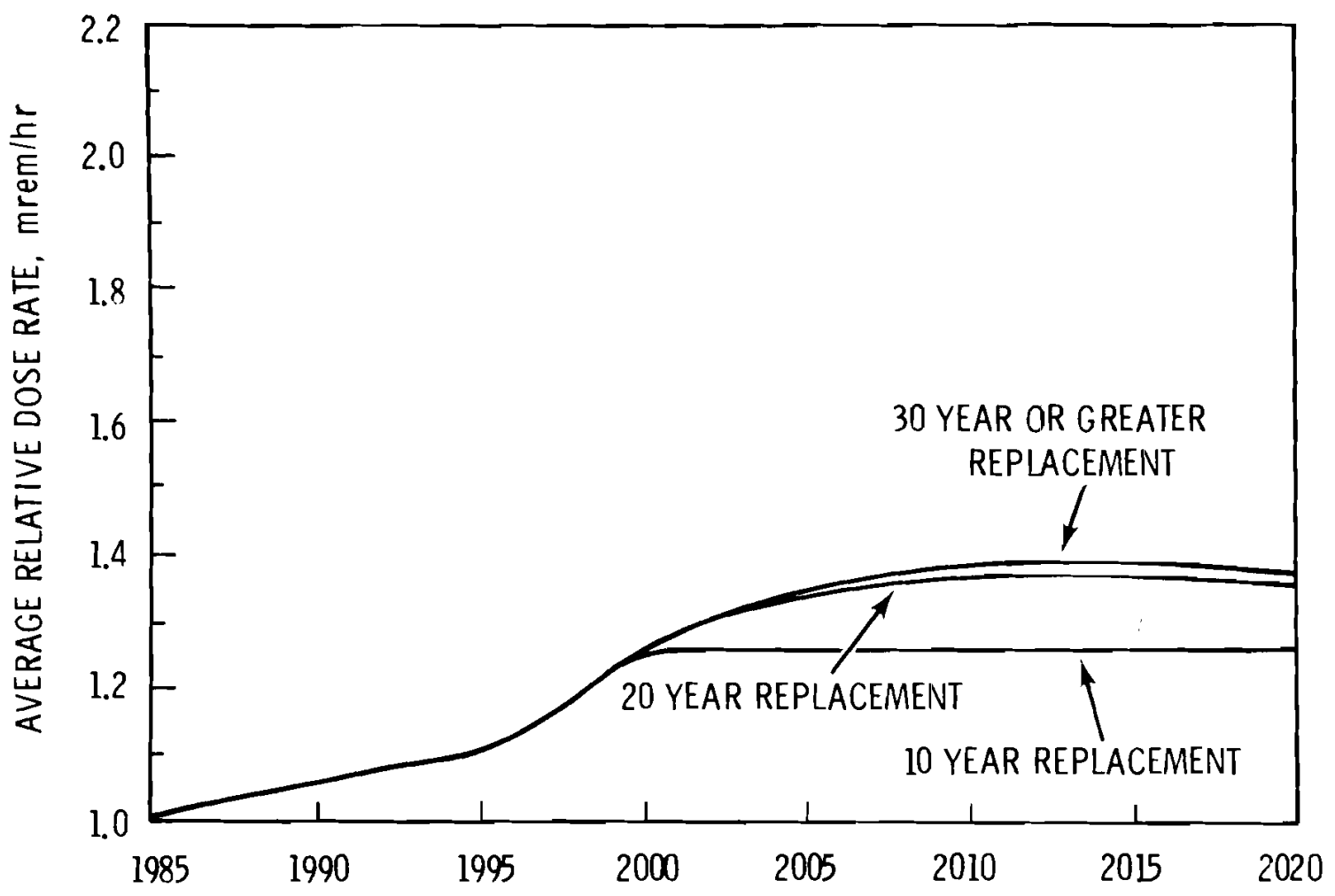

FIGURE 29. Relative Dose Rate Versus Time Weighted for All Devices in Use at Varying Device Replacement Intervals (0.3 ppm 236Pu)

In conclusion, the purpose of this report has been to develop dose to the population estimates from widespread use of ${ }^{238} \mathrm{Pu}$-powered artificial hearts. In addition this report has estimated doses to population subgroups to identify major areas of impact. However, to estimate a realistic cost-benefit associated with use of these artificial hearts, the population doses need to be expressed in terms of injurious health effects. Such analysis was beyond the scope of this report since insufficient data have resulted in major differences of opinion in this area. For example, the 1972 BEIR committee recommended using a low-level dose model which extrapolates health effects per unit radiation dose 7 inearly from high radiation doses. ${ }^{(2)}$ This, of course, was pointed out as a very conservative assumption. 
TABLE 43. Effect of Device Replacement Interval on Number of Implants

\begin{tabular}{|c|c|c|c|c|c|c|c|c|c|c|c|}
\hline \multirow{2}{*}{$\begin{array}{l}\text { Replacement } \\
\text { Interval In } \\
\text { Years } \\
\end{array}$} & \multicolumn{11}{|c|}{ Number of Implants During Program Year } \\
\hline & $\underline{1985}$ & 1990 & 1995 & 2000 & 2005 & 2010 & 2015 & 2020 & 2025 & 2030 & 2035 \\
\hline 2 & 100 & 3978 & 65737 & 120614 & 147180 & 164167 & 174319 & 180376 & 182324 & 182861 & 182593 \\
\hline 3 & 100 & 3491 & 50074 & 87798 & 104697 & 116842 & 123882 & 128194 & 129511 & 129543 & 129665 \\
\hline 5 & 100 & 3259 & 41970 & 64924 & 75966 & 83579 & 87904 & 90524 & 91419 & 91545 & 91561 \\
\hline 7 & 100 & 3200 & 40353 & 49246 & 57136 & 64102 & 67380 & 69536 & 69878 & 69870 & 70029 \\
\hline 10 & 100 & 3200 & 40093 & 40895 & 51511 & 53044 & 56460 & 57869 & 57954 & 58275 & 58129 \\
\hline 20 & 100 & 3200 & 40069 & 40135 & 41508 & 43024 & 45967 & 47006 & 47043 & 47115 & 46999 \\
\hline 30 & 100 & 3200 & 40069 & 40135 & 41503 & 42878 & 43913 & 44970 & 45284 & 45284 & 45254 \\
\hline 40 & 100 & 3200 & 40069 & 40135 & 41503 & 42878 & 43912 & 44947 & 44950 & 44950 & 44983 \\
\hline 50 & 100 & 3200 & 40069 & 40135 & 41503 & 42878 & 43912 & 44947 & 44947 & 44947 & 44947 \\
\hline 60 & 100 & 3200 & 40069 & 40135 & 41503 & 42878 & 43912 & 44947 & 44947 & 44947 & 44947 \\
\hline
\end{tabular}


However, the National Council on Radiation Protection has recently stated:

"The linear dose-effect hypothesis has been coming into frequent use in analyses in which population exposures are expressed in the form of person-rem, including doses of $1 \mathrm{mrem} / \mathrm{yr}$ or less to population groups and doses to individual organs, with linear extrapolation to damage estimates through the use of the NAS-BEIR committee report values. The indications of a significant dose rate influence on radiation effects would make completely inappropriate the current practice of summing of doses at all levels of dose and dose rate in the form of total person-rem for purposes of calculating risks to the population on the basis of extrapolation of risk estimates derived from data at high doses and dose rates.

The NCRP wishes to caution governmental policy-making agencies of the unreasonableness of interpreting or assuming "upper 1 imit" estimates of carcinogenic risks at a low radiation level, derived from linear extrapolation from data obtained at high doses and dose rates as actual risks, and of basing unduly restrictive policies on such an interpretation or assumption. The NCRP has always endeavored to ensure public awareness of the hazards of ionizing radiation but it has equaliy determined to insure that such hazards are not greatly overestimated. Undue concern, as well as carelessness with regard to radiation hazards, is considered detrimental to the public interest."(T)

As indicated by these two opinions, there is a large uncertainty in assigning health effects to person-rem dose levels which are consummed over wide ranges of dose rates. We, therefore, have considered it beyond the scope of this analysis to make any conclusions as to health effects attributable to the population doses estimated.

These results do give the population dose levels necessary to estimate health effects and indicate a very substantial potential benefit of saving approximately one million man-years of 1 ife between 1985-2000 if artificial heart devices could be implemented in this time period. 


\section{REFERENCES}

1. Review of the Current State of Radiation Protection Philosophy, NCRP Report No. 43, National Council on Radiation Protection and Measurements, January 1976.

2. "The Effects on Populations of Exposure to Low Levels of Ionizing Radiation, Report of the Advisory Committee on the Biological Effects of Ionizing Radiations," National Research Council, Washington, D.C., November 1972.

3. "Cardiac Replacement, A Report by the Ad Hoc Task Force on Cardiac Replacement," National Heart Institute, October 1969.

4. "The Totally Implantable Artificial Heart, A Report of the Artificial Heart Assessment Panel," National Heart and Lung Institute, June 1973.

5. "Final Summary Report on Six Studies Basic to Consideration of the Artificial Heart Program," Hittman Associates, Inc., HIT-235, October 24, 1966.

6. "Vital Statistics of the United States,"

a. 1938-1944, Part I - Place of Occurrence, National Office of Vital Statistics, Bureau of the Census, U.S. Department of Commerce.

b. 1945-1949, Part I - Place of Occurrence, National Office of Vital Statistics, Public Health Service, Federal Security Agency.

c. 1950-1959, Vol. I, National Office of Vital Statistics, Public Health Service, U.S. Department of Health, Education and Welfare.

d. 1960-1969, Vol. II - Mortality, Part A, National Center for Health Statistics, Public Health Service, U.S. Department of Health, Education and Welfare.

7. "Heart Disease Among Males in the 1960's," Statistical Bulletin, Vol. 52, pp. 4-7, March 1971.

8. "Vital Statistics of the United States, 1969," Vol. II - Mortality, Part A, National Center for Health Statistics, Public Health Service, U.S. Department of Health, Education and Welfare, pp. 1-172 to 1-179.

9. "Mortality Trends for Leading Causes of Death: United States 1950-1969," Vital and Health Statistics, Series 20, No. 16, Public Health Service, Rockville, MD, pp. 7-10, 60-63, March 1974.

10. "Fatal Heart Attacks Among White Men Reported on Decline," Tri-City Herald, Pasco-Kennewick-Richland, WA, p. 11, January 23, 1975. 
11. Historical Statistics of the United States, Colonial Times to 1957, U.S. Bureau of the Census, Washington, DC, p. 26, 1960.

12. "Monthly Vital Statistics Report, Annual Sunmary for the United States, 1973," National Center for Health Statistics, Public Health Service, Rockvi11e, MD, p. 21, June 27, 1974.

13. "Comparability Ratios Based on Mortality Statistics for the Fifth and Sixth Revisions: United States, 1950," Vital Statistics - Special Reports, Vol. 51, No. 3, Public Health Service, Rockville, MD p. 186, 217, February 1964.

14. 1965 - "Vital Statistics of the United States, 1965," Vol. II Mortality, Part A, Public Health Service, U.S. Department of Health, Education and Welfare, pp. 6-16.

1966 - "Vital Statistics of the United States, 1966," Vol. II Mortality, Part A, Public Hea1th Service, U.S. Department of Health, Education and Welfare, pp. 6-15.

15. "Population Estimates and Projections, Estimates of the Population of the United States by Age, Race, and Sex: July 1, 1967 to July 1, 1969," Current Population Reports, Series P-25, No. 441, U.S. Bureau of the Census, Washington, DC, pp. 18-22, 1970.

16. "Population Estimates and Projections, Estimates of the Population of the United States by Age, Race and Sex: Apri1 1, 1970 to July 1, 1973," Current Population Reports, Series P-25, No. 511, U.S. Bureau of the Census, Washington, DC, pp. 7-10, 1974.

17. "Population Estimates and Projections, Projections of the Population of the United States by Age and Sex: 1970 to 2020," Current Population Reports, Series P-25, No. 470, U.S. Bureau of the Census, Washington, DC, pp. 40-48, 1971 .

18. "Population Estimates and Projections, Projections of the Population of the United States by Age and Sex: 1972 to 2020," Current Population Reports, Series P-25, No. 493, U.S. Bureau of the Census, Washington, DC, pp. 18-19, 1972.

19. "Monthly Vital Statistics Report, Annual Summary for the United States, 1975," National Center for Health Statistics, Public Heal th Service, Rockville, MD, p. 26, June 30, 1976.

20. C. L. Chiang, Introduction to Stochastic Processes in Biostatistics, John Wiley \& Sons, Inc., New York, NY, pp. 256-258, 1968.

21. "Vital Statistics of the United States, 1972, Life Tables: 1972," Vol. II, Section 5, Public Health Service, Rockville, MD, pp. 5-6 to $5-7,1974$. 
22. "1970 Census of Population: Subject Reports, Final Report PC(2)-7A Occupational Characteristics," U.S. Bureau of the Census, Washington, DC, pp. 609-636, 1973.

23. A. Szalai, "The Multinational Comparative Term Research Project: A Venture in International Research Cooperation," The American Behavioral Scientist, Vol. 10, No. 4, pp. 1-31 and Appendix, December 1966.

24. R. E. Malenfant, "QAD: A Series of Point Kernal General Purpose Shielding Programs," LA-3573, Los Alamos Scientific Laboratory, March 1967.

25. J. E. Cline, et al., Gamma Rays Emitted by the Fissionable Nuclides and Associated Isotopes, ANCR-1609, Aerojet Nuclear Company, Idaho Fal1s, ID, JuTy 1972 .

26. R. Gunnik and R. J. Marrow, "Gamma-Ray Energies and Absolute Branching Intensities for $238,239,240,241 \mathrm{Pu}$, and $241 \mathrm{Am}$, "UCRL-41087, Cal ifornia University, Lawrence Livermore Radiation Laboratory, July 22, 1971.

27. D. N. Vandy, "Development of a General Method of Explicity Solution to the Nuclide Chain Equations for Digital Machine Calculations," ORNL-TM361 , Oak Ridge National Laboratory, 1962.

28. H. H. Van Tuyl, Calculations of Gamma Dose Rates at the Surface of Plutonium 0xide Sources, BNWL-1259, Battelle-Northwest, Richland, WA, January 1970.

29. F. Rockwe11, III, Reactor Shielding Design Manual, D. Van Nostram and Company, Inc., Princeton, NJ, 1956.

30. L. J. Mullins, Preparations and Development of Medical Grade Plutonium238 Fuels, July 1, 1967 - June 30, 1971, LA-4940, Los ATamos Scientific Laboratory, October 1972.

31. 10 CFR 20, Tit7e 10, Code of Federal Regulations, Part 20.4.

32. F. T. Cross, "Recipient Radiation Exposure: Circulatory Support Systems," Pacific Northwest Laboratory Annual Report for 1974 to the USAEC Division of Biomedical and Environmental Research, Part 4, Physical and Analytical Sciences, BNWL-1950, Pt. 4, Battelle-Northwest, Richland, WA, pp. 101-102, February 1975.

33. "1970 Census of Population: Supplementary Report PC(S1)-26, Population of P1aces of 2,500 or More: 1970 and 1960," Bureau of the Census, Washington, DC, 1972. 
APPENDIX A

ARTIFICIAL HEART ELIGIBILITY (MODIFIED ESTIMATE) 


\section{APPENDIX A}

\section{ARTIFICIAL HEART ELIGIBILITY \\ (MODIFIED ESTIMATE)}

As explained in the main report, three studies $(3,4,5)$ provided most of the basis for our estimate of candidate eligibility. The National Heart Institute (NHI) Task Force report on Cardiac Replacement ${ }^{(3)}$ provided the basic data summarized in Table A.1. The coronary heart disease data were taken from comprehensive studies done in Fromingham, MA and Tecumseh, MI. An overa 11 average of $16.4 \%$ was found to represent the potential candidates among coronary heart disease deaths under age 65 with a 95\% confidence interval between 11.0 and $21.8 \%$. Other bases were used to estimate potential candidates among other heart disease categories with no attempt made to estimate variations with age.

These data became the beginning basis for our estimates with the exception of the data on congenital heart disease. Since most congenital heart disease victims are infants and young children, the formidable problem of allowing for growth would need to be solved before a significant number of candidates would be contributed from this category. Therefore, these fatalities were not included in our candidate estimates.

Although the NHI's estimates of eligible transplant candidates offer a good beginning basis for determining artificial heart eligibility, their data base was not broad enough to make their estimates age- and sex-specific and persons over 65 were not included. Also, conditions in future time periods may differ from those in 1954-1968--the period in which the studies were made--and the study populations are not representative of the United States as a whole. On the other hand, a less clinically detailed study done in Baltimore, Maryland* tends to confirm the previous conclusions, lending more validity to their use. Since the population dose estimates are very sensitive

* L. Kuller, A Lilienfield, and R. Fisher, "Epidemiological Study of Sudden and Unexpected Deaths Due to Arteriosclerotic Heart Disease," Circulation, Vol. 34, p. 1056-1068, 1966. 
TABLE A.1. Potential Candidates for Heart Replacement Among Persons Under Age 65 Dying of Heart Disease in the United States, 1967

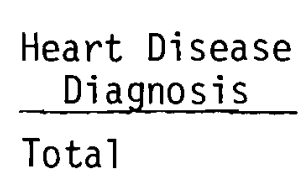

Coronary

Hypertensive

Rheumatic

Congenital

other
Deaths Under

Age 65 United States 1967 206,403 158,701 12,676 8,930 $7,000^{(d)}$ $19,096^{(\mathrm{e})}$
Potential Candidates for Heart Replacement (a)

\begin{tabular}{|c|c|c|c|}
\hline \multicolumn{2}{|c|}{ High Estimate $(\mathrm{b})$} & \multicolumn{2}{|c|}{ Low Estimate $(c)$} \\
\hline Percent & Number & Percent & Number \\
\hline 15.6 & 32,168 & 5.7 & 11,726 \\
\hline 16.4 & 26,027 & 3.8 & 6,031 \\
\hline 5.0 & 634 & 5.0 & 634 \\
\hline 10.0 & 893 & 5.0 & 447 \\
\hline 25.0 & 1,750 & 25.0 & 1,750 \\
\hline 15.0 & 2,864 & 15.0 & 2,864 \\
\hline
\end{tabular}

(a) Assumes rejection problem has been overcome.

(b) Assumes development of completely effective emergency assist devices which would allow extended survival in the terminal disease state.

(c) Assumes ideal mobilization of the best medical procedures now available, but does not assume that emergency assist devices would be available.

(d) Estimated from the total congenital malformations of circulatory system in 1967.

(d) Estimated from categories 421 and 422 (nonrheumatic chronic endocarditi: and other myocardial degeneration), and categories 430-434 (other diseases of the heart).

Source: Cardiac Replacement (see Reference 3, p. 15) 
to the eligibility estimates, we strongly recommend that efforts be directed to obtain more accurate estimates of eligibility, using a detailed study employing a broad data base.

An earlier study (1965) by Hittman Associates, Inc. ${ }^{(5)}$ also attempted to define artificial heart candidate eligibility. This study used data from a medical review of 920 case histories and, therefore, provided a large data base for age and sex determinations. However, the criteria for eligibility in the Hittman study were quite broad resulting in a candidate estimate about three times that of the NHI Task Force. While the total number of potential device recipients estimated in this study appeared too large, the distribution by age seemed reasonable and included ages beyond 65 .

To develop an estimated age profile of candidates, we used the NHI Task Force percentage estimates for high and low candidate eligibility (16.4 and $3.8 \%$, respectively, for coronary heart disease) and distributed these using the age distribution given by the Hittman data. We assumed the middle age interval of 45-54 to be the base interval in making this distribution. These calculations are shown in Table A.2.

We plotted these modified estimates by age, drawing a smooth curve through the points. Figure A.1 shows a representative plot of the high estimate. The candidate estimates in five-year age groups shown in Table 2 in the main report come from the midpoint of the curves at each five-year interval in this graph. As the table indicates, the results for coronary (ischemic) heart disease for the 35 to 64 age interval fall we 11 within the $95 \%$ confidence interval of 11.0 to $21.8 \%$.

Based on 1967 mortality data, we converted the estimates to candidates per 100,000 population in each five-year age group. The three estimates are compared on this basis in Figure A.2 for men and women combined. Our modified estimate is shown as a dashed curve. The modified age profile is the more reasonable appearing of the three. Neither the abrupt termination of the NHI curve while still rising steeply or the sharp fluctuations in the Hittman curve are reasonable expectations. However, the important point is not that the modified NHI basis is the more reasonable basis, but that it is at least just as reasonable as the original NHI Task Force basis. 
TABLE A.2. Calculation of a Modified Estimate of Artificial Heart Device Candidates Using NHI Task Force and Hittman Data(a)

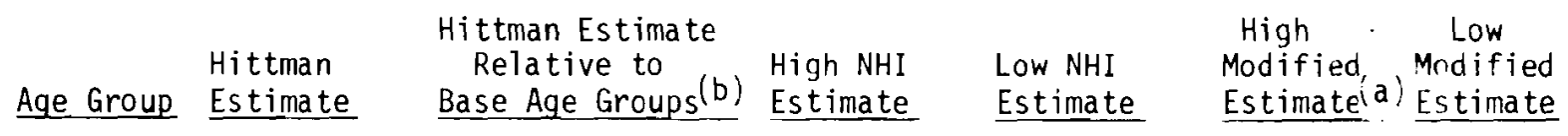

$\begin{array}{ll}-34 & 50 \\ 35-44 & 48 \\ 45-54 & 40 \\ 55-64 & 32 \\ 65-74 & 18 \\ 75-84 & 2.6\end{array}$

CORONARY HEART DISEASE

$\begin{array}{lllll}1.25 & 16.4 & 3.8 & 20.5 & 4.8 \\ 1.20 & 16.4 & 3.8 & 19.6 & 4.6 \\ 1.00 & 16.4 & 3.8 & 16.4 & 3.8 \\ 0.80 & 16.4 & 3.8 & 13.0 & 3.0 \\ 0.45 & 16.4 & 3.8 & 7.3 & 1.7 \\ 0.065 & 16.4 & 3.8 & 1.1 & 0.25\end{array}$

HYPERTENSIVE HEART DISEASE

$\begin{array}{rllllll}-34 & & 1.18 & 5.0 & & 6.0 & \\ 35-44 & 35.5 & 1.18 & 5.0 & \text { Same } & 6.0 & \text { : me } \\ 45-54 & 30 & 1.00 & 5.0 & \text { as } & 5.0 & \text { as } \\ 55-64 & 26.1 & 0.87 & 5.0 & \text { high } & 4.4 & \text { high } \\ 65-74 & 20.3 & 0.67 & 5.0 & \text { estimate } & 3.4 & \text { estimate } \\ 75-84 & 8.3 & 0.28 & 5.0 & & 1.4\end{array}$

$\begin{array}{rrrrrrr}-34 & & 1.18 & 10.0 & 5.0 & 12.0 & 6.0 \\ 35-44 & 35.5 & 1.18 & 10.0 & 5.0 & 12.0 & 6.0 \\ 45-54 & 30.0 & 1.00 & 10.0 & 5.0 & 10.0 & 5.0 \\ 55-64 & 26.1 & 0.87 & 10.0 & 5.0 & 8.7 & 4.4 \\ 65-74 & 20.3 & 0.67 & 10.0 & 5.0 & 6.7 & 3.4 \\ 75-84 & 8.3 & 0.28 & 10.0 & 5.0 & 2.8 & 1.4\end{array}$

OTHER HEART DISEASE

$\begin{array}{rrrrlrl}-34 & & 1.18 & 15.0 & & 17.7 & \\ 35-44 & 35.5 & 1.18 & 15.0 & \text { Same } & 17.7 & \text { Same } \\ 45-54 & 30.0 & 1.00 & 15.0 & \text { as } & 15.0 & \text { as } \\ 55-64 & 26.1 & 0.87 & 15.0 & \text { high } & 13.0 & \text { high } \\ 65-74 & 20.3 & 0.67 & 15.0 & \text { estimate } & 10.0 & \text { estimate } \\ 75-84 & 8.3 & 0.28 & 15.0 & & 4.2 & \end{array}$

(a) Expressed as a percentage of those dying who would be device candidates.

(b) We chose the base age group as 45 to 54 .

Sources: Hittman Estimate (Reference 5, p. II-7); NHI Estimates, (Reference 3, p. 15). 


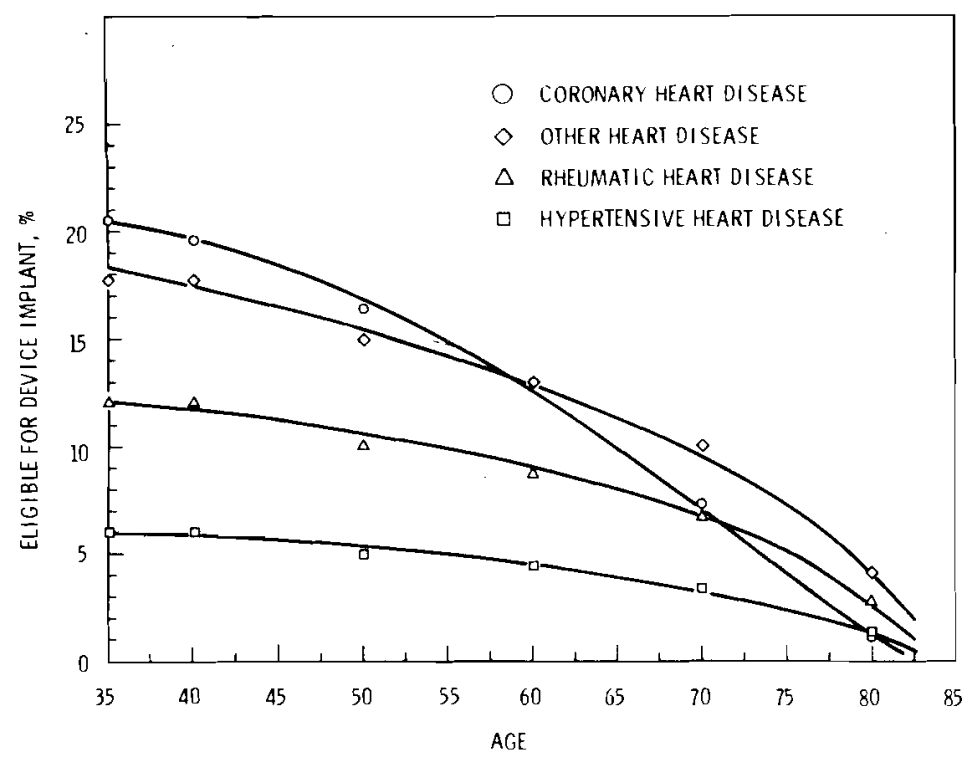

FIGURE A.1. Smoothed Data for Modified Estimate of Eligible Candidates (High Estimate)

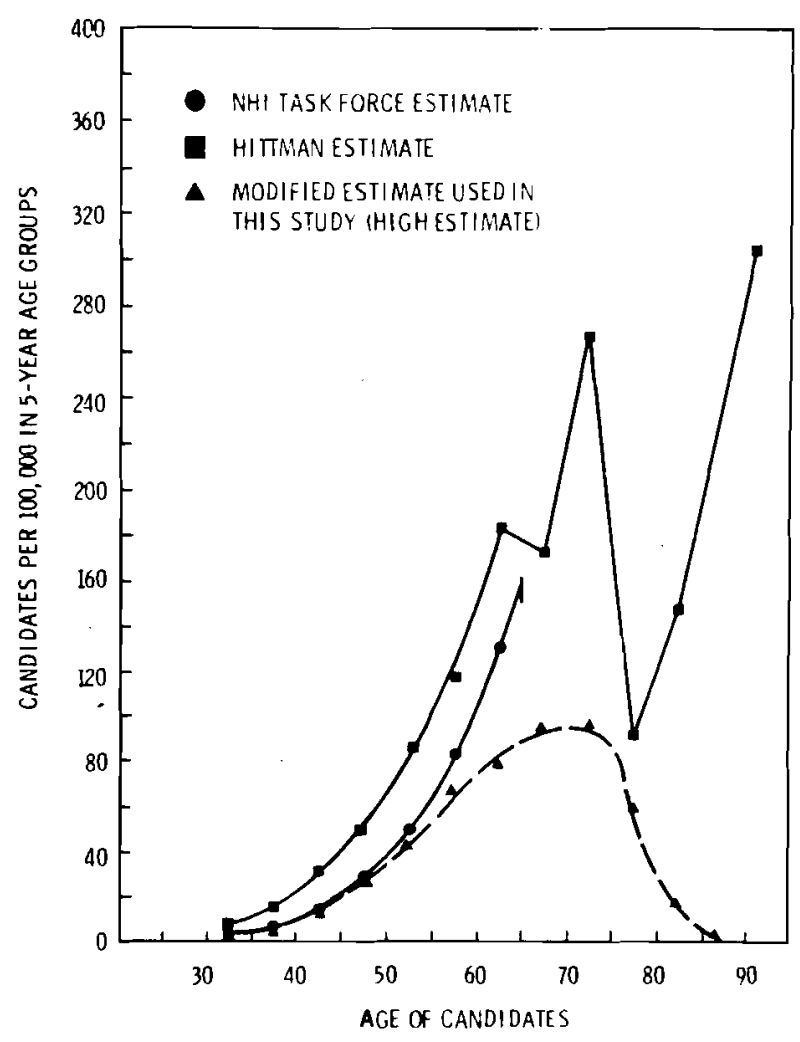

FIGURE A.2. Comparison of Three Age Profiles of Artificial Heart Device Candidate Otherwise Dying from Coronary Heart Disease (Profiles Include Both Sexes) 
Although the number of candidates is increased by the inclusion of persons over 65, the total number of devices in the population is not proportionally increased because of the lower life expectancy in the older age groups. The total accumulation of artificial hearts for our high eligibility estimate is shown in Figure A.3. Results of a parallel calculation using the NHI estimate is also shown for comparison. Even though approximately $33 \%$ more candidates are specified using our modified basis, the total accumulation is only about $25 \%$ higher because of the lower average life expectancy when the over 65 ages are included in the candidate group. The total number of potential candidates predicted in 1969 using our modified estimate was 44,825 for the high case and 12,587 using the low case. This estimate became the basir for predicting eligible candidates in a11 of our subsequent population do: calculations.

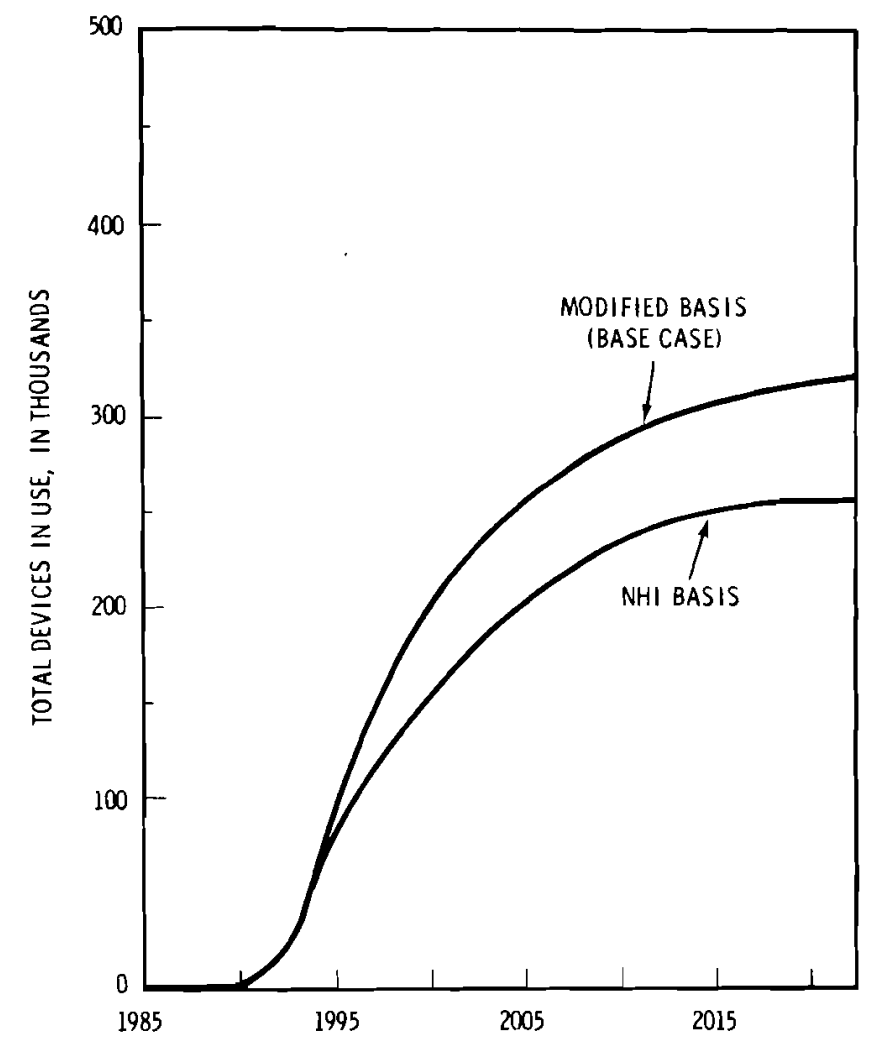

FIGURE A.3. Comparison of Total Devices in Use Using the NHI and Modified Age Distribution 
In their report on the Totally Implantable Artificial Heart, ${ }^{(4)}$ the Artificial Heart Assessment Panel (AHAP) also improved the NHI estimate. An illustration of AHAP candidate fractions is shown in Table A.3. The Assessment Panel used slightly higher fractions of eligible candidates for rheumatic, hypertensive and other heart diseases than did the NHI Task Force, as seen by comparing Tables A.1 and A.3. At the same time they substantially reduced the candidate fraction for congenital heart disease. In addition, the age group 65 to 74 for ischemic heart disease without hypertension was included. This latter change far outweighed the effects of changes in the candidate fractions and increased the estimate of potential candidates in 1969 to a maximum of approximately 50,000.

While our projections did not incorporate changes in candidate fractions (other than to eliminate congenital heart disease), they did include potential candidates up through age 84 . Because of this 1arger candidate base, our projections approximated those of the Assessment Pane1. To illustrate this, a composite sumary of Tables $A .2$ and $A .3$ is shown in Table 3 in the main report. Since our overall candidate percentage estimates are nearly the same as those of the Assessment Panel, we concluded that both estimates substantially agreed.

The next consideration is the differentiation of eligible candidates by sex. Since no data by sex were available from the Hittman report, we statistically tested the limited coronary heart disease data obtained by NHI from the Framingham and the Tecumseh studies to determine if candidate eligibility were a function of sex. Based on the available data, we found no statistically significant difference by sex. Our projections, therefore, did not include sex as a factor in determining eligibility. However, the available data base was very smal1, and analys is of a larger future data base may alter the present conclusion.

As was discussed previously, the eligible candidate fractions are distinguished by four heart disease categories as well as by age. However, our projection of heart disease death rates (discussed in the next Appendix) used only total heart disease data. Therefore, we estimated a set of eligible candidate fractions by age for total heart disease by weighting each diseasespecific fraction by the incidence of that disease in $1969^{(8)}$ and averaging 
TABLE A.3. Potential Candidates for an Artificial Heart Among Persons Dying of Heart Disease, United States, $1967(\mathrm{a})$

\begin{tabular}{|c|c|c|c|c|c|}
\hline \multirow[b]{3}{*}{ Heart Disease Diagnosis } & \multirow{3}{*}{$\begin{array}{l}\text { Deaths } \\
\text { in } 1969 \\
\end{array}$} & \multicolumn{4}{|c|}{ Potential Candidates } \\
\hline & & \multirow{2}{*}{\multicolumn{2}{|c|}{$\begin{array}{l}\text { High Estimate } \\
\text { Percent Number }\end{array}$}} & \multicolumn{2}{|c|}{ Low Estimate } \\
\hline & & & & Percent & Number \\
\hline Total & 363,999 & 13.8 & 50,336 & 4.6 & 16,749 \\
\hline $\begin{array}{l}\text { Ischemic Heart Disease Without } \\
\text { Hypertension, Under Age } 65\end{array}$ & 151,948 & 16.4 & 24,919 & 3.8 & 5,774 \\
\hline $\begin{array}{l}\text { Ischemic Heart Disease Without } \\
\text { Hypertension, Age } 65-74\end{array}$ & 157,494 & 11.2 & 17,639 & 2.6 & 4,075 \\
\hline $\begin{array}{l}\text { Ischemic Heart Disease With } \\
\text { Hypertension, Under Age } 65\end{array}$ & 20,376 & 10.0 & 2,038 & 10.0 & 2,038 \\
\hline $\begin{array}{l}\text { Other Hypertensive Heart } \\
\text { Disease, Under Age } 65\end{array}$ & 3,622 & 10.0 & 362 & 10.0 & 362 \\
\hline $\begin{array}{l}\text { Rheumatic Heart Disease, } \\
\text { Under Age } 65\end{array}$ & 8,978 & 25.0 & 2,245 & 15.0 & 1,347 \\
\hline $\begin{array}{l}\text { Congenital Heart Disease, } \\
\text { Under Age } 65\end{array}$ & 7,884 & 5.0 & 394 & 5.0 & 394 \\
\hline $\begin{array}{l}\text { Other Heart Disease, } \\
\text { Under Age } 65\end{array}$ & 13,697 & 20.0 & 2,739 & 20.0 & 2,739 \\
\hline
\end{tabular}

(a) This table corresponds to Table 7 of the October 1969 Report on Cardiac Replacement with certain modifications. Because this table includes

$\therefore$ patients 65 to 74 years old and because the criteria for artificial heart implantation are somewhat different than those for transplantation, the fraction of patients who are candidates for artificial hearts has been (1) increased from 5 to $10 \%$ for patients dying of hypertensive diseases, (2) increased from 10 to $25 \%$ for patients dying of rheumatic heart disease, and (3) decreased from 25 to $5 \%$ for patients dying of congenitial heart disease.

Source: The Totally Implantable Artificial Heart (Reference 4, p. 43).

these over the four disease types. Figure A.4 shows the value of these fractions (high estimate) for each age group. 


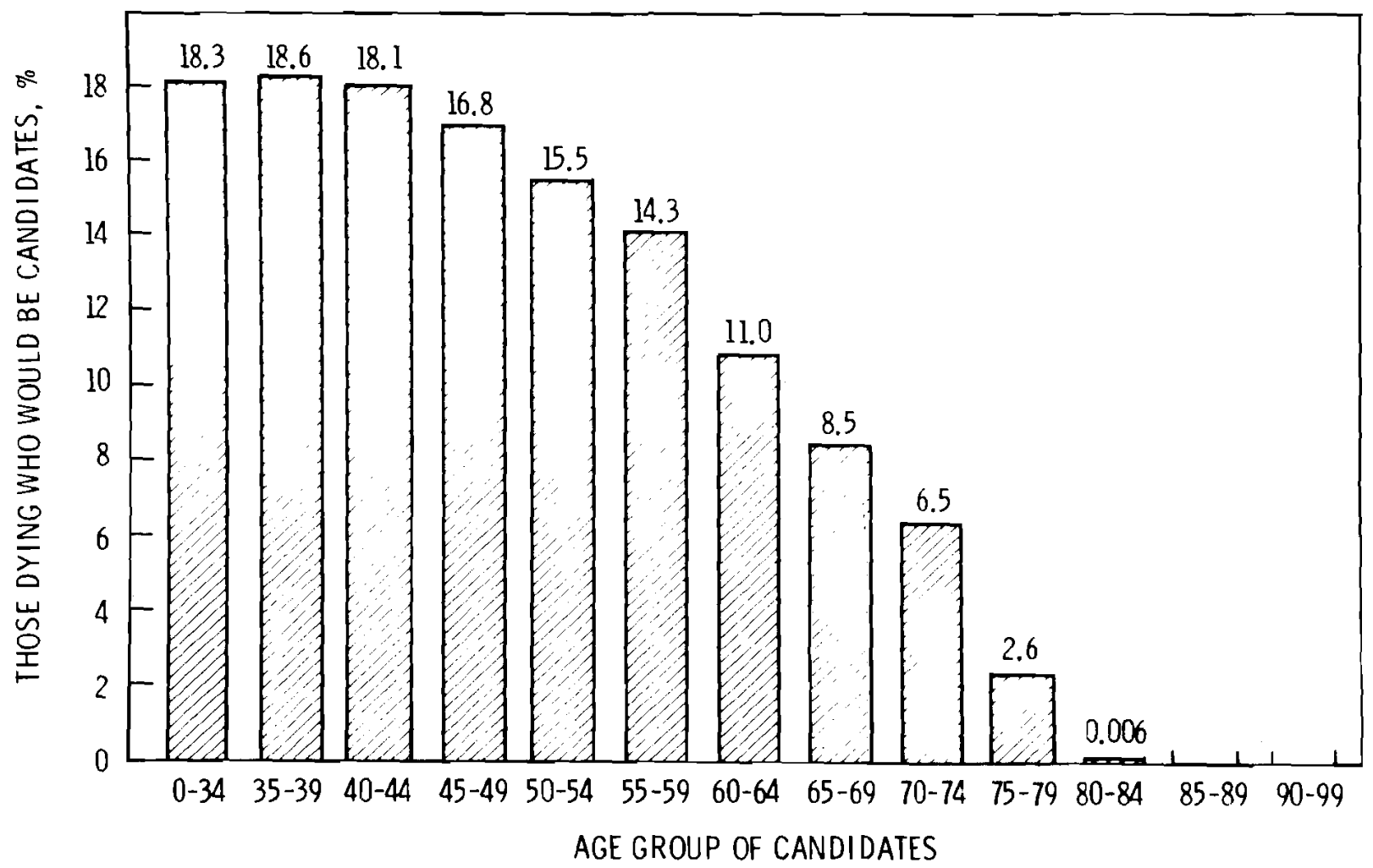

FIGURE A.4. Fraction of Fatal Heart Disease Victims Who Are Candidates (Average Both Sexes and Four Heart Diseases) 
APPENDIX B

HEART DISEASE DEATH RATE PROJECTIONS 


\section{APPENDIX B}

\section{HEART DISEASE DEATH RATE PROJECTIONS}

The first step in developing death rate projections was to develop an equation to project future total heart disease incidence and to verify its predictive ability. We termed this equation the Death Rate Equation (DRE). In developing the equation, we reasoned that the rate of decline of a fatal disease should be a direct function of the medical skill and knowledge accumulated at any point in time. The greater this fund of skill and knowledge, the more likely that additional skill and knowledge will accumulate and the more quickly the disease death rate will decline. A measure of this medical skill and knowledge at any point in time should be directly related to the number of people being "saved" per unit population, in other words, to the amount that the death rate has been reduced from its maximum.

However, the rate of decline should also be some inverse function of time since less concern and effort will be expended with time as the magnitude of the death rate for a particular disease declines and its importance to the public diminishes. There is no reason to expect that the effect of time should be linear and a simple inverse exponential effect was assumed.

Mathematically, the above statements can be expressed as:

$$
\frac{d y}{d t}=-K \frac{(Y \max -Y)}{T^{n}}
$$

where

$$
\begin{aligned}
Y= & \text { Disease death rate at a specific point in time, } \\
Y \max = & \text { Maximum death rate, } \\
\mathrm{T}= & \text { Time measured from } T=0 \text { when } Y=Y \max , \\
\mathrm{K}= & \text { Proportionality constant relating the magnitude } \\
& \text { and rate of decline, } \\
\mathrm{n}= & \text { A constant whose value can modify the importance } \\
& \text { of time in the equation. }
\end{aligned}
$$


If the above differential equation is integrated and solved for $Y$, an expression for the death rate at any specific point in time is derived.

$$
Y=Y \max -(A) \exp \left(\frac{-K T(1-n)}{n-1}\right)
$$

where

$$
A=\text { Integration constant. }
$$

This equation is, in effect, a kind of learning curve equation. It defines the path of declining incidence of deaths once the point is reached when sufficient basic knowledge has accumulated to bring a disease under control to the extent that death rates peak and begin to decline. It should be emphasized that the equation has no validity for diseases whose death rates are increasing. An estimate of the maximum death rate, Ymax, is necessary to use the equation. The predictive ability of Equation [2], hereafter referred to as the Death Rate Equation, was tested and found satisfactory as explained in the section under Minimum Incidence Projection on page B-17.

We originally used crude total heart disease death rates as the raw data input to the DRE for our heart disease incidence projections. Using crude death rates assumed that age shifts in the population would be small enough to have no discernible effect. This data on crude total heartdisease death rates showed a peaking of these death rates in the middle 1960 's. *(6) However, subsequent data from the National Center for Health Statistics (NCHS) indicated that age-adjusted death rates for total heart disease had been declining relatively steadily with no apparent peak $(12)$ (see Figure 5 in the main report).

This discrepancy between the declining, age-adjusted heart disease death rate and the crude heart disease death rate was the result of a substantial increase in the relative populations in the older age groups. The peaking observed in the crude death rate was, therefore, a population effect -- not a decline in the risk of death. Since the basis for predicting the death-rate decline requires identification of a peak in the actual risk

* See note on Page 4-7 for explanation of the measures of death rates discussed in this report. 
of death (as indicated in the derivation of the Death Rate Equation), we modified our original analysis.

In order to perform a more detailed analysis on the behavior of total heart disease death rates, we collected additional age- and sex-specific death rate data on total heart disease and its major components -- ischemic heart disease, hypertensive heart disease, rheumatic heart disease, endoand myocardial heart diseases and other heart diseases. ${ }^{(6)}$ These data allowed calculation of age-adjusted death rates using 10-year age groups for total heart disease and all component heart diseases from 1950 to 1969. Since the classification definitions for causes of death had changed twice during this time period, it was necessary to adjust death rates to a consistent basis.

NCHS develops comparability ratios for such adjustments. These are comparisons of the relative number of deaths assigned to each disease category in the year previous and the year subsequent to revisions in classifications. We obtained comparability ratios $(12,14)$ from the NCHS, for the 7 th-8th ICDA* revision in 1968, the 6th-7th revision in 1958, and the 5th-6th revision in 1948, and used them to adjust all death rates to a presumed equivalent 8 th ICDA revision basis. (Subsequent analysis, however, showed discrepancies in total heart disease death rates using these ratios.) This 8th-revision series of calculated age-adjusted death rates for total heart disease forms the basis for Figure 8 in the main report. The same plot including the component heart diseases is shown in Figure B.1.

From this latter plot it was obvious that while the total age-adjusted death rate (uppermost line) had been continuously declining as reported, the age-adjusted death rate for ischemic heart disease had been increasing to a peak in the 1960's. This was noteworthy since ischemic (arteriosclerotic**)

\footnotetext{
* International Classification of Diseases, Adapted. ** The 8th Revision ICDA uses the term ischemic heart diseases to identify the major heart disease classification. This classification includes most of the deaths that had previously been classified as arteriosclerotic heart disease plus some from other classifications.
} 


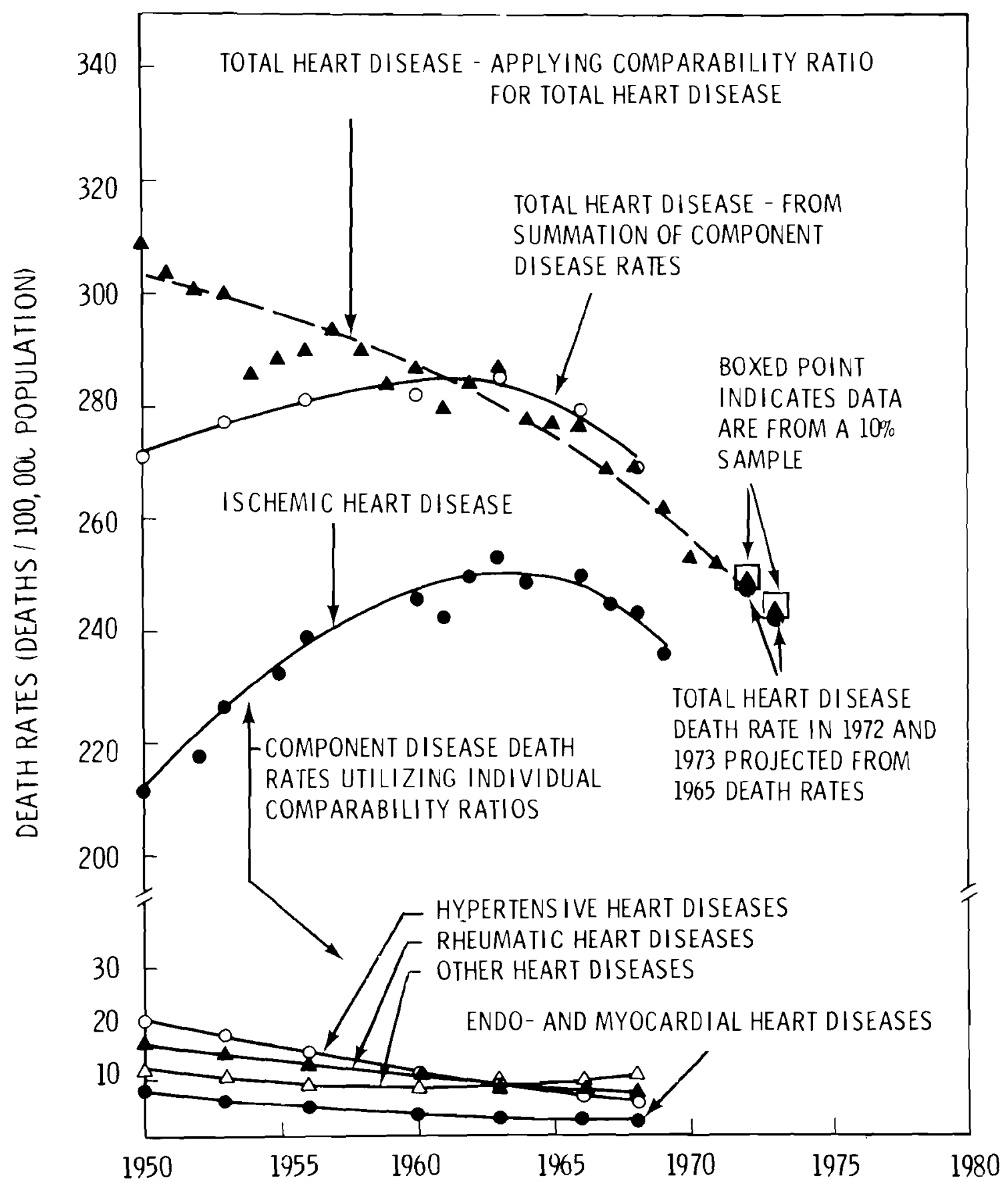

FIGURE B.1. Age-Adjusted Death Rates for Total Heart Disease and Major Component Heart Diseases Adjusted to the 8th ICDA Revision Sources: Vital Statistics of the United States (Reference 6); Mortality Trends for Leading Causes of Death (Reference 9), pp. 60-61; Monthly Vital Statistics Reports (Reference 12); Compatibility Ratios Based on Mortality Statistics for the 5 th and 6th Revisions, United States, 1950 (Reference 13), p. 217. 
heart disease presently accounts for about $90 \%$ of total heart disease deaths. However, we assumed that substantial declines in the death rates for the other heart diseases may have had enough weight to cause the decline in the totals.

To check this assumption, we summed all of the component age-adjusted death rates at two to three year intervals to obtain the total age-adjusted death rate. As is obvious from the figure, the total age-adjusted heartdisease death rate obtained by summing 8 th-revision-adjusted individual component rates was considerably lower than when using the overal1 8 th revision comparability factor applied to total heart-disease death rates. Even more significant, the total heart-disease death rate obtained by summation of 8 th-revision-adjusted component rates indicated an increasing and peaking of the death rate compared to the continuously declining trend in the total heart-disease death rates obtained by using the overall comparability factor. While the cause of such a discrepancy is not completely understood, we believe it to result from inconsistencies in the diagnosis and coding of causes of death over time.

Two assumptions are implied when comparability ratios are used to adjust death statistics from previous years to a new classification basis. First, it is assumed that the cause-of-death diagnoses have been consistently made and consistently and accurately stated on the death certificates over the time period. Second, it is assumed that the interpretation and coding of causes of death on death certificates to ICDA classifications have also been consistent and accurate over the time period. However, it is more likely that there have been inconsistencies and errors in both cases. It is also probable that the inconsistencies and errors have declined during the time period.

Since doctors not only have varying opinions, but have also been trained at various points in time and, therefore, have varying degrees of knowledge of the latest technology and definitions; there are almost certainly some discrepancies between the measured (recorded) number of heart disease deaths and the actual number of such deaths. This discrepancy should, however, be declining with time. Likewise, there have probably 
been improvements due to learning effects in interpreting and coding death certificate data. The probable net result is that differences between statistical and actual death rates for specific classifications have been declining.

Figure B. 2 demonstrates how a declining difference between measured and actual death rates could result in misleading statistical death rate trends. Two cases are shown:

Case 1. Measured rates are higher than actual rates. In this case a declining difference would result in a decline in statistical death rates while the actual rates could be either increasing or decreasing.

Case 2. Measured rates are lower than actual rates. In this case a declining difference would result in an increase in statistical death rates while the actual rates could be either increasing or decreasing.

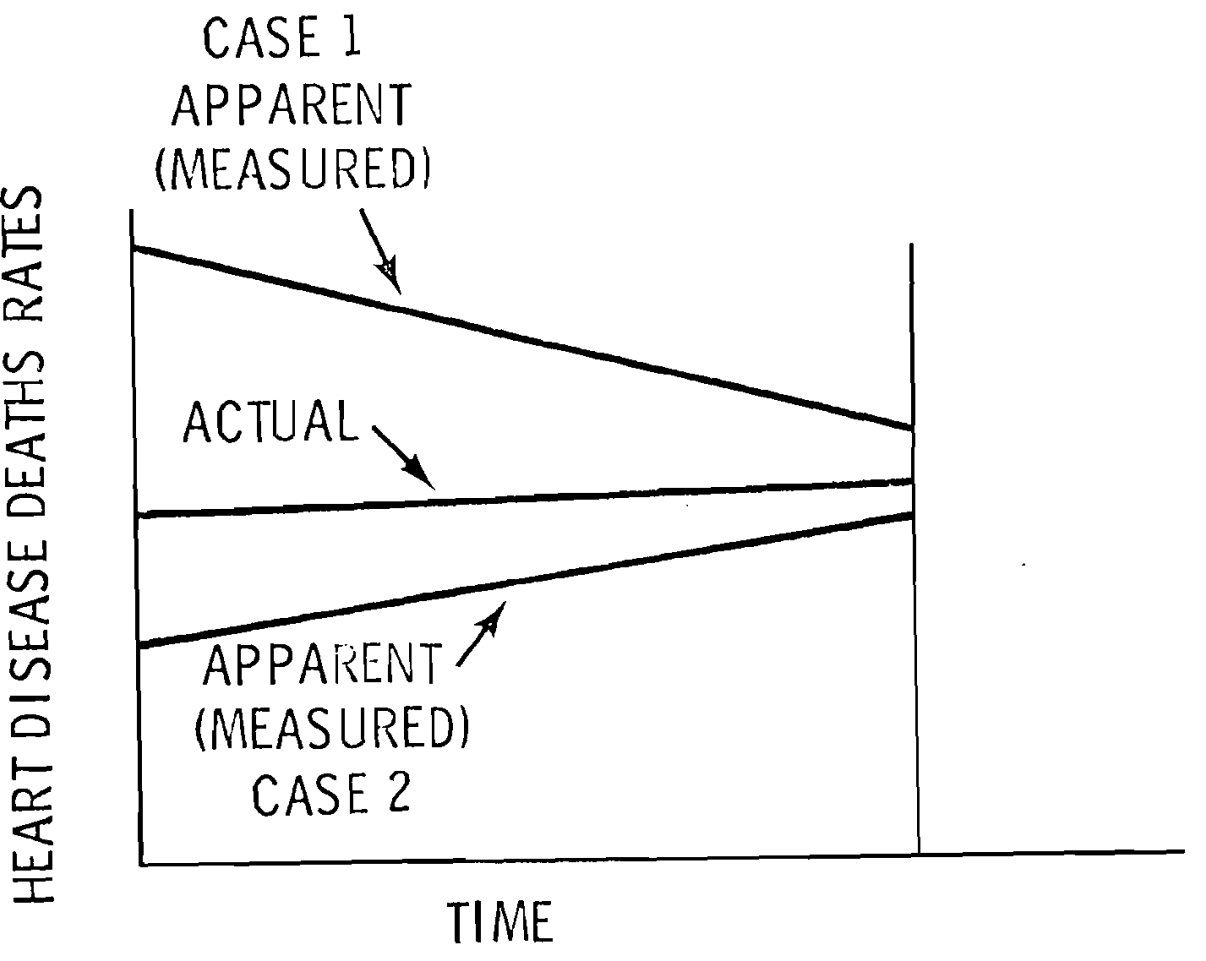

FIGURE B.2. Effect of Declining Measurement Error on Apparent Trend in Heart Disease Death Rates 
In this situation one cannot say with certainty which of the total heart disease death rates in Figure B. 1 is the most accurate. Due to an inability to resolve the discrepancy, we are not able to fully correlate current total heart disease death rates with ones in the 1950's.

The summations of the component age-adjusted heart disease death rates in Figure B.1 do, however, agree with the total in years subsequent to 1960. (The measurement error is either small or constant.) This recent data substantiates a strong decline in death rates for total heart disease, regardless of whether it was previously increasing or decreasing.

Figure B.3 is a plot of the age-adjusted death rates for total and component heart diseases without adjustments to the 8th Revision ICDA basis. $(6,12)$ (This is the same as Figure 5 in the main body of the report.) There is a well-defined maximum or peak in the arteriosclerotic (ischemic) heart disease death rate that parallels the maximum in ischemic heart disease in Figure B.1, where we used comparability ratios to convert the data to the 8th Revision ICDA basis. While we could not be absolutely certain of a peaking in the ischemic classification due to the possibility of measurement errors within this disease definition, the much narrower definition range should substantially reduce such errors. For this reason we accepted the peaking and decline of ischemic death rates as a real occurrence.

Since the method developed for projecting trends in disease death rates depends on identifying the peak death rate year, and since ischemic heart disease presently accounts for about $90 \%$ of total heart disease deaths, we decided to utilize the data on this disease as the basis for projecting trends for total heart disease. ISCHEMIC HEART DISEASE DEATH RATE PROJECTIONS

Although the NCHS has published ${ }^{(12)}$ only age-adjusted statistics, the obvious sex-dependency of heart disease and noticeable differences in the age-adjusted and age- and sex-adjusted death rates (Figure B.4) suggest adjusting for sex as well as age in the projections. A plot of age- and 


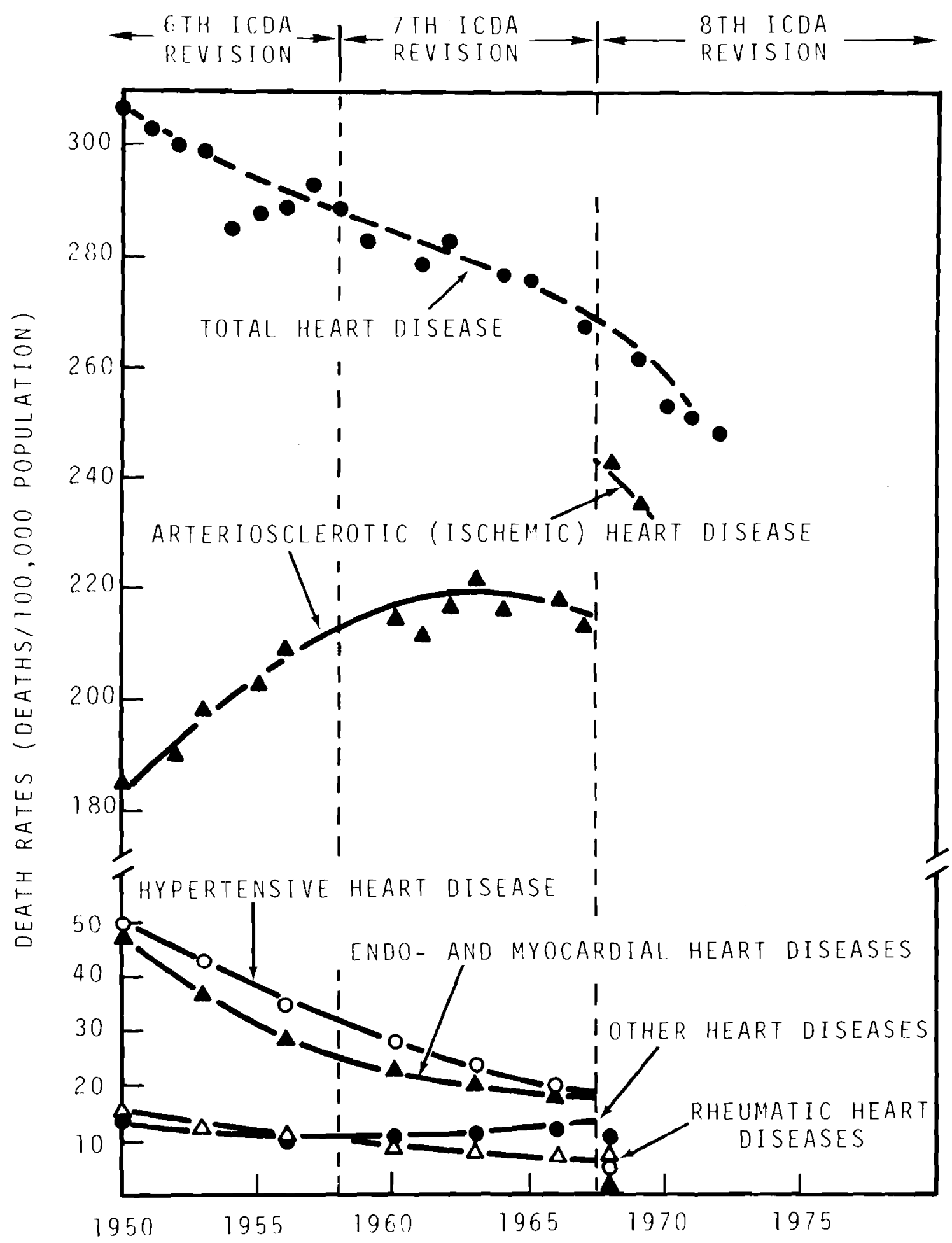

FIGURE B.3. Age-Adjusted Death Rates for Total Heart Disease and Component Diseases not Adjusted for ICDA Revisions

Source: "Mortality Trends for Leading Causes of Death" (Reference 9, p. 8); Vital Statistics of the United States

(Reference 6) 
sex-adjusted arteriosclerotic (ischemic) heart disease death rates for al1 years in the period 1940-1969, adjusted to 8th Revision ICDA definitions using comparability ratios, ${ }^{14)}$ is shown in Figure B.4. The figure shows a marked rise in the age- and sex-adjusted death rates from 1939 to a fairly well-defined peak in 1965. Plots of age-only-adjusted ${ }^{(12)}$ and crude ischemic heart disease death rates ${ }^{(6)}$ over this same period are also shown in the same figure. The divergence in the crude and age-adjusted rates shows that a shift in the population distribution is responsible for much of the increase in death rate for this disease over the past 20 years. A further analysis by age groups reveals that most of the increased deaths are in the 55 and older age groups, predominantly between ages 65 and 84 . This population shift has masked a peaking and decline in the risk of death due to arteriosclerotic (ischemic) heart disease beginning in 1965. This peak in age- and sexadjusted death rates for ischemic heart disease (IHD) was generally confirmed by the age-only-adjusted data from NCHS, (12) showing a peak in 1963 (the lowest curve in Figure B.4).

To develop future heart disease evidence projections, we plotted the ageand sex-specific death rates of IHD by 10-year age groups for 1950-1969, (6) and extrapolated to 1973 by extending the smoothed curves. The extrapolated death rates enabled calculation of an extrapolated 1973 age- and sex-adjusted IHD death rate and, combined with population data, (17) a 1973 crude IHD death rate. The calculated crude death rate compared closely with the published ${ }^{(13)}$ crude death rate in 1973. (Only the total crude death rate for IHD is presently available.) The fact that the projected crude IHD death rate (calculated from the extrapolated age- and sex-specific IHD death rate) agreed with the actual IHD crude death rate indicated that the extrapolations were valid.

The extrapolated age- and sex-adjusted death rate for 1973 combined with statistical age- and sex-adjusted IHD death rates from 1965 to 1969 (6) (age- and sex-specific IHD death rate data subsequent to 1969 is unavailable) became input into a curve fitting computer routine. The curve fitting routine uses death rate data to find the optimum values of the three constants $A, K$, and $n$ in the Death Rate Equation (DRE). Use of these three parameters 


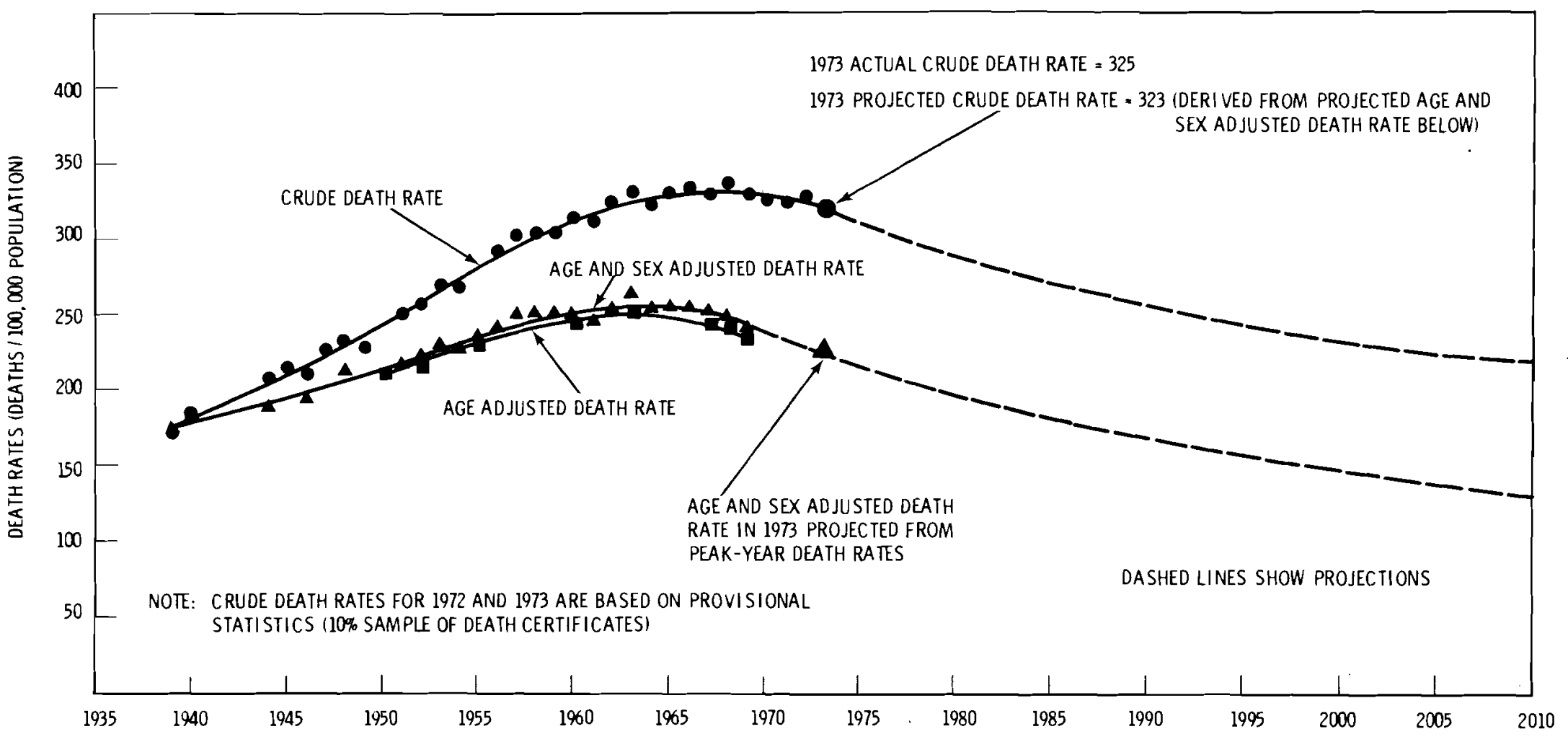

FIGURE B.4. Actual and Projected Ischemic (Arteriosclerotic) Heart Disease Death Rates. (8th ICDA Definition)

Source: Vital Statistics of the United States (Reference 6) 
in the DRE makes it disease-specific for the disease data used to define the parameters. A least squares analys is of the equation derived for IHD with a peak in 1965 showed a close fit of the equation to the data points.

Once the optimum DRE for the total age- and sex-specific IHD death rate was derived, we applied it to each of the previously plotted IHD age- and sex-specific death rates beginning at the peak year. Since the peaks of the various age- and sex-specific rates occurred at different years, the starting points for the age- and sex-specific IHD death-rate projections varied from 1960 to 1969 . Figures B.5a-B.5d illustrate the behavior of these age- and sex-specific death rates since $1950^{(6)}$ and show that the calculated projections coincide with the overall trend of the data. (The calculated projections also coincided closely with the preliminary extrapolations.) Using these projections, we calculated both ageand sex-adjusted and crude death rates for total IHD for 1973. The 1973 crude death rate projection of 323 deaths per 100,000 population for IHD agreed very closely with the actual IHD crude death rate of 325 (Figure B.4). This substantiated the validity of the IHD projection at least for the near term. The IHD projection can be made either by applying the DRE to the total IHD data or by applying it to each age and sex group and summing these up to obtain the total. Both methods yield almost exactly the same result. (The difference in the calculations is due to the peaks in age-specific death rates occurring in varying years as opposed to a single year--1965--for the total death rate.)

\section{TOTAL HEART DISEASE DEATH RATE PROJECTIONS}

\section{Best Estimate Projection}

We assumed that declines in death rates for ischemic heart disease and total heart disease would be predicted by the same Death Rate Equation (DRE) parameters. The death rates in 1965 became the maximum or starting point for the projections. We adjusted age- and sex-specific total heart disease death rates from 1960 to $1969^{(6)}$ to the 8 th-Revision ICDA basis for five-year age groups beginning with age 30 . These are plotted in Figures B.6a-B.6c. Smooth curves were drawn through the points and the 


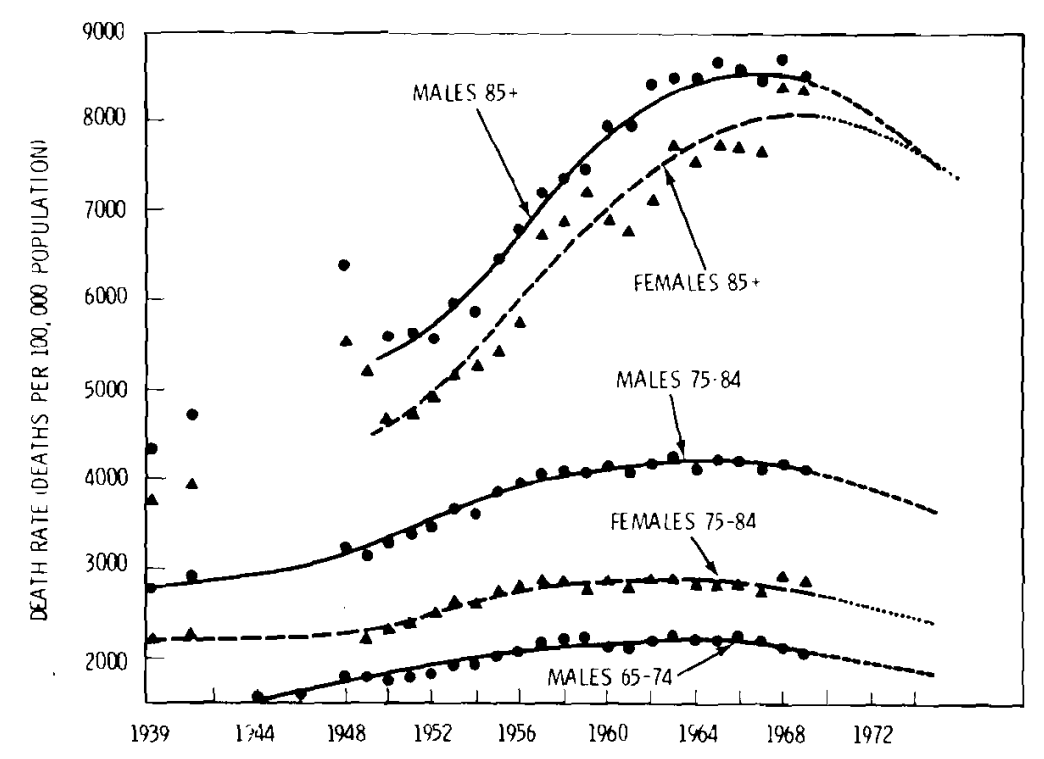

FIGURE B.5a. Age- and Sex-Specific Death Rates for Ischemic Heart Disease (Adjusted to the 8th ICDA Revision) Source: Vital Statistics of the United States (Reference 6)

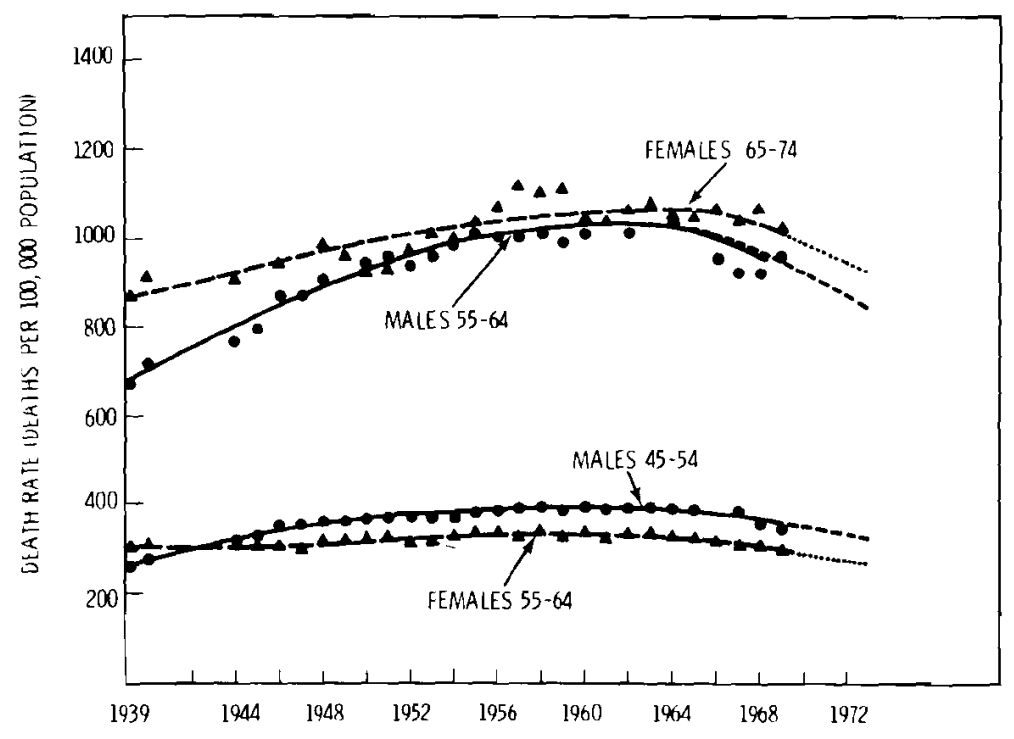

FIGURE B.5b. Age- and Sex-Specific Death Rates for Ischemic Heart Disease (Adjusted to the 8th ICDA Revision) Source: Vital Statistics of the United States (Reference 6) 


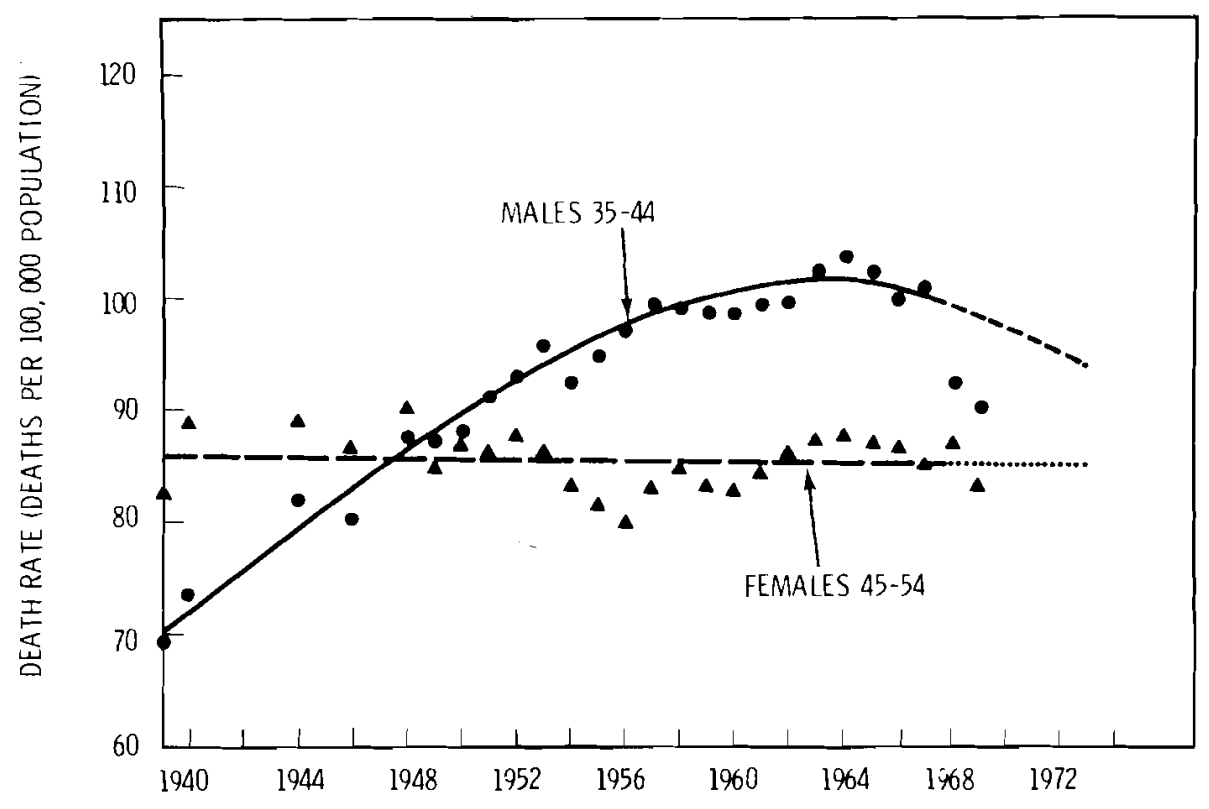

FIGURE B.5c. Age- and Sex-Specific Death Rates for Ischemic Heart Disease (Adjusted to the 8th Revision) Source: Vital Statistics of the United States (Reference 6)

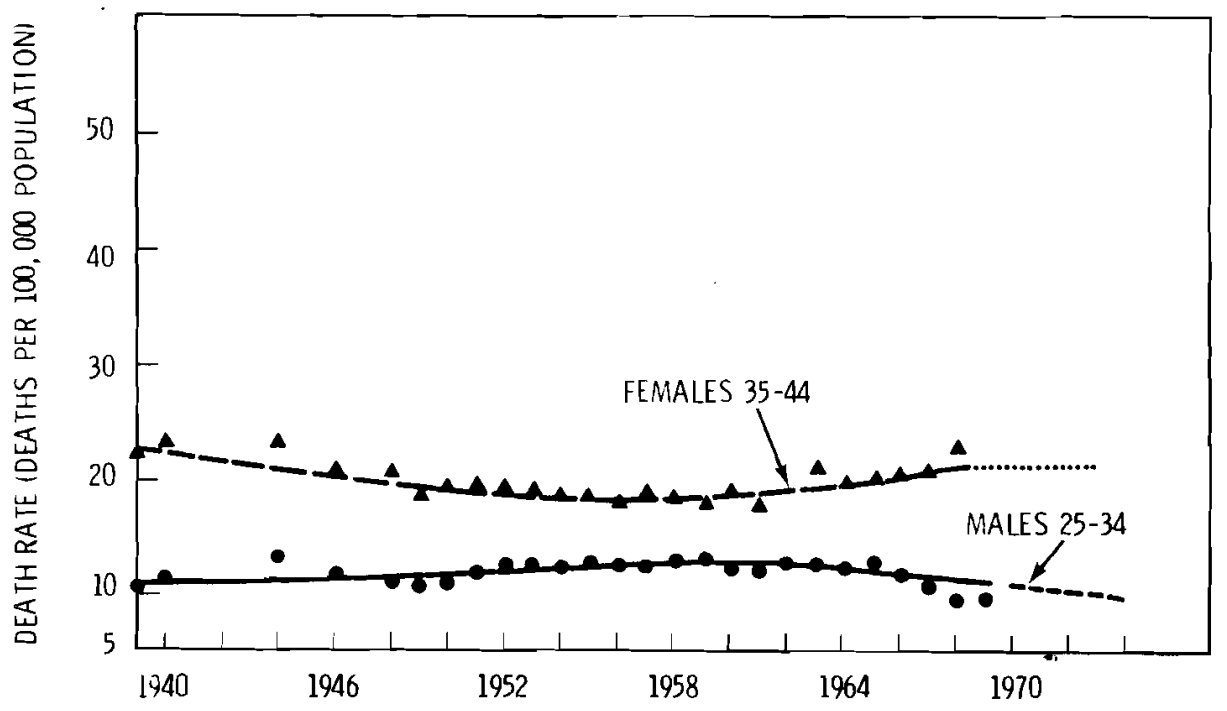

FIGURE B.5d. Age- and Sex-Specific Death Rates for Ischemic Heart Disease (Adjusted to the 8th ICDA Revision) Source: Vital Statistics of the United States (Reference 6) 

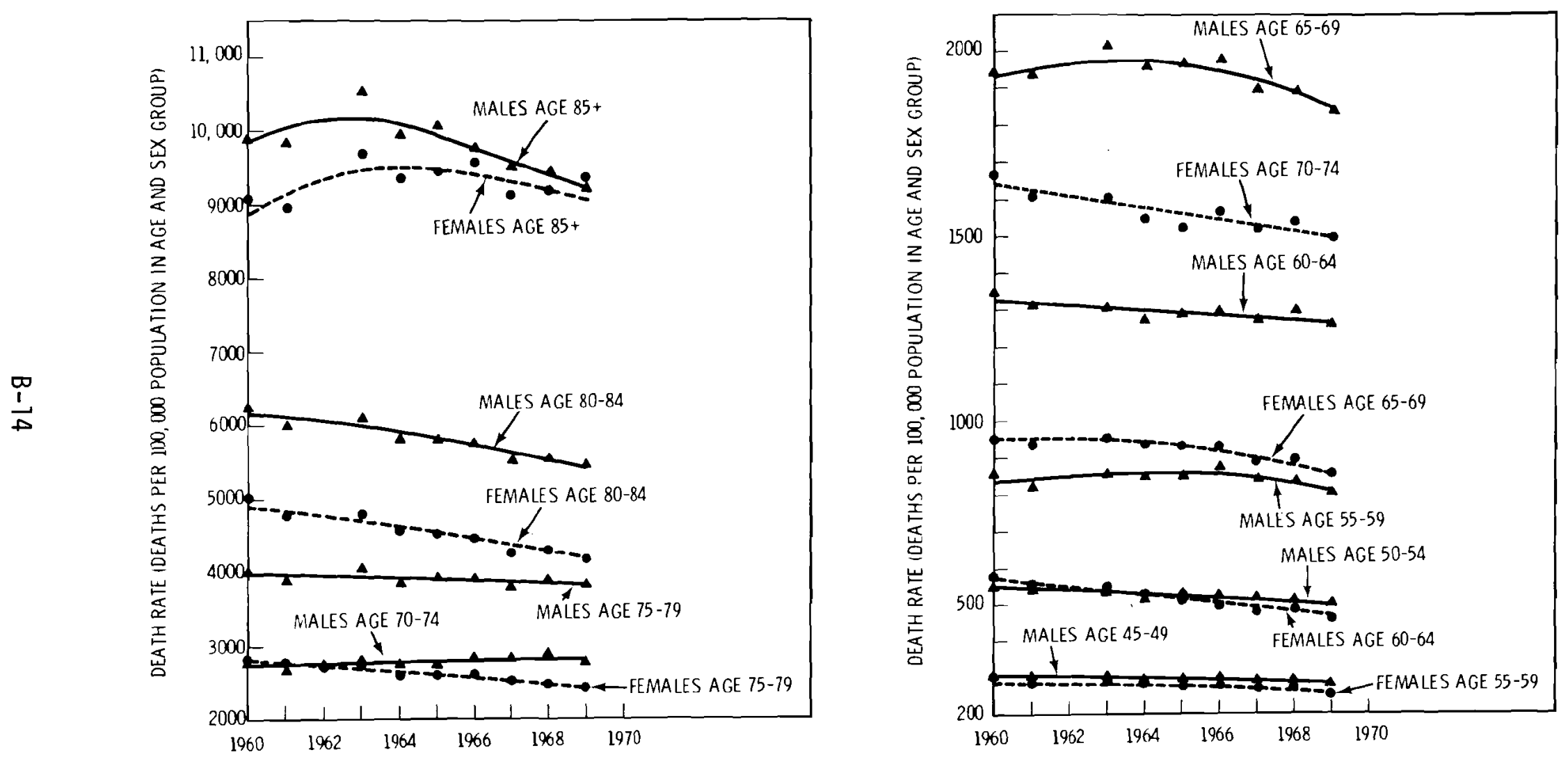

FIGURE B.6a. Age- and Sex-Specific Death Rates for Total Heart Disease (Adjusted to the 8th ICDA Revision) Source: Vital Statistics of the United States (Reference 6)

FIGURE B.6b. Age- and Sex-Specific Death Rates for Total Heart Disease (Adjusted to the 8th ICDA Revision) Source: Vital Statistics of the United States (Reference 6) 


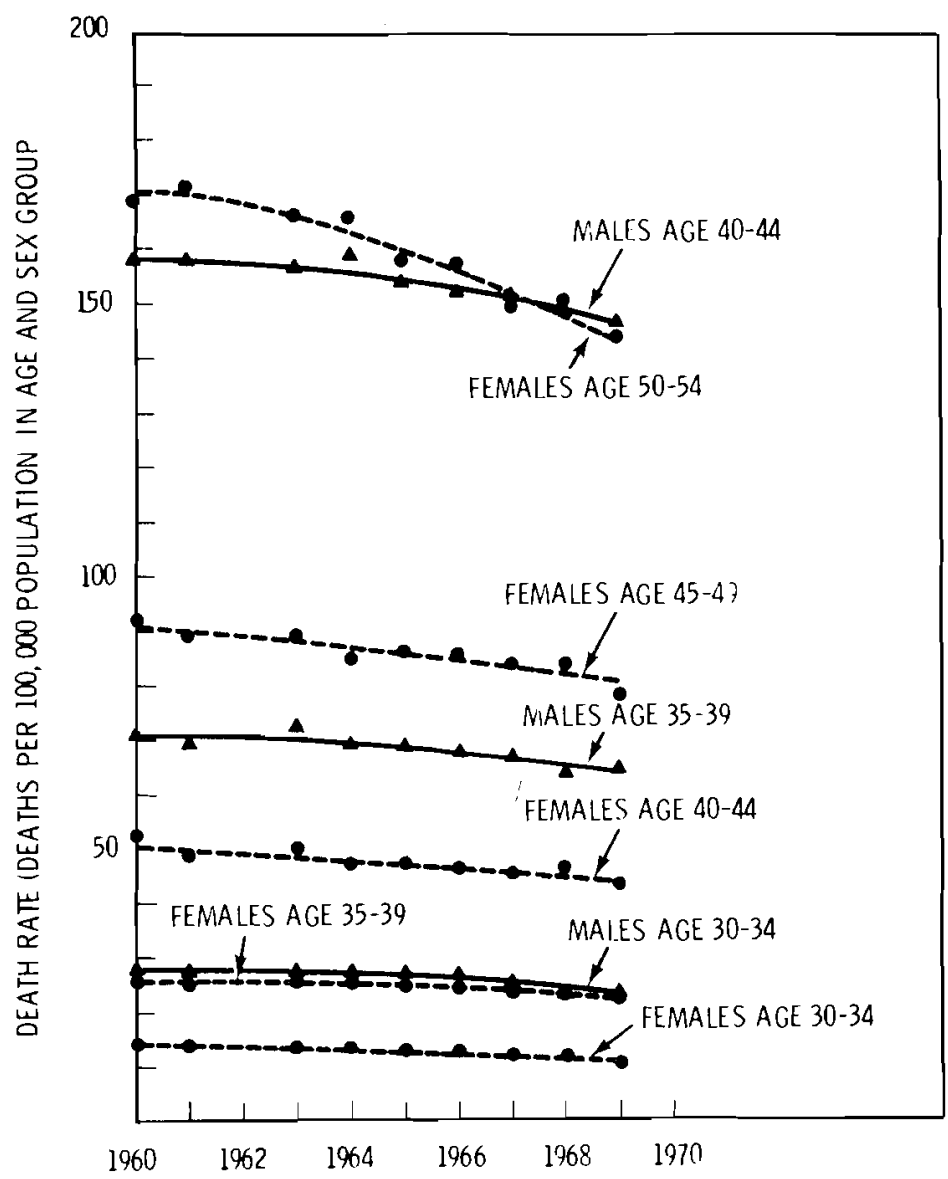

FIGURE B.6c. Age- and Sex-Specific Death Rates for Total Heart Disease (Adjusted to the 8th ICDA Revision) Source: Vital Statistics of the United States (Reference 6)

1965 death rate for each age and sex group was obtained from the smoothed data. Using projected age- and sex-specific populations, we obtained the final age- and sex-adjusted death rate projections. A graphic illustration of this best estimate projection is shown in Figures 9 and 10 in the main report along with illustrations of the maximum and minimum projections discussed next.

Maximum Incidence Projections

The maximum incidence projection basis assumes that the crude death rate would remain fixed and that variations in crude death rate data since 1965 were merely random variations (see Figure 6 in the main report for a plot of 
crude total heart disease death rate data points since 1965). The following equation expresses the relationship used to obtain age- and sex-specific death rates to match this assumption.

$$
\frac{\sum^{i}\left[\left(\text { Decline Factor }_{n}\right) *\left(\text { Death Rate }_{i}\right) *\left(\text { Pop }_{i, n}\right)\right]}{\sum^{i}\left(\text { Pop }_{i, n}\right)}=\text { Constant Crude Death Rate }
$$

where

$$
\begin{aligned}
& i=\text { Age and sex group } \\
& n=\text { Year }
\end{aligned}
$$

and

$$
\begin{aligned}
\text { Decline }_{\text {Factor }}= & \text { Factor for year } n \text { that reduces the age- and } \\
& \text { sex-specific death rates (counteracting } \\
& \text { population increase) to result in constant } \\
& \text { crude death rate. }
\end{aligned}
$$

We chose the constant crude death rate as the average of the crude death rates for total heart disease from 1965 to 1973. $(6,13)$ A set of base ageand sex-specific death rates is also necessary. These base death rates were averages of age- and sex-specific death rates for 1965 to 1969. (6) We assumed that age- and sex-specific death rates would decline uniformly (which appears to be verified in view of the correlation between the data points and our best estimate projection). Hence, the decline factor would be constant for all age and sex groups in any year $n$ and could be derived as follows:

Decline Factor $_{n}=\frac{\text { Constant Crude Death Rate } * \sum^{i}\left(\text { Pop }_{i, n}\right)}{\sum^{i}\left[\left(\text { Base Age-Sex-Spec. Death Rate }{ }_{i}\right) *\left(\text { Pop }_{i, n}\right)\right]}$

Decline factors were calculated for 1965, 1970, 1980, 1990, 2000, 2010, and 2020.

To calculate an age- and sex-adjusted death rate, the population in Equation [1] is held constant at a base year. 
Age- and Sex-Adjusted Death Rate (1940 Base) $=$

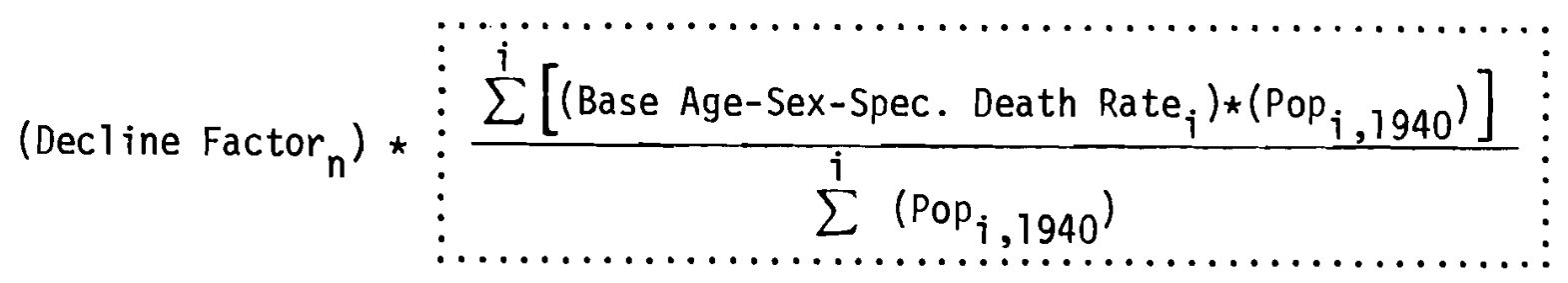

[3]

Since the portion of Equation [3] within the dotted lines is independent of year, projections of the age- and sex-adjusted death rates may be made by knowing only the constant value for the base year and the value of the decline factor for each projected year.

Minimum Incidence Projection

The minimum incidence case stems from the analysis used to test the predictive ability of the DRE. This analysis is based on DRE parameter values derived from application of the DRE to data on other diseases. The reasons for using this analysis as the minimum incidence case are outlined in the main text on page 4-13.

We tested the predictive ability of the DRE by deriving the constants $A, K$, and $n$ (see page B-2 for a description of the equation) for tuberculosis, diptheria, typhoid, influenza and gastritis using data from 1900-1970, and for hypertensive heart disease using data from 1950 to $1970 .(11,6)$ A curvefitting computer program optimized the calculated constants to obtain the best fit to the historical data points.

Using a least squares analysis, the percentage of data points explained by the equation ranged from 96 to $99 \%$ for all diseases except influenza which showed only an $80 \%$ correlation. A $95 \%$ or better correlation is considered good. Normalizing disease rates to a common base, such as percent of peak death rate, caused the values of the constants $A, K$, and $n$ to approach each other for all of the above diseases. However, considerable trial and error adjustment of the value of the constant $A$ was necessary to reach this situation. 
We obtained a single value for each constant by averaging the results for all of the diseases except influenza. Influenza did not have the characteristics of a single disease because of the periodic epidemics that have occurred, so we excluded it. Using the single (universal) set of constants, we calculated a projection for each disease. The agreement with the actual historical data was quite remarkable. A least squares analysis showed a 94 to $98 \%$ correlation for al1. The best fit projection and the projection based on the universal constant curves are shown along with the actual data points for comparison in Figures B.7a-B.7d. (Tuberculosis is shown in Figure 7 in the main text.)

The minimum projection used the universal constant values to predict future heart disease incidence.

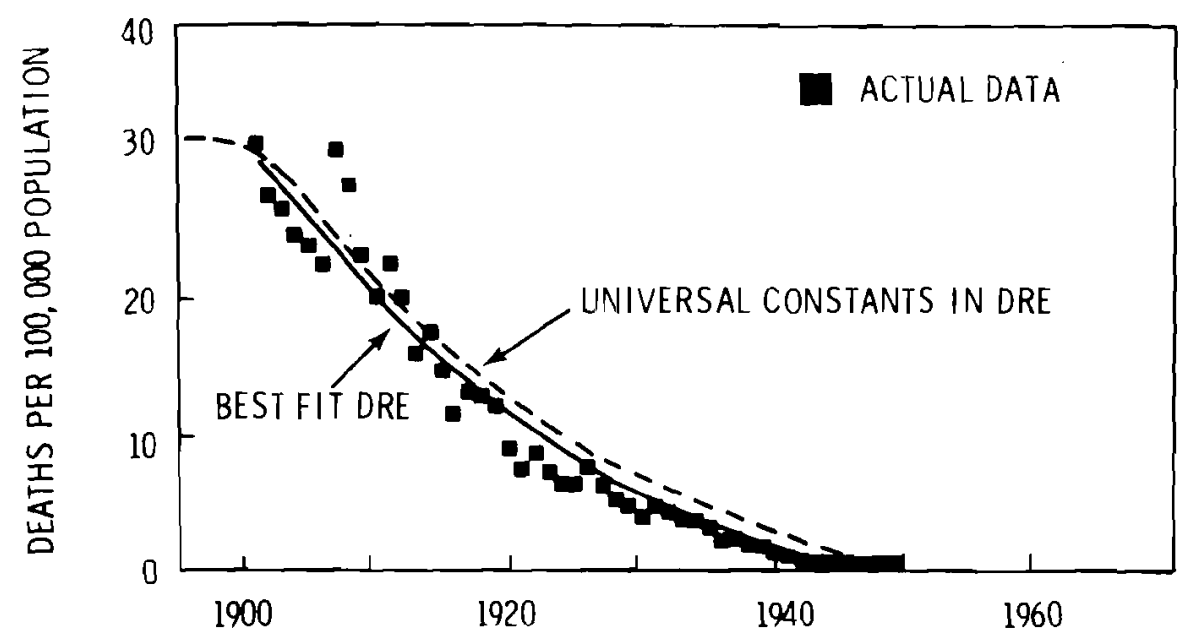

FIGURE B.7a. Comparison of Actual Death Rates for Typhoid with Death Rates Projected by Death Rate Equation. Source: Historical Statistics of the United States (Reference 11) 


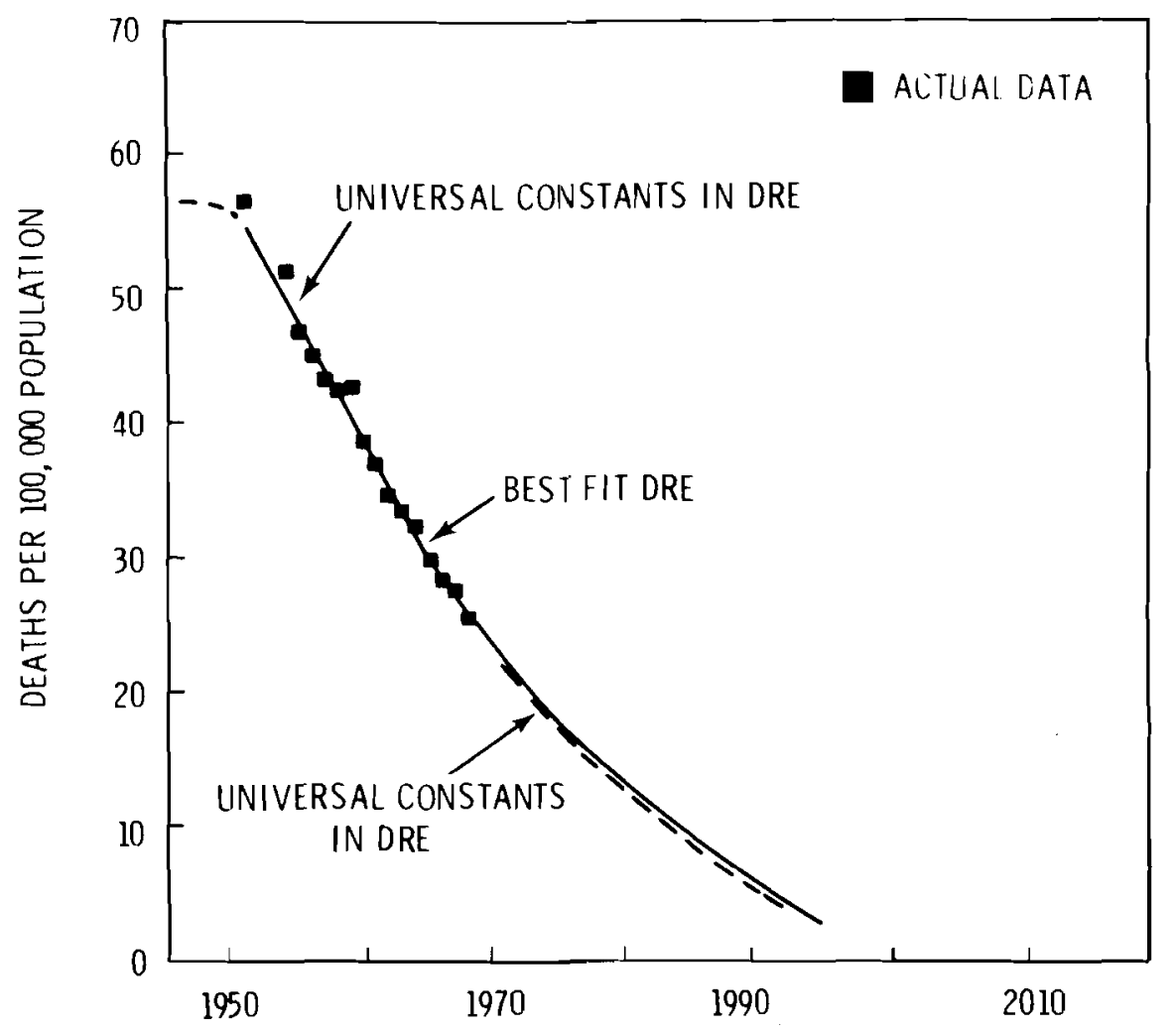

FIGURE B.7b. Comparison of Actual Death Rates for Hypertensive Heart Disease with Death Rates Projected by Death Rate Equation. Source: Historical Statistics of the United States (Reference 11) 


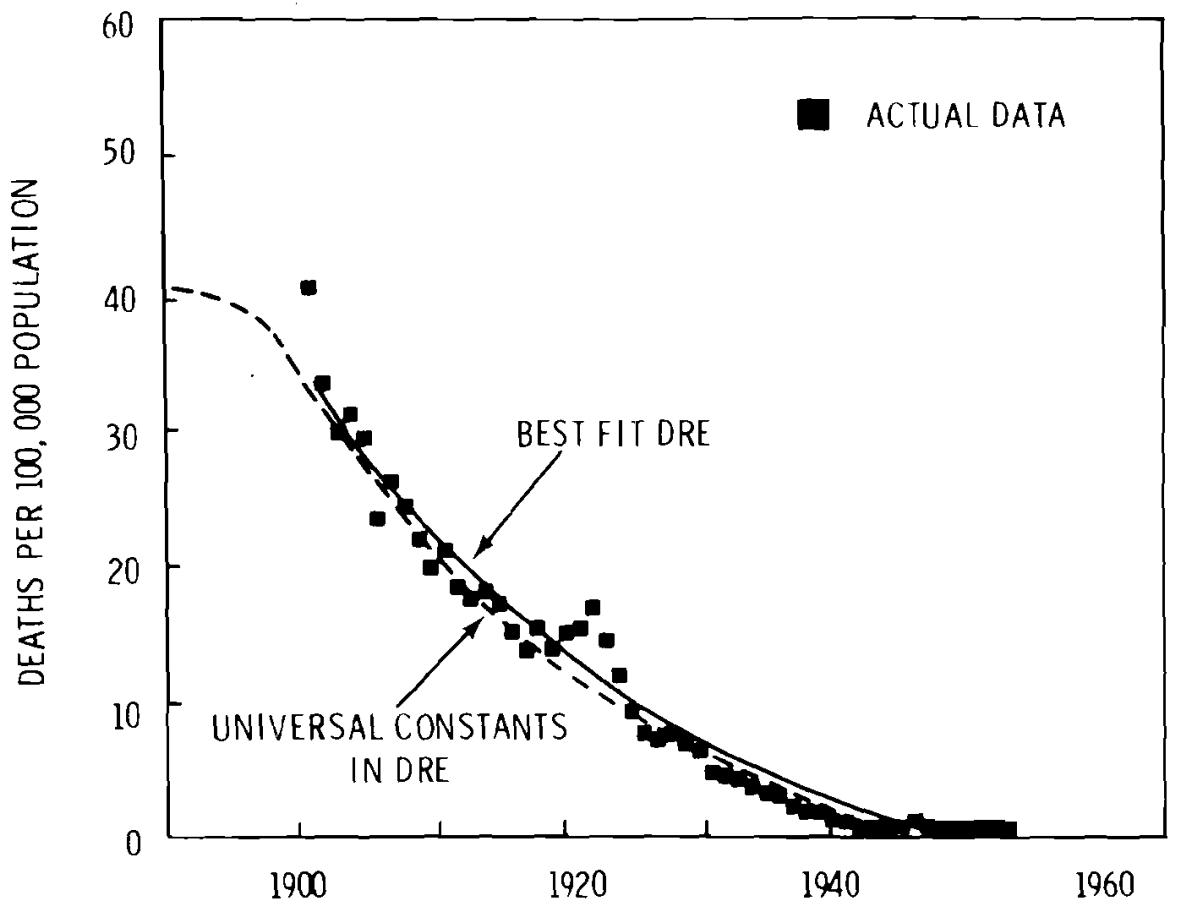

FIGURE B.7c. Comparison of Actual Death Rates for Diptheria with Death Rates Projected by Death Rate Equation. Source: Historical Statistics of the United States (Reference

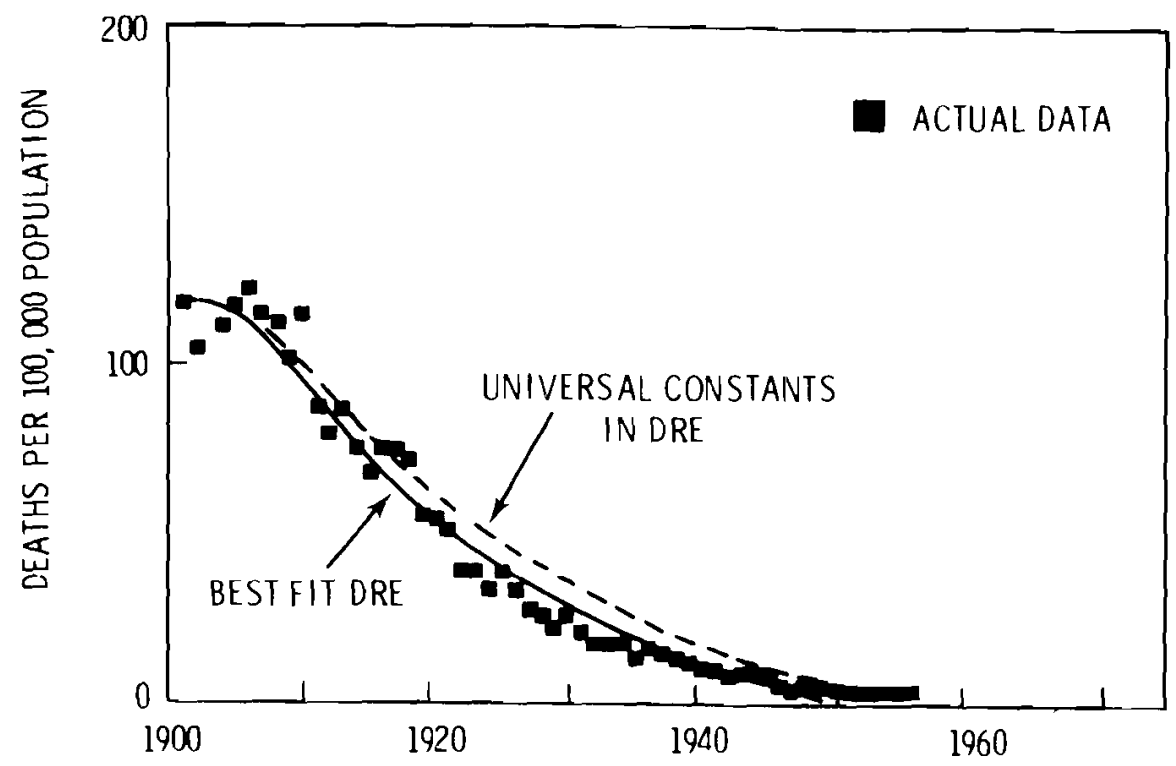

FIGURE B.7d. Comparison of Actual Death Rates for Gastritis with Death Rates Projected by Death Rate Equation. Source: Historical Statistics of the United States (Reference 11) 
APPENDIX C

OCCUPATION CLASSIFICATIONS

FOR POPULATION DOSE STUDY 
APPENDIX C

OCCUPATION CLASSIFICATION FOR POPULATION DOSE STUDY

Male Occupation Groups

\begin{tabular}{cc}
$\begin{array}{c}\% \text { of } \\
\text { 0ccupation } \\
\text { Class }\end{array}$ & $\begin{array}{c}\text { Employed } \\
\text { Male }\end{array}$ \\
\hline
\end{tabular}

Professional, Technical, and Kindred

1. Accountants and Auditors

\begin{tabular}{rl}
9.2 & 0.94 \\
4.9 & 0.50 \\
20.1 & 2.07 \\
5.4 & 0.55 \\
5.6 & 0.58 \\
10.1 & 1.03 \\
6.0 & $\underline{0.62}$ \\
\hline 61.3 & $6.29(7)$ \\
38.7 & 3.98 \\
& \\
\hline 100.0 & $=10.27$
\end{tabular}

Farmers and Farm Managers

9. Farmers

\begin{tabular}{rl}
99.1 & 6.45 \\
0.9 & 0.06 \\
\hline$\overline{100.0}$ & $\quad \overline{6.51}$
\end{tabular}

10. Farmers and Farm Managers, N.E.C. Total Farmers

6.51

Managers, Officials, Proprietors (Exc. Farm)

11. Managers, Officials, Proprietors, Buyers, Department Store Heads, and Public Administrators-Salaried-SelfEmployed

12. Managers, Officials, Proprietors (ExC. Farm) N.E.C.

$$
91.7
$$

Tota 1 Managers

$\begin{array}{rr}8.3 & 1.05 \\ 100.0 & =\end{array}$

Source: 1970 Census of Population: Occupational Characteristics (Reference 22) 
Clerical and Kindred Workers

13. Agents, Bank Tellers, Cashiers, Receptionists, and Postal Clerks

14. Mai1 Carriers and Messengers

17.3

1.09

15. Storekeepers, Shipping, Receiving, and Stock Clerks

8.0

0.51

16.2

1.02

Sub-Total-Classified Clerical

$\overline{4.1 .5}$

$\overline{2.62}(3)$

16. Clerical and Kindred Workers, N.E.C.

58.5

3.69

Total Clerical

$\overline{100.0}$

$\overline{6.31}$

Sales Workers

17. Insurance and Real Estate Agents and Brokers

20.0

18. Salesmen and Sales Clerks, N.E.C.

77.2

5.00

Sub-Total-Classified Sales Workers

$\overline{97.2}$

$6.29(2)$

19. Sales Workers, N.E.C.

2.8

0.19

Total Sales Workers

100.0

6.48

Craftsmen, Foremen, and Kindred

20. Brick Masons, Stone Masons, Tile Setters, and Concrete Finishers

10.5

2.22

21 Carpenters and Cabinetmakers

4.0

0.84

22. Electricians

17.7

3.74

23. Foremen and Stationary Engineers

2.5

0.54

24. Linemen and Servicemen - Telephone, Telegraph, and Power

$\begin{array}{rr}8.0 & 1.69 \\ 24.6 & 5.19\end{array}$


Craftsmen, Foremen, and Kindred (Continued)

27. Welders and Flame Cutters

$\begin{array}{ll}4.0 & 0.84 \\ 4.5 & 0.94 \\ 3.7 & 0.78\end{array}$

28. Painters

17.30

30. Craftsmen, Foremen, and Kindred, N.E.C.

82.0

3.81

\section{Total Craftsmen}

18.0

\section{Operatives and Kindred}

31. Assemblers

32. Checkers, Examiners, and Inspectors Mfg.

33. Deliverymen, Routemen, Truck and

Tractor Drivers, Motormen - Mine and Factory

34. Mine Operatives and Laborers

22.7

35. Excavating, Grading, Road Machinery, Crane, Derrick, and Hoist Operators

$\begin{array}{ll}3.7 & 0.69 \\ 4.2 & 0.79\end{array}$

$$
\text { Sub-Total-Classified Operatives }
$$

36. Operatives and Kindred, N.E.C. 
Male Occupation Groups

Service Workers (Exc. Household)

37. Barbers, Hairdressers, and Cosmetalogists

38. Bartenders, Waiters, Counter and Founta in Workers

39. Cooks and Kitchen Workers

40. Janitors, Sextons, Housekeepers, and Maids

41. Guards, Watchmen, Doorkeepers, and Bridge Tenders

42. Policemen, Detectives, Sheriffs, Etc.

Sub-Total-Classified Service Workers

43. Service Workers (Exc. Household), N.E.C.

Total Service Workers
$\%$ of

Occupation

Class

8.8

11.1

10.7

25.0

11.6

11.3

78.5

21.5

100.0
$\%$ of

Employed

Male

Male 
Female Occupation Groups

Professiona1, Technical, and Kindred

48. Musicians, Artists, and Teachers of

49. Nurses

50. Teachers, Elementary and Secondary

Sub-Tota1-Classified Professional

51. Professiona1, Technica1, and

Kindred, NOT ELSEWHERE CLASSIFIED

(N.E.C.)

Total Professional
$\%$ of

Occupation

Class

5.4

20.2

46.3

71.9

28.1

100.0

13.11
$\%$ of Employed Female

Farmers and Farm Managers

52. Farmers and Farm Managers

100.0

$0.70(1)$

Tota1 Farmers

100.0

0.70

Managers, Officials, and Proprietors (Exc. Farm)

53. Managers, Officials, Proprietors,

91.4

$4.24(1)$

Buyers, Department Store Heads, and Public Administrators

54. Managers, Officials, and Proprietors

8.6

0.40

(ExC. Farm), N.E.C.

Total Managers

100.0

4.64 
Female Occupation Groups

Clerical and Kindred

55. Bookkeepers, File, Payrol1, and Timekeeping Clerks

56. Agents, Bank Tellers, Cashiers, Receptionists, and Postal Clerks

57. Office Machine Operators and Typists

58. Secretaries and Stenographers

59. Telephone Operators

$$
\text { Sub-Tota1-Classified Clerical }
$$

60. Clerical and Kindred, N.E.C.

Total Clerical
$\%$ of

Occupation

Class

16.5

4.24

10.9

2.80

9.0

2.30

25.1

6.45

5.5

1.41

67.0

17.20

33.0

8.49

100.0

25.69

Sales Workers

61. Saleswomen and Sales Clerks, N.E.C.

90.2

7.57 (1)

62. Sales Workers, N.E.C.

$\frac{9.8}{100.0}$

0.82

Total Sales Workers

100.0

8.39

Operatives and Kindred

63. Assemblers

8.0

1.34

64. Checkers, Examiners, Inspectors - Mfg.

6.9

1.16

65. Dressmakers and Seamstresses (Exc. Factory!

4.3

0.72

66. Laundry and Dry Cleaning Operatives

8.6

1.44

67. Packers and Wrappers

7.7

1.30

68. Sewers, Stitchers, Spinners -

19.6

3.29

Mfg. Textile

Sub-Total-Classified Operatives

55.1

$9.25(6)$

69. Operatives and Kindred, N.E.C.

$\begin{aligned} 44.9 & =\frac{7.56}{16.81}\end{aligned}$

Total Operatives 
Female Occupation Groups

Private Household Workers

70. Babysitters, Housekeepers, Laundresses, 100.0 and Private Household Workers, N.E.C.

Total Private Household
$\%$ of

Occupation

Class

100.0
$\%$ of

Employed

Fema le

Service Workers (Exc. Private Household)

71. Attendants and Ushers

11.2

1.58

72. Barbers, Hairdressers, and Cosmetalogists

73. Bartenders, Waiters, Counter and Fountain Workers

74. Cooks and Kitchen Workers

75. Janitors, Sextons, Housekeepers, and Maids

$24.4 \quad 3.46$

21.5

3.04

20.0

2.84

76. Practical Nurses

Sub-Total-Classified Service Workers

94.8

$13.41(6)$

77. Service Workers (Exc. Private Household), N.E.C.

Farm Laborers and Foremen

78. Farm Laborers and Foremen

100.0

$1.14(1)$

Total Farm Laborers

100.0

1.14

79. Female Occupations, N.E.C.

100.0

7.27

Total Occupations Classified

71.05

Total Occupations Not Classified

28.95

100.00 
APPENDIX D

TIME IN NONWORK ACTIVITIES 


\section{APPENDIX D}

\section{TIME IN ALL NONWORK ACTIVITIES}

Mean Time (min) $\begin{gathered}\text { of Principal } \\ \text { Activity Time }\end{gathered}$
Male Female Male FemaTe

1. Preparing Food

306 Preparing Food

307 Dishes, Meal Cleanup

2. Cleaning House

308 Indoor CTeaning

309 Outdoor Chores

3. Laundry, Mending

310 Laundry, Ironing

311 Mending, Clothes Upkeep

4. Other House Upkeep

312 Repairs, Maintenance

314 Heat, Water Supply

315 Other Household

5. Gardening, Pets

313 Garden, Animal Care

6. STeep

339 Essential Sleep (Night)

7. Personal Care

334 Persona 7 Care

335 Personal Medical Care

342 A11 0ther Personal

8. Eating

337 Meals at Home

338 Eating Out

9. Resting

340 Incidental Sleep (Naps)

341 Resting

$\begin{array}{llll}9.342 & 75.550 & 69.78 & 68.00 \\ 4.046 & 35.559 & 30.22 & 32.00\end{array}$

$\begin{array}{llll}3.822 & 59.681 & 49.26 & 96.08\end{array}$

$\begin{array}{llll}3.937 & 2.438 & 50.74 & 3.92\end{array}$

$\begin{array}{llll}1.388 & 43.119 & 89.20 & 92.57\end{array}$

$\begin{array}{llll}0.168 & 3.462 & 10.80 & 7.43\end{array}$

$\begin{array}{rrrr}9.361 & 3.453 & 56.07 & 17.40 \\ 0.950 & 0.129 & 5.69 & 0.65 \\ 6.384 & 16.263 & 38.24 & 81.95\end{array}$

$\begin{array}{llll}2.518 & 4.638 & 100.00 & 100.00\end{array}$

$\begin{array}{llll}453.208 & 457.917 & 100.00 & 100.00\end{array}$

$\begin{array}{llll}45.799 & 54.508 & 80.50 & 77.14\end{array}$

$\begin{array}{llll}0.233 & 0.582 & 0.41 & 0.82\end{array}$

$\begin{array}{llll}10.864 & 15.577 & 19.09 & 22.04\end{array}$

$\begin{array}{llll}59.348 & 61.426 & 78.95 & 89.91\end{array}$

$\begin{array}{llll}15.826 & 6.891 & 21.05 & 10.09\end{array}$

$\begin{array}{llll}12.013 & 9.993 & 84.83 & 58.82\end{array}$

$\begin{array}{llll}2.149 & 6.995 & 15.17 & 41.18\end{array}$

Source: Institute for Social Research, University of Michigan (Reference 23) 
10. Child Care

$\begin{array}{ll}316 & \text { A11 Baby Care } \\ 317 & \text { Care to Children } \\ 318 & \text { Schoolwork Help } \\ 319 & \text { Read/Converse/Kids } \\ 320 & \text { Indoor Games } \\ 321 & \text { Outdoor Games } \\ 322 & \text { Medical Care/Kids } \\ 323 & \text { Other Child Care }\end{array}$

11. Other Aduit Care

336 Care to Adults

12. Shopping and Purchasing

$\begin{array}{ll}325 & \text { Everyday Buying } \\ 326 & \text { Durable Buying } \\ 327 & \text { Personal Care Away } \\ 328 & \text { Medical Care Away } \\ 329 & \text { Gov't Services } \\ 330 & \text { Repair/Cleaning Services } \\ 331 & \text { Waiting for Purchase } \\ 332 & \text { Other Services }\end{array}$

13. Nonwork Trips

$\begin{array}{ll}324 & \text { Child Care Trips } \\ 333 & \text { Shopping Trips } \\ 343 & \text { Personal Trips } \\ 351 & \text { Adult Education Trips } \\ 361 & \text { Organization Trips } \\ 371 & \text { Social Trips } \\ 390 & \text { Passive Leisure Trips }\end{array}$

14. Adult Education or Occupation

Training

\begin{tabular}{ll}
\hline 344 & FuTl-Time Classes \\
345 & Part-Time Classes \\
346 & Special Lectures \\
347 & Political/Union Courses \\
348 & Homework, Study \\
349 & Instructive Reading \\
350 & Other, NA Above
\end{tabular}

$\begin{array}{rrrr}1.398 & 0.255 & 15.54 & 6.07 \\ 1.740 & 1.621 & 19.34 & 38.59 \\ 0.000 & 0.424 & 0.00 & 10.09 \\ 0.975 & 0.000 & 10.84 & 0.00 \\ 3.065 & 1.061 & 34.07 & 25.26 \\ 0.650 & 0.000 & 7.23 & 0.00 \\ 1.168 & 0.840 & 12.98 & 19.99\end{array}$


15. Organizational Activity

352 Party Participation

353 Official Participation

354 0ther Participation

355 Civic Volunteer Work

356 ReTigious Club

358 Job Committees

359 Other Organizations

360 Other, NA

16. Television

382 Television

17. Other Passive Leisure

381 Radio Listening

383 Listening to Records

384 Reading Books

385 Reading Magazines

386 Reading Newspapers

387 Conversation, Phone

388 Reading, Writing Letters

389 Thinking, Doing Nothing
357 Religious Practice

Mean Time (min)

Male Female

$\%$ of Principal

Activity Time

MaTe Fema Te

$\begin{array}{rrrr}0.157 & 0.204 & 1.15 & 1.02 \\ 0.021 & 0.102 & 0.15 & 0.51 \\ 0.881 & 1.141 & 6.46 & 5.68 \\ 1.048 & 1.788 & 7.68 & 8.91 \\ 1.195 & 2.613 & 8.76 & 13.01 \\ 6.941 & 9.321 & 50.88 & 46.43 \\ 0.000 & 0.000 & 0.00 & 0.00 \\ 2.010 & 1.817 & 14.73 & 9.05 \\ 1.390 & 3.090 & 10.19 & 15.39\end{array}$

103.748

79.177

100.00

100.00

$\begin{array}{rrrr}4.776 & 3.209 & 7.60 & 4.48 \\ 1.122 & 0.800 & 1.79 & 1.12 \\ 4.971 & 5.861 & 7.91 & 8.19 \\ 6.488 & 4.277 & 10.33 & 5.97 \\ 26.790 & 20.632 & 42.65 & 28.82 \\ 12.891 & 23.319 & 20.52 & 32.57 \\ 3.365 & 8.623 & 5.36 & 12.04 \\ 2.415 & 4.874 & 3.84 & 6.81\end{array}$

18. Social Entertainment and Other

Social Life

362 Sports Events

363 Fairs, Dances, Etc.

364 Movies

365 Theatre, Opera

366 Museum, Exhibition

367 Entertaining, Visiting

368 Party W/Meals

369 Bar, Tearoom

370 Party/Other No Meal
1.411

3.878

2.809

0.629

0.398

31.031

11.683

5.795

0.157
0.399

4.015

1.503

0.144

0.102

37.896

18.008

0.272

1.341
2.44

6.71

4.86

1.09

0.69

53.69

20.22

10.03

0.27
0.63

6.30

2.36

0.23

0.16

59.51

28.28

0.43

2.10 


\begin{tabular}{l} 
Mean Time (min) \\
$\begin{array}{c}\text { Activity Timal } \\
\text { Activity Time }\end{array}$ \\
Male Female Male Female \\
\hline
\end{tabular}

19. Sports and Active Leisure 372 Active Sports

373 Hunting, Fishing

374 Taking a Walk

375 Hobbies, Collections

376 Women's "Hobbies"

377 Artistic Work

378 Making Music

379 Games, Cards

380 Other Active Leisure

$\begin{array}{rrrr}7.662 & 3.367 & 31.52 & 13.54 \\ 3.239 & 0.204 & 13.32 & 0.82 \\ 1.348 & 0.995 & 5.55 & 4.00 \\ 3.564 & 0.535 & 14.66 & 2.15 \\ 0.000 & 12.969 & 0.00 & 52.13 \\ 0.860 & 0.521 & 3.54 & 2.09 \\ 0.744 & 0.788 & 3.06 & 3.17 \\ 4.486 & 4.503 & 18.45 & 18.10 \\ 2.407 & 0.995 & 9.90 & 4.00\end{array}$


APPENDIX E

DESERIPTION OF SURVEYS 


\section{DESCRIPTION OF SURVEYS}

The following sections describe the surveys conducted to obtain data on the interpersonal relationships occurring during normal activities. The original activity definitions were derived by the Institute for Social Research (ISR) at the University of Michigan. In order to reduce this large number of defined activities to a number which could be handled in our surveys, we regrouped the data into larger categories. Appendix $D$ lists these broad activity groups and shows the division into subactivities with their associated time data.

\section{AT-HOME ACTIVITY}

Surveys of Battelle-Northwest employees and of random populations in Richland and Seattle, Washington, and Salt Lake City, Utah, collected data on interpersonal relationships for 13 at-home activity categories. (These activities are 1 isted in Table 12 in Section VII.) The following sections describe these surveys.

The Telephone Survey

The initial survey attempted a relatively precise measurement technique using a random telephoning method. We interviewed previously selected Battelle employees and made scaled drawings of their residences. The participants were telephoned randomly during the day to determine the activities of the Potential Heart Recipients (PHRs) at the time of the telephone call and their locations relative to other persons. Knowing this information, precise measurements could be made on the scale drawings and the interpersonal distances classified by activity. This method had the advantage of substantial accuracy in measurement, but proved to be too time consuming, posed difficulties in obtaining cooperation from unknown persons, and required too many telephone calls to obtain meaningful results. 
The Battelle Survey

We selected families from Battelle-Northwest's employee roster on the basis of age and family characteristics. Forty-nine of the candidates consented to participation in a study of family living relationships. Since the telephone survey showed that actual observation was too time consuming, we asked survey respondents where members of their families were usually located during the activities specified. While this method was less precise than the telephone method, it allowed much more data to be collected, and infringed less on respondent privacy. The consistency in replies as to people's locations during certain activities during this and subsequent surveys formed a definite pattern. This lent credence to the assumption that the respondents had an accurate idea of the usual location of other family members during common every day activities. In this and later surveys, we instructed interviewers to emphasize that they were interested in the usual situation. We considered this the best approach to estimating the mean conditions without having to make multitudinous observations.

We recognized at the outset that the Battelle sample population would have some bias in it. This bias occurred since (1) respondents were preferentially selected in older age groups to reflect the estimated age distribution of artificial heart recipients and (2) the Battelle population might also have significantly different living habits than found in a purely random population sample. Notwithstanding these drawbacks, the pilot survey used a Battelle population since company workers would be more responsive and cooperative in allowing a significant invasion of their privacy. Since questions were asked on a comprehensive list of family activities, interviews often lasted an hour or more. Had company employees not been used, it would have been difficult to find such respondents and to complete the survey in the cost and time frame allotted.

The sample population consisted of every tenth person from a roster of Battelle employees. Later we determined that more respondents were needed in the older age groups and we nonrandomly selected enough older employees to weight the sample population as desired. 
In conducting each interview, we collected data as if each eligible adult in the household were respectively the PHR. We defined eligible adults as those over 30 years of age. After explaining the purpose of the survey and determining the classification of the PHR (i.e., age, sex, etc.), we made and recorded measurements of interpersonal distances. At the conclusion of the interview we measured the approximate dimensions of the house.

The survey instrument consisted of a front page with general instructions and a data sheet coded for the various activities on which the distance measurements could be entered. Since no outside interviewers were hired, this simple instrument was adequate for the needs of the survey.

The only problem in survey techniques discovered during the Battelle interviews was an inefficient use of man power caused by the use of measuring tapes. To be conducted efficiently the interview required three interviewers -two to use the tapes to make the measurements and one to ask the questions and record the data. The interview duration was considerably longer when only two interviewers conducted it.

Upon completion of the survey, we wrote computer programs to convert the distance data into dose rates and to calculate mean dose rates for each activity. These were cumulative dose rates from the person considered as having the heart device.

Using these mean dose rates the computer code, REPRIEVE, calculated an initial estimate of population dose. The results of this initial calculation showed that approximately $98 \%$ of the total population dose to families occurred in five activities--sleeping, eating, television viewing, other passive leisure and social.

The Richland Survey

In order to enlarge the data base and estimate the effects of the bias in the Battelle data, random surveys were made in Richland and Seattle, Washington. Since we anticipated difficulty in 
obtaining cooperation in Seattle, where the Battelle name was relatively unknown, we took a small pilot sample in Richland to test response to non-use of the Battelle name. At the same time we evaluated a technique for staged random sampling and constructed a PHR target-matrix. This target-matrix proportioned the prospective PHR sample population by the age and family type distribution of Artificial Heart Recipients (derived from the preliminary REPRIEVE calculations). We used this matrix by choosing respondents fitting the descriptions of uncompleted cells in the target-matrix as PHRs for the interview. This weighted the data collection in proportion to its relevance to the overall dose calculation.

The time required to complete Battelle interviews indicated that the Battelle questionnaire would need to be substantially reduced in length. Calculations from REPRIEVE based on the Battelle data had shown that five activities accounted for most of the dose as described previously. By focussing on only these five activities, hereafter designated as main activities, in the Richland and Seattle questionnaires, we were able to considerably reduce the required interviewing time.

The sampling technique used a census map to delineate census districts. After numbering the districts, we chose six districts to be sampled using a table of random numbers. We numbered streets within these districts and repeated the random process to obtain streets to be sampled. The interviewers then made one pass on each street interviewing a 11 respondents willing to participate. The Richland survey used the same instrument as the Battelle survey except that the Richland instrument had fewer questions. The Battelle name was mentioned only when people specifically asked for the identity of the organization conducting the survey.

Lack of response and absence during the day were the main problems we encountered in the pilot survey in Richland. Although some people did not admit interviewers without knowing the company name, most were still receptive. In general, young families (only a few of which were sampled due to the low incidence of heart disease in such families) were the most 
responsive. 01der families were much more hesitant about allowing strangers into the home. The classes of people most frequently found at home during the day were housewives with children and retired couples. This pointed out the possible need to conduct evening interviews during the Seattle survey in order to complete the PHR target-matrix.

\section{Seattle Survey}

The Seattle survey followed the same basic format as did the pilot Richland survey. We made an estimate of the total sample size and calculated a target-matrix. We randomly selected streets using a city map and census tracts. One person did the interviewing, asking the questions, making the measurements, and entering the data. Use of a wheeled measuring device enabled the interviewers to make the measurements much more quickly and easily than in the previous surveys.

The main difficulty encountered in the Seattle survey was the length of time required for interviewing. In homes with multiple, eligible PHRs, this was especially true. After collection of the data, we modified the previously developed computer codes and used them to calculate the dose rates and develop their means. We developed a statistical code to analyze the mean dose rates from the Battelle, Seattle and Richland surveys for the five main activities previously described. We compared these mean dose rates using a standard $F$ test. Table E. 1 displays the results of this test. The first value in each household-type column is a tabled value of the $F$ statistic at an alpha error of $5 \%$ (i.e., at this $F$ value, the error in assuming the mean dose rates in the sampled cities to be the same, when in actuality they were not, would be $5 \%$ ). For values of the $\mathrm{F}$ statistic calculated from the data greater than the tabled $F$ value at a $5 \%$ error level, the assumption of no significant difference between cities is rejected. For calculated $\mathrm{F}$ values below the 5\% error level, the assumption is accepted. As seen by a comparison of $F$ values in Table E.1, there was no pattern of significant differences between mean dose rates by activity and family type for four of the five activities based on the data collected. 


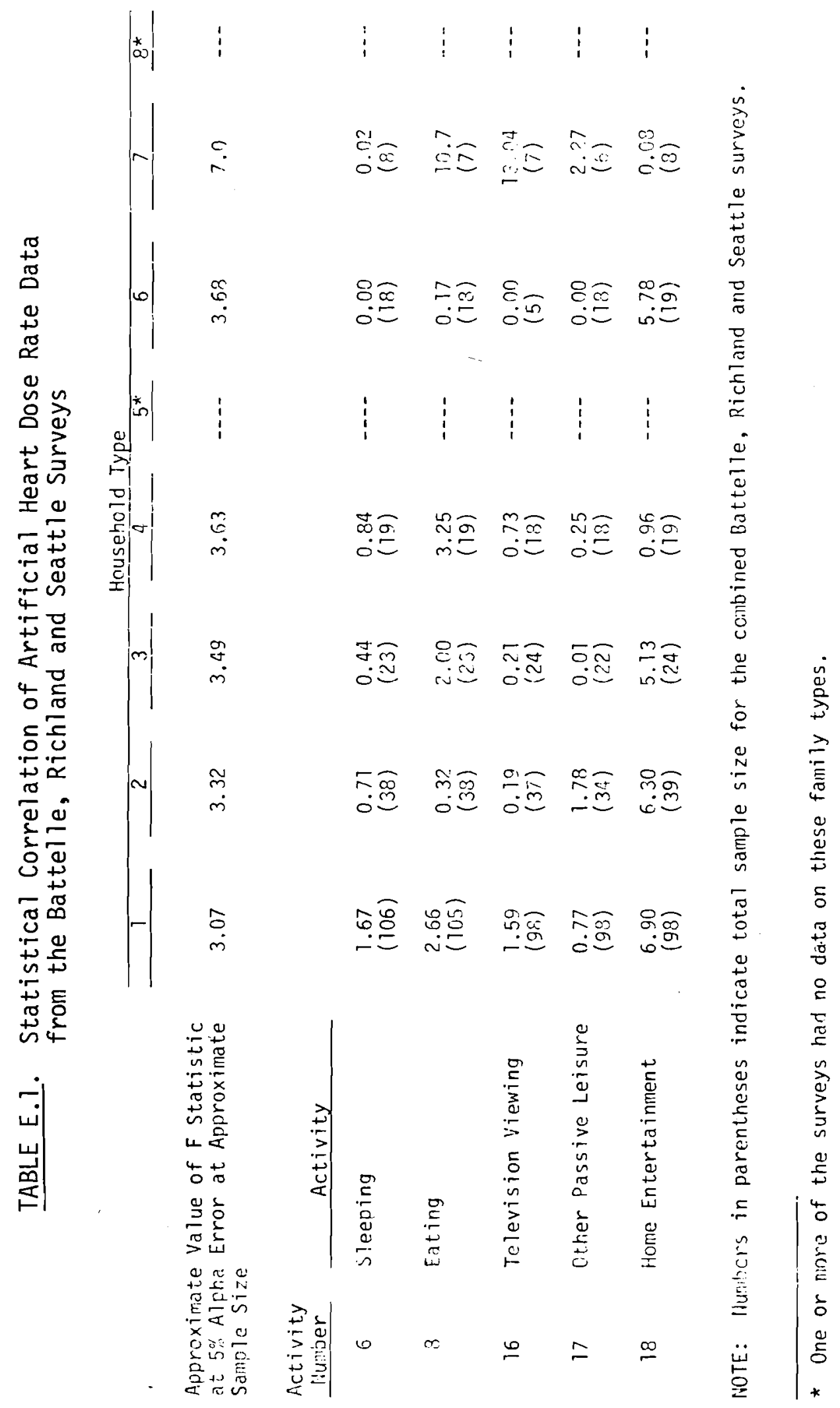


Although the home entertainment activity showed a significant difference in mean dose rates between the Battelle, Richland and Seattle samples, the method of calculating the dose rate from the raw data had changed between surveys for this activity. Using the statistical $T$ test for the difference of two means, we made comparisons of the mean dose rates for the Richland and Seattle data in which the calculational basis was the same. The results of this test are shown in Table E.2. Using the same comparison logic as explained for the $F$ test above, these comparisons showed no pattern of statistical difference. Therefore, we concluded that the change in calculational techniques caused this one difference observed between the Battelle and the Seattle-Richland surveys and that no statistically significant geographical differences in mean dose rates existed for any of the five activities.

\section{The Salt Lake City Survey}

The objective of the previous surveys was the identification of the population dose by the artificial heart recipient's (AHR's) age, sex, employment status, family type, and occupation. It was subsequently decided to expand the identification of dosage to include the age, sex, and relationship to the AHR of the persons receiving the radiation. (Reasons for this expansion are outlined in the section on Methodology.) To accomplish this, we planned large scale surveys in three cities across the United States. Time and fund constraints later limited this to one survey in Salt Lake City, Utah. However, the results of the previous surveys offered some basis to conclude that significant geographical differences might not exist.

The Salt Lake City survey collected data on interpersonal distances according to the Radiation Exposure Subject (RES) classifications mentioned above. However, we used household type classifications instead of family type classifications for PHR identification for the reasons explained in the section on classification. 


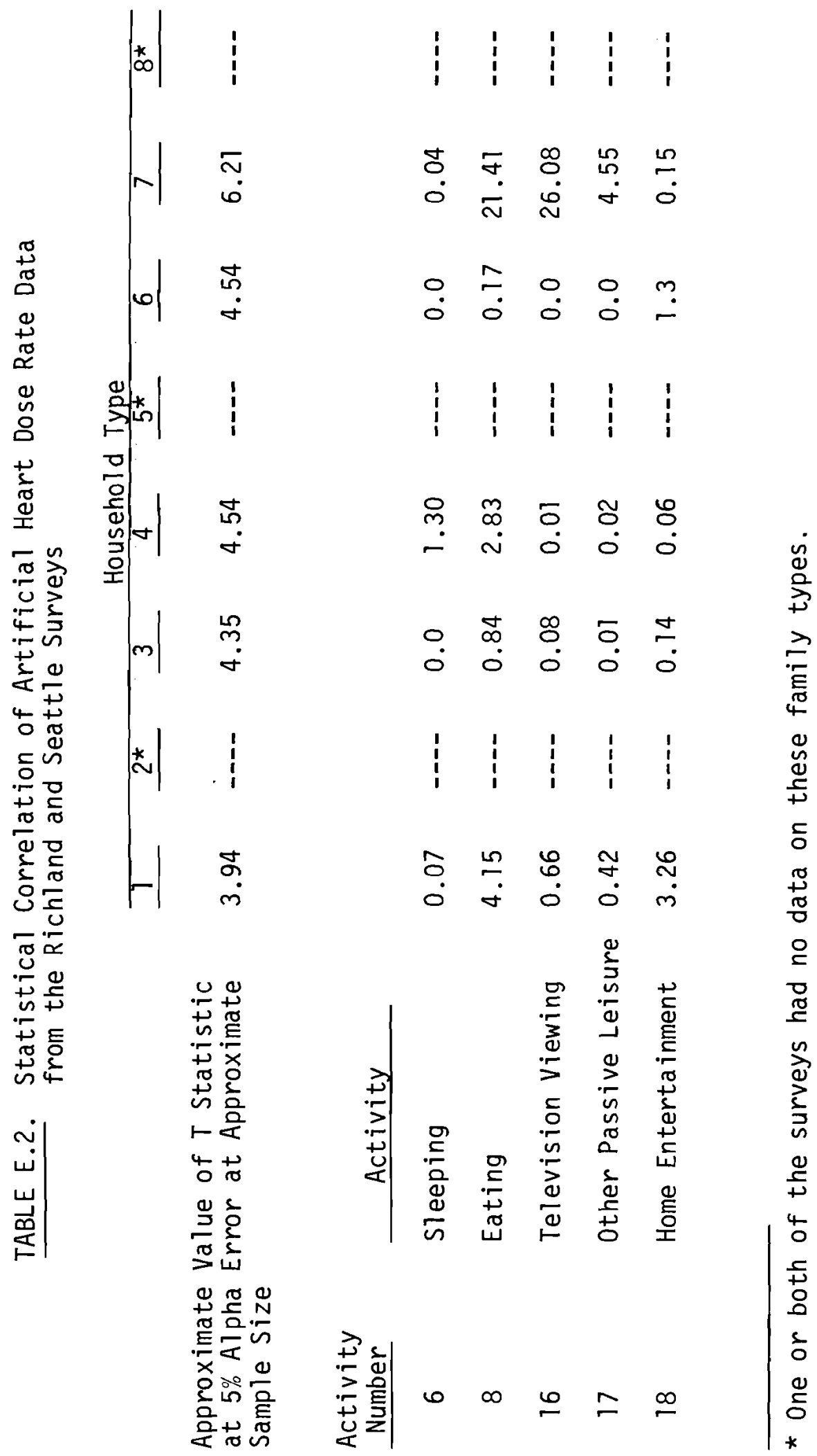


Several criteria determined the sample population. We chose the city because of its location and size, and for the ease of obtaining qualified interviewers through Dr. Altman, our previously retained consultant. The criteria for selecting census tracts included mean number of persons per household, mean income of each household, and mean density of households (i.e., urban-rural classification). A $\pm 10 \%$ range of the national average met the criterion of mean number of persons per household. This insured that the effect of household size on total dose measurements would be close to what it should be nationally. The significance of income lies in its profound effect on peoples' living habits and its tendency to be homogeneous over a given geographical area.

We defined three ranges of income for tracts within Salt Lake City relative to Salt Lake City's overall mean income of $\$ 8,800$. These ranges were:

High Income $=1.25 \times$ Mean Income or Greater $=\$ 11,000$ or greater,

$$
\text { Middle Income }=\text { Mean Income } \times(1 \pm 0.1)=\$ 7,900 \text { to } \$ 9,700 \text {, }
$$

Low Income $=0.75 \times$ Mean Income or Less $=\$ 6,600$ or less.

Since no data had been collected on possible differences in interpersonal distance patterns between urban and rural households, we selected several tracts which were estimated to fall within the rural definition. Using these criteria, we chose three high-income tracts, seven middle-income tracts, and three low-income tracts for an urban sample population. Two census areas outlying Salt Lake City itself comprised the rural sample population. With the sample population defined, we accomplished clustering by numbering the streets and using a set of random numbers to select streets to be interviewed.

We designed a completely new questionnaire for the Salt Lake City survey. The questionnaire design had the objective of collecting detailed data in as simple a manner as possible while organizing the recording of the data so that it could be easily transcribed once the survey was completed. A copy of the questionnaire is included in Figure E.2 at the end of this Appendix. The data gathered in the questionnaire enabled a precise identification of each 
family member and the distance to each identified member as well as to frequent visitors in the home for each activity. Since the collection of this detailed data for all family activities would require a substantial amount of the respondents time (especially in large families), we limited data collection to the five most significant activities (sleeping, eating, television viewing, passive leisure and social) plus one of ten other activities chosen by a rotating schedule. To obtain frequency-of-contact data, we needed some measure of how often family members were present during a specified activity (performed by the PHR). We accomplished this by averaging, for each sample group, the total number of family members present by the number of PHRs sampled. This necessitated differentiating between the absence of an individual and non-performance of the activity in question. If members of the household were absent, the interviewer entered a zero. If the PHR did not perform the activity in question, a slash was entered.

Because of the anticipated size of the Salt Lake City survey, college students did the actual interviewing. Dr. Robert Altman, our previously retained consultant from the University of Utah, screened and selected the interviewers. Dr. Altman's field of personal study is in the psychological aspects of interpersonal distances as previously mentioned and the interviewers chosen were graduate students under his direction. Due to this association, many of these students also had a personal interest in the study of interpersonal distances.

We held a preliminary meeting with the interviewers to familiarize them with the purpose of the study and to arrange other details. We also held a training session the day previous to actual interviewing. Owing to their previous interviewing experience and familiarity with the subject area, the interviewers needed only a minimum of training. 
The interviewing procedure used was the one we had developed in preceding surveys. Our previous experience had verified that in order to keep the interview to a reasonable length of time, a pair of interviewers was optima 1 ; one made measurements and the other asked questions and recorded the data. Where possible, the interviewing team consisted of both a male and a female interviewer. We felt that such a mixed team would be better received than two male interviewers requesting permission to enter the home.

The teams began their interviewing at 10:00 o'clock in the morning and continued through the afternoon and into the evening. The interviewers reported that reception was poor in the morning and evening, but good in the afternoon. As an interviewing team finished a set of streets, they took additional sets of streets in other census tracts until all of the selected tracts had been sampled. In some cases interviewing pairs went back to contact not-at-homes. Each team kept a record of house numbers, number of contacts, successful contacts and refusals.

Many interviewers had "seeded" their areas beforehand with prepared letters explaining the purpose of the study and asking for cooperation when they returned the following day. The seeding procedure worked quite wel1 in the poorer, low-income areas of the city, but proved unnecessary in the more well-to-do sections. The interviewers also reported that the respondent was more receptive when they introduced themselves as students at the University of Utah in Salt Lake City.

Interviewers had letters of introduction with them. At the door, they explained briefly the purpose of the interview and asked for the respondent's cooperation. After being invited in, the interviewers collected information on the people living in the household and then selected eligible members of the household to be PHRs. Interviewers based their selections on criteria which they received from us each day regarding the sections of the PHR target-matrix needing data. After selecting each PHR, the interviewer proceeded to determine where other household members usually were when the PHR was performing the activities in question. Then they measured distances 
to these locations to the nearest foot for distances beyond ten feet and to the nearest one-half foot for distances less than ten feet.

Distances were recorded for each member of the household and for frequent visitors. In order to keep movement in the home at a minimum, we had grouped the questions in the questionnaire according to the activities performed in each room. Instead of asking direct questions on sleeping distances, locations of the beds and bed sizes were noted.

In addition to the distance data collected, interviewers noted whether the PHR worked shifts or regular days. If the PHR was a shift worker, data on his at-home activities for each of the shifts worked was collected, since substantially different data would likely be obtained.

At the end of the interview, the teams collected data on the house size. Our subsequent analysis, however, did not incorporate this data.

The first day of surveying demonstrated that the interview time required to obtain data on every potential heart recipient in each household was prohibitive for any one household. Therefore, we 1 imited the interview to one PHR in each household. This had the additional advantage of reducing the dependency factor introduced when multiple PHRs were considered in the same household. Toward the end of the interviewing period, we relaxed this restriction for husband-wife-only households since the additional time required to interview the spouse was small and we needed additional samples in this household type.

The final distribution of PHRs in the Salt Lake City survey is shown in Table E.3. It corresponds remarkably well with the distribution in the target-matrix shown in Table E.4, considering that respondents in less common household types were difficult to find. The distribution shown emphasizes again the unique age and sex distribution of persons who would be candidates for the artificial heart. 
TABLE E.3. Matrix of Interviewed Potential Heart Recipients (PHRs) in Salt Lake City

\begin{tabular}{|c|c|c|c|c|c|c|c|c|c|}
\hline \multirow[b]{2}{*}{ Age } & \multicolumn{8}{|c|}{ Household Type } & \multirow[b]{2}{*}{ Total } \\
\hline & 1 & 2 & 3 & 4 & 5 & 6 & 7 & 8 & \\
\hline \multicolumn{10}{|c|}{ MALE } \\
\hline $30-39$ & 1 & 3 & 6 & 7 & - & 1 & 2 & - & 20 \\
\hline $40-49$ & 3 & 8 & 10 & 18 & 1 & 4 & - & 1 & 45 \\
\hline $50-59$ & 25 & 18 & 9 & 7 & 3 & 2 & 2 & - & 66 \\
\hline $60-69$ & 44 & 8 & 4 & 3 & 1 & 3 & 1 & 1 & 65 \\
\hline $70-79$ & 34 & 3 & - & - & 1 & 3 & 1 & - & 42 \\
\hline $80+$ & 8 & - & - & - & - & 2 & 1 & - & 11 \\
\hline Tota 1 & $\overline{115}$ & $\overline{40}$ & $\overline{29}$ & $\overline{35}$ & 6 & $\overline{15}$ & 7 & 2 & $\overline{249}$ \\
\hline \multicolumn{10}{|c|}{ FEMALE } \\
\hline $30-39$ & - & - & 2 & 5 & 2 & - & - & - & 9 \\
\hline $40-49$ & 4 & 2 & 2 & 6 & 4 & - & - & - & 18 \\
\hline $50-59$ & 6 & 10 & 1 & 3 & 4 & 6 & - & - & 30 \\
\hline $60-69$ & 22 & 1 & 2 & - & 2 & 9 & 5 & - & 41 \\
\hline $70-79$ & 15 & - & - & - & - & 14 & 7 & - & 36 \\
\hline $80+$ & 3 & - & - & - & - & 5 & 1 & 1 & 10 \\
\hline Total & $\overline{50}$ & $\overline{13}$ & 7 & $\overline{14}$ & $\overline{12}$ & $\overline{34}$ & $\overline{13}$ & $T$ & $\overline{144}$ \\
\hline
\end{tabular}


TABLE E.4. Target-Matrix of Potential Heart Recipients for the Salt Lake City Survey

\begin{tabular}{|c|c|c|c|c|c|c|c|c|c|}
\hline \multirow[b]{2}{*}{ Age } & \multicolumn{8}{|c|}{ Household Type } & \multirow[b]{2}{*}{ Total } \\
\hline & 1 & 2 & 3 & 4 & 5 & 6 & 7 & 8 & \\
\hline \multicolumn{10}{|c|}{ MALE } \\
\hline $30-39$ & 1 & 1 & 2 & 4 & 0 & 0 & 1 & 0 & 9 \\
\hline $40-49$ & 6 & 6 & 8 & 13 & 1 & 2 & 2 & 1 & 39 \\
\hline $50-59$ & 27 & 15 & 11 & 12 & 2 & 6 & 4 & 2 & 79 \\
\hline $60-69$ & 42 & 12 & 5 & 4 & 3 & 9 & 5 & 2 & 82 \\
\hline $70-79$ & 29 & 4 & 1 & 1 & 2 & 8 & 6 & 2 & 53 \\
\hline $80+$ & 4 & 0 & 0 & 0 & 0 & 2 & 1 & 0 & 7 \\
\hline otal & $\overline{109}$ & $\overline{38}$ & $\overline{27}$ & $\overline{34}$ & 8 & 27 & 19 & 7 & $\overline{269}$ \\
\hline \multicolumn{10}{|c|}{ FEMALE } \\
\hline $30-39$ & 0 & 0 & 1 & 1 & 0 & 0 & 0 & 0 & 2 \\
\hline $40-49$ & 2 & 2 & 2 & 3 & 1 & 1 & 1 & 0 & 12 \\
\hline $50-59$ & 7 & 4 & 3 & 3 & 2 & 3 & 2 & 0 & 24 \\
\hline $60-69$ & 13 & 4 & 2 & 1 & 3 & 9 & 6 & 1 & 39 \\
\hline $70-79$ & 12 & 2 & 1 & 0 & 4 & 14 & 11 & 1 & 45 \\
\hline $80+$ & 2 & 0 & 0 & 0 & 1 & 4 & 4 & 0 & 11 \\
\hline Total & $\overline{36}$ & $\overline{12}$ & 9 & 8 & $\overline{12}$ & $\overline{31}$ & $\overline{24}$ & 2 & $\overline{133}$ \\
\hline
\end{tabular}


Use of Time Survey

Included in the Salt Lake City survey was a survey to obtain use-oftime data. This survey was usually done in conjunction with every fifth interpersonal distance interview. In this survey, people kept a detailed record of the time they spent in activities over a 24-hour period. In order to provide incentive, we paid them five dollars for each time interview completed. The interviewing team, after leaving the diary with the necessary instructions, returned the next day to have a final interview, complete any missing portions of the diary and to pay the respondents. The reluctancy of people to keep a diary on Sunday required special efforts to collect data on this day.

STATISTICAL ANALYSIS OF DOSE RATES FROM THE SALT LAKE CITY SUURVEY DATA

The many factors defining the PHR generated an extremely large matrix of needed data for REPRIEVE. To determine if we could reduce the size of this matrix, we performed a statistical analysis on the dose rate data derived from the Salt Lake City survey. This analysis determined if significant differences existed between PHR age groups, between PHR living locations, and between employed and nonemployed PHRs. Dose rates are an exponential function of distance, and the average dose rates calculated from the data would not have a normal (Gaussian) distribution. Therefore, simple comparison of dose rates was not possible. However, the distance measurements and the number of people contributing to dose should be normally distributed within our family type definitions. Therefore, we tested these factors statistically to determine if significant differences in dose rate would exist between PHR ages. We reduced the age, householdtype activity matrix to three age groups, nine household types, and twentytwo activities in order to obtain meaningful statistical comparisons. Then we analyzed the variance of the mean distances and mean number of irradiated targets using the $F$ statistic for the reduced matrix. We made additional pairwise comparisons of each age group using the standard $T$ test for the difference of two means. While individual exceptions occurred, the statistical 
results showed no definable pattern of significant difference by PHR age for each activity.

In a similar manner, we tested the data to determine if significant differences by urban versus rural living locations could be determined. For the urban-rural comparison, the analysis only showed significant differences for about $15 \%$ of the family activities tested. An examination of these differences revealed no logical explainable trend. In view of this and the fact that the rural sample was a small one, we concluded that the existing data did not justify the use of dose factors separated on an urban-rural basis.

We also tested the data for employment and non-employment status of the PHR. For these groups, 15 to $30 \%$ of the family activities tested showed statistically significant differences. Most of these differences could be logically explained. For example, the analysis showed that significantly more family members were around non-employed women than around employed women during weekday lunch times, a normal expectation. Due to the weighting of the sample population, more significant differences occur in husband-wife-only families. On this basis we concluded that the results justified separating the dose factors on an employed-nonemployed basis for husband-wife-only families. Although the same justification does not exist for the other family types owing to the small sample sizes, dose factors for these types probably follow the same pattern. The overall result of this statistical testing was to decrease the number of dose rate factors needed for input to REPRIEVE by a factor of five. 
PUBLIC ACTIVITY SURVEYS

The data on use-of-time from the University of Michigan indicated that the most significant public activities were shopping, non-work trips, organizational activity, social and entertainment activities, adult education, and sports and active leisure activities. A list showing the subdivision of these activities in greater detail is included in Appendix D. Public surveys in Richland, Seattle, and Salt Lake City collected data on number in attendance and interpersonal distances for these activities. From this data we determined dose rates and the number of persons exposed per recipient for both sexes and two age groups. We subsequently used this data in REPRIEVE to calculate population dose during public activities.

The different conditions associated with each activity necessitated using slightly different survey methodologies in many cases. A description of each activity and the methodology used follows.

Shopping

The use-of-time data (Appendix D) for the various types of shopping activities show that everyday buying is far more prominent than any other. Our measurements were, therefore, confined to the most commonly and frequently patronized stores (i.e., grocery and variety stores).

A variety of techniques was used to make measurements. One photographic technique consisted of random polaroid snapshots taken from behind one-way mirrors (using the existing shoplifting detection system). From these we ascertained the relative positions of people and later made distance measurements. This technique had the advantage of causing the least disturbance, but suffered in accuracy since photo depth-distortion often made the relative positions difficult to estimate. An off-shoot of this technique used the cameras directly in the store to capture relative positions from two angles. This allowed fairly accurate measurements, but resulted in considerable disruption due to curiosity on the part of those 
photographed. Another technique relied upon memory to recall visual observations of random situations. Measurements of relative positions were made immediately following such observations. This method caused less disturbance, and fairly accurate measurements could be made of low people-density situations. When more than four or five persons were observed, this technique failed due to an inability to exactly recall positions.

Although our direct interpersonal distance observations covered only limited random areas within the shopping environment, dose rate estimates also included a factor developed to include dose rates to nonobservable, potentially exposed persons outside these areas. We developed this factor by estimating the average people density in the shopping environment from counts of the number of people and measurement of the environment area. An integrative model then used this average people density to calculate dose rates to nonobservable persons. Later we used the computer model, BINGO, to estimate these dose rates. These models are explained in more detail later in the Appendix.

Where possible, we made measurements in a chosen area at several different times of day to allow for the effect of the time variable.

Because of the wide variance in dose rates in such shopping situations and the 1 imitations in the number of measurements that could be made, the actual average dose rates during such situations could substantially differ from those measured. However, the very small magnitude of the average dose rate, ( $0.0065 \mathrm{mrem} / \mathrm{hr} / \mathrm{RES}$ ) indicates that even a wide variation would have little effect on overall population dose.

\section{Nonwork Trips}

Since shopping and entertainment trips account for the majority of all time spent in nonwork trip activities, we used them as representative of the entire category. We collected distance, number and type-of-persons-exposed data by observing the occupants of automobiles entering and leaving the parking lots of these types of establishments. In making the observations we noted the type of car as well as the seats 
occupied so that the effect of car size was considered. We estimated interpersonal distances by making measurements of seating space in three ranges of car sizes.

Since a relatively large number of observations could be made in a short space of time, and since the variation in dose rates for this activity was small, the sampled mean dose rate should be close to the actual.

Organizational Activity

Since religious practice accounts for more than half of the time spent in organizational type activities, and since no other activity contributed a significant individual amount of time, we chose religious practice as representative of the entire category. We assumed that the bulk of the time spent in religious practice was in Sunday services, and obtained data on attendance at these services from five different religious denominations. After obtaining these data, we made measurements of the seating arrangements in the chapels and developed scaled drawings. The BINGO code (explained later in this section) placed the average number in attendance in random seating arrangements defined by these drawings and calculated the dose rate for each arrangement. The reiteration of this calculation for many seating placements in each denominational building sampled developed an overall average dose rate for religious service attendance.

\section{Social and Entertainment Activities}

The use-of-time breakdown for this category indicated that entertaining and parties with meals were the most frequent subactivities in this set. However, because of the large contact factors in other subactivities such as attendance at sports events, movies, bars, etc., we judged these other subactivities to be significant and included them in our surveys. (See Appendix D for a list of subactivities in this category.)

We collected data on room size and on the number of people present by age, sex, and relationship to AHR for the entertaining and visiting subactivity in the at-home activity surveys. Although early surveys attempted 
to obtain actual distance data, the great amount of mobility during this activity made us question the adequacy of a single representative measurement. Therefore, we measured the area in which the activity was performed and used the integration technique to determine the average dose per person. Later this calculation was checked using the random placement feature of BINGO to calculate the average dose and the dose rates obtained using both methods were in agreement. Parties with meals were easy to measure as they had a definite seating configuration.

To collect data on sporting events we surveyed a major league basebal1 game in Salt Lake City. Measurement of the stadium seating and aisle configurations allowed us to make scaled drawings prior to the game. A random selection of seven seating divisions determined the areas to be sampled. At game time visual observations of occupied seats provided the data necessary for dose calculations. To accomplish PHR identification, adults were distinguished from children and also categorized by sex. The BING0 program subsequently used this data to calculate the average dose per person.

The technique used to determine dose rates in theater and motion picture situations in Richland and Salt Lake City was similar to that described above. Scaled drawings of motion picture theaters provided possible seating locations and observations determined actual configurations during the film showing. Estimations of dose rates in bar situations were similar. We used the BINGO code in all of these observations to calculate the dose rates.

Once we had calculated the dose rates for the subactivities, we weighted them by the time spent in each subactivity in order to develop an overa 11, weighted average dose rate per RES for both AHR sexes.

\section{Adult Education}

We obtained data on adult education from surveys in Richland and Salt Lake City. The Richland survey, conducted at the Joint Center for Graduate Study, involved sampling older, professional workers. The sample in Salt Lake City involved mainly younger adults who were completing high school educations. The survey techniques used were identical to the methods described above for sporting events, etc. 
Sports and Active Leisure Activities

This category is composed of a group of quite diverse activities as shown in Appendix D.

In considering this from the standpoint of relative amount of time spent, three subactivities were prominent -- active sports, hobbies, and games. Since the median age of persons having an artificial heart is much older than the normal population, and since persons with such a heart are not likely to be engaged in strenuous sports activities, this subactivity is not likely to be a substantial contributor to an AHR's use of time. Hobbies and games, therefore, represent this activity group.

We hypothesized the games situation to consist of two couples at a standard sized card table and calculated dose rates for this subactivity. The Battelle survey provided the data to develop dose rates during performance of hobbies. Using these data we then calculated the dose rates for the two subactivities by weighting each rate by the relative time-insubactivity and averaging them to obtain an overall dose rate for the sports and Active Leisure category.

INTEGRATED AREA CALCULATIONAL MODEL

The Integrated Area Model calculates dose rates where a single distance measurement is not considered representative of the mean distance. The data input consists of the estimated dimensions of a significant-radiation zone (converted to a circular area around the device recipient) and the number of people in that zone. The model assumes that the people-density calculated from these data is constant and equal to the average for all distances (i.e., that an equal amount of time is spent at each possible incremental distance from the source over the total time of exposure). The model calculates dose rates by integrating the dose-distance function from a minimum radius of 0.5 feet to the outer radius of the effective radiation zone and then multiplying the result by the average people-density. Since the dose-distance function (as estimated using the QADP5A model) varies with distance, three functions 
are necessary to estimate dose rates -- one covering radial distances from 0 to 1.5 feet, one covering radial distances from 1.5 to 9 feet, and one covering radial distances beyond nine feet. Distances are from center of source to surface of exposed person. The overall equation is given below.

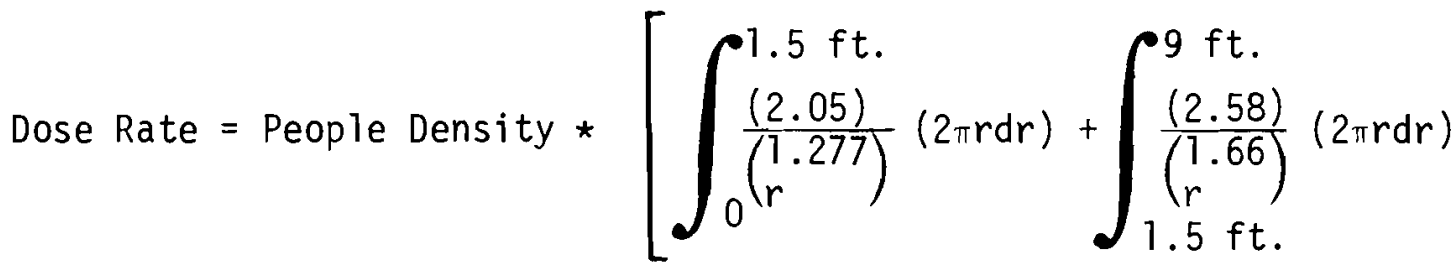

$$
\begin{aligned}
& \left.+\int_{9 \mathrm{ft}}^{200 \mathrm{ft}} \frac{(5.97)}{\left(\begin{array}{l}
2.06) \\
r
\end{array}\right.}(2 \pi r d r)\right]
\end{aligned}
$$

The main weakness in the integrative model is that no allowance is made for attenuation effects. Although few common substances exhibit significant gamma shielding effects, calculations from the QADP5A model showed a dose rate attenuation of $69 \%$ through a normal human body. In most situations the population density is low and the shielding effect minimal. However, in crowded situations, such as movie theaters, sports events and classrooms, the attenuation effect through human bodies becomes substantial; and use of the integrative model would considerable overstate the absorbed dose. To analyze these difficult situations we developed a powerful computer model entitled BINGO.

THE BINGO MODEL

BINGO is a computer program designed to calculate dose factors for situations where large numbers of people are either in specified locations within a defined area or where they are randomly located within a defined area. 
Activities where people remain stationary during the course of the activity include: sporting events, theater events, church worship services, and classroom situations. Situations where people tend to move throughout the course of the activity include: parties in the home, shopping in public places, visits to museums or exhibitions, visits to circuses or fairs, dancing, playing or practicing sports, and the general public.

BINGO allows the user to define the area size (e.g., a room $12 \times 14$ feet, a building $200 \times 400$ feet, a segment of a city $7 \times 7$ miles, etc.). This area is then divided into a grid system which defines the size of the location where people can be situated and how close they can be to each other. The grid can be any size smaller than the area (e.g., $1 / 2 \times 1 / 2 \mathrm{ft} ., 1 \times 1 \mathrm{ft} ., 10 \times 10 \mathrm{ft}$., etc.). The program places people in this grid by one of two methods -- either in defined locations specified by input data or in randomly placed locations via computerized randomization techniques. Each person is given an identity to determine if he is a potential radiation source, or just the public at large. These identities also permit the user to define the sex and age range of the individuals if it is necessary to the solution.

Once the people have identities and places in the grid, randomization techniques pick one of the potential radiation sources. A rotating ray then scans the area 360 degrees around the source to determine the relative distances to other people. This is illustrated for a classroom situation in Figure E.1. This scan also accounts for attenuation of the radiation through people based on the number of people in the path of the ray. The algorithm weights the dose by estimating which fractions of the body absorb radiation attenuated to different degrees, (i.e., part of an exposed person may be exposed by radiation attenuated by previous passage through one person, another part by radiation attenuated through two persons, etc.). Dose is calculated using the dose-distance equations described previously. 


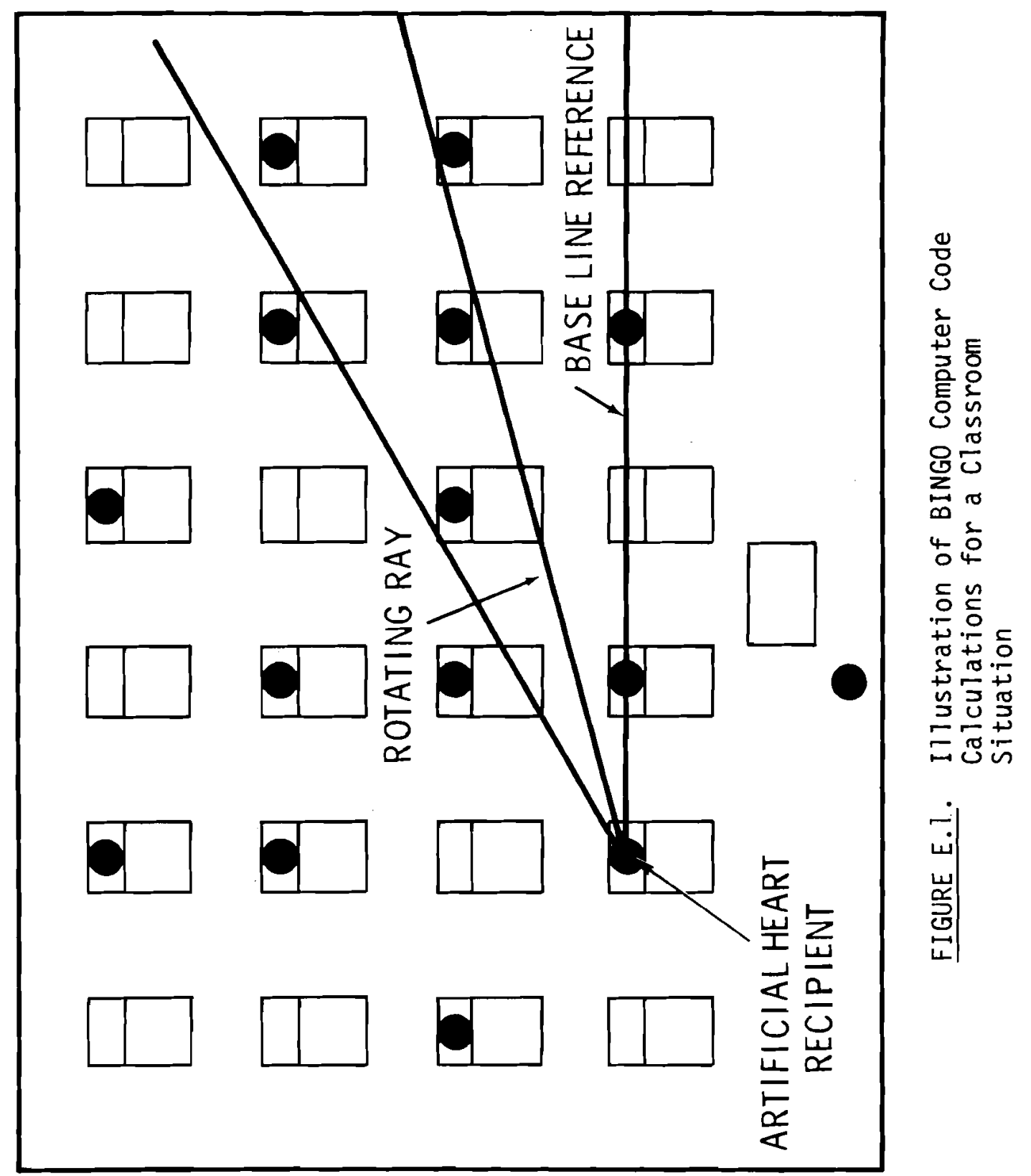


The dose given off by the source is summed and averaged for each classification by the identifiable traits of those receiving it. A new source is randomly selected and the whole process is repeated. The new averages are averaged with all preceding averages. This running average becomes the answer at the point when a user-designated convergence criteria is reached. We used several defined and calculatable examples as base-line cases to test the validity and accuracy of the preceding techniques.

Once BINGO had proven to be an accurate way of calculating dose to the public, we used it to check the dose rates for home entertainment activities which had been previously calculated using the Integrated Area model. The purpose of this recalculation was to determine if shielding was a prominent factor in this activity. We picked four households at random and processed each singly -- once with the integration method and three times with BINGO. (Because BINGO uses randomization techniques, at least three runs are necessary to converge on a true average.) The results are shown in Table E.5 and indicate that no shielding effect is discernable (i.e., it is much smaller than the normal variance of the calculations). Since BINGO allows the area to be represented by its actual dimensions, while the integration techniques work only with the calculated area (e.g., $12 \times 12$ and 144, respectively), the results using the BINGO code are still probably somewhat better.

TABLE E.5. Average Dose Per Household Member

\begin{tabular}{|c|c|c|c|c|c|c|c|c|c|}
\hline $\begin{array}{l}\text { Household } \\
\text { Member } \\
\end{array}$ & $\begin{array}{l}\text { BINGO } \\
\text { Run } 1 \\
\end{array}$ & $\begin{array}{l}\% \text { of } \\
\text { Ave. }\end{array}$ & $\begin{array}{l}\text { BINGO } \\
\text { Run 2 } \\
\end{array}$ & $\begin{array}{l}\% \text { of } \\
\text { Ave. }\end{array}$ & $\begin{array}{l}\text { BINGO } \\
\text { Run } 3 \\
\end{array}$ & $\begin{array}{l}\% \text { of } \\
\text { Ave. }\end{array}$ & $\begin{array}{l}\text { BINGO } \\
\text { Ave. }\end{array}$ & $\begin{array}{c}\text { Integration } \\
\text { Method } \\
\end{array}$ & $\begin{array}{l}\% \text { of } \\
\text { BINGo } \\
\text { Ave. }\end{array}$ \\
\hline 38 & .218 & 0 & .215 & -1.4 & .222 & 1.8 & .218 & .215 & -1.4 \\
\hline 152 & .235 & 5.4 & .231 & 3.6 & .203 & -9.0 & .223 & .205 & -8.1 \\
\hline 91 & .262 & 1.9 & .258 & 0.4 & .251 & -2.3 & .257 & .240 & -6.6 \\
\hline 78 & .172 & -2.3 & .180 & 2.3 & .175 & -0.6 & .176 & .163 & -7.4 \\
\hline
\end{tabular}


He 110, my name is , and this is We are both aturients at the Iniversity of Utah. We are currently conducting a research survey for Battelle-Northwest in connection with artifictal heart studies for the $U$. 5 . Atomic Eneray Cormission. We left a letter here yesterday telling you that we planned to call on you today for this survev. You are probabiv aware that there are many research projects designed to investiqate various solutions to the problem of heart disease. We are afflliated with one of these projects and want to ask your assistance.

We would like to come in, ask you some questions about your normal daily activities, and take some measurements of typlcal distances that separate members of your family during certain activities. The interview will take only about 30 minutes. All of the information we collect will be kept strictly confidential and will not be coded to your name or address. We have a letter of introduction here that we would 1 ike to show you, sianed by Dr. Altman, Chairnan of the Psychology Department at the University of Utah, and by Mr. Mckee, who is the orogram leader for BattelleNorthwest. May we come in?

As you may know, there is a great deal of research going on now on nuclear powered pacemakers and artificial hearts. While pacemakers, which simply heip a person's heart to beat normally, are being used successfully today, a complete artificial heart is still some years away. Because heart disease is the leading cause of death in the country, a lot of research is being done to find wavs to reduce this death rate. An artificia heart is a possible answer. One of the problems associated with a nuclear-powered heart is that a small amount of radiation would be transmitted to people near the person having the feart device. We don' $t$ expect that this will be a serious hazard, but we want to collect information that will make it possible for us to make realistic estimates of the hazard. If you were ever to have such a heart device, the amount of radiation your family would receive would depend on how far away from you they were during normal everyday activities. This is the reason we want to measure typical distances separating aduits from the rest of the household during everyday activities

"We want to begin by asking questions about each person in your home who is over 30 vears of age. How many such people are there and who are they?"

1. Enter identity under PHR 1, PHR 2, and PHR 3.

Everyone living and eating together in the housing unit is counted as a member of the household. Each adult member over 30 will be counted one at a time as if he (she) were the "Potential Heart Recinient" (PHR).

[If the respondent is over 30, choose him (her) as the first Potential Heart Recipient (PHR); if not, begin with any other adult over 30.]

Fill in the information blanks above by asking the following auestions for each Potential Heari Recipient (PHR).

2. What is the age of [the Potential Meart Recipient (PHR)]?

3. Enter the sex of [the Potential Heart Recipient (PHR)]

4. Is (the PHR) employed? (Enter full-t ime, part-time, or not employed).

5. Who are the other household members? (Enter identity) (This includes all adults other than the current PHR.)

6. What are the ages of all other household members besides (the current PHR)?

8. Enter the relationship of each of the other househoid members to the Potential Heart Recipient (PHR) according to the code below. $P=$ Parent or parent-in-law of the PHR.

$S=$ Spouse of the PHR

$\begin{aligned} C & =\text { Child of the PHR. } \\ G C & =\text { Grandchild of the PHR. }\end{aligned}$

$\begin{aligned} G C & =\text { Grandchild of the PHR. } \\ B & =\text { (Brother, sister, brother-in-law, sister-in-law) of the PHR. }\end{aligned}$

$\begin{aligned} B & =\text { (Brother, sister, brother-in-law, sister-in-law) } \\ G P & =\text { Grandparent or grandparent-in- } 7 \text { aw of the PHR. }\end{aligned}$

$0=0$ ther relative of the PHR (aunt, uncle, cousin, nephew, niece, etc.).
$N R=$ Not related to the PHR (employees, lodgers, foster children, and other unrelated cersons).

"Now we want to ask a few questions about various activities engaged in by members of the household. For each of these activities, we need to get an idea as to where various other people in the family are located in the house, and one of us will actually measure distances between various locations. These measurents are intended to give us information on distance relationships between people in the household.

For each of the activities which follow, except social parties, determine where (the PHR) is when he (she) is performing the activity. Measure the distances from (the PHR) to all other househoid members usually present when (the PHR) is performing the activity in question. Each distance thus measured must be entered under the corresponding identity of the person (Question 15) to whom the measurement was made. Also for each activity except soctal visits and parties, ask if non-members of the household are frequently present when the PHR is oerforming the activity. If yes. enter

\section{FIGURE E.2. Questionnaire for the Salt Lake City Survey}


$\underline{\text { PHR }}$

1. Identity

2. Age of the PHR

3. Sex of the PHR

4. Is (the PHR) employed?

\section{OTHERS}

5. Identity

6. Age of others

7. Sex of others (M or F)

8. Relationship to PHR

\section{PREPARING MEALS}

Generally only women PHR's will be performing this activity.

1. Enter distances from other household members to (the PHR) when she is preparing breakfast cleaning up breakfast

preparing lunch

cleaning up lunch

preparing dinner cleaning up dinner

2. Are any non-members of the household frequently present while the PHR is doing the above. If yes, enter meal and $P$ for preparing or $C$ for cleaning up, the non-members age, sex, distances to (the PHR) and how of ten the nonmember is present.

PHR 1
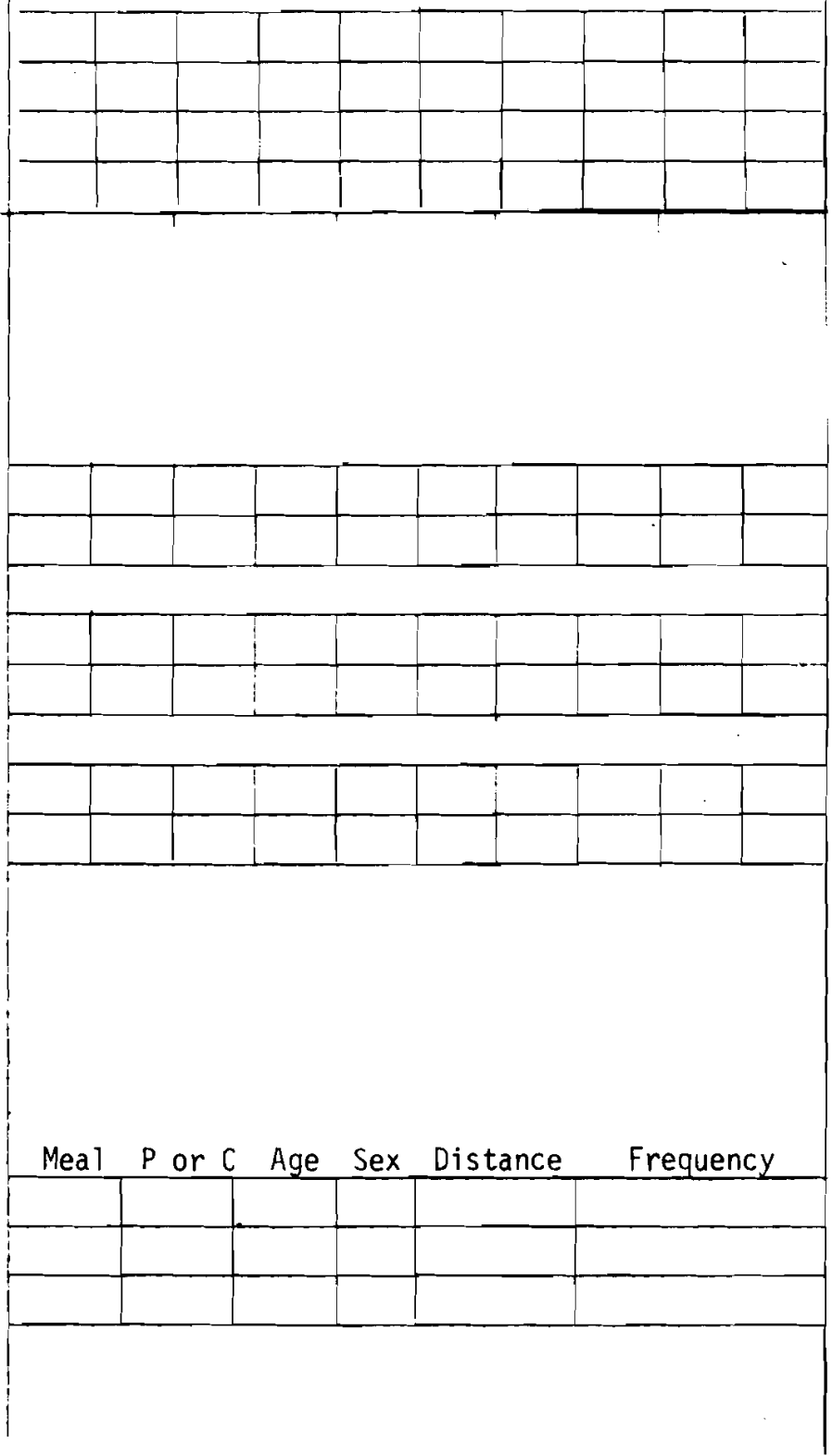

FIGURE E.2. (Contd) 


\section{CLEANING HOUSE}

Only female PHR's will be considered as performing this activity (unless only male PHR's live in the household).

1. Are any household members usually present when (the PHR) is cleaning house? If yes, enter a check under each person present.

2. What is the approximate closest distance of anyone to the PHR when she is cleaning house?

3. Are non-members of the household frequently present when (the PHR) is cleaning house? If yes, enter how many of each sex, average age, and how of ten each non-member is present.

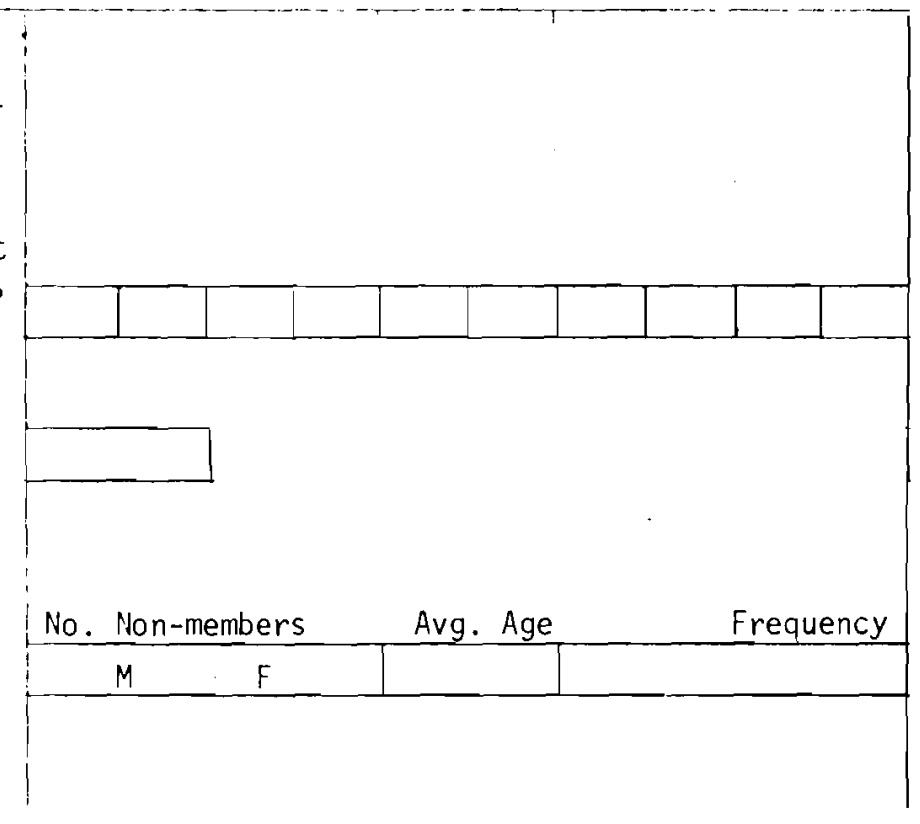

\section{LAUNDRY}

Only female PHR's will be considered as performing this activity (unless only male PHR's live in the household).

1. Does (the PHR) spend more time washing, ironing, or mending clothes?

2. Are any household members usually present when (the PHR) does the most frequent activity above. If yes, find PHR's usual location and enter distances to household members.

3. Are any non-members of the household frequently present when (the PHR) is doing the most frequent activity above? If yes, enter each non-member's age, sex, distance to PHR, and how often each is present (once a week, etc.).

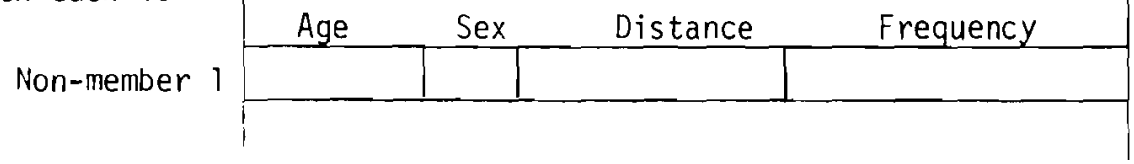

FIGURE E.2. (Contd) 
4. OTHER HOUSE UPKEEP

1. Does (the PHR) spend more time at household repairs and maintenance, or paying the monthly bills?

a. If repairs, what maintenance or repairs are needed most of ten? Where is (the PHR) while doing this? Where are the other household members? Enter distances.

b. If monthly bills, where does (the PHR) usually do this? Where are the other household members? Enter distances.

2. Are any non-members of the household frequently present when (the PHR) does la or $7 b$ above? If yes, enter non-members' age, sex, distance to (the PHR), and how of ten the non-member is present (half the time, etc.).

Non-member 1 Non-member 2 Non-member 3 Non-member 4

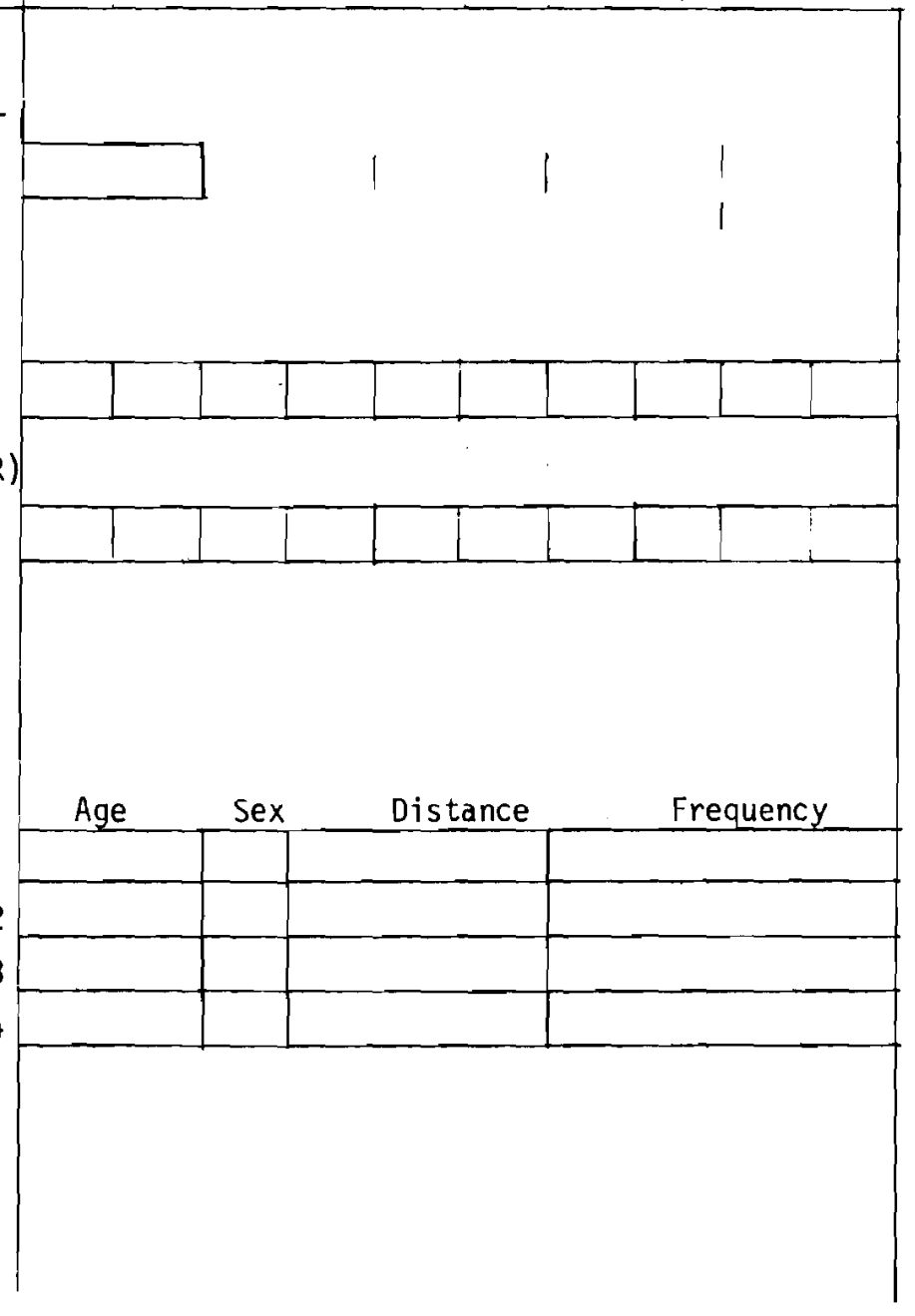

FIGURE E.2. (Contd) 


\section{GARDENING AND PETS}

1. Does (the PHR) spend more time qardening (including lawn care), or taking care of pets?

\section{Gardening Only}

a. If gardening, what would typically be the nearest and farthest distances (up to $200 \mathrm{Ft}$.) of anyone from (the PHR)?

How many persons would normally be in between these distances (include houschold members)?

What would be their average age range?

Pet Care Only

a. If pet care, where is (the PHR) usually while doing this. Where are the other hous ehold members?

Enter distances.

Are any non-members of the household frequently present while (the PHR) is doing pet care? If yes, enter each non-members age, sex, distance to PHR, and how often the non-member is present (half the time, etc.).

Non-member 1

Non-member 2

Non-member 3

Non-member 4

\section{Nearest:}

Farthest:

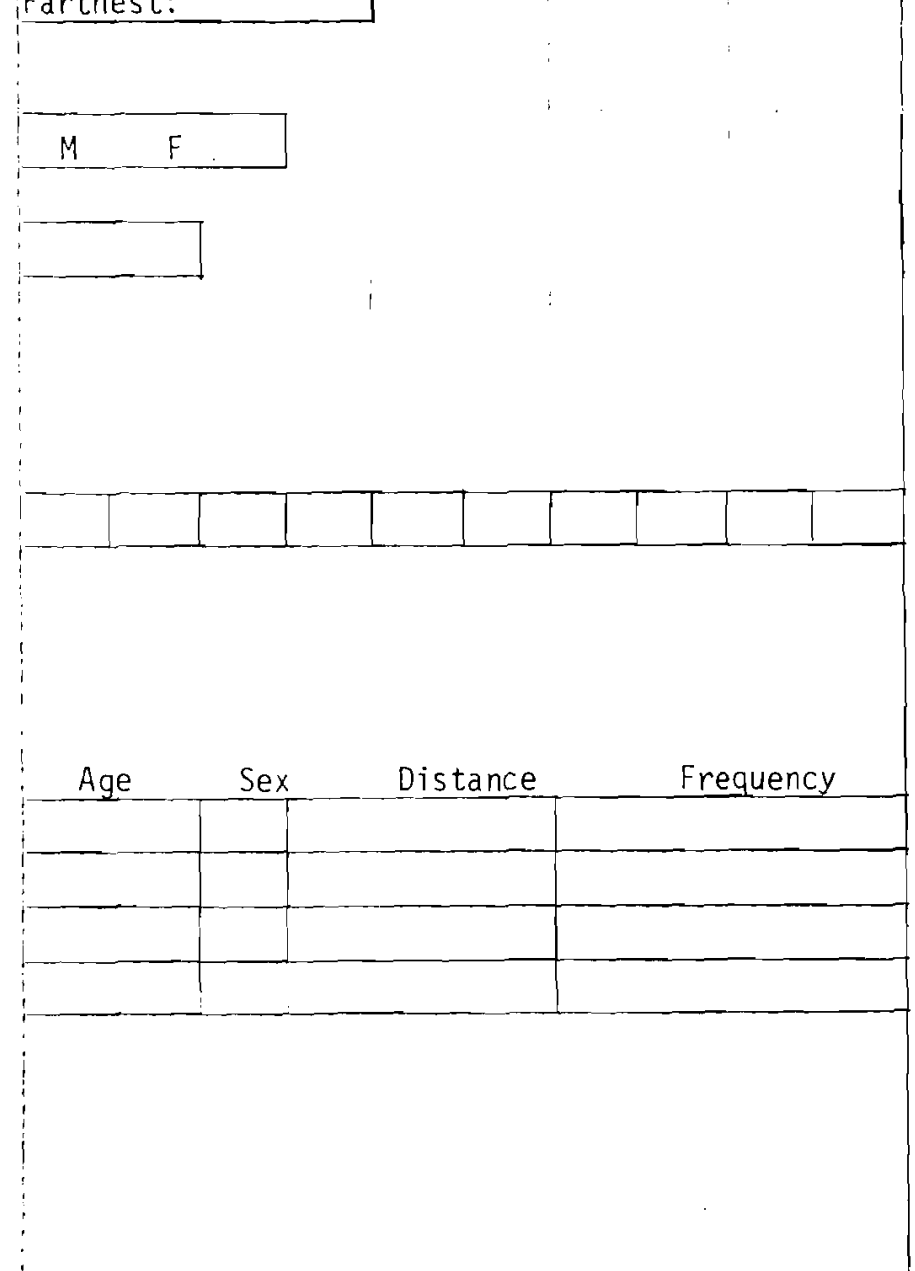

\section{FIGURE E.2. (Contd)}




\section{SLEEPING}

1. Does (the PHR) work shift work?

A. If yes, does (the PHR) regularly work the same shift?

Al. Yes - enter shift and continue with Question 2 below.

A2. No - go to special shift work sheet for sleeping.

2. Does (the PHR) sleep in the same bed with any other household member? If yes, ask all of the questions below. If no, ask only Questions 4 and 5.

3. YES ONLY

a. Enter relationship to (the PHR) of the member sleeping-with the PHR.

$H=$ Husband $\quad C=$ Child

$W=$ Wife

$0=$ Other

b. Enter bed type [double (D), king (K) queen (Q)], if other, specify.

4. a. Enter distances to other household members when (PHR) is sleeping. If Questions $1 \mathrm{la}$ and $1 \mathrm{~b}$ were answered, leave the distance for the member sleeping with (the PHR) blank.

b. Are any non-members of the household frequently present when (the PHR) is sleeping? If yes, enter each nonmembers age and sex, the distance to the PHR, how of ten the non-member is present (once a week, twice a month, etc.)

Non-member 1

Non-member 2

5. Are the doors to the bedrooms usually open or closed when people are in them?
Yes

No

Shift

Yes

No
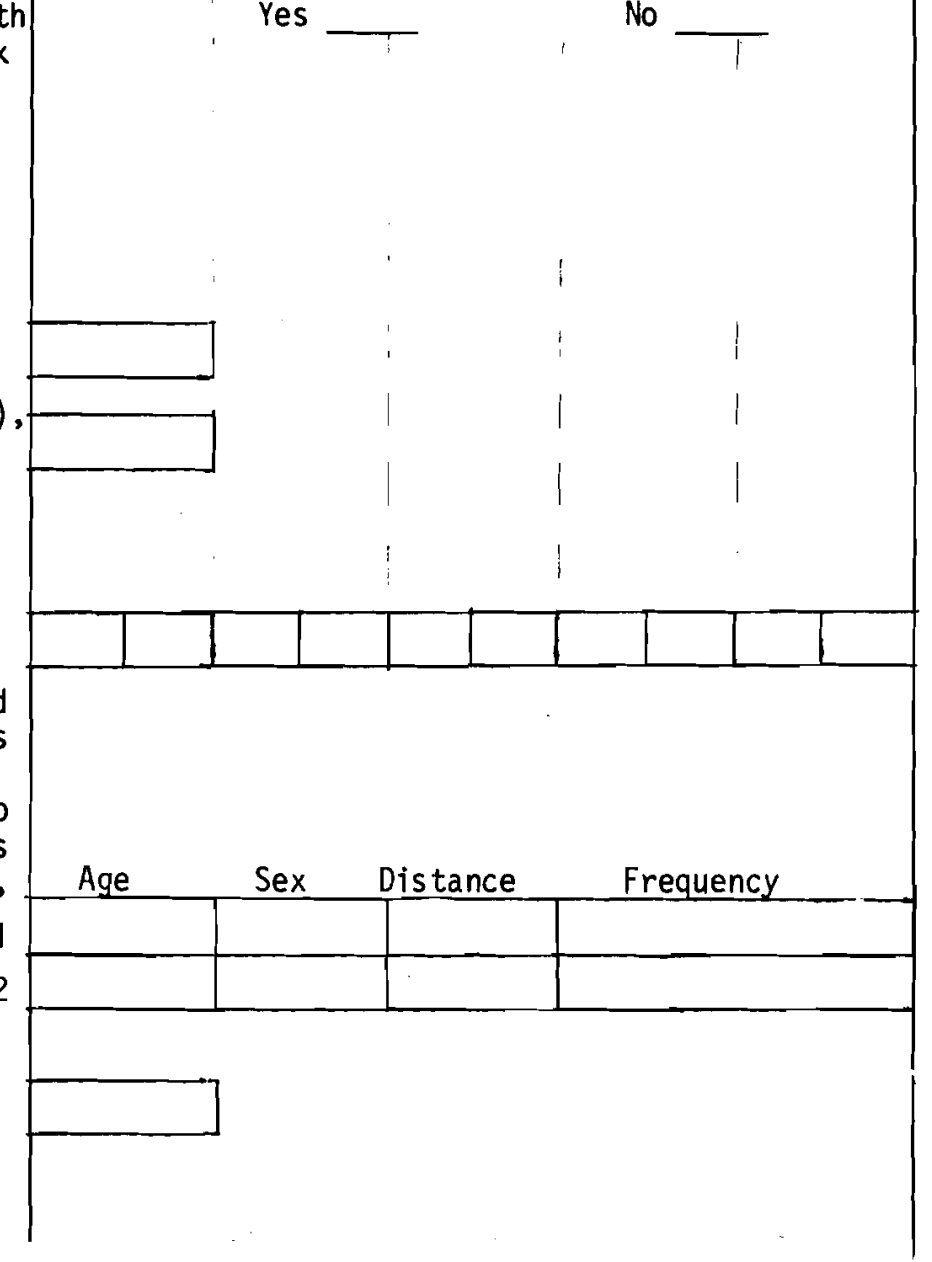

FIGURE E.2. (Contd) 


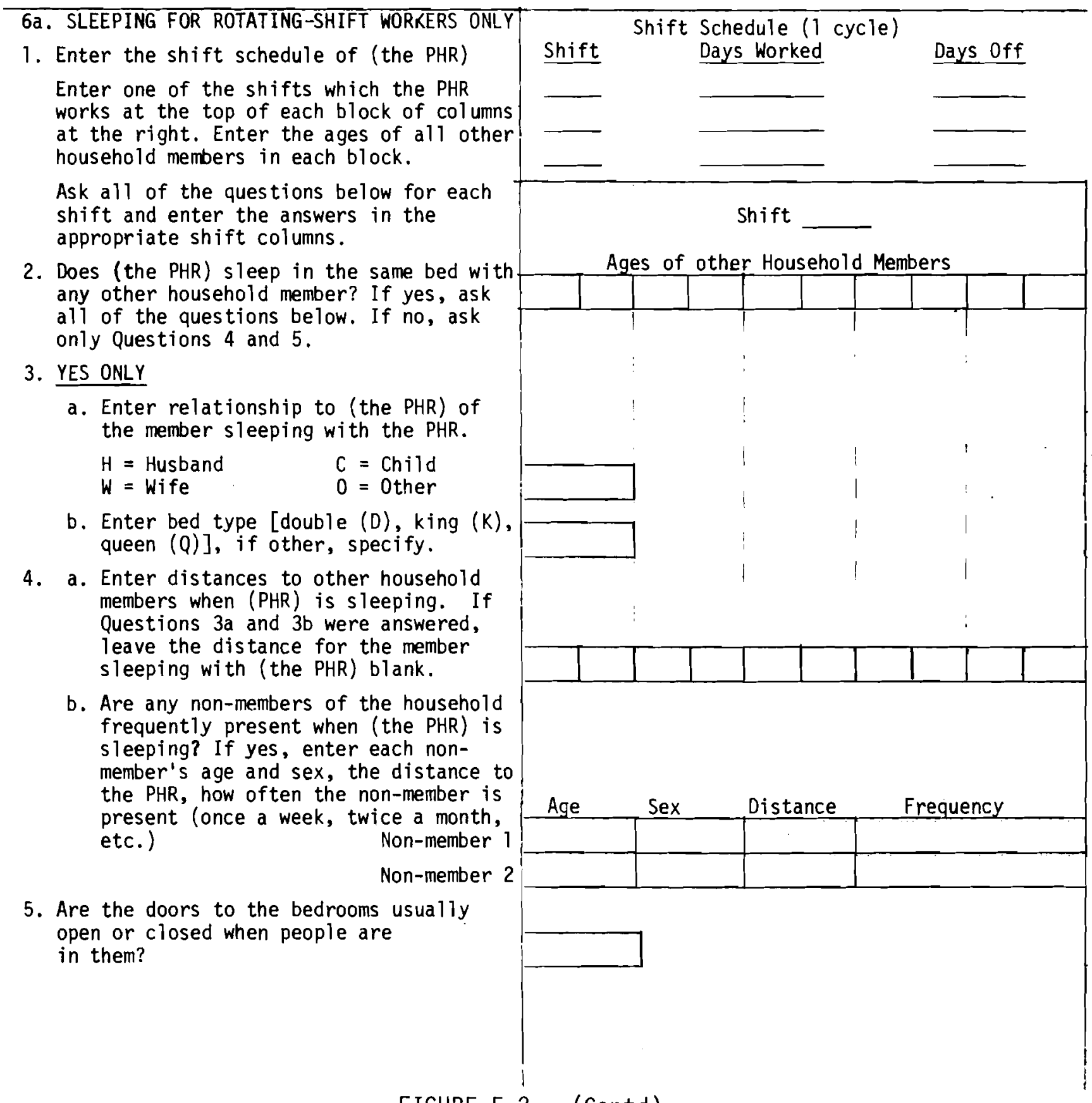

FIGURE E.2. (Contd) 


\section{PERSONAL CARE}

1. Where does (the PHR) usually attend to his/her personal care (dressing, brushing teeth, etc.)? Where are the other household members when the (PHR) is attending to his/her personal care?

\section{Enter distances}

2. Are any non-members of the household frequently present when (the PHR) is attending to personal care? If yes, enter age, sex, distance to PHR, and how of ten the non-member is present for each non-member

\section{Non-member 1 \\ Non-member 2}

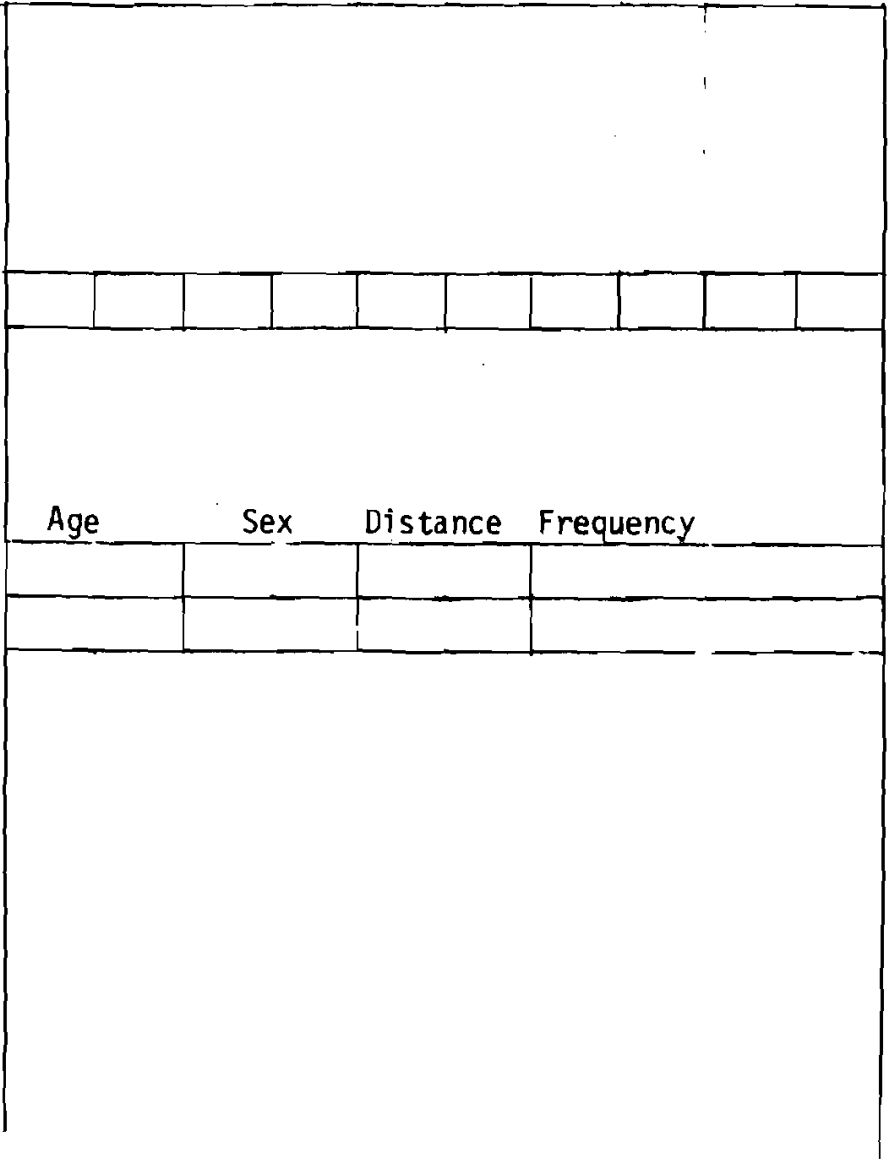

FIGURE E.2. (Contd) 


\section{EATING}

1. Does (the PHR) work shift work?

A. Yes - does (the PHR) regularly work the same shift?

A1. Yes - enter which shift and continue with Question 2 below.

A2. No - go to special shift work sheet for eating.

2. Are there any weekday or weekend meals which the PHR does not eat at home? If yes, line out the spaces opposite these meals below and do not ask the questions pertaining to them.

Ask each pair of questions below for both weekdays and weekends (unless lined out).

3. a. Where does the PHR eat BREAKFAST?

b. Where are the others when (the PHR) eating? Enter distances on weekdays

weekends

4. a. Where does (the PHR) eat LUNCH?

b. Where are the others when (the PHR) eating? Enter distances on weekdays

weekends

5. a. Where does (the PHR) eat DINNER?

b. Where are the others when (the PHR) is eating? Enter distance on weekdays

weekends

6. Are non-members of the household

frequently present when (the PHR) is eating any of the above meals? If yes, enter which meal, age and sex of each nonmember, distance to the PHR, and how often each is present.

7. Draw a small sketch of the dinner seating locations in this space. Desiqnate Father $(F)$, Mother $(M)$, Children $(C)$, other $(0)$.

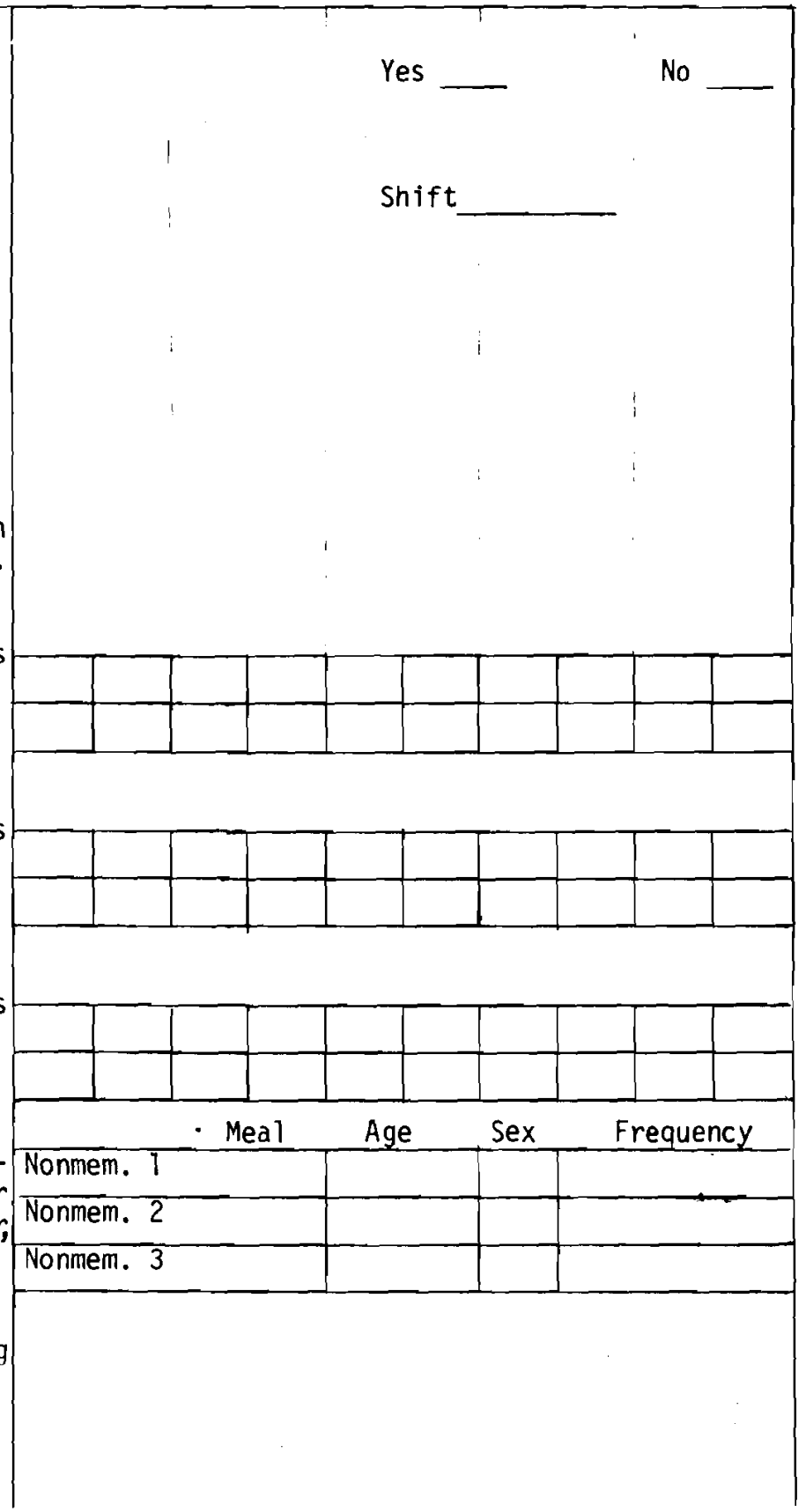

FIGURE E.2. (Contd) 
8a. EATING -FOR ROTATING-SHIFT WORKERS ONLY

1. Enter one of the shifts which the PHR works at the top of each block of columns at the right.

Enter the ages of all other household members in each block.

Ask all of the questions below for each shift and enter answers in proper block.

2. Are there any weekday or weekend meals which the PHR does not eat at home? If yes, line out the spaces opposite these meals below and do not ask the questions pertaining to them.

Ask each pair of questions below for both weekdays and weekends (unless lined out).

3. a. Where does the PHR eat BREAKFAST?

b. Where are the others when (the PHR) is eating? Enter distances on weekends

weekdays

4. a. Where does (the PHR) eat LUNCH?

b. Where are the others when (the PHR) is eating? Enter distances on weekdays

weekends

5. a. Where does (the PHR) eat DINNER?

b. Where are the other when (the PHR) is eating? Enter distances on weekdays

weekends

6. Are non-members of the household

frequently present when (the PHR) is eating any of the above meals? If yes, enter which meal, age and sex of each nonmember, distance to the PHR, and how often each is present.

7. Draw a smal1 sketch of the dinner seating locations in this space. Designate

Father (F), Mother (M), Children (C), other $(0)$.

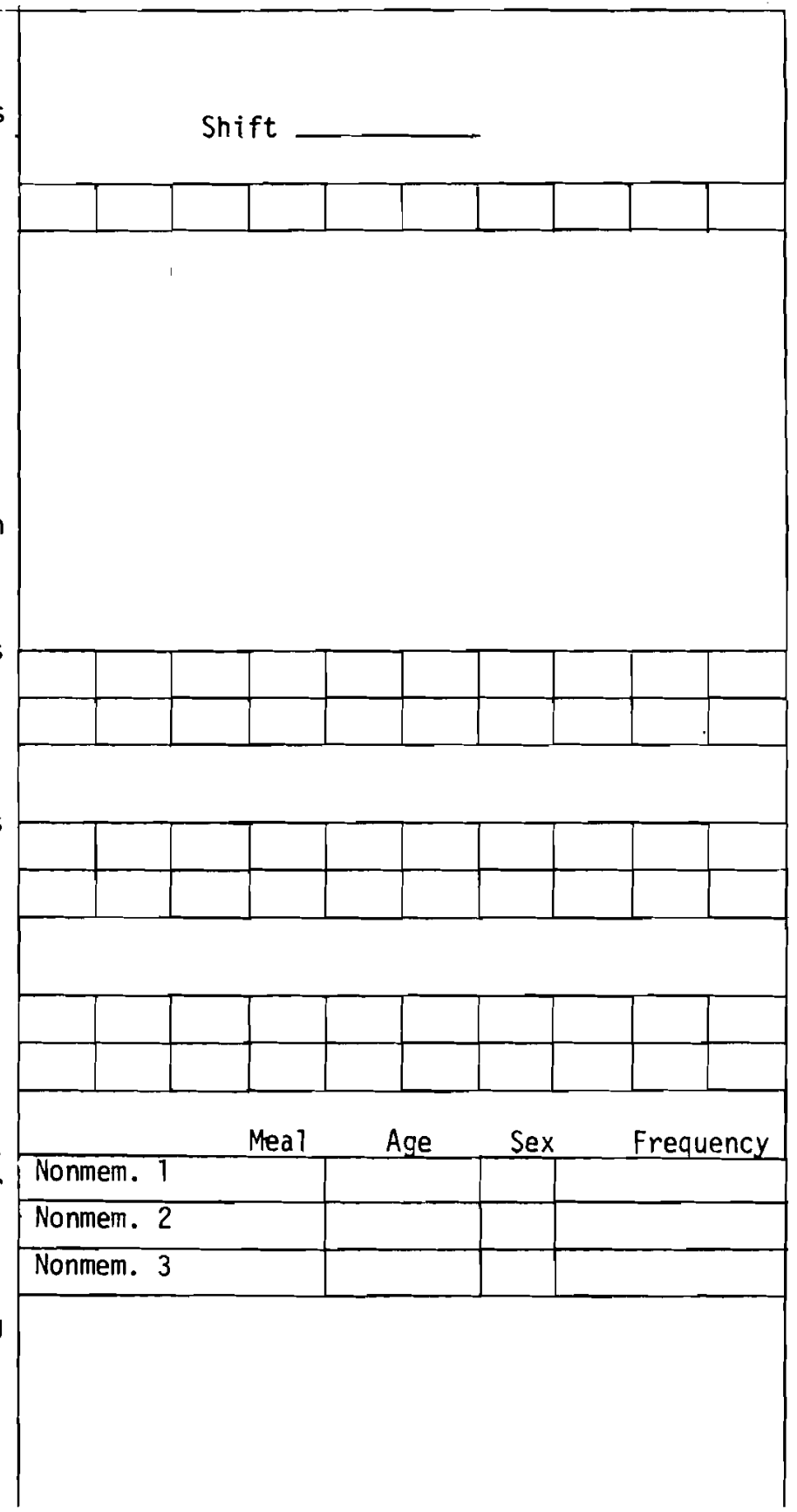

FIGURE E.2. (Contd) 


\section{RESTING}

1. Does (the PHR) ever take naps? If yes, where usually? Where are the other household members usually when (the PHR) is napping?

enter distances

2. Are any non-members of the household frequently present when (the PHR) is napping? If yes, enter each non-member's age, sex, distance to the PHR, and how often the non-member is present when (the PHR) is napping.

Non-member 1

Yes

No

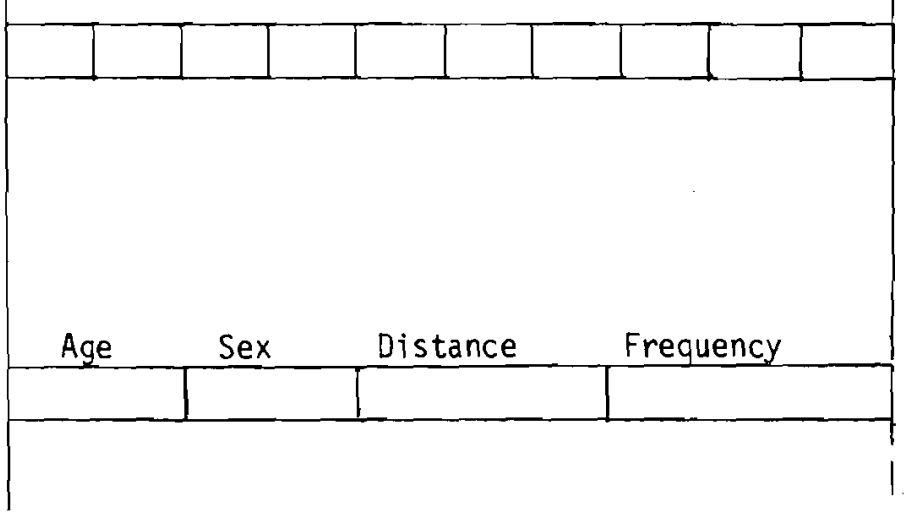

\section{CHILD CARE}

1. Does (the PHR) have any of the child care responsibilities below? If yes, check which ones and circle the one which (the PHR) does most often.

\section{Baby care}

Dressing, bathing, caring for older children School work help Reading/talking to children Indoor games Outdoor games Medical care to children Other (specify)

2. Where is (the PHR) when doing the most frequent activity above? Where are the other household members (including children being cared for).

Enter distances.

3. Are any non-members of the household frequently present when (the PHR) is doing the most frequent activity above? If yes, enter each non-member's age, sex, distance to (the PHR) and how of ten the non-member is present (half the time, etc.).

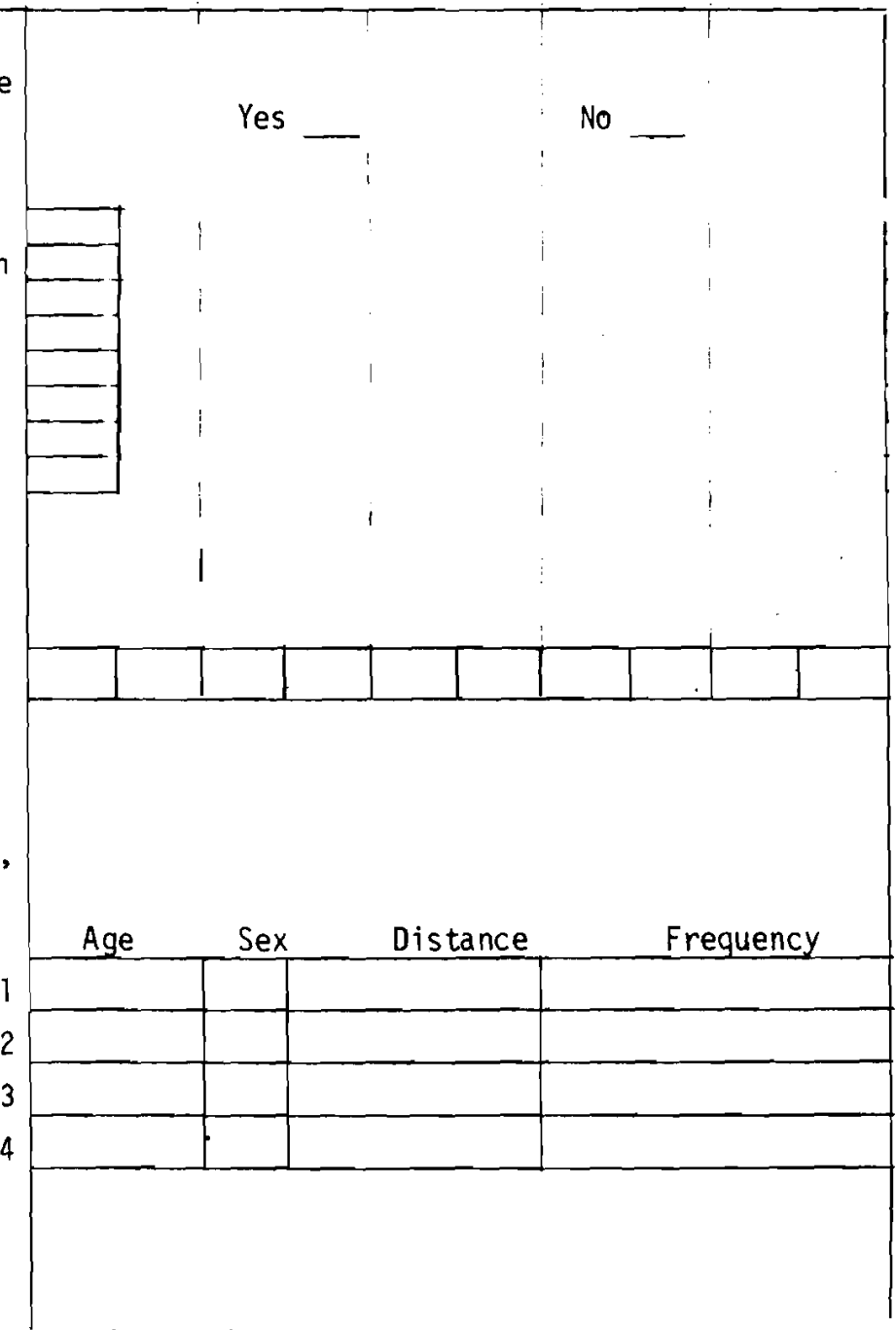

FIGURE E.2. (Contd) 
11. CARE TO OTHER ADULTS

1. Does (the PHR) give any care to adults (disabled, unable to care for themselves)? If yes, where does (the PHR) usually do this? Where are the other household members (include adults being cared for)? Enter distances.

2. Are any non-members of the household frequently present when (the PHR) is caring for adults? If yes, enter each non-member's age, sex, distance to PHR and how often the member is present (half the time, etc.).

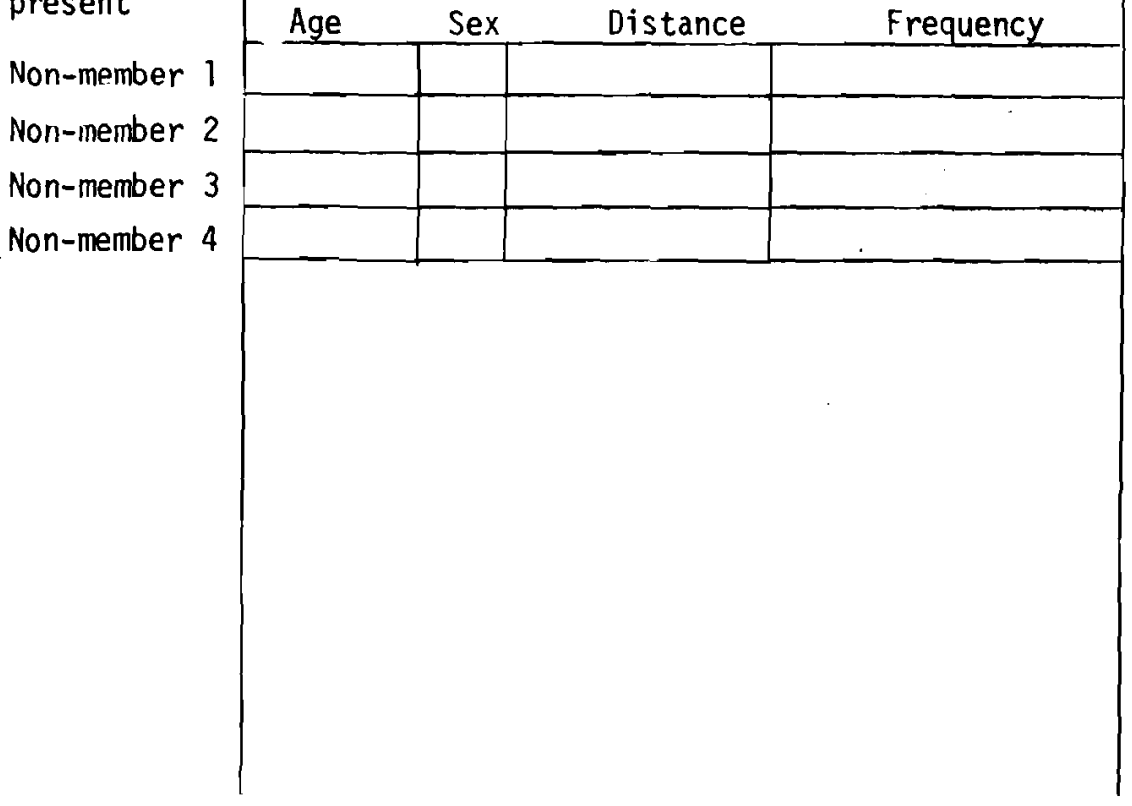

FIGURE E.2. (Contd) 


\section{HOME STUDY}

1. Has (the PHR) taken any correspondence or other courses requiring home study in the last year?

If yes, where does (the PHR) usually study? Where are the other household members when (the PHR) is studying? Enter distances.

2. Are any non-members of the household frequently present when (the PHR) is studying? If yes, enter each non-member's age, sex, distance to PHR, and how often non-member is present when (the PHR) is studying.

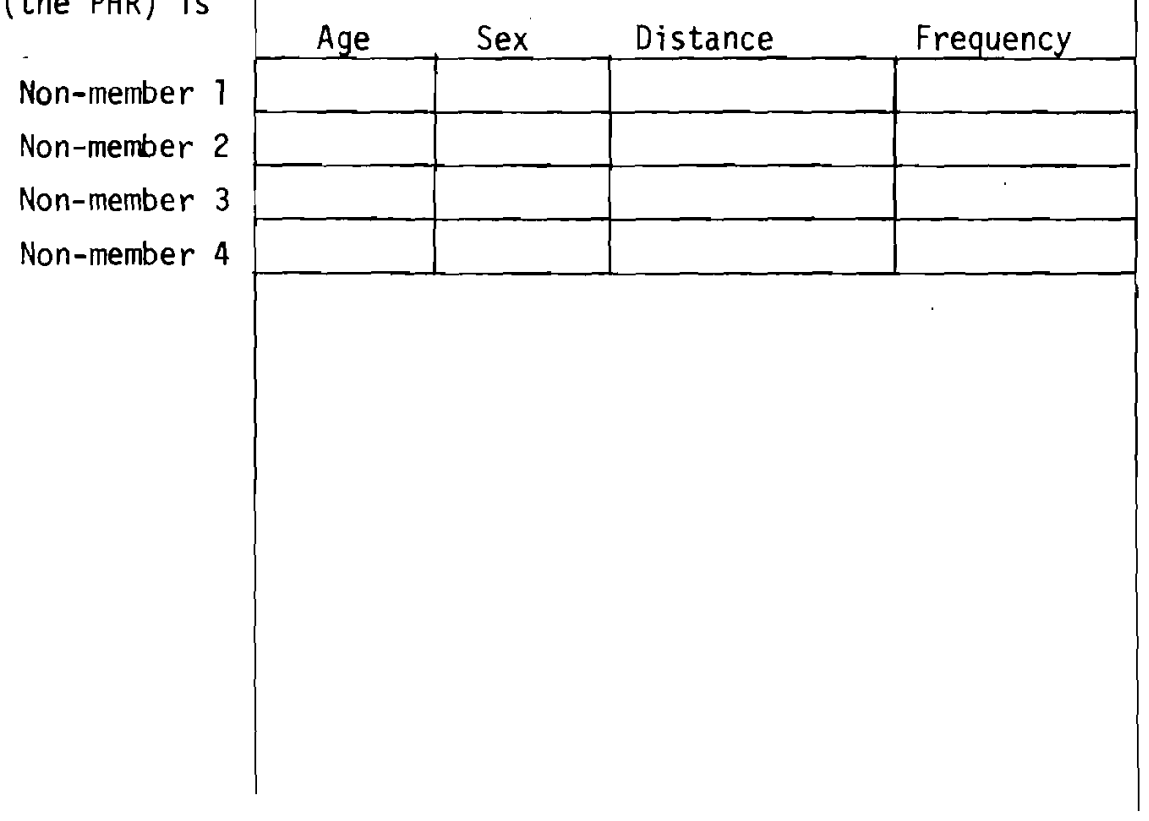

FIGURE E.2. (Contd) 
16. TV WATCHING

1. Where does (the PHR) usually watch TV? Where are the other members of the household when (the PHR) is watching TV?

Enter distances to household members

2. Are any non-members of the household frequently present when (the PHR) is watching TV? If yes, enter each non-member's age and sex, the distance to the PHR, and how of ten each non-member is present when (the PHR) is watching TV ( once a week, etc.).

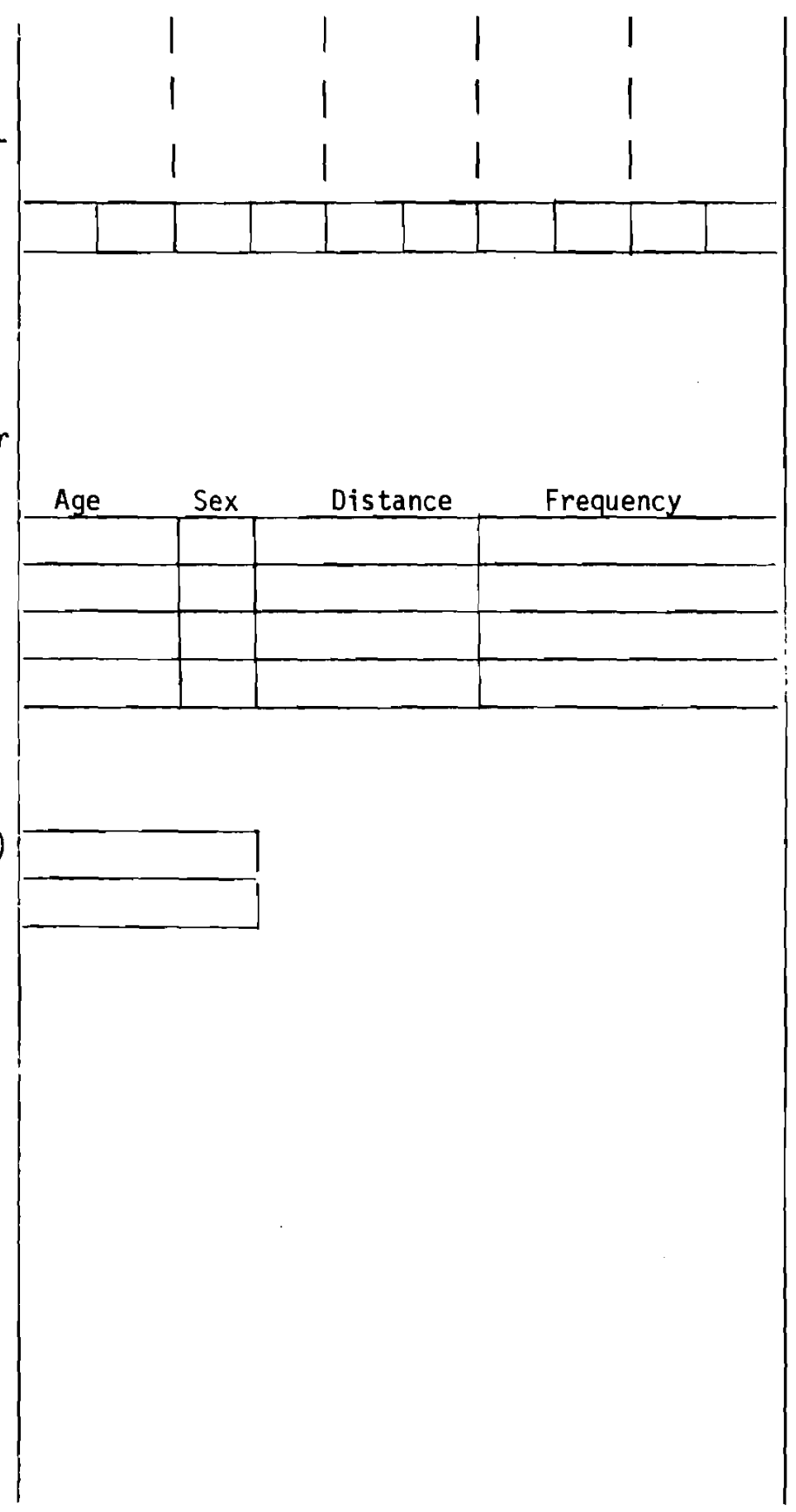

HOUSE SIZE

What are the dimensions of the house

Upper level(s)
Basement

Basement

FIGURE E.2. (Contd) 


\section{READING}

1. Where does (the PHR) usually sit during leisure reading (newspaper, magazines, books)? Where are the other household members usually located when (the PHR) is reading. Enter distances to household members.

2. Are non-members of the household frequently present when (the PHR) is reading? If yes, enter each non-members age, sex, distance to (the PHR) and how often the non-member is present (once a week, twice a month, etc.).

Non-member 1

Non-member 2

Non-member 3

\section{TELEPHONE}

1. Are any household members usually present when (the PHR) is typically on the phone? If yes, enter a check under each person present.

2. What is the closest distance of any one to (the PHR) when he/she is talking on the telephone?

3. Are non-members of the household frequently present, when (the PHR) is talking on the telephone? If yes, enter how many of each sex, a verage age, and about how often each non-member is present (once a week, etc.)?

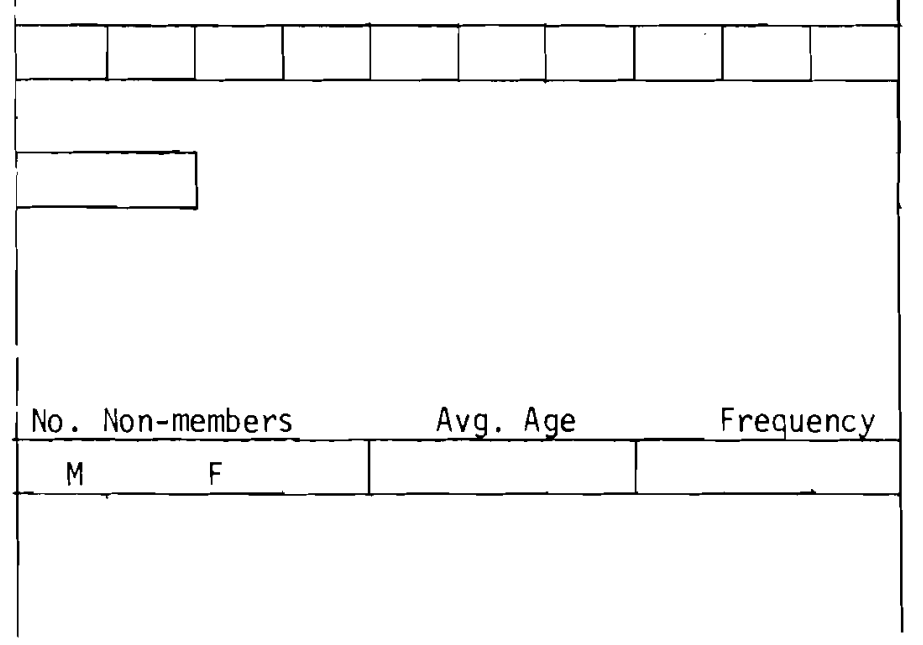

FIGURE E.2. (Contd) 


\section{8-1 DROP-IN VISITS}

Do friends sometimes just drop in for a visit? If no, go to next page.

How many adults of age 18 or over are typically present?

What are their approx. ages?

How many children do they usually bring if any?

What would be the approx. ages of these children?

Where would (the PHR) usually sit? Where would the household members who are usually there sit? Measure and enter distances to household members.

Where would the adult visitors usually sit? Measure and enter nearest and farthest distance.

Where would the children visitors usually sit? Measure and enter nearest and farthest distance.

men

women

men

women Nearest Farthest

Nearest

Farthest

Yes

No
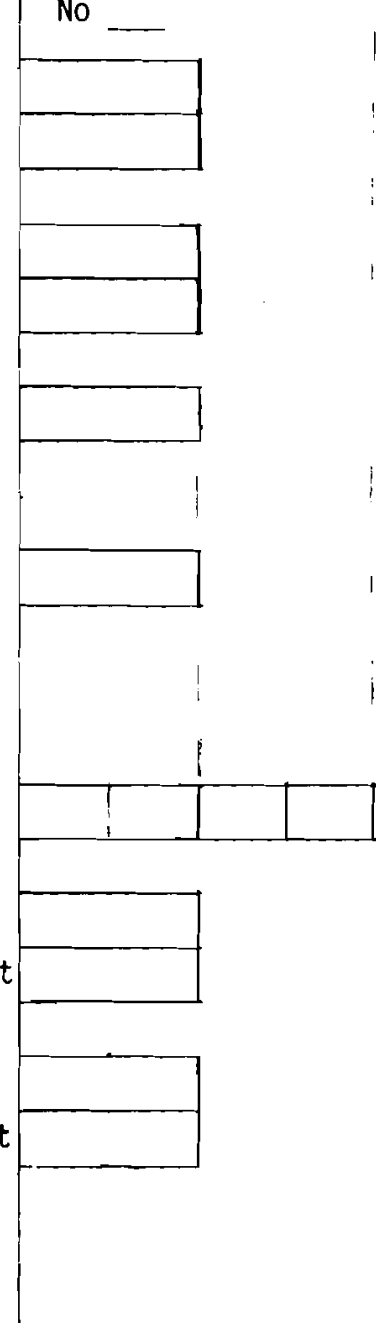

FIGURE E.2. (Contd) 


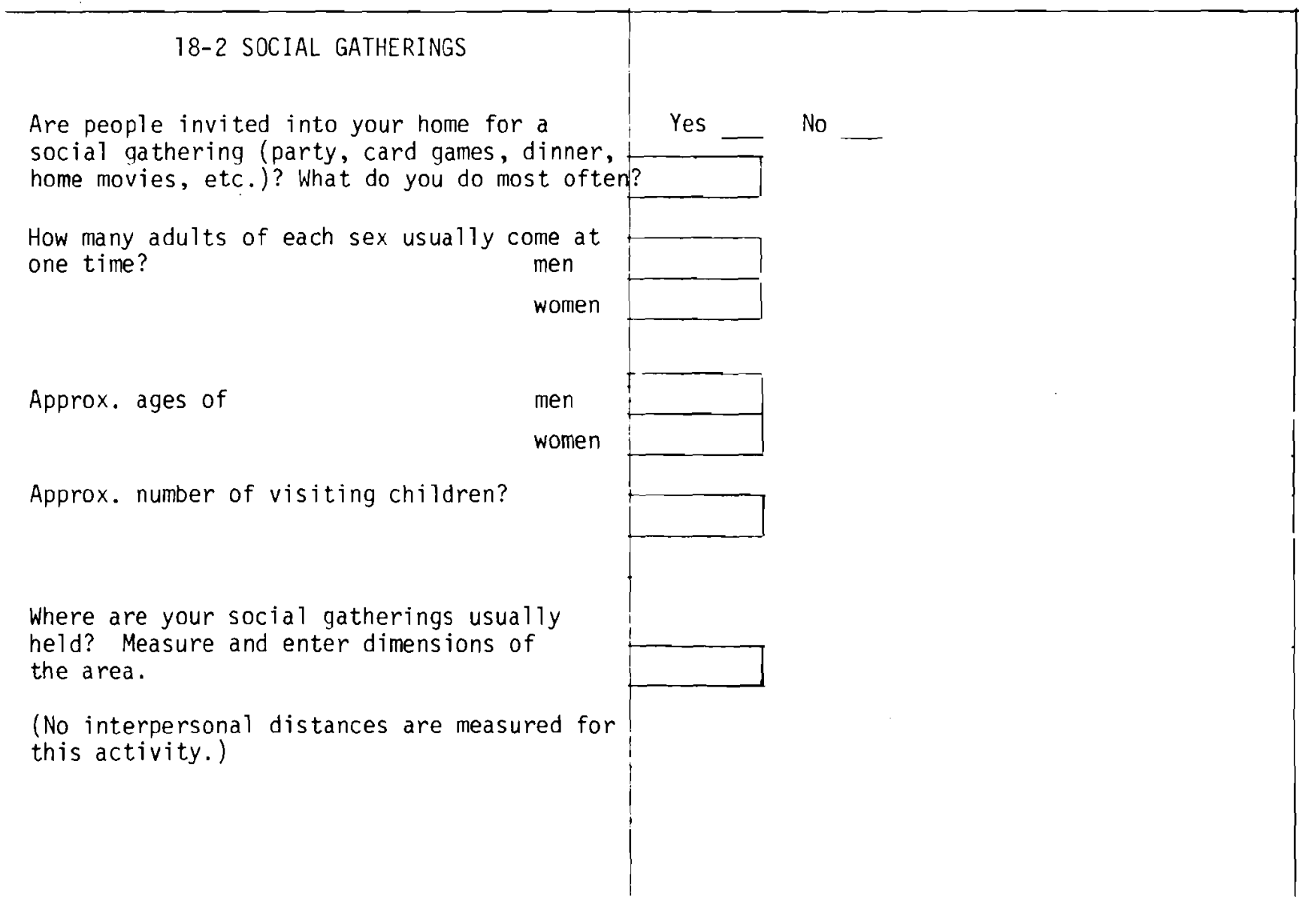

FIGURE E.2. (Contd) 


\section{APPENDIX $F$}

CALCULATION MATRIX FOR DOSE TO THE POPULATION 


\section{APPENDIX $F$}

\section{CALCULATION MATRIX FOR DOSE TO THE POPULATION}

Table F.1 illustrates the detailed calculation matrix for dose to the population. The left half of the matrix corresponds to the summation tree in the main report (Figure 27) and shows the identification of the artificial heart recipients and the exposure subjects.

The five main data matrices comprise the categories shown across the top of the table. The subscripts further defining each matrix and their values fall beneath these headings. The summations at the bottom of each matrix give the total number of different data items required for each and correspond to the totals in Table 30, p. 10-13. The data describing each calculation segment is summarized in Table F.2 for each data matrix. 
TABLE F.1. Components of Dose-to-Population Data Matrix (a)

\begin{tabular}{|c|c|c|c|c|c|c|c|c|c|c|c|c|c|c|c|c|c|}
\hline \multicolumn{6}{|c|}{ 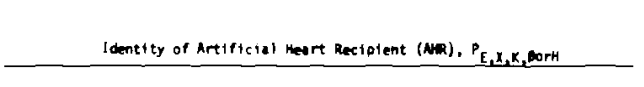 } & \multicolumn{5}{|c|}{ 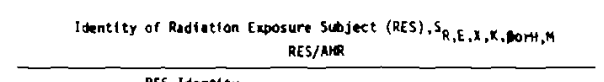 } & \multicolumn{3}{|c|}{ 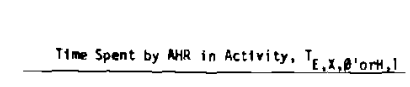 } & \multicolumn{2}{|c|}{ 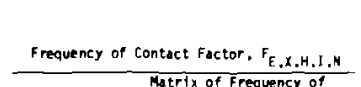 } & \multicolumn{2}{|l|}{ 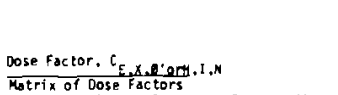 } \\
\hline 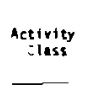 & 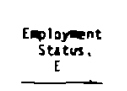 & 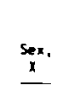 & 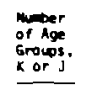 & 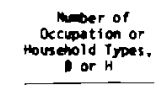 & 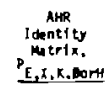 & 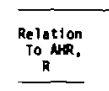 & 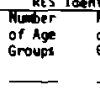 & 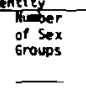 & 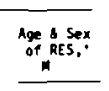 & 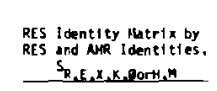 & 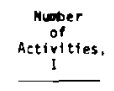 & 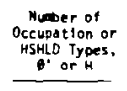 & 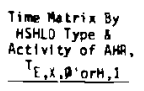 & 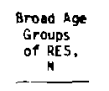 & 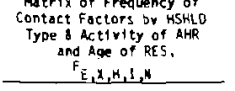 & 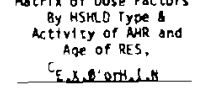 & 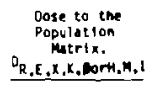 \\
\hline work & Emoloesed & mie & 12 & $"$ & ${ }^{\mathrm{sat}}$ & wore sisece. & ' & 1 & ' & $4(k \cdot 1)$ & s & 12 & 60 & - & - & 60 & 2.920 \\
\hline & & $=0$ & & ${ }^{x}$ & $\frac{304}{9+8}$ & & & & & $\overline{32}^{32(k-1)}$ & & & $\frac{60}{120}$ & & - & $\frac{60}{120}$ & $\frac{1.920}{0.720}$ \\
\hline Non-twort & Exwioned & me & 12 & s & so & spouse & 6 & 1 & 6 & 360 & 18 & 5 & so & - & 9 & $\infty$ & 6,800 \\
\hline & & & & 8 & \% & ouser susto & " & 2 & 22 & 2,112 & 18 & 8 & 194 & 2 & ${ }^{285}$ & 200 & 38,016 \\
\hline & & & 123 & $"$ & 132 & assectiteses & 3 & ' & 3 & 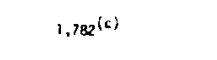 & 18 & " & 198 & $=$ & 396 & 36 & 1,128 \\
\hline & & & 12 & " & $\frac{132}{132^{(1)}}$ & nowite & $=$ & $=$ & $\therefore$ & $\frac{20(0)}{. .274}$ & s & " & $\frac{55}{198^{(1)}}$ & - & $\overline{\bar{m}}$ & $\frac{s^{\prime 2}}{199}$ & $\frac{2.600}{54,264}$ \\
\hline & & rele & $\cdots$ & 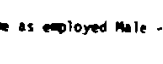 & 122 & & & & &., 274 & & & 198 & & $n$ & $m$ & $\$, 24$ \\
\hline & 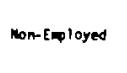 & nole & & as malosed wate. & 132 & & & & & 4,274 & & & 198 & & $m$ & $m$ & 5.264 \\
\hline ì & & ente & & 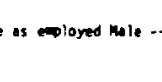 & 132 & & & & & 4,274 & & & 198 & & $m$ & $17 \%$ & s.2.24 \\
\hline rowe & & & & & $\overline{1.916}$ & & & & & $\sqrt{1,1.155^{(6)}}$ & & & $\overline{912}$ & & $\overline{3,096}$ & $\overline{3.26^{(1)}}$ & $\overline{221,196}$ \\
\hline
\end{tabular}

(a) Done wo the Poovilation - wort Activity Dose + Mon-work Activity Dose + Incidental Rancoun cose

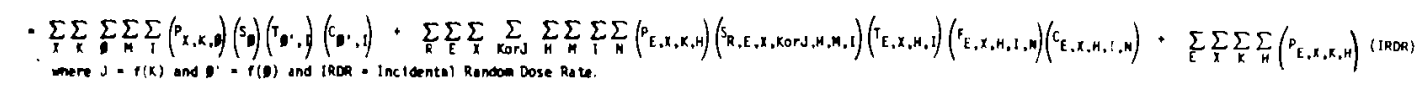

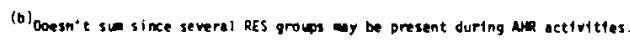

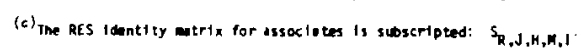

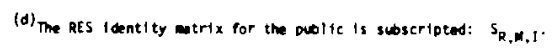

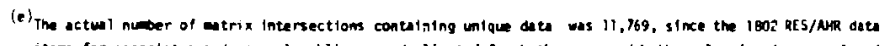

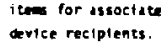

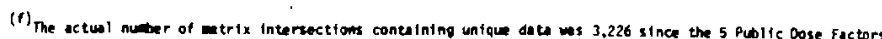

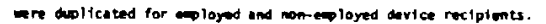

(9) 
TABLE F.2. Dose to the Population Matrix Descriptions

Identity of Artificial Heart Recipient (AHR)

Engaged in Work Activities -- Age, Sex and Detailed Occupation (Employed AHRs Only)

Engaged in Non-Work Activities -- Age, Sex, Household Type and Employment Status

Identity of Radiation Exposure Subject (RES)

$\begin{array}{lll}\text { Work Associate } & - & \text { By Detailed Occupation } \\ \text { Spouse } & -- & \text { RES: Age; AHR: Age, Sex, Household Type and } \\ & \text { Employment Status (Sex of RES Determined by } \\ & \text { Knowing AHR Sex) } \\ \text { Other Household -- } & \text { RES: Age, Sex; AHR: Age, Sex, Household Type } \\ & \text { and Employment Status } \\ \text { Associates } & -- & \text { RES: Age; AHR: Broad Age Group, Household Type } \\ \text { Public-at-Large }-- & \text { RES: Adult or Child, Sex; AHR: Activity }\end{array}$

Time Spent by AHR in Activity

Time in Work Activities -- AHR: Sex, Broad Occupation Groups and Work Activity

Time in Non-Work Activities -- AHR: Sex, Household Type, Employment Status, and Non-Work Activity

Frequency of Contact Factor (F Factor)
$F$ Factor for Spouse
-- AHR: Activity, Household Type, Sex and Employment Status
F Factor for other Household -- RES: Adult-Child Status; AHR: Activity, Household Type, Sex and Employment Status
F Factor for Associates -- RES: Adult-Child Status; AHR: Activity, Household Type, Sex, and Employment Status 


\section{TABLE F.2. (Continued)}

Dose Factor (Dose/RES/Unit Time)

Dose Factor for Work Associates -- AHR: Broad Occupation, Work Activity and Sex

Dose Factor for Spouse

-- AHR: Activity, Household Type, Sex and Employment Status

Dose Factor for Other Household -- RES: Adult-Child Status; AHR: Activity, Household Type, Sex and Employment Status

Dose Factor for Associates

-- RES: Adult-Child Status; AHR: Activity, Household Type, Sex and Employment Status

Dose Factor for Public-at-Large -- AHR: Activity, and Sex

Dose to the Population

Dose to Work Associate

Dose to Spouse

Dose to other Household

Dose to Associates

Dose to Public-at-Large
-- AHR: Activity, Age, Sex and Detailed Occupation Age, Sex, Household Type and Employment Status

-- RES: Age and Sex; AHR: Activity, Age, Sex, Household Type and Employment Status Household Type and Employment Status

-- RES: Adult-Child Status and Sex; AHR: Activity, Age, Sex, Household Type and Employment Status
-- RES: Age and Sex; AHR: Activity,

-- RES: Age; AHR: Activity, Age, Sex, 


\section{APPENDIX G}

INCIDENTAL RANDOM DOSE CALCULATIONS 


\section{APPENDIX G}

\section{INCIDENTAL RANDOM DOSE CALCULATIONS}

In arriving at a figure for total population dose, one of the questions raised was: what are the limits of the area of influence surrounding an artificial heart user? Since dose is proportional to $1 / r^{2}$ and since population is proportional to $r^{2}$. the area of influence might appear to be indeterminant. It is clear, however, that this is not the case.

Assume for the sake of analysis that a more or less uniformly dense population is concentrated along concentric circles centered around a radiation source. The dose to the population on a particular radius is proportional to $1 / r^{2}$ but the population on that radius is not proportional to $r^{2}$; it is proportional to $r^{2}$ minus the population distributed along a 11 of the smaller radii. Thus, the increments of absorbed dose to the population become smaller and smaller as the radii become larger.

We estimated the magnitude of this incidental random dose by using the computer code BINGO. By using varying people densities with the random placement capability of the code, we generated data on relative dose rates as a function of people density. Using these data, we estimated the incidental random dose in metropolitan centers of varying sizes. Table G. 1 shows a summary of the total population doses at varying people densities. These calculations indicate that the theoretical last $1 \%$ of absorbed dose may extend a disproportionate distance relative to the radius where the bulk of the radiation is absorbed. Since the dose rate and attenuation data are not highly accurate, we have used the distance where $99 \%$ of the dose is absorbed as the figure of merit for evaluating people density effects. For the high density situations shown in Columns 1 and 3 , the radius at which $99 \%$ of the total dose is absorbed is very small (19$100 \mathrm{ft}$ ) due to the strong radiation-attenuating effect of people's bodies. However, for the lower metropolitan area densities (excluding the effect of walls and other obstructions), the 1 imiting factor on total dose absorbed 
TABLE G.1. Effect of Population Density on Incidental Random (IR) Dose to the Population (a)

1

Radius at which

Density

People/100 $\mathrm{ft}^{2}$

20.0

10.0

2.5

0.25

9
1
$N$

\section{$\frac{\text { Example }}{\text { Maximum density }}$}

Maximum density situations

Density in a

Nearly Filled

Theatre

Half Filled

Maximum Urban

Population

Density (Manhattan)

Population Density

in a Small City
$25 \mathrm{Mi}$. (b) 99\% of Maximum

Maximum Possible

is Absorbed

is
$(\mathrm{ft})$

19

38

110

25 Mi. (b)
Population Dose (mrem/hr)
5.71

2.54

0.024
Population Dose At

$100 \mathrm{ft}$ or at $99 \%$ Radius (Column 3) Whichever Is the Shorter Distance $\mathrm{mrem} / \mathrm{h} r$

8.40

Essentially 100

5.71

Essential1y 100

2.50

0.38

0.011

$(0.015$ at $500 \mathrm{ft})$

-

a. The term Incidental Random (IR) dose is used here to mean the dose absorbed by a group of people who are present only in the general background of a more specific activity. In high density situations this IR dose is the dose to the population.

b. Maximum IR dose for low density situations is the dose out to a maximum distance of $b$ miles due to the curvature of the earth. This is the limiting distance at which any radiation would be absorbed by any portion of a 6 -ft individual from a source $3 \mathrm{ft}$ above the earth's surface.

COMPARATIVE DOSE RATES TO IDENTIFIED RADIATION EXPOSURE SUBJECTS DURING SPECIFIED ACTIVITIES

(All dosages shown are for urban employed male Artificial Heart Recipients living in husband-wife only families)

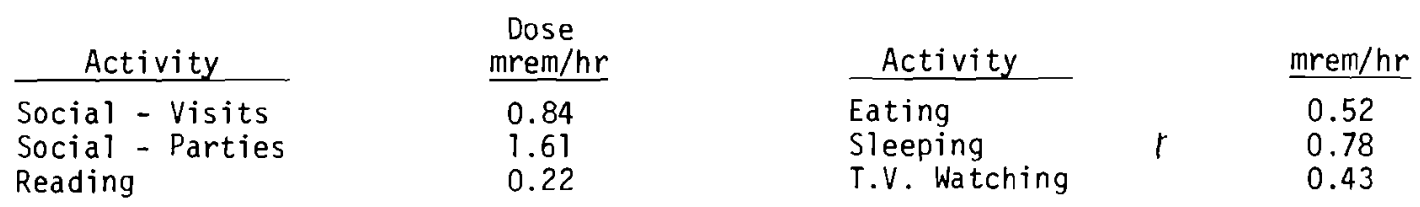


is the curvature of the earth. This can be seen by comparing Columns 5 and 6 which show the relative amounts of radiation absorbed in the first $100 \mathrm{ft}$ in terms of dose rate and percent of maximum.

For the metropolitan area densities, appreciable contributions to the total dose come at distances beyond $100 \mathrm{ft}$. However, the above analysis does not take into account the effect of walls and other obstructions normally present in metropolitan areas. Assuming the equivalent of a 6 -in. concrete wall at $100 \mathrm{ft}$, it was found that the dose beyond this point dropped off to insignificant levels. The assumption of such an obstruction increases in validity, the more dense the metropolitan population; hence the dose beyond $100 \mathrm{ft}$ will probably not be significant in highly populated metropolitan areas.

In the case of smaller sized population centers an obstruction distance of $500 \mathrm{ft}$ or the equivalent may be a more appropriate assumption. This would increase the incidental random dose for this case from 0.011 to $0.015 \mathrm{mrem} / \mathrm{hr} /$ AHR.

By comparing the dosage levels to family members and associates (lower portion of table) with the incidental random dosages, it will be noted that the relative magnitude of the latter rate is very small for medium sized metropolitan areas and only becomes significant for the few areas in the U.S. having densities comparable to those found in New York City. As a result of these calculations, we introduced an added factor in the total population dose to account for incidental random doses.

This factor (the last item in the dose-to-the-population equation on page 10-12) consists of the total number of AHRs times the incidental random dose rate per AHR. To calculate the incidental random dose rate we assumed that the geographical population distribution of AHRs would be the same as that of the general population. This calculation is shown in Table G.2. Using 1970 population density data from the U.S. Census, we obtained estimates of population density as a function of city size. We developed population dose rates for these densities using the dose rate at $100 \mathrm{ft}$ for cities having a population greater than 1 million and using 
TABLE G.2. Incidental Random Dose-to-the-Population Calculations

\begin{tabular}{|c|c|c|c|c|c|c|}
\hline City Size & $\begin{array}{c}\text { Percent } \\
\text { of the Total } \\
\text { Population } \\
\text { in } 1970 \\
\end{array}$ & $\frac{\text { Population } D}{\text { People/100 } \mathrm{ft}^{2}}$ & $\frac{\text { nsity }(i)^{(a)}}{\text { People/mi2 }}$ & $\begin{array}{l}\text { Dose Rate } \\
\text { at Density (i) } \\
\text { mrem/hr/AHR } \\
\end{array}$ & $\begin{array}{c}\text { Background } \\
\text { Population Dose } \\
\text { mrem/hr/AHR } \\
\end{array}$ & $\begin{array}{c}\text { Percent } \\
\text { of Total } \\
\text { Background Dose }\end{array}$ \\
\hline \multicolumn{7}{|l|}{$\underline{\text { Urban }}$} \\
\hline \multicolumn{7}{|l|}{$\begin{array}{l}1,000,000+ \\
\text { New York City }\end{array}$} \\
\hline $\begin{array}{l}\text { Manhattan } \\
\text { Brooklyn } \\
\text { Bronx } \\
\text { Queens } \\
\text { Rest }\end{array}$ & $\begin{array}{l}0.76 \\
1.28 \\
0.72 \\
0.98 \\
0.14\end{array}$ & $\begin{array}{l}0.243 \\
0.733 \\
0.128 \\
0.066 \\
0.018\end{array}$ & $\begin{array}{r}67,808 \\
37,013 \\
35,721 \\
18,393 \\
5,138\end{array}$ & $\begin{array}{l}0.34 \\
0.17 \\
0.16 \\
0.088 \\
0.025\end{array}$ & $\begin{array}{l}0.00258 \\
0.00218 \\
0.00115 \\
0.00086 \\
0.00004\end{array}$ & $\begin{array}{r}10.0 \\
8.5 \\
4.5 \\
3.3 \\
0.2\end{array}$ \\
\hline $\begin{array}{l}\text { Philadelphia } \\
\text { Chicago } \\
\text { Detroit } \\
\text { Los Angeles } \\
\text { Houston }\end{array}$ & $\begin{array}{l}0.96 \\
1.66 \\
0.74 \\
1.39 \\
0.60 \overline{9.23}\end{array}$ & $\begin{array}{l}0.054 \\
0.054 \\
0.039 \\
0.021 \\
0.010\end{array}$ & $\begin{array}{r}15,164 \\
15,126 \\
10,953 \\
6,073 \\
2,841\end{array}$ & $\begin{array}{l}0.072 \\
0.072 \\
0.051 \\
0.028 \\
0.015\end{array}$ & $\begin{array}{l}0.00069 \\
0.00120 \\
0.00038 \\
0.00039 \\
0.00009\end{array}$ & $\begin{array}{l}2.7 \\
4.7 \\
1.5 \\
1.5 \\
0.4 \overline{37.3}\end{array}$ \\
\hline $500,000-1,000,000$ & 6.40 & 0.025 & 6,838 & 0.034 & 0.00218 & 8.5 \\
\hline $250,000-500,000$ & 5.10 & 0.019 & 5,284 & 0.026 & 0.00133 & 5.2 \\
\hline $100,000-250,000$ & 7.0 & 0.017 & 4,652 & 0.023 & 0.00161 & 6.3 \\
\hline $50,000-100,000$ & 8.2 & 0.018 & 5,152 & 0.025 & 0.00205 & 8.0 \\
\hline $25,000-50,000$ & 8.8 & 0.016 & 4,499 & 0.022 & 0.00194 & 7.5 \\
\hline $10,000-25,000$ & 10.5 & 0.012 & 3,302 & 0.017 & 0.00179 & 7.0 \\
\hline $5,000-10,000$ & 6.4 & 0.010 & 2,834 & 0.015 & 0.00096 & 3.7 \\
\hline $2,500-5,000$ & 4.0 & 0.0095 & 2,649 & 0.014 & 0.00056 & 2.2 \\
\hline Urban less than 2,500 & 0.4 & $20.0095^{(a)}$ & $\sim 2,649$ & 0.014 & 0.00006 & 0.2 \\
\hline $\begin{array}{l}\text { Unincorporated urban } \\
\text { Rura ? }\end{array}$ & $7.5 \overline{64.3}$ & $20.0095(a)$ & $\sim 2,649$ & 0.014 & $\frac{0.00105}{0.02306}$ & $4.1_{\overline{52.7}}$ \\
\hline $1,000-2,500$ & 3.3 & & & & & \\
\hline Rural less than 2,500 & 1.9 & & & & & \\
\hline Other rural & $21.3 \overline{26.5}$ & & & $\sim 0.010^{\star}$ & 0.00265 & 10.0 \\
\hline TOTAL & 100.0 & & & & 0.02571 & 100.0 \\
\hline
\end{tabular}

Incidenta I Random Dose $=0.02571 \mathrm{mrem} / \mathrm{hr} / \mathrm{AHR} \times \frac{8760 \mathrm{hr}}{\mathrm{yr}} \times \frac{1 \mathrm{rem}}{1,000 \mathrm{mrem}}=0.225 \mathrm{rem} / \mathrm{yr} / \mathrm{AHR}$

(a) Estimated

Source: Population of Places of 2,500 or more, 1970 and 1960 (Reference 33) 
the dose rate at $500 \mathrm{ft}$ for cities with a population of less than 1 million. From these data we then developed the weighted average population dose rate of $0.225 \mathrm{rem} /$ year/AHR used in the population dose calculations. 
APPENDIX $\mathrm{H}$

DOSE-TO-THE-POPULATION SUMMARIES OF VARIOUS REPRIEVE CASES 
TABLE H.1. Case 1B Dose to the Population in the Year 2000 from 220,330 Radioisotope-Fueled Devices

Basis: 1. High Candidate Estimate

2. Sest Heart Disease Incidence Estimate

3. Natural Death Rate = PND $(a)$

4. Device Failure Rate = Twice NHFR(b)

Population Category

1. Spouses

Females - Age 49 and Under

- Age 50 and Over

Males - Age 49 and Under

- Age 50 and Over

2. Other Household Members

$$
\text { Age } \begin{gathered}
0-17 \\
18-49 \\
50+
\end{gathered}
$$

3. Non-work Associates

4. Work Associates

General Populace

Total

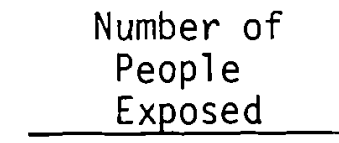

31,418 .

78,753

7,771

36,637 .

$$
\begin{array}{r}
114,388 . \\
77,027 . \\
31,265 .
\end{array}
$$

$4,731,132$.

$2,199,332$.

$265,000,000$. (c)

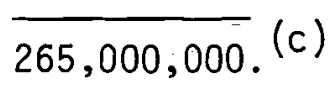

Percent of Total Dose to the Population

rem/yr

28,514 .

64,709

7,535 .

29,896 .

$$
\begin{array}{r}
21,225 . \\
12,237 . \\
4,651 . \\
34,442 . \\
39,034 . \\
128,573 . \\
\hline 370,216 .
\end{array}
$$

8.1

5.7

3.3

9.3

10.5

34.7
Average Dose

Per Person

$\mathrm{rem} / \mathrm{yr}$

0.908

0.814

0.970

0.816

0.186

0.159

0.149

0.0073

0.0177

0.00049

100.0 Average 0.00140

(a) Probability of normal death

(b) Normal heart failure rate

(c) The entire U.S. population is assumed to have received some exposure 

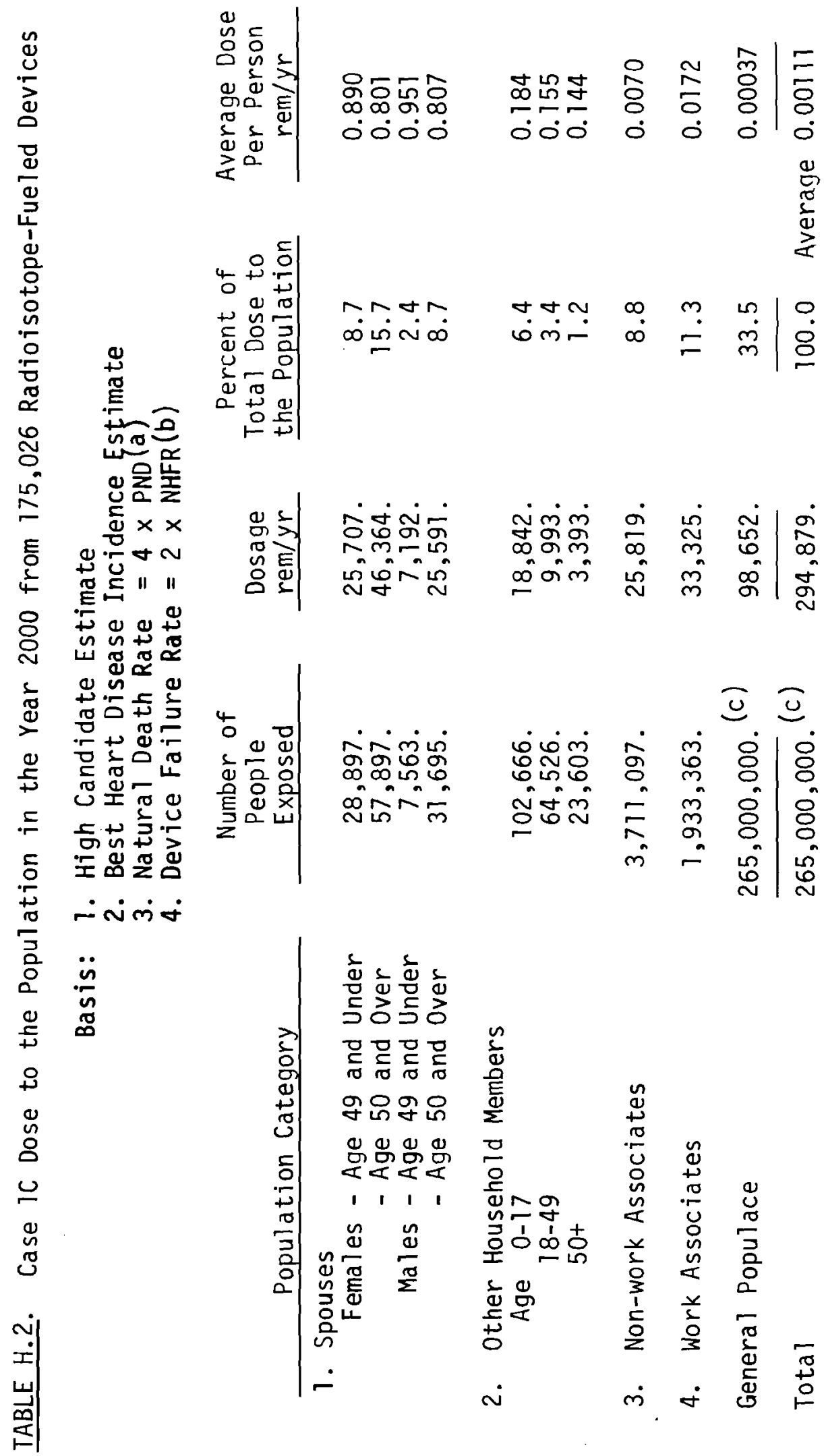

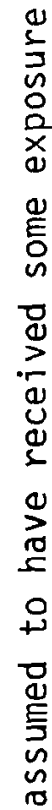
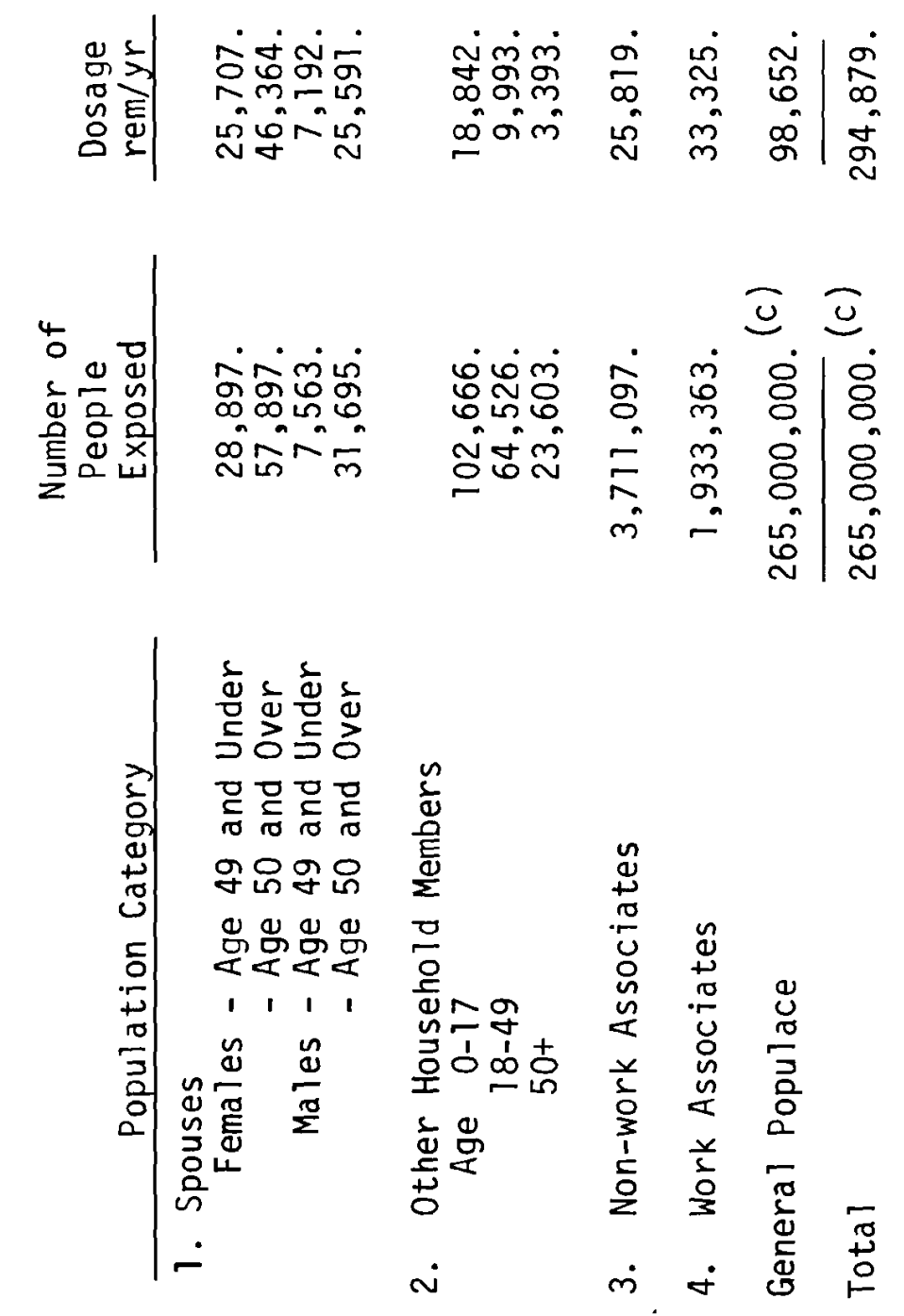

秃 包告 ชั 통 主 응 음.

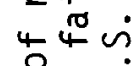

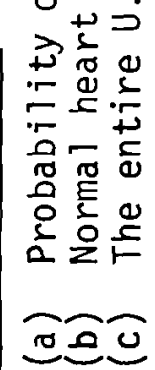


TABLE H.3. Case 10 Dose to the Population in the Year 2000 from 247,446 Radioisotope-Fueled Devices

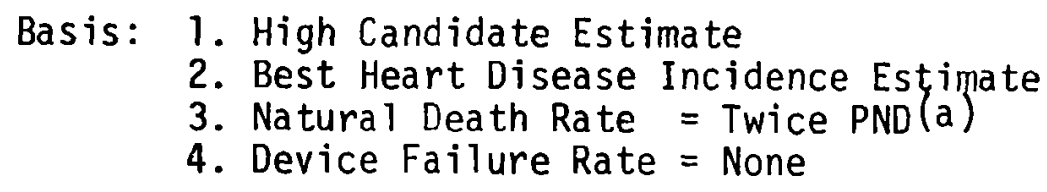

Basis: 1. High Candidate Estimate

2. Best Heart Disease Incidence Estimate

3. Natural Death Rate = Twice PND(a)

4. Device Failure Rate $=$ None
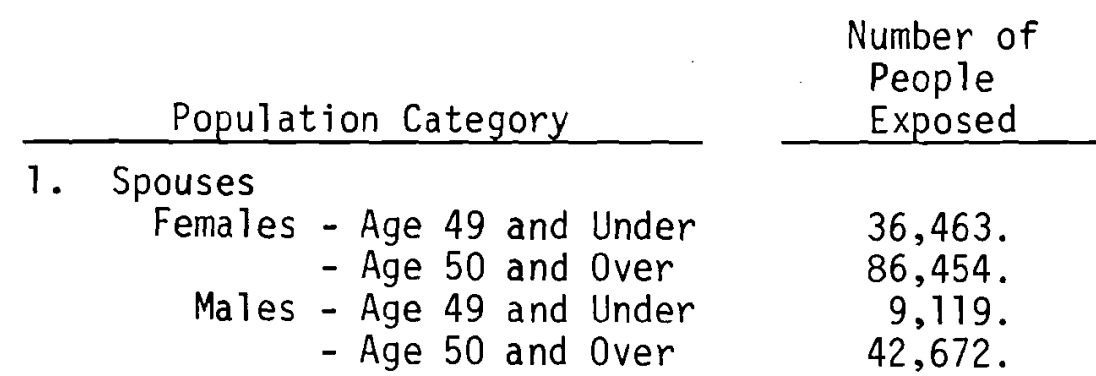

\begin{tabular}{l} 
Dosage \\
rem/yr \\
\hline
\end{tabular}

\begin{tabular}{l} 
Percent of \\
Total Dose to \\
the Population \\
\hline
\end{tabular}

Average Dose

Per Person $\mathrm{rem} / \mathrm{yr}$

- Age 50 and Over

2. Other Household Members

$$
\text { Age } \begin{gathered}
0-17 \\
18-49 \\
50+
\end{gathered}
$$

3. Non-work Associates

4. Work Associates

General Populace

Total

(a) Probability of normal death

(b) The entire U.S. population is assumed to have received some exposure
36,463 .

86,454

9,119 .

42,672 .

$\begin{array}{rr}7.9 & 0.922 \\ 16.9 & 0.828 \\ 2.1 & 0.984 \\ 8.4 & 0.830\end{array}$

\begin{tabular}{rr}
$131,884$. & $24,921$. \\
$87,814$. & $14,161$. \\
$34,566$. & $5,211$. \\
$5,293,428$. & $38,896$. \\
$2,539,459$. & $45,642$. \\
$265,000,000$. (b) & $145,686$. \\
\hline $265,000,000$ (b) & $\frac{424,053 .}{4}$
\end{tabular}

$$
5.9
$$

3.3

1.2

0.189

0.161

0.151
9.2
0.0073

10.8

0.0180

34.4

0.00055

100.0

Average

0.00160 
TABLE H.4. Case 3A Dose to the Population in the Year 2000 from 105,306 Radioisotope-Fueled Devices

Basis: 1. High Candidate Estimate

2. Minimum Heart Disease Incidence Estimate

3. Natural Death Rate = Twice PND (a)

4. Device Failure Rate $=$ Twice NHFR(b)

Population Category

\begin{tabular}{|c|c|c|c|c|}
\hline \multirow[b]{2}{*}{ Population Category } & \multicolumn{4}{|c|}{$\begin{array}{l}\text { 1. High Candidate Estimate } \\
\text { 2. Minimum Heart Disease Incidence Estimate } \\
\text { 3. Natural Death Rate = Twice PND (a) } \\
\text { 4. Device Failure Rate = Twice NHFR (b) }\end{array}$} \\
\hline & $\begin{array}{l}\text { Number of } \\
\text { People } \\
\text { Exposed }\end{array}$ & $\begin{array}{l}\text { Dosage } \\
\mathrm{rem} / \mathrm{yr}\end{array}$ & $\begin{array}{l}\text { Percent of } \\
\text { Total Dose to } \\
\text { the Population } \\
\end{array}$ & $\begin{array}{c}\text { Average Dose } \\
\text { Per Person } \\
\text { rem/yr } \\
\end{array}$ \\
\hline $\begin{array}{l}\text { 1. Spouses } \\
\text { Females - Age } 49 \text { and Under } \\
\text { - Age } 50 \text { and Over } \\
\text { Males - Age } 49 \text { and Under } \\
\text { - Age } 50 \text { and Over }\end{array}$ & $\begin{array}{r}16,486 \\
39,131 \\
2,446 \\
16,015\end{array}$ & $\begin{array}{r}15,160 \\
32,317 \\
2,398 \\
13,033\end{array}$ & $\begin{array}{r}8.5 \\
18.1 \\
1.3 \\
7.3\end{array}$ & $\begin{array}{l}0.920 \\
0.826 \\
0.980 \\
0.814\end{array}$ \\
\hline $\begin{array}{l}\text { 2. Other Household Members } \\
\text { Age } 0-17 \\
18-49 \\
50+\end{array}$ & $\begin{array}{l}53,623 \\
36,527 \\
14,828\end{array}$ & $\begin{array}{l}9,883 \\
5,781 \\
2,223\end{array}$ & $\begin{array}{l}5.5 \\
3.2 \\
1,2\end{array}$ & $\begin{array}{l}0.184 \\
0.158 \\
0.150\end{array}$ \\
\hline 3. Non-work Associates & $2,264,423$ & 16,430 & 9.2 & 0.0073 \\
\hline 4. Work Associates & $1,042,262$ & 19,023 & 10.7 & 0.0183 \\
\hline General Populace & $265,000,000 .(c)$ & 61,911 & 34.8 & 0.00023 \\
\hline Total & $\overline{265,000.000 .}(c)$ & $\overline{178,160}$ & 100.0 & ge 0.00067 \\
\hline
\end{tabular}

\footnotetext{
(a) Probability of normal death

(b) Normal heart failure rate

(c) The entire U.S. population is assumed to have received some exposure
} 


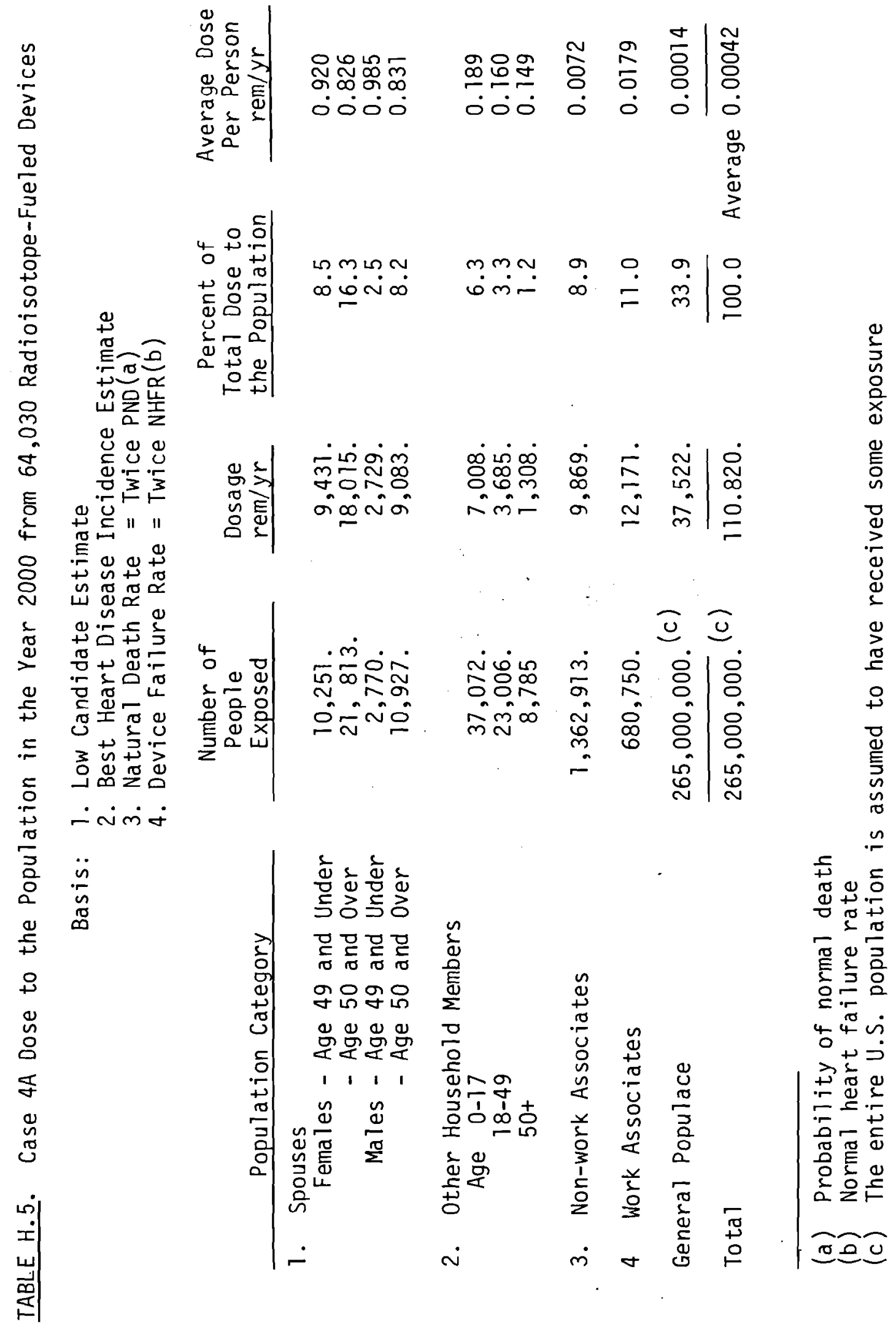




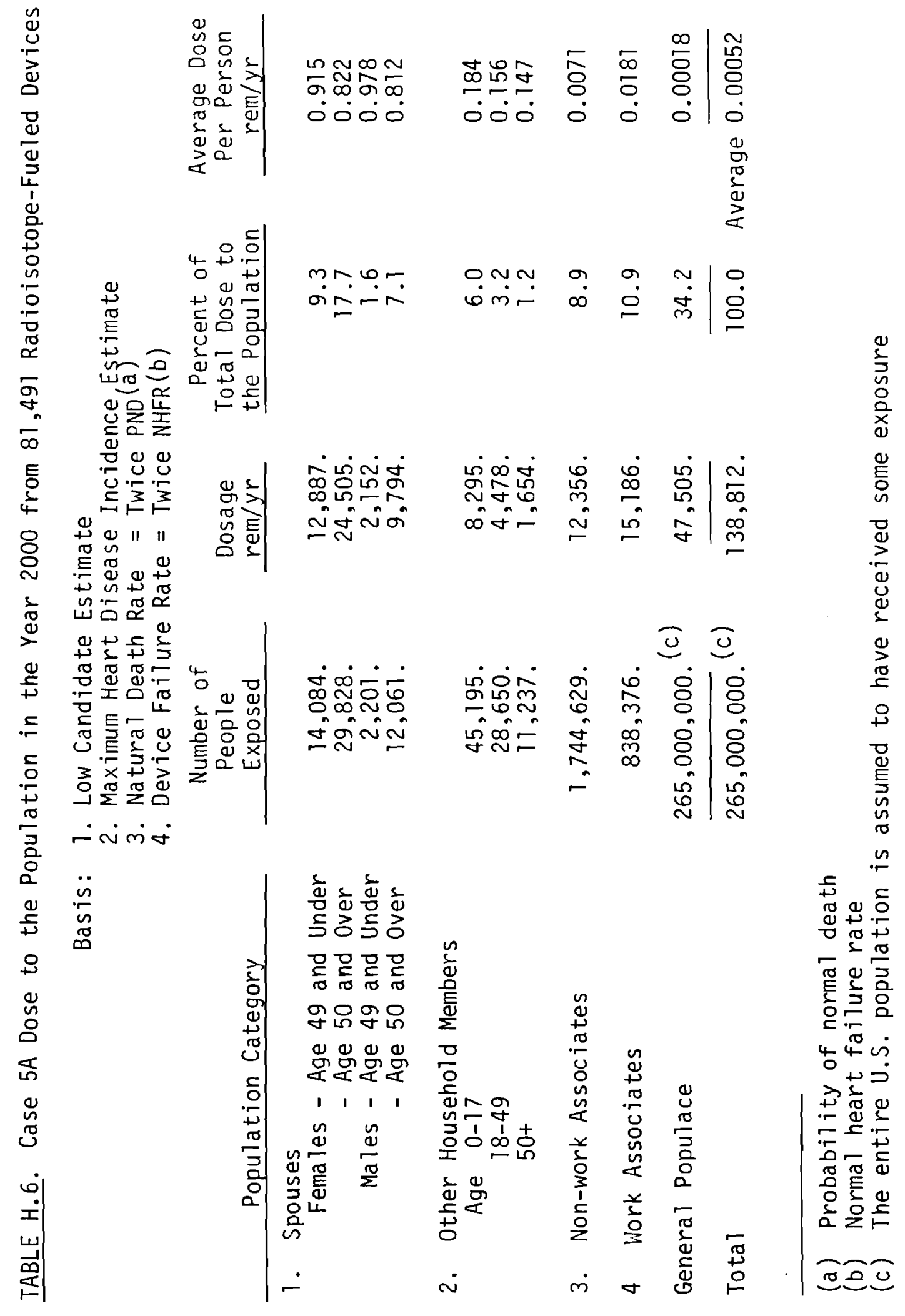


TABLE H.7. Case 7 Dose to the Population in the Year 1990 from 4,160 Radioisotope-Fueled Devices

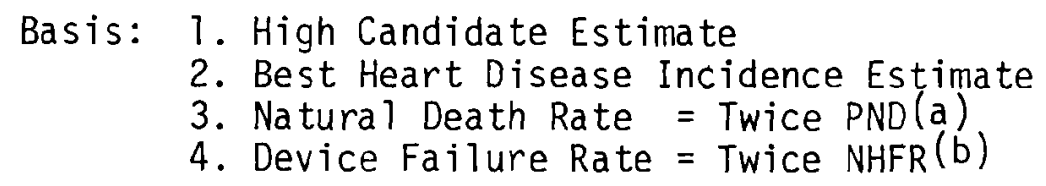

3. Natural Death Rate = Twice PND(a)

- Device Failure Rate = Twice NHFR(b)
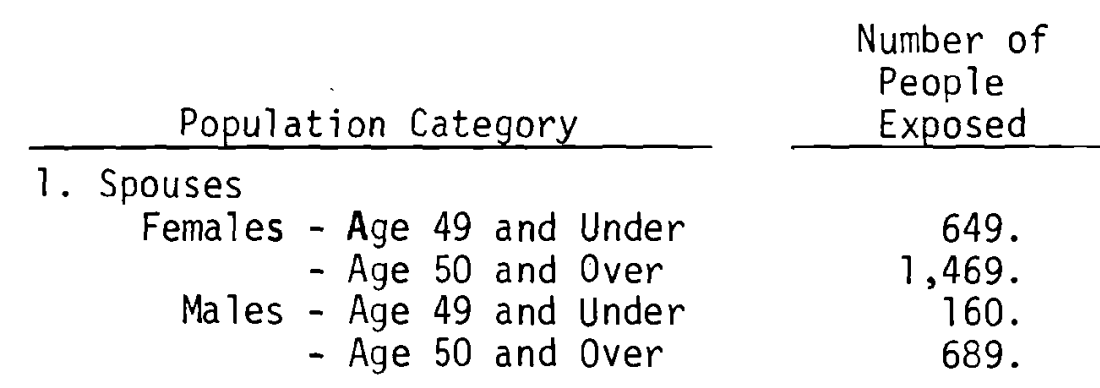

$$
\begin{array}{r}
649 . \\
1,469 . \\
160 . \\
689 .
\end{array}
$$

2. Other Household Members

$$
\text { Age } \begin{gathered}
0-17 \\
18-49 \\
50+
\end{gathered}
$$

3. Non-work Associates

4. Work Associates

General Populace

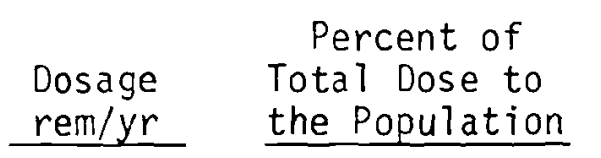

Total Dose to
the Population

8.4

17.0

2.2

7.9

6.2

3.2

1.1

8.8

10.7

34.6

$\frac{265,000,000 \text { (c) }^{\text {(c) }}}{265,000,000 .}$ (c) $\frac{2,112 .}{6,106 .}$
Average Dose Per Person rem/yr

0.787

0.705

0.848

0.701

0.160

0.137

0.128

0.0061

0.0154

0.00001

$\overline{100.0}$ Average 0.00002

(a) Probability of normal death

(b) Normal heart failure rate

(c) The entire U.S. population is assumed to have received some exposure 


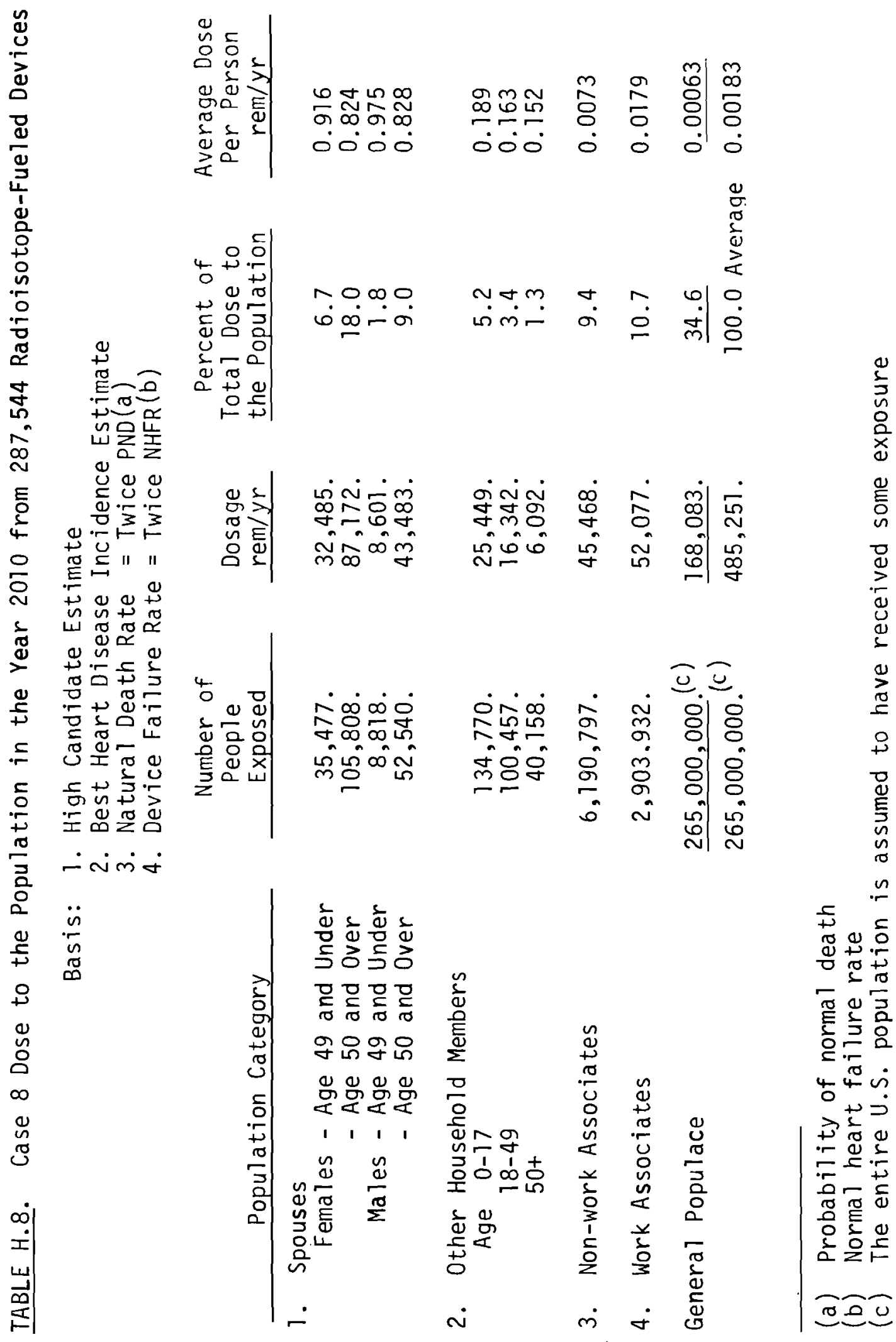


TABLE H.9. Case 9 Dose to the Population in the Year 2020 from 317,746 Radioisotope-Fueled Devices Basis: 1. High Candidate Estimate

2. Best Heart Disease Incidence Estimate

3. Natural Death Rate = Twice PND(a)

4. Device Failure Rate $=$ Twice $\operatorname{NHFR}(b)$
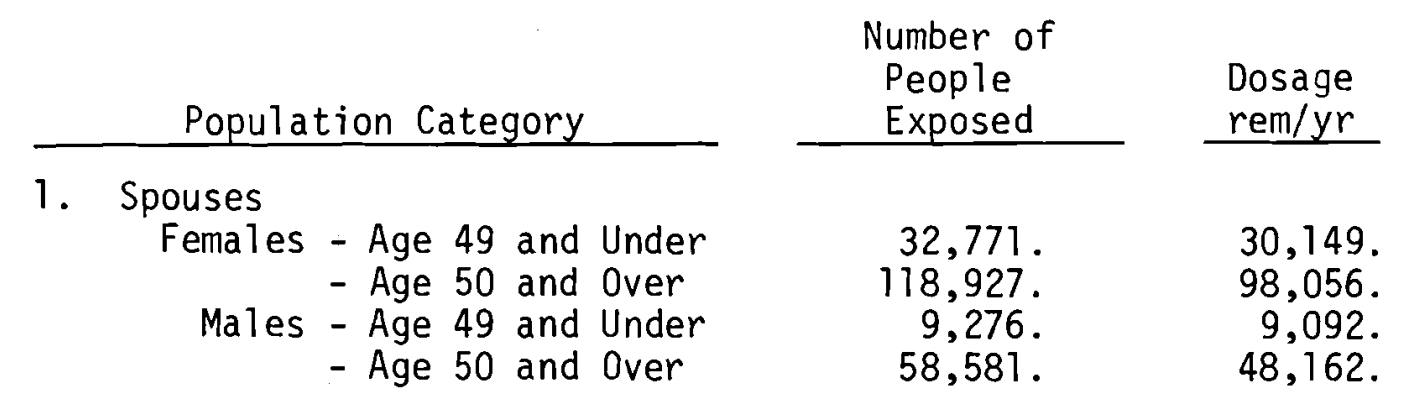

\begin{tabular}{l} 
Percent of \\
Total Dose to \\
the Population \\
\hline
\end{tabular}

Average Dose

People

(2)

2. Other Household Members

$$
\begin{aligned}
& \text { Age } 0-17 \\
& \text { 18-49 } \\
& 50+
\end{aligned}
$$

$32,771$.
$118,927$.
$9,276$.
$58,581$.

$30,149$.
98,056
$9,092$.
$48,162$.

Per Person

$\mathrm{rem} / \mathrm{yr}$

3. Non-work Associates

136,183 .

105,718 .

44,629 .

25,727 .

17,553

6,893 .
5.7
18.5
1.7
9.1

0.920

0.825

0.980

0.822

4. Work Associates

General Populace

Total

$\begin{array}{cccc}6,860,783 . & 51,469 . & 9.7 & 0.0075 \\ 2,950,456 . & 53,317 & 10.1 & 0.181 \\ \frac{265,000,000 .}{265,000,000 .} \text { (c) } & \frac{188,982 .}{529,402 .} & \frac{35.7}{100.0} & \text { Average } \frac{0.000200}{0.0071}\end{array}$

(a) Probability of normal death

(b) Normal heart failure rate

(c) The entire U.S. population is assumed to have received some exposure 


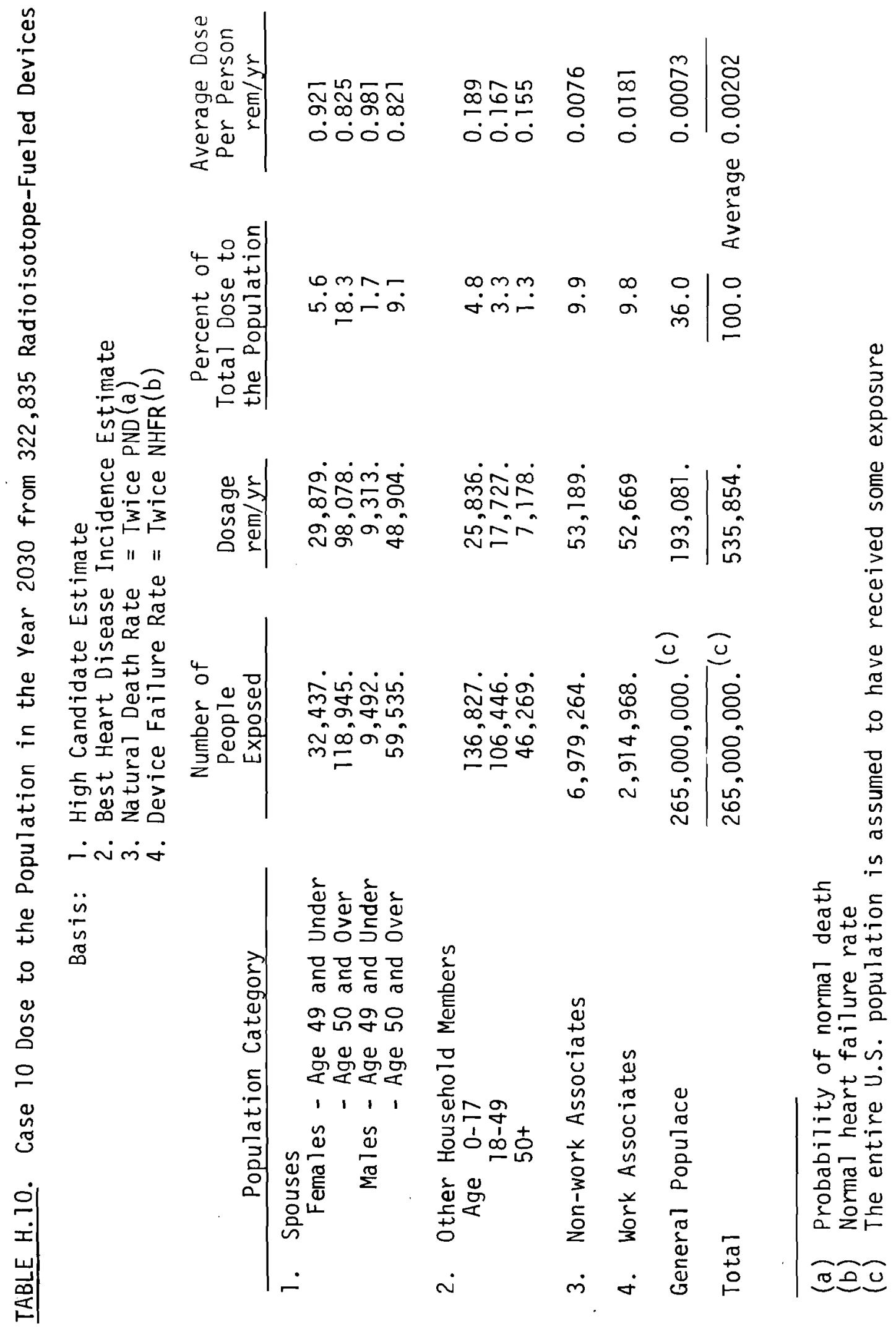




\section{DISTRIBUTION}

No. of

Copies

OFFSITE

1 ERDA Chicago Patent Group U.S. Energy Research and Development Administration Argonne, IL 60439

A. A. Churm

19 Division of Biomedical and Environmental Research U.S. Energy Research and Development Administration Washington, D.C. 20545

D. W. Cole

J. R. Mason

W. E. Mott

W. Weyzen

R. W. Wood

87 ERDA Technical Information Center

1 Medtronic, Inc. 3055 01d Highway Eight Minneapolis, MN 55418

B. I. Griffin

1 University of Utah Department of Psychology Salt Lake City, UT 84112 Dr. Irwin Altman, Chairman

1 Weiner Associates, Inc. 107 Industry Lane Cockeysville, MD 21030

R. I. Weiner

1 Institute for Social Research University of Michigan Ann Arbor, MI 48104

J. P. Robinson

1 Washington State University Radioisotopes \& Radiation Laboratory

Pul1man, WA 99136

J. C. Sheppard
No. of

Copies

OFFSITE

1 Aero Liquid Rocket Co.

P. 0. Box 13222

Sacramento, CA 95813

Barry Breindel

1 Lawrence Livermore Laboratory

P. 0. Box 808

Livermore, CA 94550

Stuart Winter

ONSITE

1 ERDA, Richland 0perations Office B. J. Melton/P.F.X. Dunigan, Jr.

72 Battelle-Northwest L. W. Brackenbush

C. L. Brown

L. L. Clark

B. M. Cole

F. T. Cross

D. E. Deonigi

P. J. Dionne

L. G. Faust

J. C. Fox

M. F. Gillis

J. L. Harris

A. J. Haverfield

R. A. Libby

R. W. Mckee

I. C. Nelson

J. M. Selby

J. K. Soldat

E. C. Watson

M. G. Zimmerman

Economics Library (1)

Technical Information Files

Technical Publications

(1) 